\title{
Feeding the Wrong Wolf: Work, Gender, and Generosity in a Northern Alberta Oil and Gas Community
}

\author{
By \\ Dan E. Houser \\ A dissertation submitted to the Faculty of Graduate and Postdoctoral Affairs \\ in partial fulfillment of the requirements for the degree of \\ Doctor of Philosophy \\ in \\ Anthropology \\ Carleton University \\ Ottawa, Ontario \\ (C) 2018 \\ Dan E. Houser
}




\section{Abstract}

This thesis is an ethnography of Grande Prairie, an oil and gas community in the Peace Region of north-western Alberta. Drawing on 21 months of fieldwork, the cultural values of workers in the oil and gas industry are explored, along with how they navigate and understand their roles within that industry. It is found that the views held by such workers are heavily influenced by the nature of the exchange relationships that peripheral communities enter into with oil and gas companies, relationships that simultaneously support the community and embolden the scale and scope of industry activity. As such, notions of masculinity, gender, work, place, economics, and history co-mingle and contribute to the assembling of a series of masculine cultural value systems, including those that: encourage residents who profit from working in the industry to reinvest their time and money into the community; validate and maintain belief in the value, necessity, and enduring need for the goods, services, and jobs that result from oil and gas exploration in Alberta and Canada; imagine and summon peripheral and frontier communities as masculine spaces of economic, metaphoric, and social opportunity; and support and perpetuate traditional understandings of sexuality, manhood, gender, and femininity in working and community life. While those in Grande Prairie who resist normative gender and masculinity find support in a localized arts scene, other groups in the Peace Region, such as First Nations peoples and religious communities concerned with the social and environmental impacts of industry activity, lack similar support. Ultimately, these groups express their dissatisfaction with the industry through protest and subversion, but as with those who work within oil and gas, are largely powerless to avoid its impacts. 


\section{Acknowledgements}

There are many people that need to be both acknowledged and thanked here, and it is likely that someone will be forgotten. For this, I apologize in advance.

First up is my dedicated partner and spouse, sulyn bodnaresko. sulyn has been unwavering in her support of my work, acting as editor, confidant, ass-kicker, and sounding board. Without her, I would not have been able to complete this multi-year learning journey.

My parents - Sheila \& Barry - are deserving of appreciation. They supported this project in a myriad of ways, including financially and emotionally. Their patience is appreciated.

A hearty 'Thank you!' to all who chose to participate in the study, including co-workers, those I connected with through social media, and those I met in time-tested ways: in bars, taxis, and on airplanes. I am grateful for your trust in me and willingness to indulge seemingly endless questions. I hope that such trust has been rewarded, and that your voices have been represented in the best possible way.

There are a number of people and organizations within the Peace Region and the City of Grande Prairie deserving of mention. I want to express my sincere thanks to the Centre for Research and innovation (CRI), and particularly, its director, Dr. Bruce Rutley. Dr. Rutley was instrumental in assisting my access to Grande Prairie's academic and business sectors. Many thanks to Grande Prairie Regional College for conferring Visiting Scholar status upon me, and for general support. Thank you as well to Connie Korpan, Dawn Moffat McMaster, René Gadacz, Darryl White, Laurie Nock, and Alan Segal.

At Carleton University, I extend my gratitude to staff and faculty members of the Anthropology \& Sociology Department, including the ever-capable Paula Whissell. A department 
runs on its staff, and Paula's fine example was evident to me each day on (and off) campus. I am also indebted to Blair Rutherford, Jackie Kennelly, and Louise de la Gorgendière for their insights and knowledge.

Much respect and gratitude to my esteemed supervisor, Dr. Danielle Dinovelli-Lang, for challenging me intellectually, and supporting my research and writing. I owe many thanks as well to my venerable committee members: Thank you to Dr. Donna Patrick, co-supervisor, for wisdom and grace, well received. Thank you to Dr. Peter Gose, for sharing his deep understanding of work-related literature freely, being supremely approachable, and possessing what is surely Ottawa's most colourful collection of shirts. I have been well supported by such a team.

I also thank my fellow graduate students from across anthropology and sociology at Carleton - I sometimes felt like a (Western) fish out of water, and so many of you were gracious, kind, and encouraging. I will never forget that.

Thank you as well to Jane Parpart and Tim Shaw for dinners, offers of accommodation, and unending interest in the project.

Lastly, my gratitude to the staff at Mike's. I enjoyed a pint and curry there with good friends as often as possible. 


\section{Dedication}

This thesis is dedicated to the memory of Blake MacMillan, who came into the PhD program at Carleton the same year as I. Despite backgrounds in different disciplines, we fell into a quick and easy rapport, sharing many epiphanies while taking a seminar course together, several years ago. Blake was bright, capable, and a complete pleasure to be near. The fact that we can no longer joke about forming a heavy metal band in tribute of the works of Foucault is shattering. More comfortingly, Blake's legacy of scholarship, humour, volunteerism, and curiousity continues to reverberate throughout the $7^{\text {th }}$ floor of the Loeb Building, and far beyond.

Thanks for the inspiration, B.

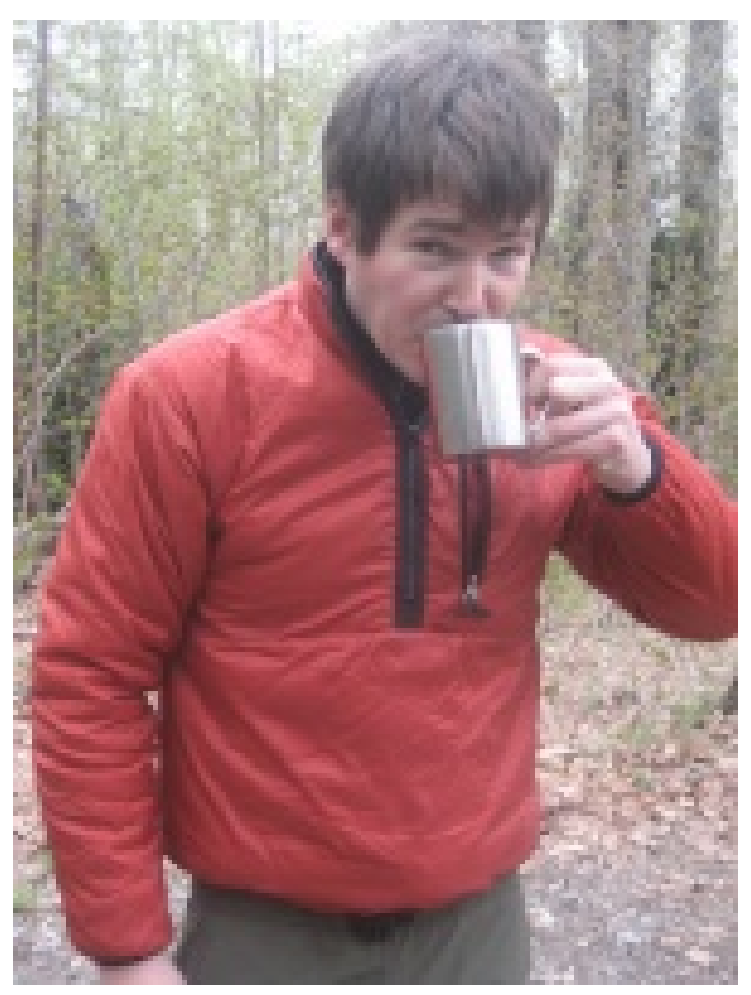




\section{Table of Contents}

ABSTRACT

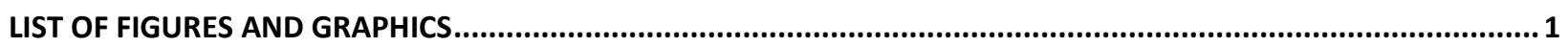

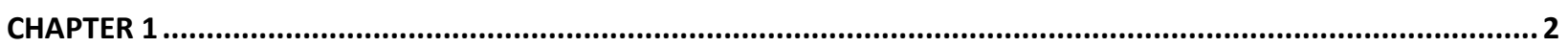

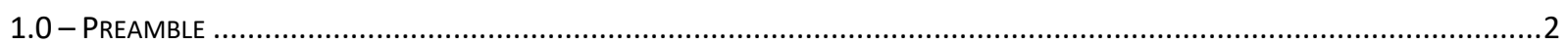

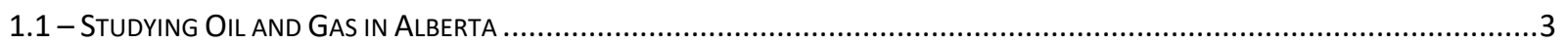

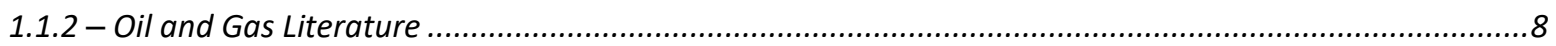

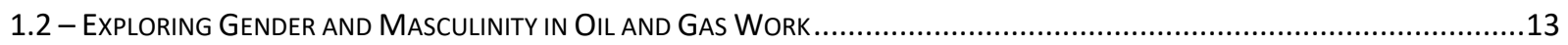

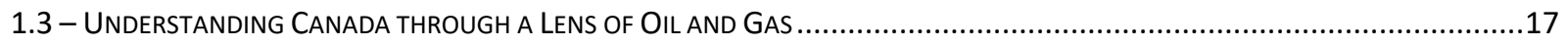

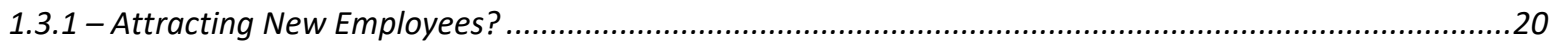

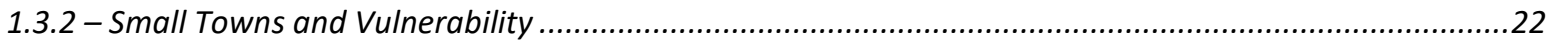

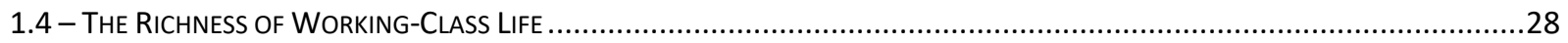

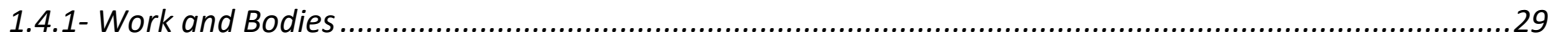

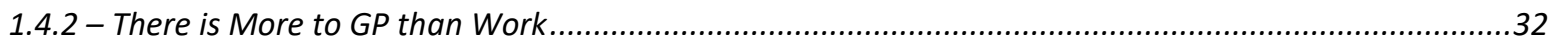

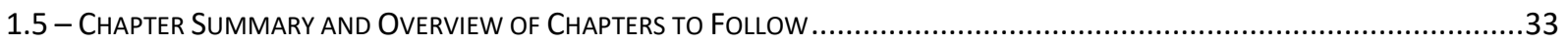

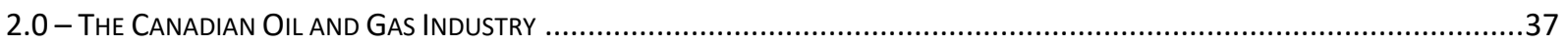

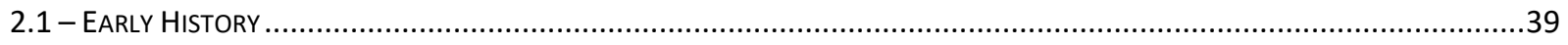

2.2 - Modern Context: Conventional OIL, OffShore, OIL (TAR) SANDS, AND HydRaUlic Fracturing............................43

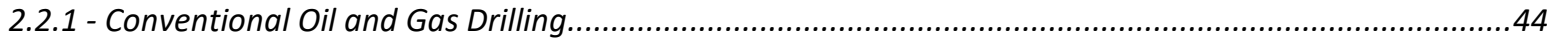

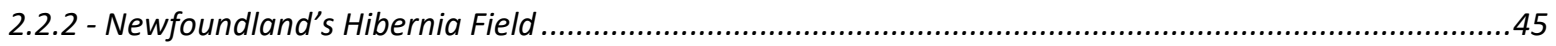

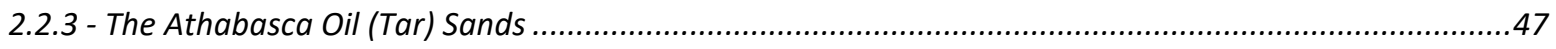

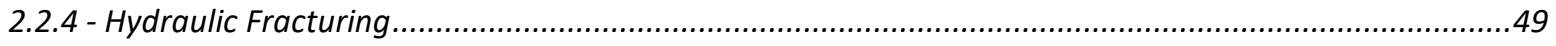

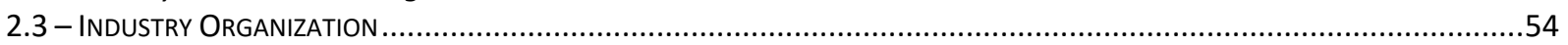

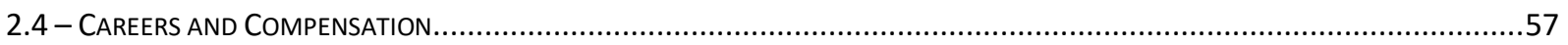

2.4.1 - Alberta Communities \& Oil and Gas Businesses............................................................................59

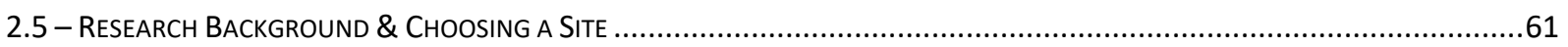

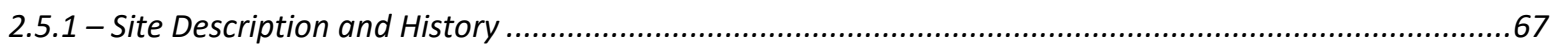

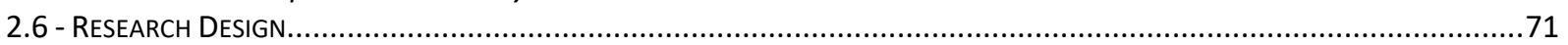

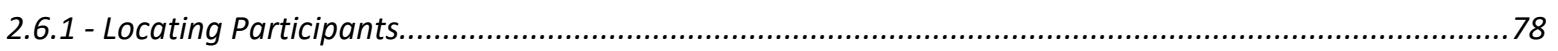

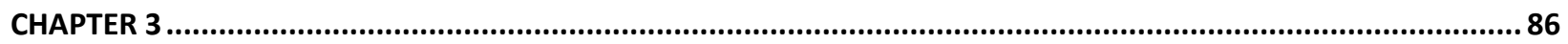

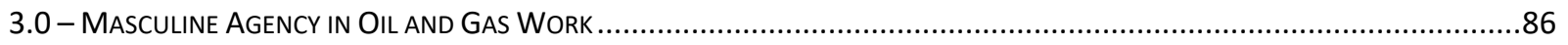

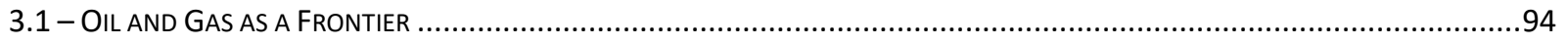

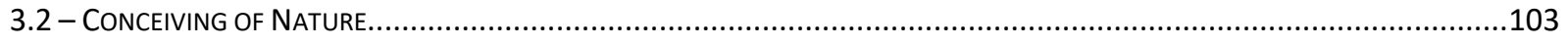

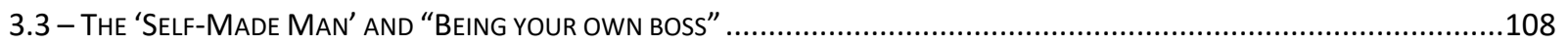

3.3.1 - Company Man or Contractor.......................................................................................... 113

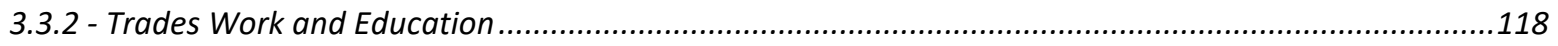

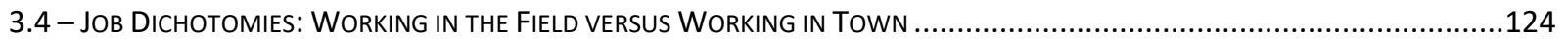

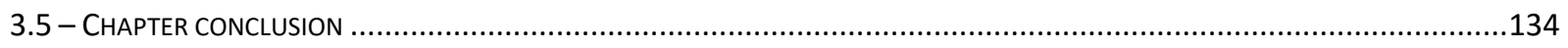

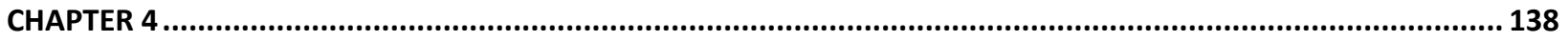

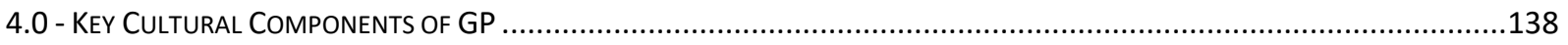

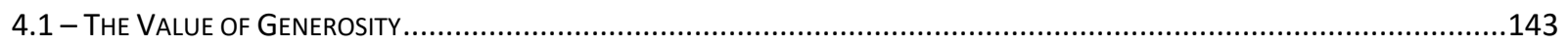

4.1.1 - The Good Citizen: Make Money and Turn It Back into The Community ............................................150

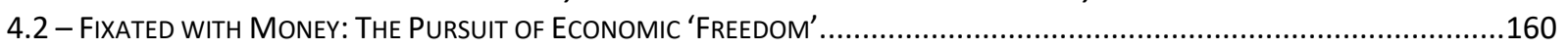

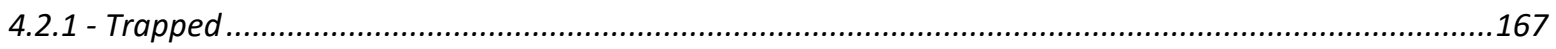

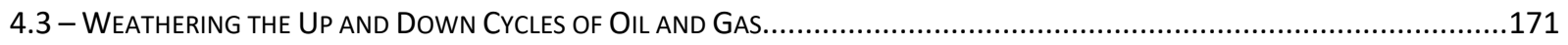




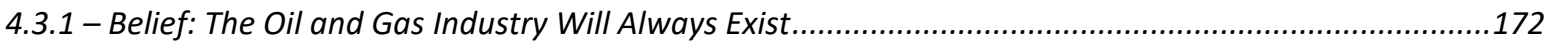

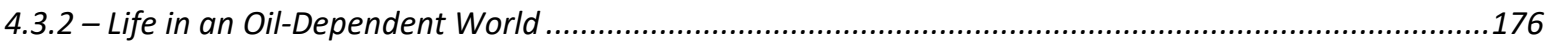

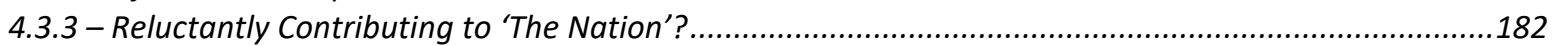

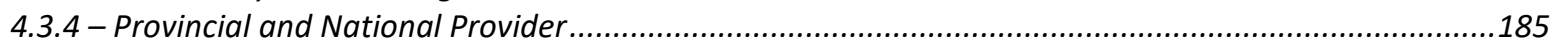

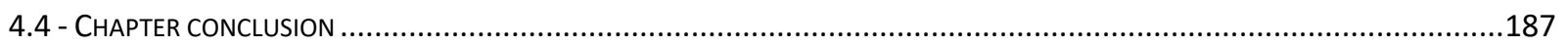

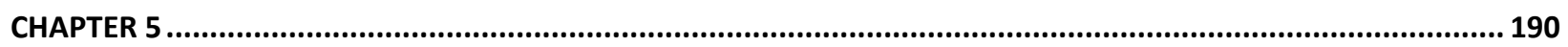

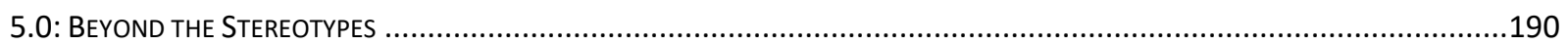

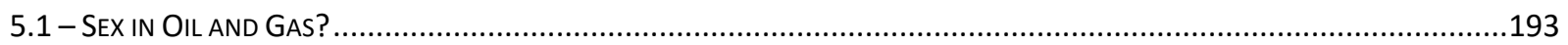

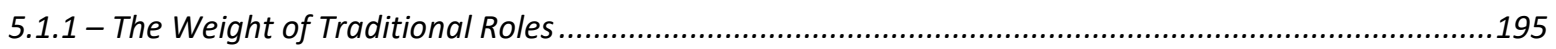

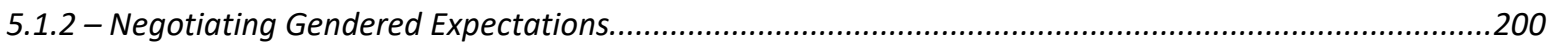

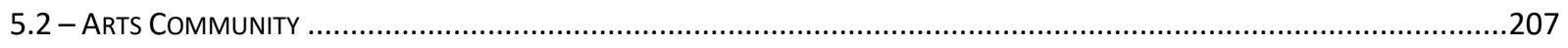

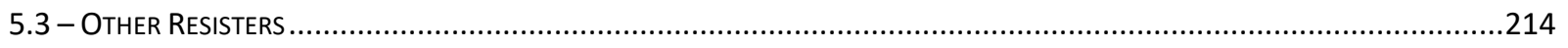

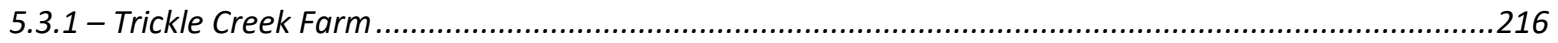

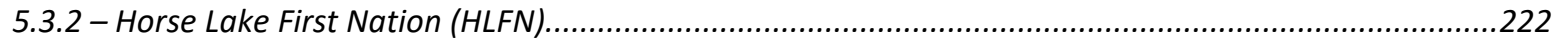

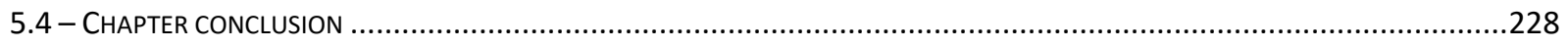

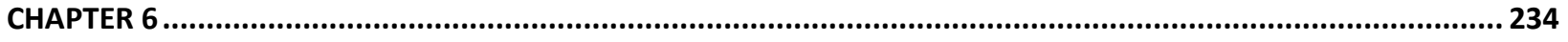

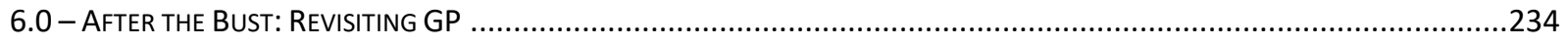

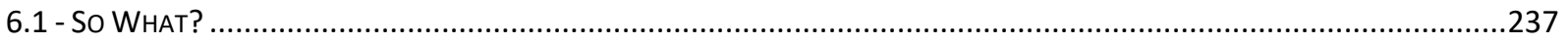

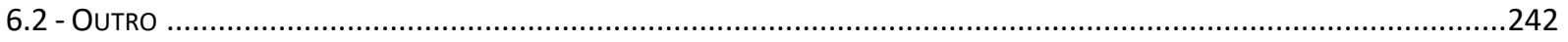

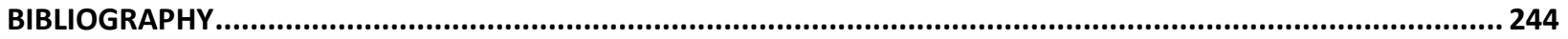




\section{List of Figures and Graphics}

Figure 1.0 - View of drilling rig in early evening

Figure 1.1 - Hibernia offshore drilling platform

p. 46

Figure 1.2 - Suncor Plant at Fort McMurray

p. 49

Figure 1.3 - Shale gas extraction graphic

p. 50

Figure 1.4 - Casing and borehole diagram

p. 53

Figure 1.5 - Map of Alberta's Peace Region

p. 66

Figure 1.6 - Map of Alberta

p. 67

Figure 1.7 - City of GP at dusk

p. 69

Figure 1.8 - GP sunset in spring

p. 69

Figure 1.9 - Kijiji recruitment notice

p. 83

Figure $2.0-4 \times 4$ truck usual to GP

p. 133 


\section{Chapter 1}

"It's like that whole story, you have two wolves inside you, fighting, at all times. Oil patch people feed the wrong wolf, the one that will never be satisfied. That's Alberta".

- Anne, 28

\section{0 - Preamble}

It is early, and very cold, on a November Sunday morning in northern Alberta. At least the cab of this huge diesel truck is warm, and I remembered to bring boots, mitts, a toque, and lunch. Stealing a look over at the driver, Terry, he catches me staring, and flashes a crooked grin. In the seats behind us, wrapped from head-to-toe in snow gear, his twin sons, aged 8, alternate between dozing off and loud outbursts of excitement. I arrived here only a week earlier, and somehow convinced this lone acquaintance that I should be allowed to tag along, to participate in an outing filled with the promises of rounding up wild horses and hunting for elk.

Fourteen hours later, and Terry is driving up into my cul-de-sac. I dreamily thank him for everything, and he shows me that crooked grin again. The day's adventures play in my mind like children in a park: winding our way around backroads, through the woods, and finding wild horses, then actually lassoing one, and delivering it to a family who had recently suffered the loss of their own horse. Hunting for elk in heavy timber, and seeing deer, wolves, and other wildlife. Meeting Terry's jovial wife, and eating an enormous turkey dinner, while watching their sons play video games at hyper speed (and sound). I find myself feeling incredibly grateful to these people, who hardly know me, for their hospitality, their quiet humour, and their simple ability to defuse my culture shock. 
In the next 21 months, I will meet many people like Terry, people who work in the oil and gas industry, and whose beliefs in the power of capitalism and in our unquenchable thirst for consumption drive the quest for new frontiers of resource exploration. I will observe deeply rooted displays of masculinity and gender inequality. I will come to know the seductive power of earning an eye-wateringly high salary, and learn how the oil and gas industry impacts the communities it operates within. I will witness ways in which oil and gas workers practice and justify the consumption that hallmarks their lives. I will observe people in a community seek to help their own, and study the forms and meaning that such help takes. I will see the best and worst that a resource-extraction community has to offer, and it will leave me deeply conflicted. I will be present during the contentious present times of a northerly town, while its uncertain future, which includes a struggle to retain the best and brightest citizens despite collapsing oil prices, lurks nearby. And I will try to document, interview, research, interrogate, and analyze everything that I experience here. At times I will be overwhelmed with wonder; at others, I will be bitterly repulsed by this place and the people in it. In the end, I will have gathered a clearer picture of a Canadian community in thrall to the oil and gas industry, and how it understands itself within that thrall. It will have been the hardest, and the most meaningful, two years of my life.

\section{1 - Studying Oil and Gas in Alberta}

This thesis is an ethnographic examination of Grande Prairie (hereafter, GP), a northern Canadian hub city that is supported and sustained through natural resource extraction. It shows that this city, and many of its neighbouring communities, have entered into reciprocal relationships with the oil and gas industry, ones that support and perpetuate masculine and 
gendered cultural understandings. Here, hard, physical work for financial gain is prioritized, and men and women are simultaneously placed into tightly bounded categories. While it can be 'good' to be a man in such a community, especially a working-class white one, such rigid categories are not universally appealing, and this thesis finds that workers often leverage their earnings with a plan to leave the industry and pursue other interests. With the oil and gas industry being both a significant employer and contributor to Canada's economy, continued exploration of the normative cultural underpinnings of extractive resource communities is needed. For all the uncertainty that accompanies life in the shadow of oil and gas, such communities are diverse and complex, and residents are thoughtful about their economic positionality. Their words, stories, and experiences are integral parts of the fabric of the social narrative of working and living in an oil and gas community.

Research was conducted between October 2012 and May 2014, a period when oil prices reached well over $\$ 100$ per barrel. During those 21 months, high oil pricing rendered my community of study a significant draw for job seekers. By December, 2014, six months after leaving the field, the price of oil had dropped to approximately $\$ 60$ per barrel, and job opportunities had lessened significantly. By September, 2016, oil prices were holding steadily at around $\$ 50$ per barrel, and the oil and gas sector across Alberta was experiencing deep layoffs and cutbacks. The province has weathered the changeability of an oil-driven economy before, but this particular recession appears poised to last a considerable length of time.

The above qualifiers are laid out early in the thesis because my study represents a snapshot of a resource community with an overheated economy, one that has subsequently cooled, and which may heat up again. Resource communities reside in the shadow of booms 
and busts, and the bulk of my fieldwork took place near the end of a significant boom. The interviews, observations, and findings speak to that reality, while acknowledging the potential for rapid reversal of economic fortune. This extreme changeability of existence in an extractive resource community - from high wages and indiscriminate consumption to unemployment and crushing debt - provides a powerful incentive to study it. However, ethnographic study of resource communities is layered with difficulty: cycles of rapid economic reversal and social upheaval are normalized, and the attitudes displayed by residents during an up cycle often brim with confidence, hope, and entitlement, while those shown during times when jobs are scarce and earning opportunities few can be fearful, bitter, and dejected. The researcher, as a perpetual outsider, can quickly shift from an object of interest or placation to one of intense scrutiny and hostility. Admittedly, research within a community where the potential reversal of fortune is high can be exciting. The other side of this excitement is that the same research can also be exhausting, but the stories, experiences, and interactions that were shared between myself and participants could not have been accessed without a long period of immersive study in the host community.

In examining an oil and gas community, this thesis explores categories that are meaningful to those who labour in oil and gas, including community, gender, work, and history. Because the views explored are those of working-class white men (and a few working-class white women), these categories are framed and apprehended in particular masculine and 'common-sense' (a la Geertz, 1975) ways. Dunk's (1991) work focused on working-class males in Northern Ontario is instructive, in that it illuminates the particular ways of being that are usual to labourers. He writes, "The working class is neither essentially good nor essentially bad; 
it is a complex social grouping which contains many positive features and some less admirable qualities" (1991: 4). Oil and gas workers share this kind of complexity, and theirs is further complicated by a spirit that celebrates the industry as one that is inherently productive and beneficial to Albertans, Canadians, and the larger world. Turning a critical eye to the oil and gas industry is an intricate undertaking, one made more so when the project is an ethnographic exploration of workers within that industry. Oil has many specificities: it is a product, an outcome, a political entity, one with geopolitical consequences, as well as a resource and a means of political and social leverage. It also exists as desire, a feature pivotal to the capitalist vision: oil is thick with possibility, and especially possibility that can be rendered into profit. Within this confluence of factors, oil and gas workers are proud of the work they do, understanding themselves to be major contributors to Canada's economy. Like Dunk's (1991) 'Boys', oil and gas workers "do actively attempt to fill the experience of work with meaning" (1991: 66), and a major factor in doing this is to understand their work as enabling Canadians and the rest of the world - to access the gasoline necessary to power cars, trucks, commercial vehicles, and ATVs, as well as the other goods and services enabled by petroleum extraction. Their own enthusiastic consumption of these products and services, and especially gasoline, resonates with cultural values that support the promotion of the oil and gas industry, and which extend into consumer branding, lifestyle choices, and class identification.

Within this celebration of living and dead resources, oil and gas workers conceive of their labour as productive but not in the Marxist sense of generating surplus value. Rather, oil and gas work is understood as productive in that it produces tangible outcomes, realized through the extraction of raw petroleum and minerals, requiring forms of physical labour. 
Instead of being thought of as exploitive, these things are sources of pride to the workers. Unlike intellectual work, such as knowledge generation, oil and gas work is work of the body, and for oil and gas labourers, this is a key distinction, and an admirable one. Such 'productive' work is both a goal and an ideal for the industry, because it is predicated on locating large reserves of raw oil and gas, and is highly reliant on a massive combination of technology and labour to achieve successful extraction. As a result, workers are inculcated into a labour process whereby the economic rewards for their labours are substantial, but rather than being understood as inherently exploitive, workers believe themselves to have both choice and agency within this process (for more on worker agency, see Chapter 3, Section 3.3).

Before moving on to the review of oil and gas literature, it is appropriate to briefly comment on the issue of homogeneity in an oil and gas community. As readers of this dissertation will discover, many of the participants, despite holding or espousing particular views about community homogeneity or the homosociality of working cohorts, do not neatly fit into popular stereotypes and categories usual for oil and gas workers. As well, their assumptions about the nature of community, masculinity, gender, and work can be at once complex and simplistic. It is not the intent of this thesis to comprehensively explore the degrees of diversity usual to a community such as GP, but this is not to say that diversity remained unencountered; indeed, I explore the category at a number of intervals throughout these pages. However, the bulk of focus is trained on the lives and attitudes of workers and residents of GP that are intimately connected with the impacts and connections of the oil and gas industry, and as a group, these are people who share many similarities, and who predominantly fall under the categories of working-class and white. It is to be noted that GP 
was and is home to a growing population of African groups, but that these are not wellrepresented in oil and gas work for a host of reasons, including religious and familial value systems that are largely incompatible with the demands of such jobs. Some of these same reasons also apply to groups of temporary foreign workers (TFWs), and to GP's largest immigrant group (during my fieldwork, at any rate), people originating from the Philippines. Clearly, GP is not a monolithic entity, but representations of diversity are diluted when focusing on a specific category of worker and community resident, and this must be considered in the larger context of an investigation into such entities.

\subsection{2 - Oil and Gas Literature}

Canadian oil extraction, production, use and discard has a lively and controversial history, and one that has been well documented. The Canadian journalist Peter Foster $(1979 ; 1983 ; 1985)$ authored a series of books that chronicled and explored backroom deals, billion-dollar buyouts, and the 'old boy' cronyism that undergirded the business side of Alberta's oil and gas development in the 1970s and 1980s. In tapping into the volatile interplay between industry dealmakers based in Alberta, he helped bring to light how decisions made in boardrooms in Calgary impacted the rest of the country. Sociologist JD House (1980) explored the culture of 'oilmen' in Calgary, and found it to be based around the notion of free enterprise. He argued that this was a convenient myth, one propped up by a kind of Durkheimian logic, wherein the proliferation of an idealized past and present functions to unite and encourage solidarity among members of the particular social group. As my research will show, such idealized logics continue to be valued and to operate in Alberta's oil and gas communities. 
Historians such as Chastko (2004), have explored the complex political and financial jockeying that took place in leading up to the development of Alberta's oil sands resources, while Gow (2005) has provided a comprehensive review of the evolution of Canadian oil well drilling equipment and techniques. Breen (1993) delivers a detailed account of the political and financial machinations in advance of the province of Alberta installing an early energy and resources regulatory body in 1938, named the Petroleum and Natural Gas Conservation Board, and the resultant challenges and successes it faced through the 1950 s.

There are also richly detailed accounts from insiders, those who lived their lives in service to the project of Canadian oil and gas, as workers and wives. These include GarstadRosenau (1997), Hotchkiss (2009), Hunter (1995), Jones (1995) Kerr (1986; 1991; 1994; 1998), Nielsen (2012) and Sawatsky (2009). These works span a spectrum of lives, encounters, ideologies, successes and failures, fed by the shared notion of contributing to a project that was larger than any one person or place: a contribution to the building of Canada into an industrialized country that was respected on a world stage.

Journalists have also made important contributions to these literatures. Earle Gray (1970; 1982; 2000) assembled a history of Canada's 'oil patch' ('oil patch' is a colloquial catchall phrase for the oil and gas industry) from its early beginnings in Ontario through the discoveries of gas in Southern Alberta, and into the era of oil sands; contributed a portrait of Francis Murray Patrick McMahon, an entrepreneur responsible for the creation of the first natural gas pipeline to Canada's west coast; and detailed a four decades-long history of the policies and evolution of the National Energy Board. Nikiforuk's (2002) incisive biography on Weibo Ludwig, the acerbic Dutch-Christian pastor who moved his family to an isolated 
community in northern Alberta and there ran afoul of the oil and gas industry, provides keen insight into the heart and mind of a controversial opponent of the industry.

Well into the $21^{\text {st }}$ century, the oil and gas industry continues to attract attention, and with it, the critical views of today's journalists, authors, and public. In 2013, Canadian variety magazine The Walrus published an interest piece about life in Fort McMurray, the community which serves as the primary base for Alberta's oil sands activity. In it, author Taras Grescoe offered a bleak portrait of a community occupied by "a depressingly large population of desperately lonely guys blowing ridiculously fat paycheques on steroids, tattoos, monster trucks, and peelers [nude dancers]" (Grescoe, 2013). Public reaction in Canada to the proposed Enbridge Northern Gateway pipeline spawned more than 130 protests in November of 2013 alone, according to the Huffington Post ('Enbridge Northern Gateway Protest Rallies Held Across BC', 2013). In a May 2013 piece, Christopher F. Schuetze noted that Canadian oil was increasingly considered 'dirty' by EU regulators and policy makers ('Is Canada's Oil Too Dirty for Europe?', 2013). The proposed Keystone XL oil pipeline, which is to originate in Alberta and terminate in Texas, passing through Nebraska and Illinois, has encountered vociferous opposition, and by July of 2016, had its own Wiki entry with over 190 references. In late 2015, sitting US president Barrack Obama cancelled the building of Keystone XL (Canadian Broadcasting Corporation, 2015), but then-Republican nominee, Donald Trump, argued for the project to be revitalized (Canadian Broadcasting Corporation, 2016). As of mid-2017, the pipeline project had been greenlighted by the Trump government, but continued to face criticism and protests (The Guardian, 2017). Despite controversial press, negative stereotypes, and market vacillations, the oil and gas industry has long been a prime draw for workers 
seeking top wages (see, for example, Huffington Post, 2013; The Globe and Mail, 2014). Whether it is able to remain so, especially given that the impacts of the 2014 economic downturn are being felt through 2017 , is yet to be seen.

My own relationship and interest with the oil and gas industry has a long history. The rural farming community in Saskatchewan where I was raised was a hotbed for oil production, and crews of men and equipment were a common sight. Through repeated contact with workers and crews, I grew fascinated by the stories of hardy people, toiling in harsh conditions, determined to succeed. Our farm was located near the Alberta border, which increased opportunities to interact with industry personnel, view equipment installations, and observe oil well drilling projects. After completing high school, and needing to save money to attend university, I found employment with a fluid transfer company. I returned to this job for the next several summers, becoming conversant in the language and bodily practices of transporting oil and the service industries usual to it. Relocating to Calgary brought opportunities to work in hydraulics, repairing or troubleshooting equipment specific to drilling and oilfield processes. While not working directly in the oil and gas sector at that time, my interest continued to deepen.

Through taking evening courses at the University of Calgary, I earned a BA in anthropology, and encouraged by faculty, enrolled in a Master's program. I spent three months researching on an oil well drilling rig in southern Alberta, and learned much about consumption, safety, and social mobility, as viewed through the lenses of drilling rig workers. Wanting to undertake a concentrated research project, I applied for doctoral studies in anthropology, hoping to undertake field research in northern Canada, along the Beaufort Sea, 
an important and contested region for oil and gas extraction. The remoteness of the site proved too challenging in terms of my own time and resources, so I decided instead to focus on a north-western region in Alberta, home to GP, an acknowledged oil and gas hub city. I moved across the country and lived in that city for nearly two years, assembling a broader understanding of the social networks, values, and frameworks of a host of communities supported by resource extraction.

Moving beyond the Canadian stage, the literature, perspectives, and theoretical orientations on oil and gas are legion. Oil has many specificities, and its deep global interconnections are usefully explored through the lens of political economy. Anthropologists, economists, political theorists, and others have done much work in this vein, from Fernando Coronil's (1997) historical exploration of Venezuela's petroeconomy, Timothy Mitchell's (2011) consideration of the tenuous frameworks of economies built upon the assumption that access to oil will remain unending, through to Ariweriokuma's (2008) examination of African countries that increasingly contribute oil and gas to global markets, while negotiating their own futures in developing economic frontiers. While this thesis does not take an explicit political economic point of view, the analysis and historical exploration it contains are not unrelated. Beyond simply existing as an extractive resource or an economic commodity, we can understand oil, as a category, to be truly global, occupying political, social, historical, economic, intellectual, and developmental spaces. The focus here is on a community in northern Alberta, but those specificities of oil as an idea, an entity, a dream, and a nightmare reach across space and time, implicating Albertans, Canadians, and the world. 


\section{2 - Exploring Gender and Masculinity in Oil and Gas Work}

Studying a 'boom town' offers a rich canvas for observing and engaging with performative masculinity, notions of gender, and how work and social roles are navigated and enforced. That the oil and gas industry can appear to outsiders as monolithic and indifferent of gender and ethnic diversity is not a coincidence. Rather, it has been built on the labour ideals of workingclass masculinity and its attendant values and orientation. Conservative political beliefs, traditional expectations of sex and gender roles, and the heroism and celebration of the male body as a vector for physical accomplishment are usual throughout the GP region, and the larger industry.

As this thesis shows, female participants struggled to establish themselves as equals or superiors among their male co-workers. Diversity continues to be problematic for an industry that does not easily admit (nor much want to) women or minorities into its cultural value categories, and without such diversity, challenges to the dominant cultural value systems are rarely sustained or effective. If the oil and gas industry is understood to value practicality, 'common sense', and homogeneity, then factors such as gender and ethnic diversity, which do not easily submit to tightly-bounded categorization, introduce uncertainty and tension into a system predicated on simplicity through sameness. The value systems of oil and gas only respect difference in so far as it contributes to innovative thinking in terms of solving on-the-job problems and leveraging personal worth. Other expressions of difference are inherently problematic, even threatening, to the dominant cultural structures that undergird the way the work is perceived of, performed, and promoted.

The turbulent history of the oil and gas industry in Alberta, its rough and tumble developing years, and the aggressive plays for resources and profits that characterize it have all 
contributed to a climate that broadly promotes masculinity and stresses adherence to tightlyconscripted working roles. Peering beneath these masculine surfaces, it is useful to consider the potential web of connections in what is physically produced at the sites of oil and gas - the raw, extractive resources, in various forms - acting upon those who produce it. If we, as Malm (2016) has done in the introduction to his book, Fossil Capital, consider just the proliferation and impact of the automobile, it becomes clear that the worker is enmeshed in a significant chain of consequences: "Cars, to begin with, run on fossil energy... The choice to travel in them rather than trams or buses or on bicycles is conditioned by a vast infrastructure of oil terminals, petroleum refineries, asphalt plants, road networks, gasoline stations - not to speak of the film industry, the lobbying groups, the billboards" (2016: 7). For workers in oil and gas, the act of producing petroleum is one of many processes nested within a hive of activity that both supports and reifies the industry's dominant values.

Ferry (2011), in her ground-breaking work on mining for precious minerals in Mexico and their subsequent sale to collectors in Arizona, notes that "... Men and women make themselves not only through their relations to each other but also through their relations to the things they produce and consume" (2011: 916). She finds that for those who labour in the mines, almost always men, "gendered objects" are produced alongside the physical specimens, which then act back upon the miners, rendering them "gendered subjects". The mine is then "a site that brings together processes of human labor, embodied and sensory experience, and the organization of social networks in the making of gendered subjectivity" (2011: 915). So too, the production of oil and gas acts back upon those who are enmeshed within it, both reifying that which is culturally and socially acceptable and delineating where the boundaries of such 
acceptability should lie. In this, the sites of oil and gas are potent places of meaning making, shaping the actions of men and women, and acting and reacting to both physical and socially produced phenomena.

If there are implications for the performance of masculinity within the relationships between producer and produced, then, as Ferry (2011) notes, there are also implications for certain of Marx's assumptions regarding workers and labour alienation. She muses, wondering if "talking about the creative relationships that producers have with their products would mean saying that producers are not really alienated from their labor and its products in the way that Marx described" (2011: 940). A further, unsettling implication looms, which Ferry then names, specifically that given the preceding, it could "mean saying that these workers are not really being exploited" (2011: Ibid). But, of course, there is exploitation in the labour of Mexican miners, as there is among Canadian workers in oil and gas, albeit expressed in different ways.

As the sites of oil and gas work shape meaning, so too shaped are the physical and social bodies of those who perform the work of extracting oil and gas. The body is integral to labour work, and oil and gas work demands that bodies labour in specific ways, for specific intervals, shaping how those bodies perform tasks, and informing those bodies in terms of the expectations of relationship to their work. Timothy Morton has argued that there exists no such thing as "the" body - a container beyond the touch of categories - but rather that bodies can be thought of as "site[s] of revised aesthetics" (2007: 106). While there is utility in the former, it is not for the reasons that Morton would hold to be evident: oil and gas workers are intimately aware of their own bodies as fallible. As the vassals of the construction of a nature that is predicated on rewarding work, pursuit, and mechanization, they are complicit in the 
remaking of the aesthetic of their work into a form that suits the goals of late modern capitalism: heavily productive, mechanized, unrelenting, and unquestioning. This all has inscriptive consequences, and while the body may be a container, as the hypermasculine forms of several research participants can attest, it is hardly untouched.

Those who perform this work engage in a variant of ethopolitics (Rose, 2000), in this case a technologized self-surveilling citizenship, one in which members guide and sanction each other. Particular to the ethopolitics of oil and gas work is a membership whose essence is based on exchanges of capital value, and one which ensures substantive effort towards that end each from the other. As such, workers, when faced with potentially difficult or unsettling decisions related to the environmental and social impacts of the projects being undertaken, are encouraged to focus heavily on the technologization of their occupations, and to concern themselves with production numbers and targets. In this way, there is an emotional removal or 'flatness' - an idealized form of masculine expression, to be sure - that accompanies work projects, one further assuaged through the opportunity to earn a prodigious salary. Successful immersion within the cultural value system of the oil and gas industry requires a buy-in of the two factors noted above, and the cultural framework of the industry is supported through significant economic incentivization and the maintenance of a strong culture of emotional distance, presented in a guise that values hard work, stoicism, and the performance and maintenance of traditional expressions of working-class North American masculinity. As the industry promotes masculinity as both a type of pre-requisite for the work, and encourages the ongoing maintenance and development of it throughout the job cycle, workers are keenly incentivized to measure up to the particular masculine standards. 
And so, in any analysis of those who work in oil and gas, and of a community that supplies and supports its projects, gender and masculinity must be considered. The expressions of these categories are necessarily performative, and oil and gas has particular value systems that shape the ways masculinity and gender 'are done'. The labour work force of oil and gas is largely built from the ranks of conservative, working-class white males, and the admiration and mythologization of lone wolf and hypermasculine characters resonates strongly with this group, as do traditional understandings of gender roles and of work suitable for men and women. Through the perpetuation and maintaining such traditional categories of work, masculinity, and gender, the oil and gas industry suffers from a narrowness of vision. If wishing as an industry to continue to operate freely, it must regenerate significant public good will, and have the blessing of the community to act. It would follow then, that diversifying the ranks of workers, creating more inclusive, supportive work spaces that value the ideas of women and minorities, and instituting policies of increasing transparency when engaging with the public would go far in revamping the industry's reputation. However, any of these changes would require a remarkable transformation of oil and gas culture, one that attracts and values workers that perform tightly-bounded emotional and physical actions. It remains to be seen if the industry is willing to undertake such reforms, but based on my research and experience with oil and gas, it is more likely to continue on in what is so often a highly masculine, opaque and confrontational manner.

\section{3 - Understanding Canada through a Lens of Oil and Gas}

In examining oil and gas exploration in a community such as GP, larger implications for Canada emerge. This thesis contributes to a broader understanding of those implications. Through 
interacting with and exploring the lives of those who live and labour in oil and gas, the intersections between work and community, and why what happens in places such as GP matters for the rest of the country, can be better apprehended. That oil and gas work continues to be both an economic engine of the country and enduringly controversial does not imply, however, that understandings of it must be relegated to a simple binary. Rather, the complexity of the relationships between the industry and Canadians reaches across socioeconomic, political, social, and provincial boundaries: Canadians are heavily reliant on oil and gas, benefitting from its production in terms of job and wealth creation, and through the products, services, and items that it begets. A future absent of oil and gas in Canada is difficult to envision, and doubly so for Albertans, where the industry is intimately connected to the economy, history, and working and political identity of the province.

In Alberta, the downturn in oil and gas pricing that began in mid-2014 has led to significant cutbacks in job creation and public spending. It has also meant a sharp rise in outmigration, and corresponding rises in unemployment figures and political cynicism. Three years later, a scan of oil-industry publications reveals the uncertainty and turmoil that analysts are tracking, but signs of changing attitudes or of questioning the sustainability of continued large-scale production are in scant evidence. In June, 2017, JuneWarren-Nickle's Energy Group (JWN), an industry consortium which publishes both Daily Oil Bulletin and Oilweek, released a special report on the production and economic outlook for oil sands production in Alberta. The report details the uncertain climate for oil sands profitability and stability, noting that costs must decrease in order for companies to continue to be competitive: "Dramatic changes are required in capital and operating costs as well as greenhouse gas emissions in order to enable 
oil sands projects to compete for new investment dollars with other shorter-cycle global plays like U.S. shale oil" (JWN Energy, 2017: 45).

The report also suggests that a substantial part of the drive to reduce operating costs will be found in further technologization of procedures and production sites (p. 61-70). While there are numerous references to a continued drive to reduce greenhouse gases and emissions, no mention of harnessing innovative and technological capabilities to move away from carbonbased exploration is made. In fact, at the outset of the report, author Deborah Jaremko, JWN Oilsands Editorial Lead, writes:

"While the world is undergoing a transition to lower carbon energy sources, projections are that demand for fossil fuels and specifically oil will continue for decades into the future. Analysts with McKinsey \& Company recently forecast that by 2030 oil producers around the world will need to add 35 million bbls/d [barrels per day] of new production capacity to meet demand. The question is what role Canada's oilsands will play in that growth".

(JWN Energy, 2017: 45)

Her words echo a common view in the Canadian oil and gas industry, that it would do well to focus on best benefitting from the projections, rather than mimicking global trends in moving away from traditional energy sources. This narrowness of view is well-established in Alberta, and has undergirded much of the history of oil and gas development in the province. Rather than conceptualizing the economic slowdown as an opportunity for rethinking attitudes and approaches to carbon-based resource exploration, the industry instead continues to participate in a race to the bottom. The perpetuation of a 'business as usual' attitude will be a welcome one for provinces rich in oil and gas, but in terms of the rest of Canada, it is likely that the public and political discord aimed at the industry will continue to grow. 


\subsection{1 - Attracting New Employees?}

In a recent survey, Ernest \& Young (EY) sampled respondents aged 16-19 (known as Generation Z) and Millennials aged 20-35, so as to gauge attitudes toward the attractiveness of careers in oil and gas. The survey found " $62 \%$ of Generation $\mathrm{Z}$ respondents consider a career in oil and gas unappealing. A surprising 39\% ranked it as 'very unappealing', compared with just $4 \%$ of young respondents who said it was 'very appealing'” (EY, 2017: 1). Among Millennials, respondents were moderately more interested in the industry: " $45 \%$ ranked industry careers as appealing versus $44 \%$ unappealing, and $11 \%$ were unsure" (Ibid). The report also noted that, "The results disintegrate further when we delve into more detail", and "Perhaps most concerning, more than two out of every three teens believe the oil and gas industry causes problems rather than solves them. And teens and millennials are far less likely than older consumers to agree that oil and gas are 'good for society'" (Ibid). Similarly, a recent article in Oil Price speculated as to reasons why Millennials are uninterested in oil and gas work, concluding that many young, career-minded people view the energy industry as lacking in innovation, stability, and environmental transparency (OilPrice.com, 2017). To date, the effectiveness of industry strategies designed to accommodate a new class of worker in Millennials remains questionable, and it is likely that for those young people who grow up outside the immediate sphere of oil and gas activity, or who have environmental or sustainability concerns, work within the industry would be less attractive still.

In Alberta, mainstream media has regularly focused on the duration and impacts of the current economic recession, the possibility of an eventual rebound, and the degree to which such a rebound is tied to the fortunes of oil and gas. Chris Nelson, in an October, 2016 opinion piece written for the Calgary Herald, in considering what sort of future Alberta could have 
without a significant energy infrastructure, asks, “But what if oil doesn't come back? What if we can't rely on royalties to keep taxes low and spending high? What if we have to knuckle down and really work at finding ways to keep enjoying a high standard of living? Do we have what it takes?" (Calgary Herald, 2016). His speculations echo the economic and future concerns of many Alberta residents, most especially those who are employed in oil and gas, either directly or indirectly, and those who can recall a dark time when Alberta was not known as an economic powerhouse.

A 2016 article by the Canadian Broadcasting Corporation reflects some of the findings made public in the EY report. In the piece, two groups are interviewed: business owners whose services are reliant on oil and gas activity and young people examining various career options. Not surprisingly, the business owners interviewed were supportive of the industry, but young people entering the job market out of high school or university were less certain. Within the article, a national survey is referenced, one that was conducted in February of 2016 with a sample size of over 2000 , and which found that young people have significant concerns about the longevity and environmental impacts of oil and gas, and that they recognize that the economy and environmental awareness share linkages (Canadian Broadcasting Corporation, 2016). That such attitudes have reached the ears of those on job sites and field offices in communities such as GP is certain, but thus far, the industry has shown itself to be more concerned with attracting new talent through time-tested means, rather than opening up discussions around revamping practices and planning exit strategies. 


\subsection{2 - Small Towns and Vulnerability}

As labour and material providers to the projects oil and gas, communities such as GP can act as a significant barometer for the health of the oil and gas industry in Alberta. During both boom and bust cycles, head offices in Calgary closely monitor industry trends, changes in pricing and cost, and analyze insider gossip and speculation. Reactions to these are then issued, and are quickly reflected in the field operations of communities such as GP: with a marked drop in pricing for oil or gas, new projects may suddenly be halted, workers laid off, and operations suspended, indefinitely. Conversely, when prices rise, new bids are made, capital and expertise is poured into new projects, and field personnel are in demand, driving operations forward at a high rate of speed - the preferred state of activity within the industry. However, the operational state of the oil and gas industry in Alberta appears only to exist in two extremes, those being near inactivity or approaching mania. This is well-illustrated in my experience in revisiting GP briefly in the winter of 2016, nearly two years into a protracted economic downturn. At that time, with oil prices hovering around the $\$ 50$-per-barrel mark, the equipment yards of oil and gas companies that line the main access roads to the city were crowded with unneeded machinery. Two years prior, with oil nearer to $\$ 100$-per-barrel, these same yards were conspicuously vacant, indicating that all useable machinery was in service (for more on the return to GP, see Chapter 6).

During this brief visit, I caught up with a participant, one with many years of experience working internationally. I learned that he believed this 'on/off' reactivity to changes in oil prices to be particularly Canadian in manifestation. During a conversation, he indicated that "the oil patch doesn't work like this in other countries, the curve isn't so steep or sharp" (personal communication, 2013). Knowing this man's working background, I understood that 
he had spent time (many years, in fact) working in Middle Eastern countries, where the regulatory controls for oil production and export differ from Canadian ones. It is possible he did not appreciate this fact to a significant degree, which is suggestive of the narrowness of expertise: one can be acknowledged as experienced and well-traversed in an occupation and yet remain unaware of larger factors that substantially impact that occupation. Similarly, Karen Ho, in her 2009 ethnographic study of workers on Wall Street, also noted that for her participants, "... the construction of booms and busts are simply conflated with 'the market' and are not understood as arising from particular workplace models, corporate culture, and organizational values of Wall Street financial institutions... or the specific and personal experiences of those who work for them" (2009: 10-11). Ho's observation had implications for this thesis, as my own participants were often framed as experts in the cultural material and practices being investigated. However, expertise does not necessarily mean awareness, and I discovered throughout the research that it is erroneous to assume that a person working in the oil and gas industry is more broadly knowledgeable about geopolitical factors that impact it than someone who does not.

Beyond market downturns, with the industry struggling to find ways to both broaden its appeal and attract new generations of workers, the communities that house and provide labour to the projects of oil and gas are increasingly vulnerable. GP, as a northerly city in Alberta, cannot continue to be a viable destination, one that attracts and retains working talent, families, and retirees, unless it has a strong and flourishing economy. As this thesis explores, opportunity in GP is largely tied to labour-related economic possibilities, heavily enabled by oil and gas exploration (and, it must be said, a well-established and forward-thinking local forestry 
industry). As a result, a crucial issue is that the region's heavy reliance on resources that are either non-renewable or slow-to-renew will signal difficulties for the growth and sustainability of GP in the long term. If the trend of fewer young people entering the industry continues, GP will languish, as nearby communities without significant natural resources to draw upon have already done. Without a significant economic draw to the region, migration will slow and then decrease, and local young people will be likely to move to larger centers, those with more expansive working, social, and life opportunities. Due to its economic diversification, including forestry, ranching, and agriculture, GP is reasonably well-positioned to withstand a prolonged oil and gas downturn, but it is unlikely to see a return to the halcyon days of high oil prices, which attracted people, ideas, and capital to the region, and served to keep them there. Canada can appear a country that is post-industrial, one where the famed mines of Ontario and staggering coal production in British Columbia is a historical whisper. However, Canada is not truly post-industrial: it is actually engaged in a type of modern industrialism, one that includes forestry, fishing, and nuclear power, and oil and gas exploration accounts for a large portion of this type. The simple fact is that for most Canadians - those who increasingly live in large, urban centers - industrialism is not frequently evident in daily life, beyond the ever-changing cityscapes wrought by incessant construction. Where it is evident is in peripheral communities, and in Alberta, that means places adjacent to hub centers such as Fort McMurray, Lloydminster, and GP. Already at the behest of geographic removal, these peripheral communities experience a slow withering, and with the ongoing economic recession in the province, the impact of industrial decline is felt all the more acutely. Life in such communities is effectively, as noted by Fortun (2012), a type of "late industrialism, a historical 
period characterized by degraded infrastructure, exhausted paradigms..." (2012: 460). As young people elect to relocate to larger centers that offer greater social, education, and working options, these small towns and cities effectively vanish. This trend has a long trajectory in Canada, as the country has been transformed from a largely rural population to a metropolitan one (see, for example, Lucas, 1971, on the instability of single-industry Canadian communities in the 1960s). The history of small communities has often been created and supported through industrial occurrences, and oil and gas is likely to be the last one of those to impact communities in northern Alberta.

While the impacts of declining populations in small towns in northern Alberta were evident during the research period, agricultural and ranching communities north of GP appeared more cautious about courting the oil and gas industry as a means of revitalizing. I frequently traveled to meet participants for interviews, and was able to observe a number of communities that had ceased to thrive, and that were seeking assistance in planning for the future. Through my involvement with Grande Prairie Regional College (hereafter, GPRC), which included being taken on as the College's first Visiting Scholar, I collaborated with a number of municipalities and counties to plan community rejuvenation projects. Interestingly, these projects were tied to agriculture and animal husbandry - none were related to oil and gas. For many of the people involved in the planning phases of these projects, the oil and gas industry was less than attractive: the boom and bust cycles, in addition to concerns about the environmental and agricultural impact of extraction, led to reluctance to partner with extraction companies, or to outright refusal and protest. In the case of a community councilor who agreed to be interviewed, the oil and gas industry was likened to a virus that came into 
communities, sapped the resources, and then moved on. This councilor lived and worked in a small town north of GP, and was nervous for the future of the town itself, and the area it occupied in the larger Peace Region. As she remarked, "You can't keep them [the oil and gas industry] out forever". For a number of communities, far from being an answer to various problems of succession, the oil and gas industry was unwelcome, and understood to be disruptive and polluting.

Regardless of views that support or decry the industry, those that lived in these small communities were aware of their precariousness, and the attitudes they displayed were mostly sober and realistic. As one participant, who grew up in a community that had tried a number of revitalizations strategies, remarked, "People just want some measure of control, ya know? They wanna feel like they have some power, some say in how the community changes, for better and worse" (personal communication, 2014). As these peripheral communities dwindle, their younger populations seek opportunity elsewhere, which then means that centers such as Vancouver, Calgary, Toronto, and Montreal must absorb the new migrants. It also means that over time, those who leave are less likely to return to the communities of origin to raise children or reaffirm their roots. These communities are already at a low ebb, and those that refuse the economic promises of the oil and gas industry may slide into decline sooner than those that do not. However, the ongoing slump in oil and gas fortunes also means that communities closely tied to the industry are not faring well, and their own futures are highly uncertain. This suggests that there is a choice in terms of how these communities erode, but that the erosion itself may not be halted. 
Despite such a potentially bleak future, the same spirit that permeates the oil and gas industry, what could be named a 'can do' attitude, embracing of challenge, is also evident in the smaller communities in the GP area. Simply living in the area requires a spirit of fortitude, as winters are long, summers short, and the lifestyle is an isolated one - unlikely to attract newcomers and young people, or encourage those raised in the region to stay on. Oil and gas work certainly provides income and stability to these communities, but recall that the Peace Region is also heavily active in farming, ranching, and timber, which provides economic alternatives should the price of oil and gas decline. Throughout the research, I remained optimistic that nearby small communities would find ways to weather changes in the oil and gas industry, but ultimately that their peripherality was engendering a continual, slow decline. The irony implied, of course, is that entering into partnerships with oil and gas could both encourage community growth and enrichen local entrepreneurs, but simultaneously bring environmental and social problems to the fore. As noted above, a number of these small communities had decided to forgo oil partnerships and focus on community rejuvenation based around their skill sets. They were determined and were developing useful resources and strategies. This rejection of the potential economic advantages of oil and gas was notable not only for being unusual, but also for signaling that these communities wished to pursue their own agenda, in their own way. They were taking control of the situation, and preferred to band together and pool their own resources, rather than depending on outside assistance with a number of contingencies. Despite a future without assurances, these communities were determined to make attempts at improvement, and that kind of agency is both usual and necessary when dwelling in the periphery. 


\section{4 - The Richness of Working-Class Life}

In examining the working and social lives of GP residents, this thesis shows them to have significant complexity and depth, which operate in concert with and beyond the economic opportunities usual to the region. The study of working-class life is well-documented in the academy, and many social scientists have contributed to the canon. A significant British tradition of working-class studies exists, and includes the work of pioneering scholars such as Hoggart (1958), Thompson (1963), and Williams $(1958,1961)$, and later Willis (1977). While their collective output made a strong case for the value in studying working-class life in Britain and documented and analyzed various expressions of it, the current climate for examining working-class culture in North America is markedly different: modern industrialism in North American society has its own patterns and rhythms, and the categories of analysis must reflect this reality. Compared to the coal and smelting industries of 1950's Britain, the oil and gas industry in Alberta is less homogenous, and is (slowly) admitting diversity.

The study of industrial professions from an anthropological and sociological point of view reached a zenith a few decades ago, but there has been a modest resurgence of interest (see, for instance Austen et al, 2006; Ferry, 2005; Higgins, 2005; and Tubb, 2015). No doubt some of that interest has resulted from the massive shift in how industrial labour processes are currently enacted. Also, wide-spread economic uncertainty, evolving displays and interpretations of masculinity, and an increasing interest in the impacts of culture on businesses and organizations must play a part in this renewal. 


\subsection{1- Work and Bodies}

The Marxist philosopher André Gorz wrote a thoughtful book about the transition from

industrial-to-post-industrial socialism, proffering nine themes for politically-leftist engagement.

Gorz is instructive in terms of grappling with ideas about work and economics, and writes that 'work' is understood as "an imposition, a heterodetermined, heteronomous activity, perceived by those who 'have it' or are 'looking for it' as a nondescript sale of time" (1997: 1). He also notes that the words 'work' and 'job' are essentially interchangeable, and that any sort of 'work' nearly always implies that a form of payment will be expected. In this way, to work is to be commanded, but also, to always be both seeking and attaining. The relationships between 'workers' and 'work' are necessarily elaborate, and a desire to investigate them constitutes a significant impetus for undertaking this study.

In exploring the working complexity of an extractive resource hub such as GP, one can see Gorz's definition at play within the ethos of both oil and gas labour work and in those who populate it. For those who labour, 'work' is a central tenet of being: it is both a focus and a pressure, a pursuit and a submission, and for those who live and labour in the larger Peace Region, work is an encompassing category that supersedes family, social obligations, and leisure pursuits but which also enables a material-rich lifestyle out of reach for the average working wage-earner. This is no simple binary, however, as the expectations of the job are beyond the simple trading of labour for a wage. The work of oil and gas work requires human removal, the taking of people and bodies out of social environments and placing them into working ones. The tradeoff for such removal is compensation and attainment, but the bargain is potentially Faustian, in that a labourer offers bodily effort for a salary, but oil and gas companies understand that in purchasing such labour, they also can access and demand the 
labourer's time outside the job, and any intellectual property or creative innovations generated while on the job. Working for an oil and gas company requires a total submission of body and mind from the worker.

Sustained physical effort is usual to a working body. Much like what boxers undergo in the "theater of bruising" explored by Wacquant (2004: 4), such a body is both shaped and reshaped by its activity, through patterns of repetition and tension. For those who work in oil and gas, the activities and demands of physical labour have evolved, but there remains a high priority placed on physical competence, skill, and ability. As a result, there are found normative types of bodies on job sites and work spaces in oil and gas, and they are overwhelmingly male and stoic, and especially when younger, muscular. In earlier oil and gas history, the built-up nature of such bodies was frequently due to the physical repetition of the job performed, and was largely functional - the demands of the work required stamina and strength, to be called upon regularly in all weathers. These are bodies that Bourdieu (1978) understood as 'instrumental', in that they are navigated as instruments of necessity, and accordingly must be kept best able to respond to their key use, i.e., ready for a long working day and able to shift heavy loads.

However, Bourdieu also noted that such bodies are not simply instrumentally oriented, and among the bodies of modern oil and gas workers, especially among those who labour on drilling rigs, are often found examples that are muscular beyond functionality. An aesthetic that is focused around an enlarged, visible muscularity has emerged, and in some cases, become highly valued among younger men who work in the industry. This enhanced physicality has roots in the functional capabilities of workers from the recent historical past, but its current 
representation is closely tied to the dominant types of performative masculinity usual to the GP region. As such, the muscularized body is both a sign of capability and one of status: practically, it indicates that the possessor of such a body can successfully navigate heavy, physical work, thus fulfilling the value expectation of masculinity with the job and community. Less practically but more socially, such a body also demonstrates that the possessor has both the discipline to spend copious amounts of time building it up, and the financial wherewithal to access private trainers, specialized gym equipment, nutritional supplements, and so on. In this way, the highly muscularized body of a labourer (who does not necessarily require such a body to function effectively at work) contravenes Bourdieu's understanding of how bodies fit into social strata.

It is worth noting that Bourdieu was interested in how bodies were trained and separated across social classes, and that his analysis did not consider the potential economic mobility of extremely well-paid labourers. In accounting for a body aesthetic that has moved beyond function to a significant expression of visible muscularity, it is tempting to consider such bodies as highly symbolic, contained groupings, operating at the behest of larger market forces. And while analysis that follows such a course is certainly viable, there are further factors to consider. For instance, Shilling (1991) cautions against the reduction of the body to sets of categories. In his words, "[i]t is necessary to see the body as more than just a construction of discourses" (1991: 663), implying that lived experience, what he terms "the phenomenology of the body" (1991: 664), lies beyond categories and discourse. It should be noted that even though a mesomorphic body is not a requisite for working in oil and gas, it resonates at a cultural level as being conversant with understandings and expectations of physical masculinity, capability, and endurance. In this sense, this type of body is an idealized version of both how 
the industry views itself, and how the industry constructs itself, so as to appear independent, capable, and self-sufficient - all things valued in oil and gas. The working bodies of oil and gas labourers intermingle functionality and aesthetics in culturally-acceptable ways, and localized sensibilities of these things result in the production of a unique hybrid: the muscular worker who embodies an ideal that is not actually necessary, but which is laden with (highly rewarding) symbolic capital.

\subsection{2 - There is More to GP than Work}

While trading one's labour for a salary and building a hyper-aesthetic body are major pursuits, life in an oil and gas community has other features. We can understand time passed at field and job sites as representing a different category of being than does time spent 'in town': time in town is usually 'off the clock', and so the transition can be made from working to not working, thus opening the door for other pursuits, hobbies, and interests. As is discussed in Chapter 4, GP's values regarding generosity, high rates of volunteerism, and the willingness of the community to support local causes and activities both draws people in and provides depth to the city. As is shown in Chapter 5, the dynamism of the local arts scene and its positive contributions to people and culture serves to provide an anchor for creatives and those seeking community beyond the usual working and leisure categories. These alternatives to work exist because people have made GP their home, and their community, and they have invested into it. While it is true that many residents have been drawn to the area due to economic opportunities, those who simply passed through, as well as those who have stayed, have all contributed in some way, and left an imprint on the community. 
The result of all those contributions - the money, the volunteerism, the organization of groups, clubs, charities, and guilds - is manifested in a community that appears much deeper than it is wide. Rather than simply existing as a feeder for industry, it is a vibrant, complex, socially-integrated regional hub with many generations of residents. As a northern destination, GP has the educational, intellectual, governmental, and social centers of a much large city and community. That it is located some 450 kilometers north-west of Edmonton does not mean it is a backwater, devoid of innovation or imagination. As is discussed throughout this thesis, GP at the time of research was a hotbed for talent, ideas, and entrepreneurialism, drawing people, companies, and groups from all over the country and beyond. It is a place that can embody engagement and agility, and one that bowls over stereotypes about the sleepy, laid-back orientation of northern or peripheral communities.

\section{5 - Chapter Summary and Overview of Chapters to Follow}

This introductory chapter has a number of aims. Key to these are to: outline the rationale for querying the oil and gas industry in Alberta; provide an overview of the author's previous experience in studying oil and gas workers in Alberta; situate the research in terms of the gender and masculinity frameworks employed; introduce into discussion a number of implications of oil and gas development in Canada and for Canadians; sketch out the particular vulnerability of small towns and small-town ways of living in modern Canadian society; suggest that a richness and vibrancy accompanies working-life, and that such richness is often experienced through the transformational power of physical work; and acknowledge that GP must be understood as comprising more than a simple 'oil and gas town'. 
In Chapter 2, the discussion will first focus on Canada's oil and gas history, and include an exploration of modern methods and styles of extracting oil and gas, specifically the use of drilling rigs, offshore platforms, bitumen retrieval from the Athabasca oil (tar) sands, and the employment of hydraulic fracturing. Second, the organization of the industry will be discussed, along with career options and trajectories, including usual salaries and compensation, and will include an overview of how prominently oil and gas businesses feature in communities in Alberta. Third, rationale is provided for choosing the community of GP as a base for the field research, including a description of the site and its history. Fourth and finally, the research design is outlined, and includes a discussion on the difficulties associated with recruiting participants for an oil and gas study, and the various methods employed to increase success.

In Chapter 3, the scope and shape of the oil and gas industry is theorized from a number of vantage points. First explored is the performance of masculinity integral to oil and gas work, where physical ways of knowing and being are valued and reinforced among workers. Second, the broader oil and gas industry is envisaged as a form of frontier, a peripheral destination that is at once full of economic promise and opportunities for the transformation of people, roles, and power. Third, how the oil and gas industry - and by extension its workers - understand nature is examined, which includes a discussion of how the rise of Western rational thought has influenced the ideological shape of the present-day industry. Fourth, the choices faced by skilled workers in GP are examined, including those of passing through the usual channels of labouring for a particular oil and gas company as a career versus leveraging and mustering capital and connections in order to build a small business and compete directly with the industry. Finally, the work and life choices of those who labour remotely, away from the city, 
and those who labour in GP, as 'town workers', are probed. It is found that there exists a significant dichotomy between these two groups, and that the choices and value systems that characterize the them are largely incompatible.

In Chapter 4, the cultural makeup of GP is explored. The chapter begins with an examination of resource extraction communities, and proposes three cultural components that are pivotal to life in GP. In the second section, the first of the three cultural components are considered, this being the value of generosity, in which residents of GP understand 'good citizenship' to be reflective of a willingness to volunteer, practice philanthropy, and support community initiatives. In the third section, GP's fixation with money, and how it understands the concept of 'economic freedom' to be inherently tied to the accumulation to capital, is scrutinized. In the fourth and final section, the last key cultural component of GP is assessed, that of living through the sudden boom and bust cycles of the oil and gas industry. It is found that workers retain an unshakeable belief in the power of the industry to endure financial and geopolitical shakeups, a belief connected to the necessity of oil and gas in the modern world, the importance of Alberta's contribution to Canada's economic standing, and the ongoing exchange relationships forged between communities like GP and the oil and gas industry.

In Chapter 5, the complexity of GP as a community is considered. In this consideration, it is found that despite the stereotypes that surround resource extraction communities, there are a number of persons and groups in and around GP who fall beyond the usual spectrum of support for the projects of oil and gas, and who practice various forms of resistance. In the second section of the chapter, the expectation of sex roles is examined, as experienced and understood through the lenses of three female participants. What is found is that expectations 
relating to sex roles in GP, and the categories of what men 'do' in work and in social life versus what women are expected to do in these same settings, are inflexible. The lived experiences of female participants demonstrate their frustration and commitment to pushing against such expectations, and the trials and successes of doing so. In the third section, the role of the local arts community is discussed, along with its importance as a gathering point for those who seek creative and permissive outlets as an alternative to the dominant work and social narratives of GP. My own experience as a member of a musical group is also explored, and framed as a creative response to the alienation of daily working life. In the final section of Chapter 5 , the resistance history and activities of two groups, Trickle Creek Farm and Horse Lake First Nations, are outlined and discussed. It is suggested that although such groups can try to position themselves against or away from the impacts and influences of the projects of oil and gas, they cannot entirely escape or avoid them.

Chapter 6, the final chapter of this thesis, opens with an exploration of my experience in revisiting GP nearly two years after the research had been completed, and well into a prolonged economic downturn in Alberta. This downturn had also significantly impacted the GP region, and local businesses and attitudes were struggling to cope with the 'new normal'. The second section of the chapter grapples with the implications of the research and its findings, and explores the troubling relationship that Canadians have with oil and gas. The final section, the outro, offers a brief reflection on an event that is symbolic of life in an oil and gas town. 


\section{Chapter 2}

\section{0 - The Canadian Oil and Gas Industry}

Industry comprises a significant portion of Canada's economy. According to Natural Resources

Canada, the country's natural resource sectors (including mining for minerals and coal, quarrying, forestry, and oil and gas extraction) account for approximately sixteen percent of the country's Gross Domestic Product, and over 800,000 jobs (Natural Resources Canada, 2017). Resource extraction is well established, and according to the Canadian Association of Petroleum Producers (hereafter, CAPP) oil and gas exploration occurs in 12 of 13 provinces and territories (CAPP, 2014). According to British Petroleum's Statistical World Review of Energy, Canada is a world-class oil and gas producer, ranking $6^{\text {th }}$ on their list. Proven reserves include 173.9 billion barrels of oil, 70 trillion cubic feet of natural gas, and 6.58 billion tonnes of coal (British Petroleum, 2013).

Demand for produced oil and gas is considerable in Canada: petroleum-based fuels power vehicles, and natural gas products heat homes and water tanks, and fuel large appliances. Canadians spend significant amounts of time driving, and the number of vehicles in active service reflect this reality: in 2015 , there were more than 33 million motor vehicles registered (Statistics Canada, 2015). Canada's northern latitude and long, freezing winters make it necessary for residences and indoor work spaces to be continuously heated. According to a 2015 report by Natural Resources Canada, nearly 50 percent of Canadian homes are heated by natural gas, and nearly 65 percent used natural gas to heat water (NRC, 2015). In 
2006, the sales totals for refined energy products by Canadian customers reached 100 billion liters (GOC-NRC, 2014).

In addition to domestic demand, Canada is a major oil exporter, with approximately two-thirds of annual production sent outside of the country. According to the National Energy Board's estimates (2013), Canada exported an average of 2.5 million barrels of oil per day. The majority of this unrefined oil was shipped to US customers through a series of pipelines, such as those operated by Enbridge (see CAPP, 2015, for a comprehensive pipeline map).

The Canadian oil and gas industry employs both onshore (land-based) and offshore (water-based) exploration and drilling. Canada's offshore exploration history began in Newfoundland, with the drilling of early test wells in the 1950's (see Section 2.1 of this chapter). While offshore exploration was initially slow to develop, companies such as Dome, Esso, Imperial, and Sun undertook northern projects along the Beaufort Sea beginning in the early 1970s. The Beaufort Regional Environmental Assessment (2012), a northern regional research initiative, notes that production projects from 1972 until 2005 totaled 92. More recently, Atlantic Canada has hosted a number of established and long-term offshore projects, including Hibernia, Terra Nova, and White Rose. A fourth project, Hebron, commenced late in 2017 (CAPP, 2017).

Onshore production is of two basic types, those being extraction through the use of drilling rigs or the digging up of oil sands for bitumen collection. The bulk of modern onshore production is focused around the prairie provinces of Alberta, Saskatchewan, and Manitoba; however, exploration of north-eastern British Columbia continues to increase. Regarding the use of drilling rigs, exploration is limited by factors such as freezing and thawing of access roads 
and the ecological ramifications of operating in sensitive areas with heavy equipment. Oil sands exploration, such as those in the Athabascan region, which includes Suncor's operations at Fort McMurray, are pursued year-round. Despite the magnitude of oil sands operations, drilling rigs remain an integral part of Canada's exploration strategy, and during a busy season (typically from November until May), the number of active drilling rigs is typically in the several hundreds (CAODC, 2016).

\section{1 - Early History}

Crude oil and bitumen have been known to First Nations people in Western Canada for several centuries. As early as 1714, Hudson's Bay traders encountered First Nations peoples who regularly used oil that had seeped to the surface as a sealant on their canoes (Energy BC, 2016). In 1717, the Cree Chief, Waupisoo, on a mission at the behest of English commander James Knight, brought samples of bitumen collected from the banks of the Athabasca River (Kelsey, 1993). Later that century, fur trader and soldier Peter Pond mapped waterways in the Athabasca region, while the explorer Sir Alexander Mackenzie traversed the Peace River and founded Fort Chipewyan, near Fort McMurray (Canadian Encyclopedia, 2016). Both noted significant accumulations of surface oil and bitumen at various intervals along the banks of the Athabasca River.

While Alberta is typically considered the nexus of oil and gas extraction in Canada, the commercial beginnings of onshore oil and gas exploration in Canada are rooted in the provinces of Ontario and New Brunswick. Oil Springs, in the Township of Enniskillen, Ontario, was the site of the first well in the country, dating to 1858 . An asphalt producer named James Miller Williams purchased land near Black Creek, and when digging a water well, struck oil. His 
discovery triggered a small boom in the area, and over the next three years, nearly 400 wells were drilled in surrounding areas (Canada Cool, 2015). Further east, natural gas was discovered in Stoney Creek, NB, in 1859, and the resulting exploration field was productive for nearly 80 years (New Brunswick Museum, 2015).

While initial discoveries were focused in central and Eastern Canada, by the late 1880s, 'wildcatters' (persons who searched for oil and gas outside of established production areas) were combing the prairies, seeking lucrative finds. As it happened, natural gas was discovered at Langevin, $A B$, although not by prospectors or an energy company. Langevin (later named Carlstadt, and then Alderson) was a small village near Medicine Hat, and unremarkable except for being located on a railway line. In 1883, the Canadian Pacific Railway drilled a well nearby, hoping to access a pool of fresh water. Instead, they struck natural gas (Petroleum History Society, 2014). Another well drilled less than a year later also yielded natural gas close to the surface, heralding the arrival of the gas industry in Alberta.

Two decades later, in 1902, the first successful commercial oil well in Western Canada was drilled at what is now Waterton Lakes National Park, in Southern Alberta. The Lineham Discovery Well \# 1, named for its operator and speculator, John Lineham, struck oil at approximately 300 meters, and produced a few hundred barrels of oil per day for a period of nearly two years (Parks Canada, 2009). Despite initial success, the well was not a reliable producer, and speculators made moves toward the central regions of the province.

By 1914, central Alberta was an established hotbed of oil and gas activity, fueled by the discoveries at Turner Valley, a modest ranching town about 70 kilometers south-west of Calgary. Previously, in January of 1913, a company named Calgary Petroleum Products, 
managed by A.W. 'Archie' Dingman, had begun drilling. It was not until May 14, 1914, that the first well, named Dingman \#1, 'came in'. When a well 'comes in', there is sudden influx of oil and gas into the hole being drilled, and at Dingman \#1, this happened with a roar. An equally successful Dingman \#2 followed closely behind, and launched Alberta's first commercially successful oilfield, one that remains active and productive in the present (Government of Alberta, 2014). The successes at Turner Valley birthed numerous companies and ventures, and prospecting for oil and gas sharply increased throughout the War years.

However, another find as significant as the one at Turner Valley remained elusive until 1947, when oil was struck at Leduc, a small town south of Edmonton. Imperial Oil, one of Canada's premier and longest-running oil companies, was struggling to locate a new field, having drilled dozens of wells in Alberta and Saskatchewan. In 1946, in a last-ditch attempt, the company proposed a number of exploratory wells. The reasoning was that if the wells came up 'dry' - no oil - or simply didn't produce enough to make them commercially viable, Imperial would be done with exploration in Alberta.

The first site to be drilled was in a farmer's field, about 50 kilometers south of Edmonton, and it was named Leduc \#1. Drilling began in November of 1946, and the well was officially 'brought in' on February $13^{\text {th }}$ of 1947 , complete with a local politician opening a valve to let the oil flow (Collections Canada, 2002). It was an auspicious beginning, and Leduc \#2 was drilled soon afterwards. Importantly, Imperial had drilled deep into the Western Canadian Sedimentary Basin, a geologic formation that has proven to be the richest in oil and gas in Alberta (Alberta Geological Survey, 2012), and into a section of reef that came to be known as the Leduc Formation. Beyond that, the quality of oil found in Leduc was high, and it was easy to 
recover. Leduc \#1 remained in continuous production until early 1974 , and the geologic field it is situated in became an important gas reservoir by 1989 (Brune and Sweeny, 2013). The discoveries at Leduc helped to solidify Canada's position as a major oil producer.

Further oil and gas exploration and finds followed in short succession, in places like Woodbend, Redwater, Stettler, and Wizard Lake. Exploration activity bordered on frantic, and another pivotal discovery came in 1953, at Drayton Valley, a small farming and timber community approximately 130 kilometers south-west of Edmonton. Mobil One, an American company, struck oil on February 23 ${ }^{\text {rd }}, 1953$ (Town of Drayton Valley, 2014). The resulting field became known as Pembina, and it was to become the largest producer in Canada (CPSG, 1984). The impact on Drayton Valley was immediate and overwhelming: the local population grew from about 75 to over 2000 people in a single year. In a sign of the excitement over the find, more than 70 oil and gas companies established a new presence in the area (Town of Drayton Valley, 2014).

The wealth of discoveries triggered substantial work migrations to the province of Alberta, with southern destinations including Medicine Hat and Lethbridge, and northern ones like GP, Fort McMurray, and beyond. Anchoring both the waves of industry and migration were the larger cities of Edmonton and Calgary. The history of Edmonton and Calgary has been one of rivals: both were competing fiercely (and continue to do so) for the distinction of being home central for Western energy operations (see Avenue Edmonton, 2014, for recent mayoral perspectives on this history). Over time, Edmonton has come to be viewed as the operations centre - the 'feet on the ground' headquarters of Western energy ambitions - and Calgary, with its cluster of downtown high-rise buildings, the southern base for the executive offices of 
oil and gas companies. Perhaps surprisingly, Edmonton, with its progressive politics and multiculturalism platforms has been a largely blue-collar destination, while Calgary, whose image was fashioned by settlers - cowboys, ranchers, farmers - from the United States, evinces a brand of smooth urbanity and white-collar reassurance (see Zoeller, 2016, for a thorough discussion on inter-city tensions). Local dynamics aside, both cities have established themselves as gateways for oil and gas operations in Alberta.

\section{2 - Modern Context: Conventional Oil, Offshore, Oil (Tar) Sands, and Hydraulic Fracturing}

Canada's modern oil and gas industry is highly technologized. In its infancy, locating oil and gas reservoirs and then producing them was largely the result of trial and error (arguably, mostly error), and was reliant on simple equipment, labour and ingenuity. As the industry developed, exploration equipment and means grew more sophisticated. For example, early drilling rigs were constructed of wood, and featured a series of pulleys, rope, and chains for driving the boring tools into the ground. Modern drilling rigs feature advanced steel construction, computer systems, and are heavily-reliant on hydraulic lifts, rendering the equipment much less pervious to fires or explosions, and enabling it to withstand heavier loads, which increases the depth of drilling capabilities. Simultaneously, geologic exploration was evolving, and cuttingedge techniques enable companies to more accurately read stratigraphic zones and uncover pockets of raw petroleum.

By the mid-20 $20^{\text {th }}$ century, industry notions of accessible production sites were also changing. Fueled by technological and geological advances and increasing demand and profitability, previously inaccessible physical landscapes became more suitable for oil and gas 
exploration. Prior to 1950 in Canada, oil and gas had been accessed in the conventional way: through the use of a land-based drilling rig. As the industry developed, projects became larger, costlier, and more experimental, requiring new techniques to meet broader exploration goals. Sections 2.2.1 - 2.2.4 of this chapter examine four methods of exploration: first, conventional oil and gas procurement utilizing drilling rigs. Second, the mid-1960s offshore platform exploration for oil off the coast of Newfoundland. Third, the development of the Athabasca oil sands near Fort McMurray. And finally, the increasing use of hydraulic fracturing for both exploration and stimulation of wells and fields that are past their production prime.

\subsection{1 - Conventional Oil and Gas Drilling}

Since the early years of commercial oil and gas exploration, the most ubiquitous piece of equipment in use has been the drilling rig. The function of a rig is relatively simple: it acts as boring machine, penetrating the Earth's surface and drilling vertically (although modern rigs also have diagonal and horizontal drilling capabilities) through layers of rock to reach pockets of oil and gas. Over time, drilling rigs have evolved from simple wooden structures that utilized horse and human power, to hydraulically-driven, highly-technologized tools capable of reaching depths of 5000 meters or more (a modern drilling rig usual to Alberta can be seen in Figure 1.0, below). Each rig is staffed by a group of personnel, arranged hierarchically according to job specialization. The junior most of these is the leasehand, followed by roughneck (also known as floorhand), motorhand, derrickhand, and, atop the hierarchy, the driller. Rig work is dangerous, repetitious, and highly lucrative in a busy season (for more on wages for drilling workers, see this chapter, section 2.3).

The majority of research participants in this study were not employed on drilling rigs, 
although a number of them had worked on such rigs previously. The GP region has been a hotbed for drilling rig activity for several decades up to and including the research period between 2012-2014. Although I had hoped to be able to access another rig for the doctoral research, little progress was made, and eventually the idea was abandoned. I instead focused on interviewing, observing, and job shadowing participants in various other work roles in the industry. As a result, drilling rig work is only briefly backgrounded in this thesis (for a more detailed description of a drilling rig and its employees, see Houser, 2010).

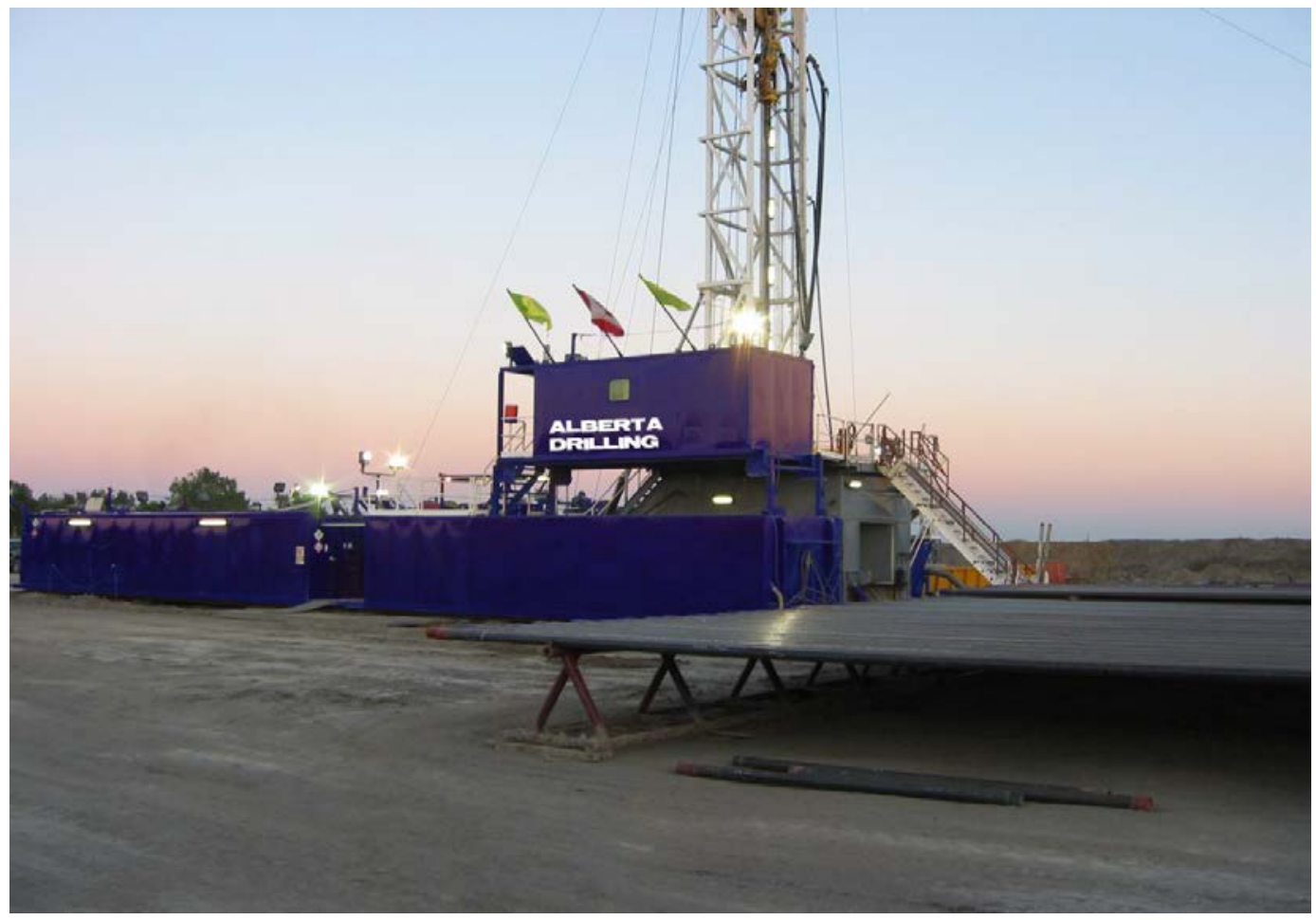

Figure 1.0 - View of a drilling rig in early evening (Houser, 2008)

\subsection{2 - Newfoundland's Hibernia Field}

Fusco (2007) notes that during the 1960s Newfoundland was considered a potential source of offshore oil and gas. However, there was little interest in developing its potential, given the availability of land-based fields. The political machinations between various Arab states, the 
USA, and Israel, which resulted in the 1973 'oil crisis' (see Mitchell, 2011) impacted Canadian attitudes towards oil production and procurement. By 1979, the Hibernia field had been established, one that continues to be a significant producer at the time of writing (2017). Newfoundland's sudden ability to prospect and produce significant quantities of oil and gas were a boon to a province with chronic low employment rates and a stagnant economy. The province's premier through the 1970s, Frank Moores, advocated for provincial control over economic and development resources, a stance that resonated with many of his successors, including the popular (and polarizing) Danny Williams. Newfoundland now has a wellestablished program of offshore oil and gas production, one that is likely to continue as long as there is a demand for hydrocarbons and it profitable to seek them (see Figure 1.1 for a photo of the offshore drilling operation).

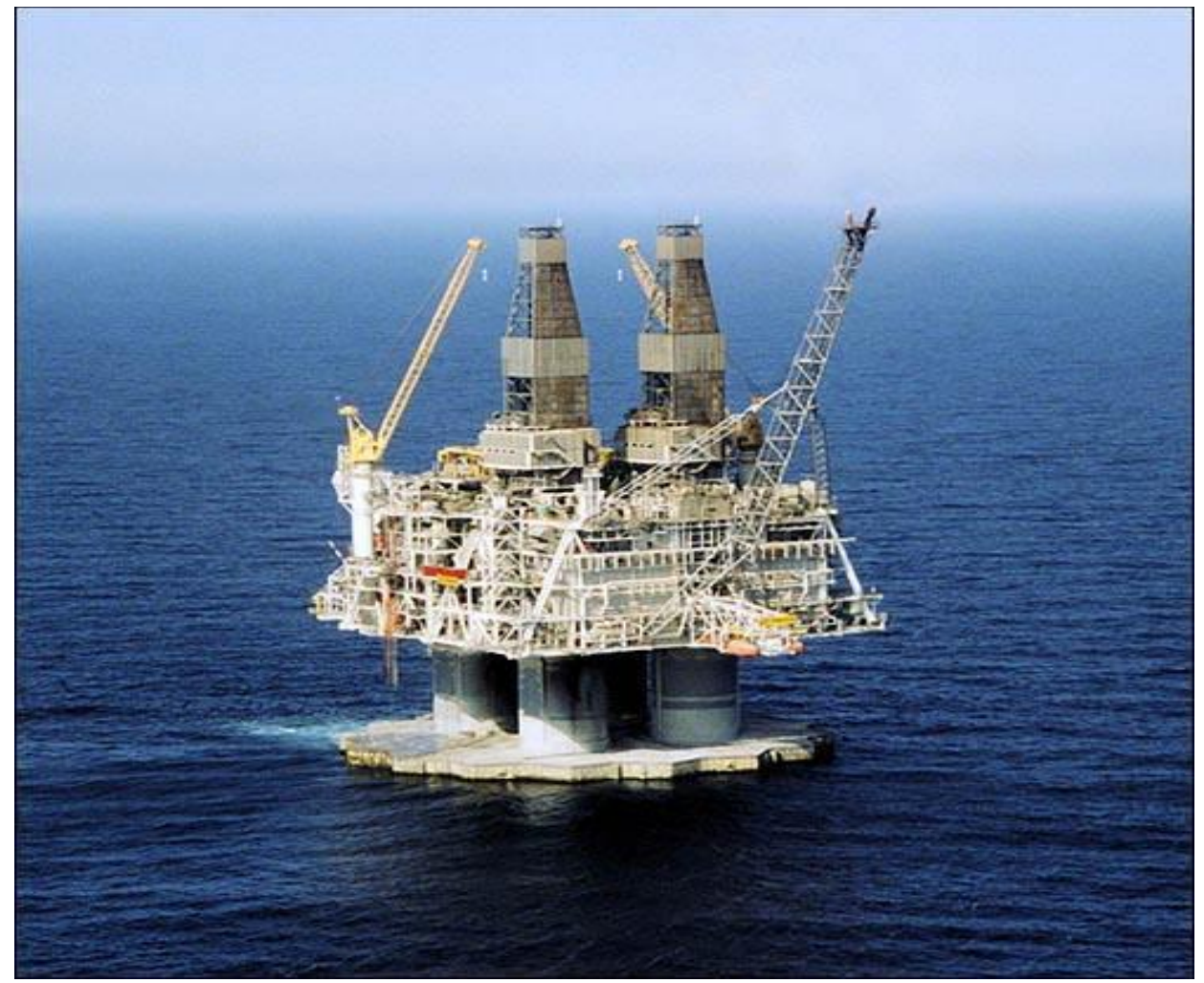

Figure 1.1 - Hibernia offshore drilling platform (courtesy of energy-pedia.com) 


\subsection{3 - The Athabasca Oil (Tar) Sands}

The Athabascan oil sands are named for the Athabasca River, a large body of water in northeastern Alberta that bisects the deposits of bitumen, a sticky, tar-like substance. Defined as the "naturally occurring mixture of sand, clay or other minerals, water and bitumen" (Alberta Energy, 2015), the oil sands deposits are vast. The Calgary-based Pembina Institute reports that the area accessible for surface extraction is "an area about the size of Florida that covers $20 \%$ of the province" (2009), and CAPP has estimated the size of reserves at 134 billion barrels (CAPP, 2015), or roughly 78 percent of all of Canada's proven reserves.

Long known to First Nations and Metis peoples in the area, European fur traders noted the sticky, dark sands of the river's banks in the 1700s (Hein, 2000). Early attempts at separating the bitumen from the sand were unsuccessful, but the potential of the region was obvious. Prospectors were essentially hoping to find 'easy oil' - petroleum that was mixed with sand, laying on the subsurface, without the need for drilling to procure it. By 1921, a researcher from the University of Alberta, Dr. Karl Clark, had devised a hot water separation strategy, and obtained a patent for it (Canadian Petroleum Hall of Fame, 2016; Chastko, 2004). Reclaiming the bitumen was not easy, and no one strategy was widely successful, but these attempts were sufficient to encourage further development of strategies.

By the early 1950s, Alberta geologists and prospectors were keen to commercially develop the oil sands, despite the difficulty of removing the useable bitumen from the sandstone deposits that it naturally occurs within. Once bitumen is recovered, through the application of high pressure steam and chemicals, the remaining sandstone must be cleaned and returned to its place of origin. This is an expensive, time consuming, and laborious process - but the sheer volume of available bitumen encouraged development. An early champion was 
the Montreal-based Sun Company, an offshoot of a United States parent company of the same name. Sun Company (later Suncor), famous for its 'Sunoco' brand of gasoline products, undertook systemic evaluations of the oil sands with a view to commercial production (Suncor, 2015). By 1953, Sun Company had acquired leases and patents for test exploration in the Athabasca region, near Fort McMurray. A decade later, with backing from the United States, Sun Company, invested nearly $\$ 250$ million into a Fort McMurray-based project named the Great Canadian Oil Sands. Plants for processing the bitumen and cleaning the sands were envisioned, and the building projects began in 1964 (see Figure 1.2 for a view of modern Suncor operations). The construction would run late into 1967, when the project was completed " 5 days ahead of schedule" (Suncor, 2015). On hand for the grand opening was then Alberta Premier, Ernest Manning. In an address to those gathered, he famously opined, "This is a redletter day, not only for Canada but for all North America. No other event in Canada's centennial year is more important or significant" (Sweeny, 2010: 100).

In the years following 1967, oil sands development in northern Alberta has grown exponentially under Suncor's direction. Hundreds of millions of barrels of oil have been manufactured from the bitumen removed from the Athabasca oil sands. Economic spinoffs have induced a massive migration to the Fort McMurray area for over 40 years, as well as major influxes to the cities of Edmonton and Calgary. Significant oil sands development further established Alberta as a petroleum-producing powerhouse, leading to public pronouncements of success, such as Calgary's controversial 2003 slogan, 'Heart of the new West' (Alberta Venture, 2011). Accompanying these achievements is a long list of concerns, which are well documented in scientific and social science literatures. Of particular consequence are 
environmental impacts (see, for example, Charpentier et al, 2009; Kelly et al, 2009; Kurek et al, 2013); problems of corruption (Carter, 2016; Shrivastava and Stefanick, 2012; Smandych and Kueneman, 2010); lack of transparency, accountability and sustainability (Bocking, 2011; Nikiforuk, 2010); and ongoing controversy surrounding the consideration and inclusion of First Nations input on oil sands development (Huseman and Short, 2012; Preston, 2013; Taylor and Friedel, 2011). While the above feature in oil sands operations, they can also be understood to be reflective of issues that pervade the larger culture of the industry itself.

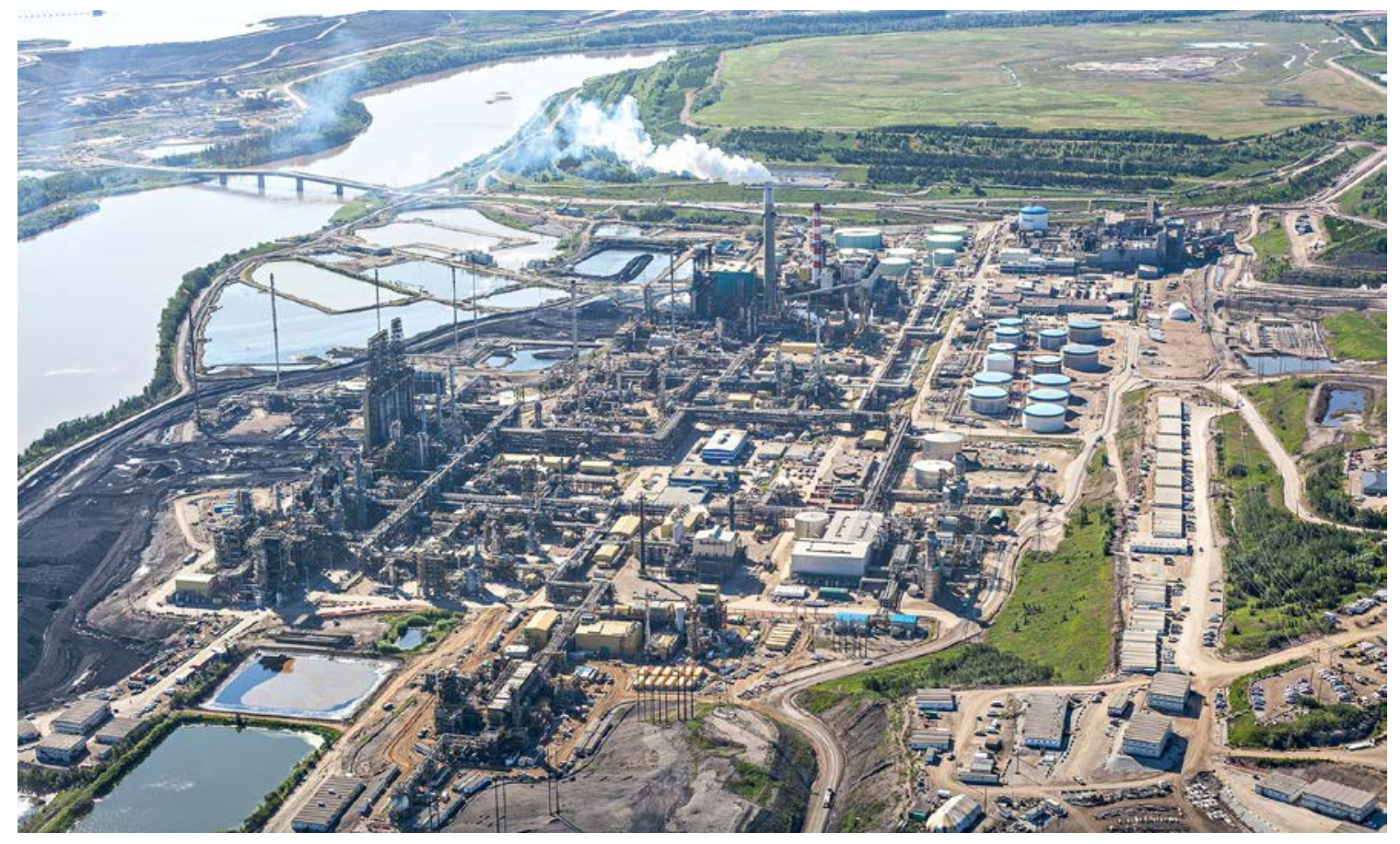

Figure 1.2 - Suncor Plant at Fort McMurray (courtesy of Work Above Aerial Photography)

\subsection{4 - Hydraulic Fracturing}

Hydraulic fracturing, or 'fracking', is an increasingly utilized oil and gas exploration technique (see Figure 1.3 for a simple graphic). The Canadian Society for Unconventional Resources (CSUR) defines fracking as "the process of transmitting pressure by fluid or gas to create cracks or to open existing cracks in hydrocarbon bearing rocks underground" (CSUR, 2012). 


\section{Shale gas extraction}

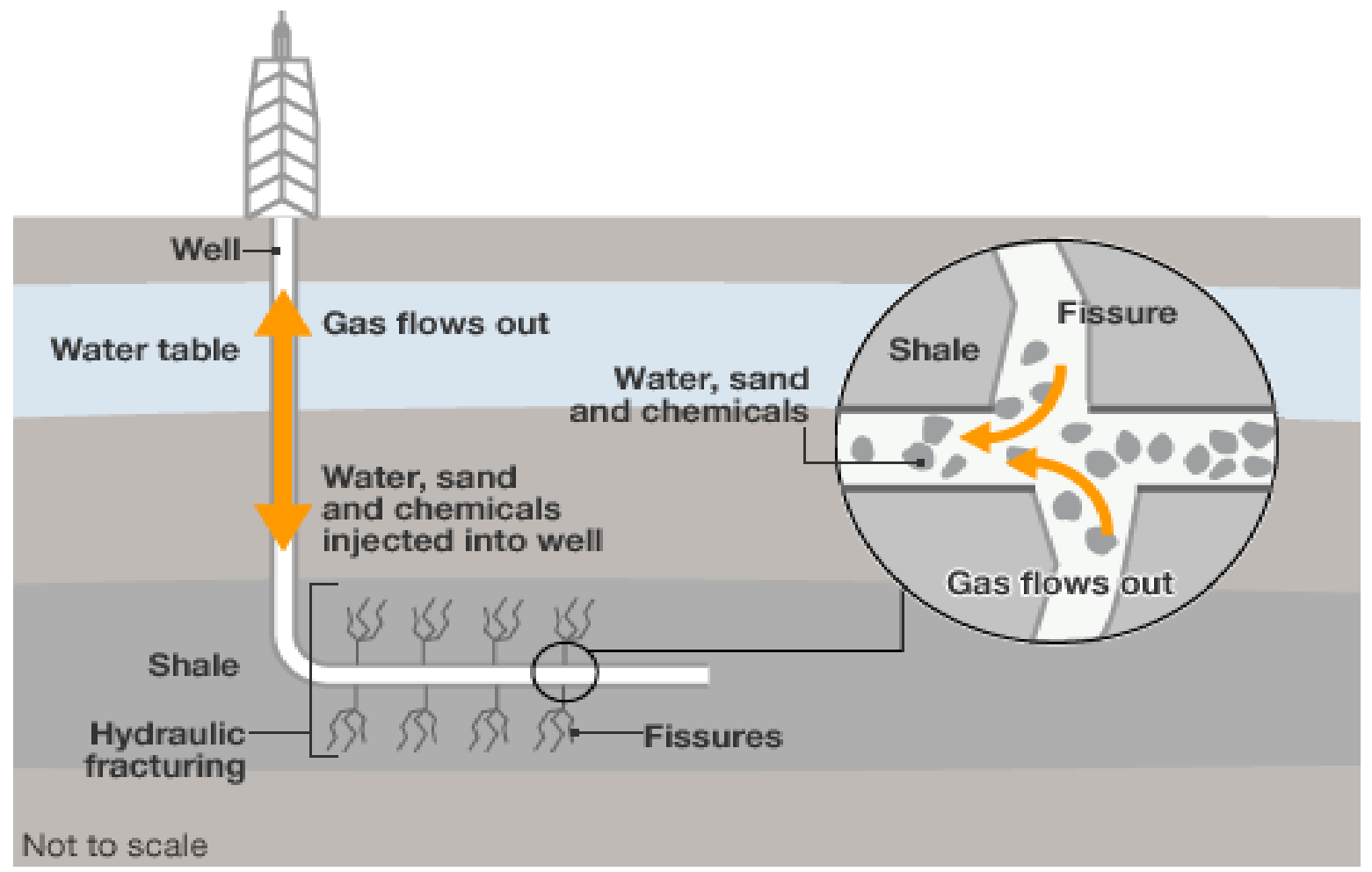

Figure 1.3 - Shale gas extraction graphic (courtesy of OilFinity)

The Petroleum Services Association of Canada (2015) adds to the definition:

In hydraulic fracturing, fluids are injected at pressures that exceed the natural stresses on the rock and cause it to crack, or fracture. Creating these fractures in hydrocarbon-bearing rock layers deep underground is not enough to allow oil and gas to flow into the wellbore.

Once the fractured reservoir rock is held open with fluid pressure, proppant, usually sand or ceramics, is introduced into the fluid to prop open the fractures. After the hydraulic fracturing process, the fracturing fluids are recovered and the fractures remain held open by proppant. The hydrocarbons trapped inside the rocks can now flow more easily through the cracks to the wellbore.

The Government of Alberta categorizes fracking as "the opening up of fractures in the [rock] formation to make gas flow more freely... done to increase or initiate commercial production and is conducted in a controlled manner" (Alberta Energy, 2015). They add, "Fracturing is a 
standard technique to enhance hydrocarbon recovery that has been used in Alberta's oil and gas industry for many years" (Ibid).

Fracking was employed on a small-scale in the United States as early as 1865 , when a veteran of the American Civil War, one Colonel Edward A. L. Roberts, applied for a patent for an “exploding torpedo" (Oilprice.com, 2015). The patented device consisted of an actual torpedo, immersed in an iron case filled with gunpowder, which would be lowered into the wellbore and then detonated by fuse. The resulting explosion would perforate the walls of the wellbore, increasing oil and water production substantially. Several decades would pass before fracking technology improved, and the technique has only been used commercially in Canada since the early 1950s. By the mid-1970s, fracking had entered into regular use in the Canadian energy industry, especially in the Peace River region. The Pembina field of central Alberta was an early test bed for the technique, and success there influenced the spread of fracking throughout gasheavy exploration sites in southern parts of the province. As easily accessible oil and gas deposits diminished, fracking enabled the industry to reinvigorate expended production fields, and to explore new ones not previously viable, such as the sustained retrieval of shale gases (see CAPP, 2015, for an overview).

Drilling a new well that will be 'fracked' requires much technical planning, equipment, and labour support. Field operations begin by erecting a drilling rig and beginning to bore a vertical hole in the ground, approximately 30 - 60 centimeters in diameter. The hole is known as a wellbore, and it is through this wellbore that all activities related to the drilling, completion, and maintenance of the well will occur. Once the depth of the wellbore is below the level of any potable groundwater, drilling stops, and the drilling equipment (known as the 
drill string) is removed from the hole. Lengths of steel pipe, called casing, are then inserted partway into the wellbore to ensure that the hole does not collapse and does not allow any matter to leak out into adjacent rock layers or water aquifers. A further seal is added in the form of cement pumped at high pressure into the space between the rock formations and the casing, which, when dry, fixes the casing solidly in place (for a diagram, see Figure 1.4).

Drilling then resumes and continues to a predetermined vertical depth, calculated by petroleum engineers and geologists, which varies from approximately 2000-6000 meters. Once the desired depth is reached (also known as 'True Vertical Depth', or TVD), the remaining vertical portion of the well can be cased and cemented. When drilling recommences, the drill string 'kicks off' (deviates from the initial vertical plane) and begins to move horizontally, at distances of several hundred meters to over a kilometer. Once the terminus is reached, the horizontal section of the well is also cased and cemented. The well is now ready for perforation, which takes placed in the horizontal section of the casing. Perforation is achieved using specialized discharge tools that deliver a series of controlled detonations, puncturing the steel casing at pre-determined intervals. The perforated casing is now ready for fracking fluid to be pumped through it, which, under extreme pressure, will be forced into the overlaying and underlying rock layers, causing pockets to split open and release oil and gas. Constant pressure is maintained inside the well bore, which assists released oil and gas, along with fracking fluid and rock particles, in rising to the surface.

Despite its increasingly common use, fracking remains highly contentious. Potential environmental effects include the triggering small earthquakes (see the New York Times, 2016, for an Alberta-based example), polluting water aquifers, and difficulties surrounding the safe 
retrieval and disposal of waste water and chemicals. In Alberta, government oversight for energy exploration, including the use of fracking, is provided by the Alberta Energy Regulator (AER). The AER requires energy companies to be licensed to operate and to uphold established protocols when fracking, including well depth, forbidding the use of certain types of chemicals during fracking, and ensuring water sources do not become contaminated. The AER also collaborates with Alberta Environment and Sustainable Resource Development (ESRD) to "ensure responsible resource development" (ESRD, 2016). Notwithstanding formal regulation and oversight, fracking remains controversial and its long-term future is not assured.

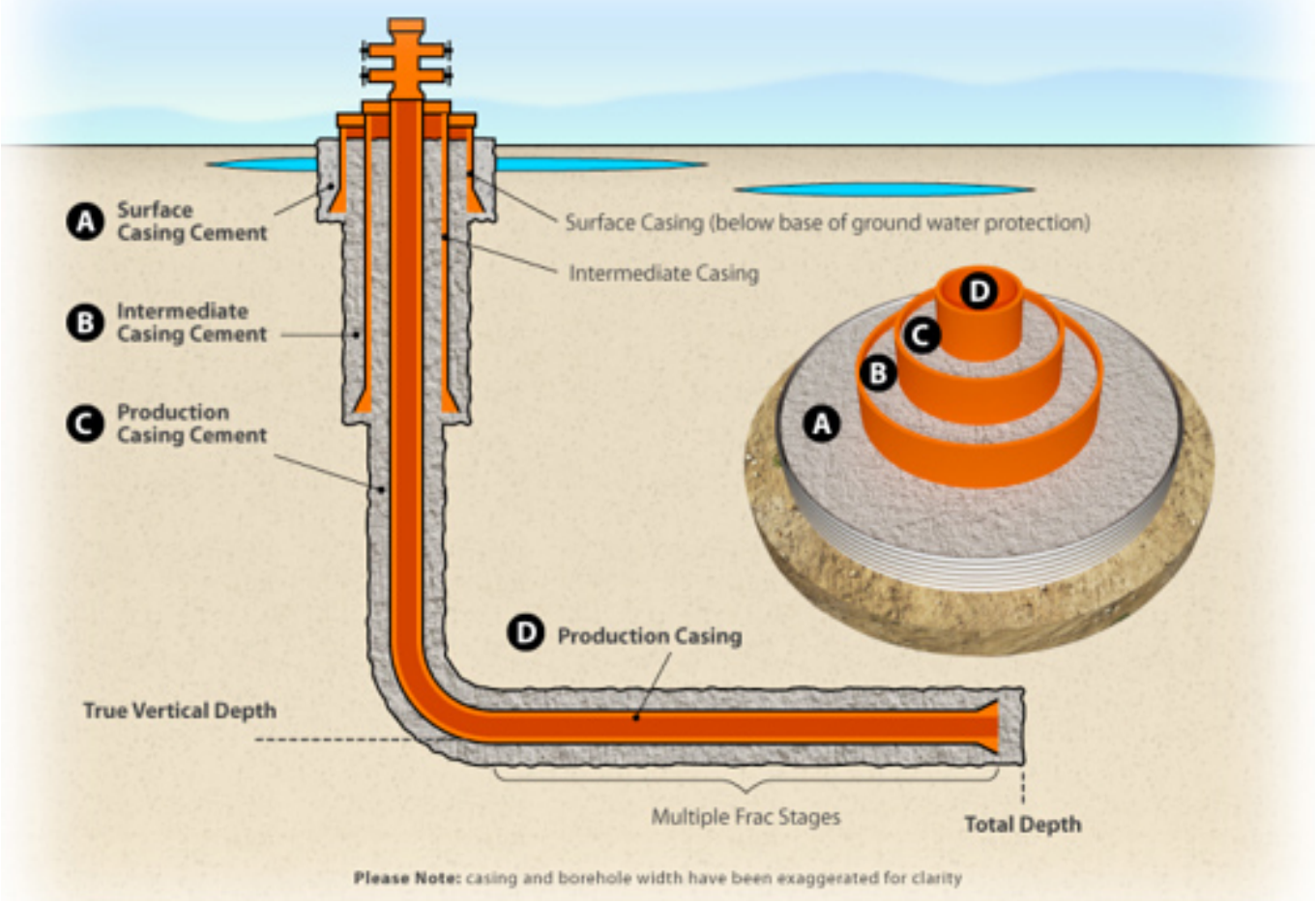

Figure 1.4 - Casing and borehole diagram (courtesy of Tri-Can Well Services)

The steady growth of interest in studying fracking and its impacts since the late 2000s coincides with the scaling-up of oil and gas projects. Fracking a single well can use a tremendous amount of fresh water, somewhere between 2 and 9 million gallons (Manitoba 
Water Caucus, 2014), a large percentage of which becomes so contaminated that it cannot be returned to the water table. According to CAPP (2015), Alberta fracked 3,396 wells in 2014, which required the use of approximately 12 million cubic meters of water. Such consumption raises significant questions about the sustainability of the practice, about who has rights to water, who governs those rights, and how are they enforced. Questions such as these have provoked a wide range of academic interest and a growing body of literature. These include observations and critiques from environmental and legal scholars (Cricco-Lizza, 2012; Wiseman, 2009); theologists (Peppard, 2012); policy analysts (Davis, 2012); health practitioners (Lauver, 2012; Merkel, et al, 2012); science and technology studies (Kinchy, et al, 2014); anthropologists (de Rijke, 2013; Drew University, 2012; Paladino and Simonelli, 2013; Poole and Hudgins, 2014; Willow and Wylie, 2014); and sociologists (Hannigan, 2014; Ladd, 2014; Matz and Renfrew, 2015; Theodori, 2009). As concern continues to grow over the safety and sustainability of fracking practices, long-term environmental impacts, the question of who profits from the activity, and how communities are to respond to this type of oil and gas development, this body of literatures will only increase in scope and breadth.

\section{3 - Industry Organization}

To better comprehend the oil and gas industry, it is necessary to understand how it is organized. It is useful to envision the industry as a horizontal chain, with three key links, which are termed upstream, midstream, and downstream. The upstream sector encompasses field operations - the actual exploration and production of natural oil and gas resources. This includes seeking new fields of exploration, undertaking seismic and geologic surveys to 
determine the exact location of the resource (and the potential quantity), the drilling of test wells, and the eventual operation of these wells to produce oil and gas.

The midstream sector refers to all the operations and processes usual to transporting oil and gas from sites of production. Transportation of the raw resources can occur by tanker truck, by railway, by ship, and by pipeline (which is commonly utilized in Alberta). Natural Resources Canada (2017) notes that there are approximately 415,000 kilometers of pipeline in the province, through which both oil and gas flow. As of 2013, Alberta also had four major pipelines (known as large diameter transmission lines), which send product to British Columbia, Central and Eastern Canada, and to the United States (Frasier Institute, 2013).

Movement of oil and gas with tanker trucks and by rail has also been common in Alberta. Increasing public concern over the safety of high-volume pipelines had seen rail transport loads steadily grow since 2010. However, the derailing of a Montreal, Maine \& Atlantic Railway (MMA) train carrying oil at Lac-Mégantic, QC on July 6, 2013, which produced fiery explosions and resulted in forty-seven fatalities (CTV News, 2013), produced a marked slowdown on rail-load carrying across the country. Federal and provincial investigations into the accident in Quebec took place for thirteen months, and the ensuing report issued by the Transportation Safety Board of Canada (TSB) identified sixteen risk findings and made five recommendations "aimed at addressing systemic safety issues" (Transportation Safety Board of Canada, 2014) for railways transporting oil. The TSB concluded that the fatal accident was a result of multiple factors, and publically stated that they would be monitoring the compliance of the new safety recommendations. At the time of writing (2017), it remains unclear if the TSB's recommendations have been widely adopted (see The Star, 2016 for more). Meanwhile, 
the community of Lac-Mégantic remains permanently impacted by the disaster (Canadian Broadcasting Corporation, 2016).

The downstream sector is where the refining of raw petroleum products, including oil and natural gas, occur. The Petroleum Services Association of Canada (PSAC) includes "oil refineries, petrochemical plants, petroleum products distributors, retail outlets and natural gas distribution companies" in this sector (Petroleum Services Association of Canada, 2015). In addition to refining raw oil and gas, downstream operations also include the production of pharmaceuticals, pesticides for garden and agricultural applications, synthetic rubbers, plastic composites used in manufacturing in petroleum-based products besides fuels, including antifreeze for vehicles, and asphalt, used mainly for road construction.

Downstream operations have also evolved to include the marketing and delivery of these resource products directly to consumers. A common example is natural gas: the downstream sector refines and delivers it to customers, while also offering additional products and services that attract new users. In some cases, large oil and gas producers also operate their own refineries or upgraders (a conversion plant that turns low quality oil into a lighter synthetic product). As an example, Husky Energy, one of Canada's largest energy companies, owns and operates a number of industrial concerns, including an asphalt refinery in Alberta, an oil upgrader in Saskatchewan, oil refineries in Saskatchewan and British Columbia, and various ethanol plants in Manitoba and Saskatchewan (Husky Energy, 2015). The wide footprint of downstream activities in Canada highlights the cross-national importance and impact of the oil and gas industry. 


\section{4 - Careers and Compensation}

The Canadian oil and gas industry is complex and expansive, and there are a multitude of job options within it, ranging from entry-level field-based work, to the management of multiple billion-dollar companies. For those with labour backgrounds, and seeking physical challenge and high salaries, it is usual to enter through the upstream sector, working in field operations such as on drilling or service rigs. Field workers often labour on shift-work, are well remunerated, and can ascend to field or service management positions. Those with trade certification or technical training may compete with established companies and organizations by incorporating their own business in the exploration and services sectors. Persons trained in technical fields such as engineering, physics or geology, are valuable within all sectors of industry, and may divide working time between field projects and a corporate office.

For those who labour in the oil patch, the standard working shift is 12 hours in length. Drilling rigs and service companies regularly undertake these shifts day in and out, and arrange major equipment moves, over long distances, and in all terrain and weather conditions. For some workers in oil and gas, it is usual to have daytime and nighttime working shifts during a rotation (number of days worked, followed by time off). For example, if the rotation is 21 days, the crew begins with a week's worth of day shifts, then has a 24-hour 'turnaround' (off-shift), followed with a week's worth of night shifts. The crew would then have seven days off work, marking a complete rotation. Significant rates of compensation attract workers to the job: during a busy season, a junior employee on a drilling rig can gross $\$ 80,000$, with the same position on a service rig paying around $\$ 60,000$. Moving up the hierarchy, top-tier rig employees can earn $\$ 130,000$ per year or more (the recommended wage schedule for 2015 put drillers at an hourly rate of $\$ 46.80$. Assuming an 84 -hour work week, a driller could earn over 
$\$ 11,000$ per month - see the Canadian Association of Oilwell Drilling Contractors, 2015 for more). Other skilled labourers, such as tradespeople, can earn significantly more.

For many workers, the duration of oil and gas employment is variable and without guarantees, and for those who are not tradespeople, no union representation currently exists. There are, however, a number of oversight groups and associations that shape the industry landscape and culture - and influence pay rates. The most prominent of these is the Canadian Association of Oilwell Drilling Contractors (CAODC). Founded in 1949, the CAODC identifies itself as "the unified voice of the Canadian drilling and service rig industry, and promotes safer and more efficient operations through advocacy, communications and needed products and services" (CAODC, 2015). The CAODC is governed by a board of directors comprised of prominent figures in the oil and gas industry in Canada. The association is heavily involved with worker training, from equipment operation through the promotion of safe work practices, and continuous skills-based certification and upgrading. The CAODC also offers educational scholarships to employees of its membership, regularly hosts media campaigns and radio events, and keeps a running tally of drilling and service rigs working in Canada by week, month, and quarter. It also publishes and promotes a yearly drilling and service rig wage schedule, which has become the de facto industry standard for rates of hourly compensation for rig employees. To the best of my knowledge, no such association exists for any other sector of the oil and gas industry. The only other representation of this kind would be found in the local union charters for various tradespeople. Unskilled labourers outside of a drilling or service rig context have no access to such programs or support, unless they come directly from within the company of employ. 
The CAODC, while decidedly not a union, does resemble one: it advocates on behalf of workers and its membership; it provides education and scholastic support to industry; and it issues reports and promotes public outreach. The information found on its website, in reports, and in media campaigns conjures an organization that seeks to "Act in the best interests of its member companies, their employees and the industry", and "To be the leading advocate for the Canadian petroleum service industry" (CADOC, 2016). While research participants often did not agree with the mission statements and values promoted by the CAODC, they acknowledged the power of the organization in its bid to transform the image of oil and gas workers from a collection of largely negative stereotypes into one of highly-trained, well paid professionals.

\subsection{1 - Alberta Communities \& Oil and Gas Businesses}

Statistics Canada places oil and gas work in the 'Natural Resources' sector, and this category includes forestry, fishing, mining, and quarrying. In 2014, of the 372,600 Canadians working in this natural resource sector, $47.9 \%$ of those were in the province of Alberta (Statistics Canada, 2015). That same year, CAPP alleged that the number of people who work in the Canadian oil and gas industry alone was approximately 550,000 (CAPP, 2014) ${ }^{1}$. The Provincial Government of Alberta indicates that in 2014 , approximately 121,500 people were employed in mining or the oil and gas industry, and that one in every 16 jobs in Alberta was in service to the energy industry (Alberta Energy, 2014).

\footnotetext{
${ }^{1}$ It is important to remember that CAPP takes account of those who work in service to the industry, if not directly in it, while federal statistics do not.
} 
The number of oil and gas-related businesses registered in Alberta is significant, and listservs and public Web pages reflect this. According to Manta (www.manta.com), an online business directory and discussion forum, which catalogues and provides links to registered businesses in North America, as of February 2015, there were over 7,700 energy-related businesses registered in the province of Alberta. 1,109 of those were in the 'Oil and gas field exploration services' category, while 3,933 were registered in the 'Oil and gas field services' category.

Detailed exploration of Manta's resources showed that over 380 communities in Alberta hosted oil and gas-related businesses. The city of Edmonton was home to 459 of these, while Calgary recorded a robust 2,630. Red Deer, an industrial sector town located halfway between Edmonton and Calgary, showed 310. Historical oil and gas communities such as Drayton Valley (151), Medicine Hat (150), and Rocky Mountain House (109) reflect their heritage through the significant number of local energy-focused ventures. In 2015, more than 20 communities in Alberta were home to 50 or more oil and gas-related businesses, and more than 80 had at least 10 such businesses. These numbers help to demonstrate the degree to which the oil and gas economy is entrenched in Alberta.

In considering the sheer number of oil and gas businesses and companies active in Alberta communities, a question suggests itself: what is the nature of the relationships these communities have with the industry? As was learned in GP, the framework for these relationships is known as social license, the permission that communities have granted the oil and gas industry to pursue their extractive regimens (the concept of social license is introduced here, so as to illuminate one of the key inner workings of an oil and gas town. For a more 
comprehensive treatment of the concept, see Chapter 4). This license is predicated on exchange relationships, one in which the host community agrees to support the activities of the particular company in question, both in terms of socially accepting it presence and through providing labour, while the extraction company then employs members of the community and provides economic and corporate support for local events and traditions. In this way, the extractive company is perceived as a benefactor for the community, and the residents of the community pledge their support by choosing to work for the company and defending its activities to outsiders or others who may be critical. Without social license, oil and gas companies could not operate in the long-term in small communities, so citizens and representatives of active companies are highly attuned to the subtleties of these exchange relationships.

\section{5 - Research Background \& Choosing a Site}

During Master's fieldwork, I spent three months spent researching the work crews on a drilling rig in 2008. At that time, 'safety' was a popular byword in industrial work, and especially in the oil patch. I had intended to base the research around learning about the existence (or nonexistence) of safety cultures on drilling rigs. As I learned, questions about safety were not well received, by either those who worked on, supervised, or serviced the drilling rig. For a time, I was unsure how to proceed, but realized the need to ask questions that resonated with research participants. These tended to be focused on such things as the 'oil patch lifestyle' (money, recreational vehicles, partying), the importance and controversy of their work, and where they saw themselves in Alberta's (and Canada's) social hierarchies. 
In time, I did learn much about safety, and its history in the drilling sector, but without explicitly interrogating it. Instead, I earned the trust of my participants by spending many hours with them, and assisting wherever possible with daily work. I came to understand that in the 1990s, oil companies with poor safety records were pressed by provincial regulatory agencies to adopt more stringent operating policies. The intent was to improve safety and performance records, thus reducing lost time work accidents and worker injury payouts. Over the next decade, these policies became refined and adopted by most oil and gas companies operating in Canada. Less compliant companies (referred to as 'pirates') continue to operate on the margins of industry, but is it increasingly difficult to remain employed in the oil and gas sector with poor safety performance records.

I discovered that the word 'safety' carried an inherent tension within it because for drilling rig workers, it represented a disconnect between theory and practice. In Alberta, safety protocols are often developed in executive suites in Calgary, and then drafted into voluminous field policy manuals. Field operators receive these manuals, and are expected to comply with their contents. At times, situations fall outside the dictates of the manual, and so workers alter or bypass procedures, something I witnessed regularly on drilling sites. I also noticed procedures being sidestepped or ignored out of sheer pique at how ridiculous they appeared to workers on the ground, but more often this occurred when a rule or set of rules was physically or logistically impossible to follow (see Houser, 2010, for more).

The doctoral research that forms the basis for this thesis was informed by my Master's experience, in particular as regards questions about the value of the communities oil and gas workers reside in, what roles masculinity and gender play in the work, and how workers 
understand their relationships to the industry and the forces that govern it. The framework for the doctoral research was broadened to include many other types of oil and gas workers beyond those found on drilling rigs. My sense was that in order to seek a wider group of participants, it was critical to reside in an established oil and gas community and base the research there. In searching for a suitable field site, a number of towns and cities in Alberta were researched, including Edmonton, Fort McMurray, Grande Cache, Lethbridge, and Medicine Hat, and one in Saskatchewan, being Estevan. Fort McMurray seemed an obvious choice, so I made a brief preliminary survey of the city. A number of factors encountered in that short visit caused me to consider other sites more seriously. As an example, finding acceptable housing posed a financial hurdle, as a one-bedroom apartment could easily cost $\$ 2000$ per month or more. Further, casual interactions with people around the city were not encouraging. Fort McMurray boasts large numbers of migrant and seasonal workers, those who often live elsewhere and leave the area when not on the job, and this ongoing liminality has impacted the social landscape of the city. Given its international infamy surrounding oil sands operations, highly-visible environmental shortcomings, and fragmented sense of community (see, for example, Dorow \& O’Shaughnessy, 2013; Ruddell, 2011; Taylor, et al 2007), there was a detectable wariness on the part of area residents. Those approached were clearly uninterested in being further scrutinized by a curious outsider. Based on this experience, and armed with the knowledge that locating research participants within the oil and gas sector is challenging, I chose to consider other sites.

Following the Fort McMurray visit, a list of potential alternatives emerged. I decided against Estevan, choosing instead to focus on Alberta-based industry. Edmonton's large 
physical size removed it from serious consideration, with only approximately 18 months of research time available. Having previously spent time in Medicine Hat and Lethbridge during the Master's fieldwork ruled them both out. Grande Cache, a former coal mining town, was too small and remote for my purposes, so the only viable choice left on the list was GP, which was not a last or undesirable choice in any way; in fact, it was the logical first or second choice. All other towns and cities were weighted against it and Fort McMurray. GP kept emerging as the most viable option, so the city of approximately 60,000 people, with considerable oil and gas, timber, agriculture and ranching histories, became my home and research base from late October of 2012 until the end of July, 2014. Located approximately 450 kilometers northwest of Edmonton, in the Peace Region, the city incorporated in 1914, and celebrated its centennial anniversary in 2014, drawing tens of thousands of visitors from all over the region (City of Grande Prairie, 2014). It is a known hub centre in the area for work and recreation, regularly drawing day trippers, shoppers, hunters, and recreationalists from all over northern Alberta, British Columbia, the Territories and beyond. Importantly, GP is located in the heart of Alberta's Peace Region, and has an active oil and gas footprint larger than South Korea (AlbertaCanada, 2014). It is part of a community that has attracted workers, investors, and entrepreneurs, as well as hustlers and thrill seekers from across Canada, and internationally. By making that community my research base, opportunities arose to explore related social networks as they connected across working, living, and social mores.

Preliminary research showed that GP was home to hundreds of small and medium size enterprises, with oil and gas extraction and services, leisure, and shopping accounting for the bulk of these (Manta, 2014). It also boasted a young population: in 2011, the median age was 
30.3 years, well below the Alberta average of 36.5 (Statistics Canada, 2011). Most notably, 2012 estimated household earnings were some of the highest in the country, at $\$ 126,877$, with the 2014 unemployment rate hovering at 4.7 percent (City of GP, 2014). The city has endured crime rate spikes over the past decade, mostly related to drunk driving, vehicular theft, and drug trafficking (In 2010, Maclean's magazine ranked GP as the seventh most crime-ridden city in Canada). On paper, the city seemed to have much in common with Fort McMurray, minus the massive work migrations.

Although I lived in GP, my fieldwork took place across the Peace Region (see Figure 1.5), an area with a wealth of First Nations, trapper, trader, agricultural, and settler history. Sonamed for its proximity to the Peace River (Leppard, 1935), this vast parkland region occupies the north-western corner of the province, and spans an area of $390,000 \mathrm{~km}^{2}$, making it larger than Norway. The Peace Region sprawls from northwestern Alberta into British Columbia, and meeting with research participants meant routinely traveling hours by vehicle, including driving west to Fort St John, BC; south to Fox Creek, AB; north to Peace River, AB; and east to Slave Lake, AB. In the early stages of research, a willingness to cover long distances, in all weather conditions, was crucial to meeting up with participants. Doing so connected me with many people that would have been missed if research activities had been limited to GP proper and nearby surrounding areas (for a map of Alberta, see Figure 1.6). 


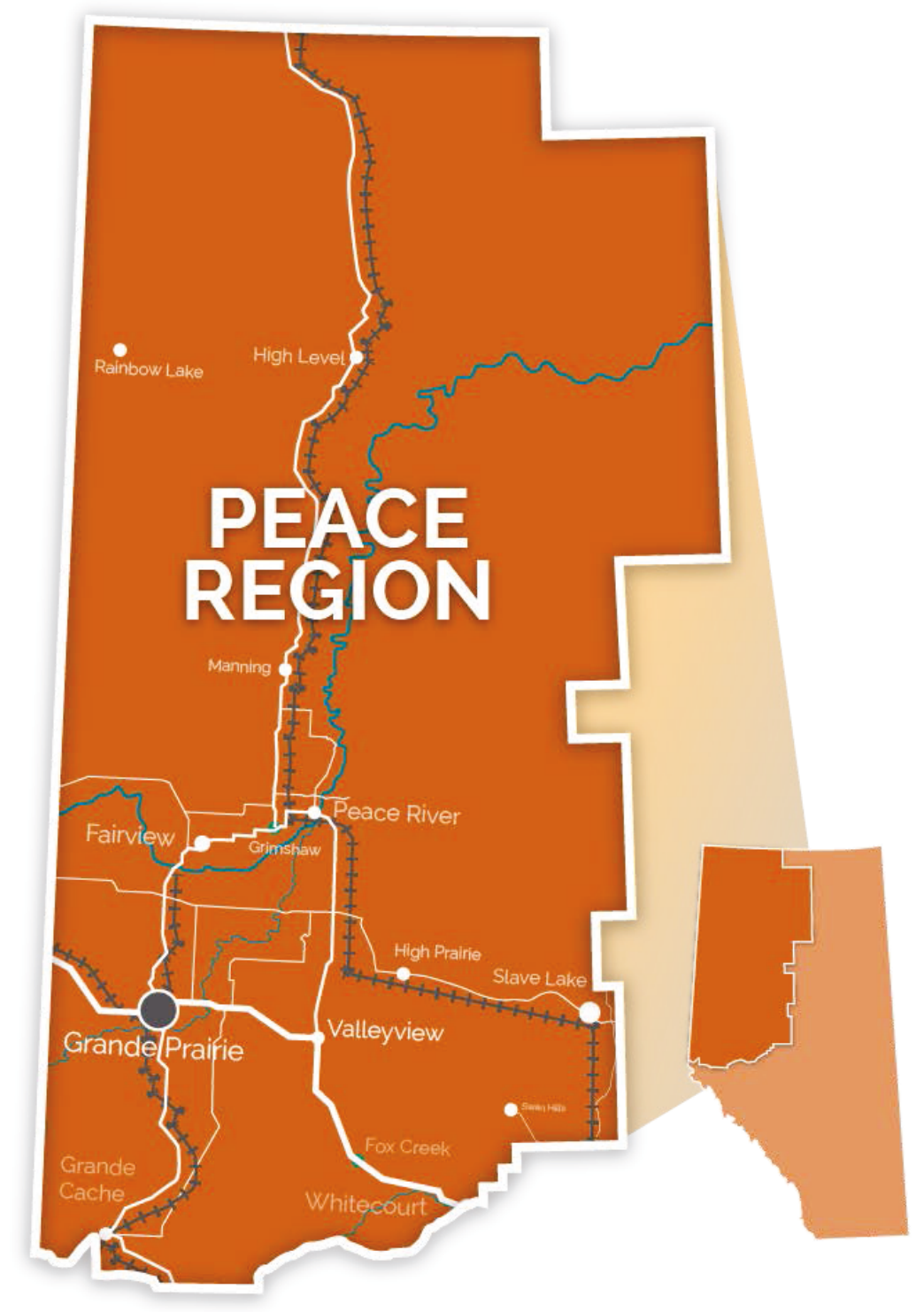

Figure 1.5 - Map of Alberta's Peace Region 


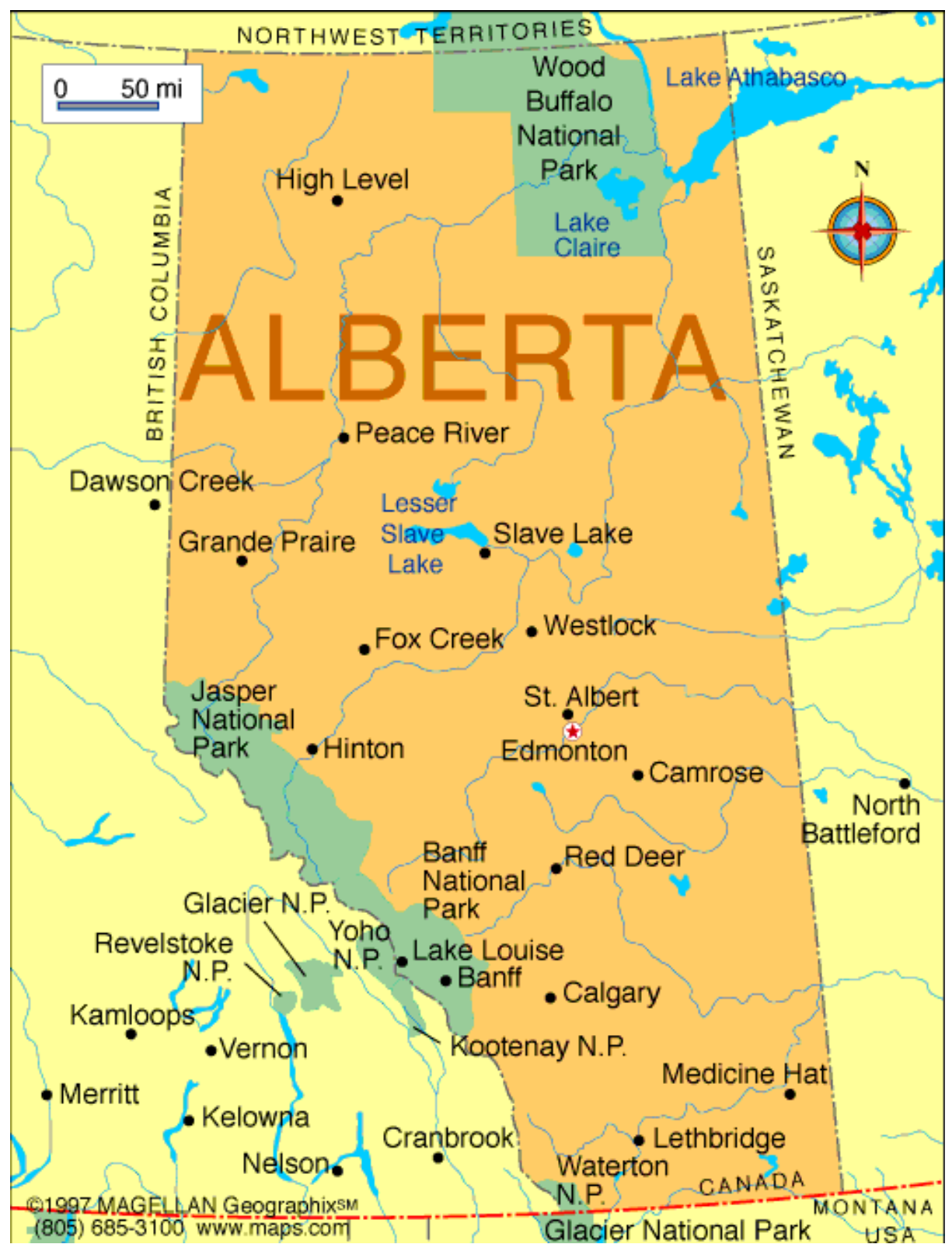

Figure 1.6 - Map of Alberta (courtesy of www.maps.com)

\subsection{1 - Site Description and History}

As noted in the section previous, GP is a northern Alberta community, and as determined by the 2016 Canadian Census, the $7^{\text {th }}$ largest city in Alberta (Statistics Canada, 2016). The city is surrounded by large tracts of prairie and mixed farmland to the west, north, and east, and to the south lie vast arboreal forests, which support the timber industry in the region (See Figure 
1.7 for a photograph of the city, facing south). Being the largest center in the Peace Region, GP has evolved into a hub for commerce, employment, and tourism. Primary industries include forestry, oil and gas, and agriculture, and the cultural makeup up of the city reflects this working heritage: businesses open early and close late, to accommodate the unpredictable schedules of workers and travelers. Entering the city by vehicle from any direction yields roadways dotted with restaurants, gas bars, and hotels. Employment signs and banners seeking skilled workers and tradespersons are frequently posted on major in-bound roads, further evidence of GP's reliance on labour economies. In further homage to a culture of shift work, 24-hour convenience food and gas bar offerings are numerous, and the access ways to them are large, to accommodate the oversized vehicles that are usual to the area.

Roadways in GP are notoriously variable, given that they have been constructed on the unconsolidated terrain usual to the area, which locals refer to as 'muskeg'. In winter times, it is usual for cracks, impressions, and potholes to open up on major roads, and to expand throughout the season. By the time the snow has melted, they can be of significant size, and are referred to humorously by residents. For example, one participant, when describing a city landmark, made reference to a "crater that you could lose a Civic [small car] in". As a result, roads in the area are often patchwork, and continuously under construction.

Seasonally, the climate in the Peace Region is highly varied. Winters are long and arduous, with much snowfall and cold temperatures. By comparison, spring and summer are short and warm, with high humidity and frequent wind gusts. GP's northerly latitude restricts the amount of sunlight hours available in winter time, and amplifies it during spring and summer months (See Figure 1.8). It is not unusual for twilight to fall after midnight during the 
months of July and August, offering residents the opportunity to extend participation in outdoor activities. As such, locals are active in many outdoor activities, including camping, recreational sports, canoeing, hunting, boating and river rafting, and driving off-road vehicles.

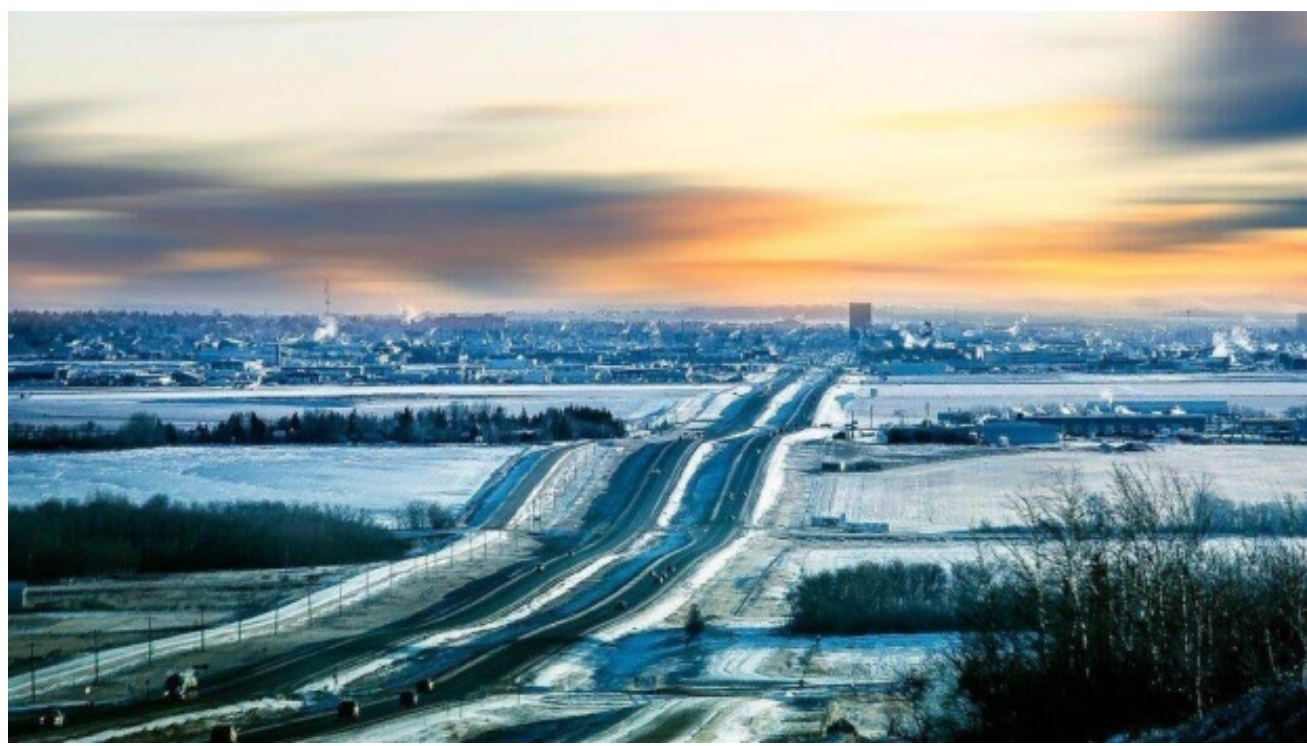

Figure 1.7 - City of GP at dusk (courtesy of CBC)

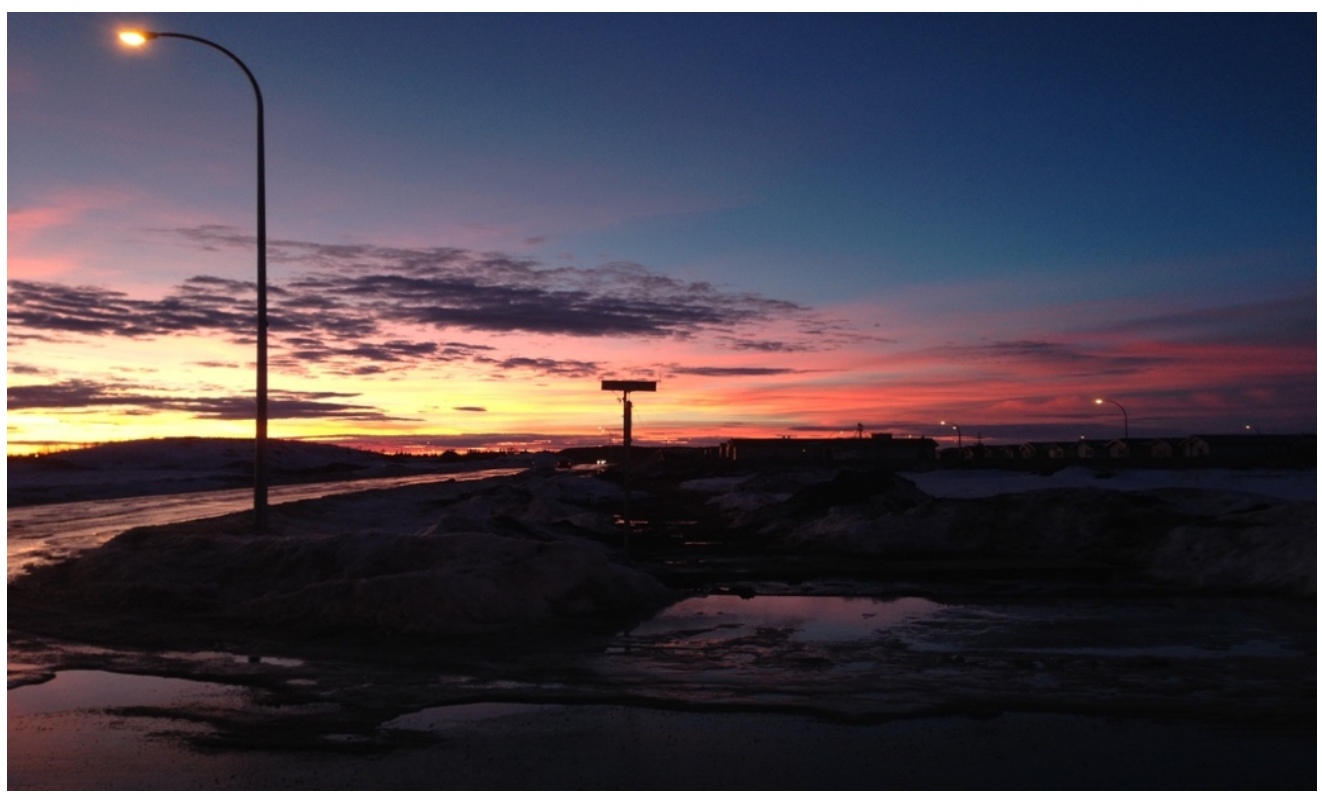

Figure 1.8 - GP sunset in spring (Houser, 2014) 
Although designated a village in 1914, the history of GP begins much earlier. Originally the hunting territory of a number of First Nations peoples, including the Dane-Zaa (or Beaver), Cree, and Iroquois, by the $19^{\text {th }}$ century, the plains region north of GP had become increasingly a destination for homesteaders and agriculturalists (Leonard, 2005). A fledgling town site sprang up in the early $20^{\text {th }}$ century, and by $1919, \mathrm{GP}$ had received designation as a town. By 1958 , it had achieved city status (City of GP, 2017), and had a population of around 7,600. The oil and gas discoveries at Leduc ten years earlier had spurred interest in exploring the Peace Region, and as a result, the GP grew dramatically in size. The 1974 opening of a Proctor and Gamble paper and pulp mill near the city triggered a significant population boom in GP (Pulp \& Paper Canada, 2003), as did the 1977 discovery of the Elmworth deep basin gas field (City of GP, 2017). The crash of oil prices in the early 1980s saw GP resized as residents left for other job opportunities, but another population boom occurred in 2006-2007, due again to excitement over rising oil and gas prices. In recent years, GP has continued to attract new residents at rates higher than the Canadian average: census data from 2016 shows that GP's population grew 12.8\% between 2011 and 2016 (Statistics Canada, 2017), despite the economic downturn that has been plaguing Alberta since mid-2014.

Demographically, the city of GP is a mixed Anglo-European community, with English spoken as the primary language by nearly all residents. According to the 2016 Census, of the 61,380 residents accounted, 61,100 spoke English, with 4130 speaking French (Statistics Canada, 2017). The third most spoken language in GP, Tagalog, showed 2,595 speakers (Ibid, 2017). Prior to 1981, GP experienced low immigration rates, with spikes from 2006-2010 and 2010-2016. However, the majority of GP residents $-46,405$ of the 61,340 accounted - identify 
as third-generation or more in terms of their status as Canadian, with 42,885 identifying as being of European origin, specifically, English, Scottish, Irish, German, and French, in that order (Ibid, 2017). Filipinos are the most visible minority in GP, numbering 3,105 in the 2016 Census (Ibid, 2017), and accounted for a large percentage of the workers represented in the food service and hospitality industries usual to $\mathrm{GP}^{2}$.

\section{6 - Research Design}

The research that forms the basis for this doctoral thesis grapples with questions of how gender and masculinity are understood and performed in the ebb and flow of working and social life in an Alberta oil and gas community. Tugging at these threads proved challenging, and throughout the research and the subsequent writing, my own notions of anthropology, specifically what the discipline can offer and how it is performed, were both contested and reinforced. If anthropologists, trained to problematize, employ what Heggenhougen has termed a "Yes, but..." (1993: 282) approach to learning and inquiry, then it is fair to say that for many oil and gas workers, the framework for inquiry would manifest in a statement, rather than a question: "Get it done, no matter what". For the oil and gas industry, expeditious outcomes are highly valued, and researching among outcome-oriented people and cultures can test one's ability to practice nuance and consideration.

Good anthropology, though, is methodical, and attenuated to scales of difference. My own understanding of the practice of anthropology places the focus around observing, being with, and asking about people, places, and ideology, and then attempting to make clear the

\footnotetext{
${ }^{2}$ As noted in the introduction, GP demonstrates ethnic and migrant diversity, but such diversity is significantly less represented in oil and gas work.
} 
why of it all. And, if necessary, to offer an informed justification of practices or actions that appear unusual out of context. It stands to reason, however, that some people, places, and ideologies are not easily justifiable, and in such cases, the anthropologist must be willing to draw inferences and reach conclusions that do not provide neat resolution. In this, the anthropologist is more likely to be what Lynd termed, "a constructive troublemaker" (1939: 189). As this thesis makes clear, residents of oil and gas communities have a vested interest in the prosperity that the industry can bring. This also means there exists a willingness to query the intent of outsiders who appear questioning or critical of the industry. As is shown in later chapters, considerations of environmental, social, and other issues that extractive resource work can raise are not automatic on the part of the industry and those who labour within it. Those who question the benevolence of the industry are likely have their masculinity questioned, or simply be disregarded as extremist or politically radical. The industry is broadly intolerant of criticism, and inculcates this intolerance into its workers, which can complicate undertaking social research that asks difficult questions of participants.

Prior to beginning field research in GP, beyond one casual acquaintance, I had no previous contacts. Preliminary research into a number of drilling and service companies headquartered in GP yielded a considerable pool of potential contacts, and I was confident in my abilities to meet and attract participants. As it happened, my lone acquaintance proved well connected, and was instrumental in assisting me in finding local employment, providing insider oil and gas gossip, and suggesting interesting people to interview. One of his early remarks, "You are in the right place, man, the right place for what you wanna do" often rang true, and I remain indebted to him and his family. 
In designing and planning my research project, three key components needed to be accounted for: the type of methods to be used in collecting data; the type and quantity of research participants desired; and the reasonable duration of field study. As my research was expected to encompass a number of sites, actors, and interests, ethnographic methods such as participant observation, interviewing, and job shadowing could prove useful in eliciting rich and comprehensive data. Previous research had demonstrated that the above methods worked well among drilling rig workers, and having learned that much of what happens on a job site, for example, is loaded with symbolic meaning, employing participant observation and job shadowing would be integral in decoding such meaning, while being unobtrusive. As Hammersley and Atkinson (2007) note, ethnography does not announce itself to research participants, but its power lies in the careful and systematic analysis of seemingly mundane occurrences. Tanya Murray Li takes this notion further when she writes "Ethnographic research obliges the ethnographer to confront the gap between the chaotic 'common sense' of lived realities and the schemes he or she must apply in making sense of them. It disrupts the ethnographer's prior categories and assumptions, exposing uncharted territory where familiar categories don't hold" (2014: 5). Many times, during the writing of this thesis, her concise words rang true, and they served as both a challenge and warning.

Good ethnographic interviewing seeks to elucidate participants' understandings of how they live and navigate their particular worlds (Seidman, 2006; Van Manen, 1990). While many researchers overestimate the number of interviews they can expect to conduct, I was at pains to be realistic. With a proposed research timeline of 18 months, a goal was to achieve 50 formal interviews. In order for an interview to meet the criteria of 'formal', it had to be pre- 
arranged, audio-captured, and be organized around a rubric of specific questions. As it happened, I was able to arrange formal interviews with 22 persons, 7 women and 15 men. Eight of these participants agreed to follow-up interviews, on as many as three separate occasions, and a number of interview 'sessions' exceeded three hours in length. For all formal interviews, the question rubric, which totaled 15 initially and evolved to 21 , was administered, and it was usual that interviews deviated significantly from pre-selected topics. It was also usual that those interviewed had a particular agenda or focus, and pains were taken to both capture the spirit of their words and practice "the art of hearing data" (Rubin and Rubin, 2012).

Additionally, 13 semi-formal interviews were conducted. These were not audiocaptured or organized around a standardized question rubric. I took comprehensive written notes during these interviews, however, and sought clarification from a number of interviewees at later dates regarding questions or assumptions that resulted from the original interaction. One of these interviewees eventually agreed to a formal session, and became a key participant in the later stages of the research. By that time, we had developed very good rapport, and he was instrumental in filling in historical timelines and connecting me with other persons in the community who had both worked in and been familiar with oil and gas for many years. Not to be discounted were the dozens of smaller, less regimented interviews, chats, and conversations had in coffee shops, at the grocery store, on the job, and in bars, cafes, and company vehicles. The substance of these interactions was often focused around the more mundane occurrences of working in oil and gas, which offered many opportunities to understand how participants understood these experiences. 
Previous research with drilling rig workers had led me to understand that the oil and gas industry can be suspicious of outsiders. I theorized that finding employment within it would improve access. Prior to being employed in the industry, early recruitment strategies were met with very limited success. Obtaining employment with a local electrical company was a significant breakthrough, and overnight, access to trades workers increased exponentially, and added depth and scope to the research. Being able to accompany co-workers to remote job sites, attend company meetings, and participate in setting up a new equipment shop brought richness and direction to the research. An unexpected bonus emerged from my lack of formal work skills: as a new employee without trades certification, I was actively mentored by coworkers and managers. This had the effect of exposing me to multiple teaching and demonstration styles, along with accompanying worker ideologies. This made for particularly rich job shadowing, and as I was expected to ask questions, enabling the combining of research with learning new work skills.

Unlike the Master's work, which was largely confined to the action of the drilling rig on a particular work site, the doctoral research was necessarily multi-sited. Choosing to seek participants from all sectors within oil and gas is to situate oneself on constantly shifting terrain, and it was often a struggle to make the necessary code switches from chatting with a field worker while knee-deep in mud, to conducting a formal interview with a company manager hours later. As well, having multiple sites meant regular travel was necessary, in all weather conditions. Driving for two hours during a winter blizzard only to experience a lastminute interview cancellation or a failure on the part of the interviewee to turn up entirely was markedly frustrating and maddeningly usual. The fact of the matter is that the study of an oil 
and gas community is a considerable test of one's ability to 'do good anthropology'. There can be found many qualities and characteristics worthy of admiration in an oil and gas community, but also encountered are the practice and promotion of highly-gendered, dogmatic, and noninclusive forms of industrial capitalism. Given this, there is value in exploring the ideologies, actions, and understandings of a community for which the perpetuation of oil and gas ideals those values, attitudes, and expectations that yoke people together in their labour pursuits are necessary. The preceding should best be discussed in bright light, regardless of the researcher's own sensitivities towards co-workers, those with whom he shared meals, and those who formally participated in the study.

In understanding that natural resource extraction is a key component of Canada's economy, it can be assumed that there are economic, social, and political impacts felt far from the sites of production. In ways, GP can be viewed as a living case study, one in which economics, migration, and work commingle and offer up larger insights into Canada's economic development and history, the gender and masculinity values that both prop up and problematize the oil and gas industry, and the vibrancy and alienation of rural community life. Places such as GP exist as centers that both provide the labour necessary for extractive resource work, and simultaneously act as the destination for such work. Workers themselves are expendable resources, in that they trade their labour for an opportunity to earn a large salary, complicit in the fact that they can also be used up, like the oil and gas they seek deep in the ground. The work and the resulting lifestyle has many costs, including social, human, and environmental. 
It is the contradictions of life usual to GP that are at the root of its complexity. The undercurrent of oil and gas that runs through the region, drawing people in, overworking and overleveraging them, only to crush them in times of market upheaval stands in marked contrast with a community that prides itself on inclusiveness, entrepreneurialism, and community development. The existence and maintenance of such differing ideologies within a relatively intimate space adds to GP's electricity as a place, one where narratives are complicated by both internal and external factors, and where people can rise from modest beginnings to the upper echelons of the working class, only to return to humble beginnings during the next bust cycle. This balance of tensions, a complicated and varied history, and the impressions left on the region by those who live, work, and pass through it all conspire to render GP a community that is vibrant, complex, and disquieting.

Adding to this complexity, many residents of GP understand there to be an inherent societal need for oil and gas, and an equally powerful incentive for Alberta to provide for such need. It is little wonder that oil and gas workers are highly supportive and protective of their livelihoods: Alberta's economy is largely based on extractive resources, and without the considerable wealth generated by oil and gas revenues, the province risks a return to the humble pre-oil years, when it was a relative backwater, agricultural in orientation, and lacking in political clout. The province's particular economic history, its relatively sudden success as an energy provider, and its working-class sensibilities have all fed a culture that is at best reactive, innovative, and accessible, and at worst, small-minded, nepotistic, and politically narrow. All these things have implications for Canada. 


\subsection{1 - Locating Participants}

Much of this thesis is focused on examining the working and social lives of residents of GP, to demonstrate that such lives are imbued with complexity, contrast, and, at times, contradiction. Throughout the chapters that follow, a host of ideals that act to support, sustain, and render impervious to criticism the projects of oil and gas that are usual to the GP region are explored. Included are those which encourage GP residents and workers to promote tightly-bounded and conservative gender roles and masculinity expectations; to carry out acts of random and purposeful generosity; to perpetuate the understanding that earning large salaries leads to forms of 'freedom'; to instill a firm belief in the ability of oil and gas exploration to endure; to nurture the notion that the projects of oil and gas are a major contributor to Canada's economic stability and world prestige; to endorse oil and gas work as an opportunity to negotiate or write one's own economic and social history; and to embolden workers in leveraging their labour in an favorable job market. It is hoped that through exploring these ideals, a clearer view of how GP sees and sustains itself, and how it copes with the more challenging aspects of life in a resource extraction community, has emerged.

In interrogating masculinity, gender, work, and life in a northern Alberta oil and gas community, it could be assumed that race and ethnicity would also be categories of examination. In fact, this thesis and the research that comprises it do not explicitly focus on these categories, and the reason for this exclusion has to do with demographics: the ethnic makeup of GP is relatively homogenous, as is shown in Chapter 2, Section 2.5, and this homogeneity is even more focused where oil and gas workers are concerned. In fact, the only participant in the research that was not identifiably Caucasian had originated from Algeria, 
while one other participant hailed from Quebec and identified as a Francophone. These two persons constitute the sum of ethnic diversity among research participants in this study.

This homogeneity extended to the employment I held with an electrical company: during my 9-month tenure, the branch that employed me, and which had a few dozen employees, hired one mechanic who originated from Senegal, and another who had come from Mexico. Neither employee fitted well into the existing company culture, and within a few months, the mechanic from Senegal took a job with a different company, relocating to a larger city. In speaking with research participants about their own experiences with diversity and ethnicity, it appears that the particular demands of labour work in the oil and gas industry can heavily influence the ethnic composition of a work force: oil and gas work demands much of an employee, and these demands reach far beyond simply 'being on the clock'. For those whom family or religious priorities supersede job obligations, oil and gas work is a poor fit. Given the high rates of remuneration for the work, it is also likely that those who do not fit well into the cultural categories usual to the oil and gas industry can quickly be replaced by those who can or do. This thesis acknowledges this point, but is focused on the interplay of gender and masculinity in work and social life in GP, so as to better pull at the layers of complexity that drive and support the industry, while attracting and recruiting men and women that can be profitably molded by its culture.

A good deal has been written about accessing hard-to-reach research populations (Abrams, 2010; Atkinson and Flint, 2011; Faugier and Sargeant, 1997; and Levine et al, 2011), and the focus has typically been oriented to marginalized populations that suffer from chronic violence, economic depression, and health care crises. I contend that oil and gas workers 
should be included under the umbrella of 'hard-to-research' populations, but for different reasons: they are generally not economically deprived but advantaged, and although crime and drug activity occur within resource-based communities (see Parkins and Angell, 2010; Ruddell, 2001; and Ruddell et al, 2014), this does not necessarily make them difficult to access. Oil and gas workers can and do experience social marginalization, but their earning capability offers them outlets, in the form of hobbies, pursuits, and leisure, that other labourers can never realize.

Oil and gas workers are difficult to access for two significant reasons, those being that they are often suspicious of outside interest in their work and working lives, and that the work they do is encoded in a type of performative masculinity that prioritizes 'doing' the job over talking about it. Faced with this and other obstacles that barred access, it was necessary to develop a three-pronged approach to attracting participants: making use of 'cold calling'; posting on local social media and physical message boards; and building my local social capital through volunteering and involvement in community affairs. This multi-tiered approach did not yield immediate results, but eventually led to networks that significantly impacted the research and experience of living in an oil and gas community.

Early on in the research, it was useful to assemble a list of names of companies that were well established in GP. Initial attempts to recruit participants were undertaken through cold calling such companies, which meant phoning unknown persons or arriving unannounced at a place of business. This method was largely unsuccessful, as companies construct safeguards that are difficult to pass through without accreditation. As I usually had no appointment of particular name to pass along, the cold-call often ended abruptly. Deciding to 
take a more aggressive approach, I decided to try appearing in person at a company. However, without an appointment, this strategy was no more successful than making phone calls: my lack of contacts was a considerable barrier, and interested outsiders were not easily admitted. Without a concrete reason for making an appointment, such as a job interview, a meeting, or a sales pitch, receiving one was unlikely. This proved doubly so if the word 'research' was mentioned, especially outside of a natural sciences context. As I learned, the word 'research' conjured notions of undercover journalists or spies in the employ of competing companies (as relayed by a participant in 2013).

Trying to fail forward, I drafted a telephone and email message that ran as follows: Good morning, [Name], my name is Dan Houser, and I am a graduate student who is doing a year-long research project focused on oil and gas work in the Peace Region. I am wondering if it is possible to schedule a brief meeting with you, to discuss the goals of my project, and if [Company] would like to be involved. I can be reached at [my local cell number]. Thank you, [Name], and I look forward to hearing back from you soon.

Over time, the draft was modified to include names of persons I knew, and the language was made less timid - assertiveness being a quality much admired in the oil and gas industry. As my local reputation established and expanded, it became usual to dispense with a formal opener and simply ask if a certain person would be able to meet briefly at a convenient time. Furthermore, my affiliation with GPRC as its first Visiting Scholar conferred considerable local legitimacy with companies and entrepreneurs. My own university, far away in another province, could well have been on a different continent in terms of its importance to my research participants; it simply was not local enough to have any significance. 
After a few months of living in GP, the usefulness of local social media suggested itself. In relocating from Toronto, I had used the web-based classified service, Kijiji (www.kijiji.ca), to find accommodations. I had been overwhelmed with responses to my advertisement, leading to the hypothesis that web-based classifieds were well-utilized in GP. This assumption proved correct, and in particular, Kijiji, is very popular in GP. It is both an on-line service for buying and selling, and a meeting place for soliciting volunteers, offering rideshares, promoting community outreach groups, and viewing local and area cultural events and happenings. It also fits well with GP's sense of adventure and spontaneity. In time, Kijiji became a part of my own social backdrop, being used to find new accommodations, join volunteer groups, search out likeminded musicians, and generally catch up on local gossip.

Realizing the potential to reach a wide local audience, I placed a concise recruitment notice on Kijiji, complete with a photograph of oil well pumpjack at sunset, a scene that would be familiar to the people who could contribute to the study (see Figure 1.9). The language of the advertisement was carefully chosen: it need to sound enthusiastic, but the tone kept light. It must also assure potential participants that any meeting would be brief, and could be arranged around their own schedule. As it happened, the first response came in within 5 days, which led to the first formal interview of an oil and gas industry worker. Over the next 12 months, I posted regular notices on Kijiji, and it proved to be an effective way to gain access groups of workers through snowball sampling, as they then connected me to others, building a pool of networks and resources. 


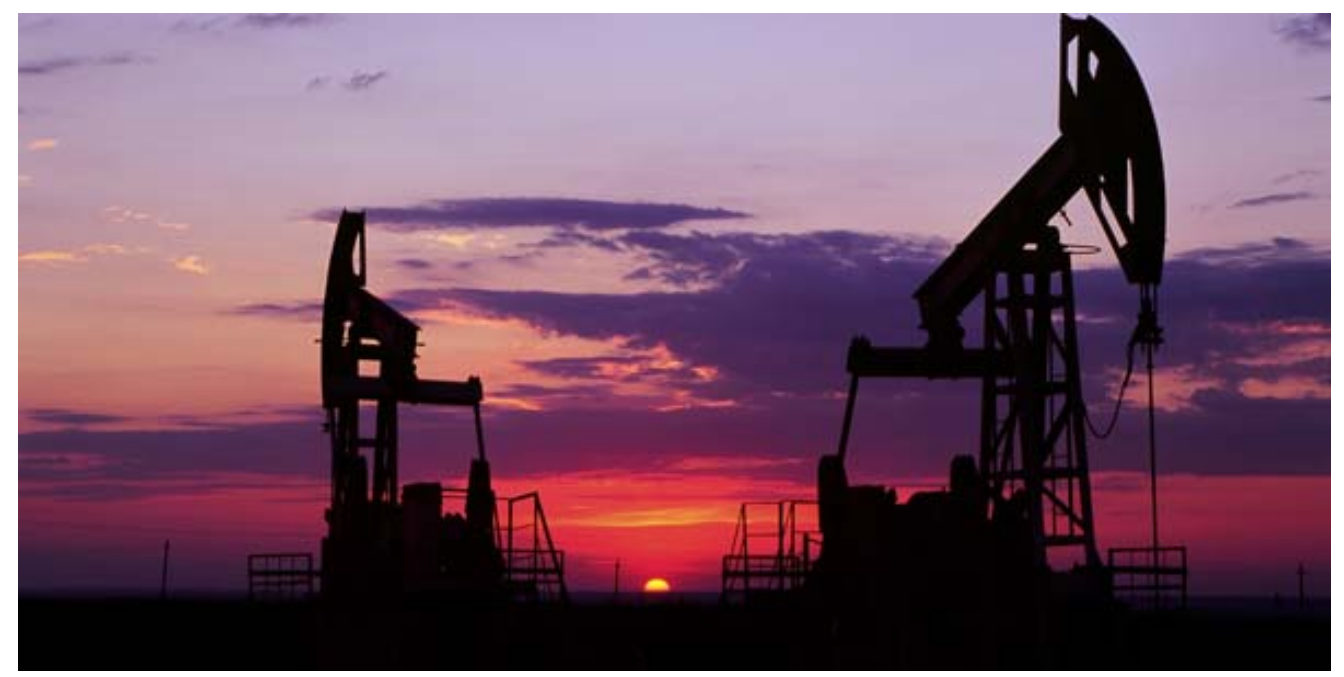

\title{
Work in the Oil and Gas Industry? \\ I want to talk to you!
}

I am an anthropology student interested in the stories and experiences of people who work in the Alberta oil patch. We can meet at a time and place of your choice, and I will ask you some questions about what you do, how long you've been doing it, and what your career path looks like. These questions only take about 30 minutes, but if you have more to say, I am happy to hear it.

For more information, please contact:

Figure 1.9 - Kijiji recruitment notice (Houser 2013)

\author{
Dan Houser \\ Phone: [Redacted] \\ Email: [Redacted]
}

Modest success was also realized in posting recruitment notices in grocery stores and hardware shops. Additionally, these notices were placed on the GPRC campus, which resulted in a number of interviews and referrals. Given that the College offers both academic and trades training, there was ample opportunity to interact with students who were actively working in the oil and gas industry. These interactions often led to interviews, and in some cases, job shadowing (see below for more on this). Furthermore, many students at GPRC come from families that work in the industry, and success in targeting that population for research was 
assisted by my regular presence on campus, teaching guest lectures, and having access to a private office space for interviews. Overall, student participants were less suspicious of my research, and in some cases, offered support for the topic of study. Their views also contributed integrally to my understanding of GP's place as both an oil and gas producer and as a community.

In addition to cold calling and posting on social media to access participants, applying to volunteer with a local learning council yielded another subset of participants. Having previous experience as an adult English language tutor, I was able to assist a number of educationally disadvantaged adult learners during the time in GP. Learning with them was both personally rewarding and an excellent way to connect with educators, civil servants, and community outreach groups. Being affiliated with the learning council meant it was permissible to attend monthly meetings, where I could mingle with local artists and mental health activists, as well as long-time local volunteers and charity representatives. While volunteering did not directly yield as many participants as other strategies, it did connect me with residents and social groups in a myriad of ways, including local government officials, mental health workers, outreach coordinators, and historians. As a result, a more nuanced understanding of the views and values of civil and social actors in an oil and gas community was discerned.

As mentioned above, being able to job shadow participants, and eventually co-workers in my job with the electrical company, added significantly to the depth and width of the research. I noted a tendency among participants to want me to witness and participate in their labours, rather than to simply describe them to me. This was a way of both communicating and experiencing the work they performed in a fashion that was understood to be superior to 
description. In one instance, on a hot summer's day, far from paved roads and deep into the timber, myself and a co-worker sweated and struggled with repairing a machine. While keeping an eye out for bears in the area, he remarked, "See, ya gotta experience this, ya can't just talk about it, means nuthin'”. It was during this type of job shadowing that I came to understand that for many workers in the GP region, experience was the greatest teacher and the litmus test of capability. Being able to demonstrate one's working worth is far more important than simply talking about it, and such ideals are in line with masculinist assumptions that are explored throughout this thesis: they inform the kinds of work that men do, how they understand such work, and how they perform it. Without being able to job shadow, it would have been much more difficult to access this deep stream of gendered, experiential learning that is offered up while on the job. 


\section{Chapter 3}

\section{0 - Masculine Agency in Oil and Gas Work}

Oil and gas work, as Miller (2004) observed, is a masculine enterprise, "not only in the historical and contemporary demographic composition of its employees, but in its assumptions, values and everyday practices" (2004: 48). Within this enterprise, performances of masculinity play out in multiple sites. One site of particular interest to this thesis is the act of manual labour, a common feature of oil and gas work. All of the research participants who were currently working in or had worked in oil and gas had spent time in labour positions. Labour work has its own sensibilities and values, and generates notions of what it means to work and who should do what kinds of work. These notions are powerful, and can serve as ways to characterize and reinforce class distinctions. Dunk (1991) discovered that for 'the Boys', working-class males in small-town northern Ontario, work was less a meaningful pursuit than one in which time is marked off by doing as little as possible or in having fun, especially at the expense of bosses or supervisors (1991: 140-147). Here, work is understood as a simple activity that enables men to earn money such that they can pursue hobbies, namely playing softball, gathering at a local bar, or hunting and fishing. For 'the Boys', life is best apprehended through sets of lenses that support the importance of their interests and understandings. Since they rarely have the opportunity to overcome their working-class status, 'common-sense' approaches to the world are favoured. These include being suspicious of strangers, keeping conservative politics, having traditional heterosexual relationships, and valuing practical knowledge that demonstrates 'hands-on' experience (Ibid.: 132-160). For many who labour manually, lived experience and 
physical knowledge of the job trumps other ways of knowing, and this is especially true for oil and gas work.

Many forms of labour work, including jobs in the oil and gas industry, are predominantly male in their demographics and as such, are often sites of concentrated enactment of masculinity. During a three-year stint as a female carpenter among mostly white men, Paap's (1998) gender and sexuality were constantly called into question, as was her rationale choosing to perform such work. Her male co-workers understood women to be physically incapable of doing the job well, and it was commonly believed only a certain 'kind' of woman would want a job as a carpenter, such as "a bitch, a dyke, or a whore" (1998: 82). Her male co-workers, including supervisors, assigned her demeaning nicknames, and routinely made crude, racist, or inappropriate remarks to her and around her. Despite their coarse behaviour, Paap's coworkers frequently complained that the freedom to properly express themselves was constrained by company policies pertaining to harassment or discrimination (Ibid.: 95-107), making what Carroll (2011) categorized as "appeals to injury or claims to disproportionate representation that figure prominently in late twentieth-century discourses about the plight of white manhood in American culture" (2011: 1). In this, they failed to recognize the privileges that gender and masculinity can confer on white males. As Kimmel has pointed out, "White men of all classes benefit from a system based on racial and gender inequality" (2011: xii), including ones who perform labour and understand themselves to be disadvantaged or victimized by nebulous societal structures.

Also usual to labour work are disconnects between the lived realities of those who perform the work and those who oversee it. Finn (1998) found that in the mining communities 
of Butte, Montana and Chuquicamata, Chile, men who worked in mines were resentful of "big shots" (1998: 120-123), office administrators and executives, and of former co-workers who had taken jobs as managers. Feeding this alienation was sense of direct connection to the work of mining: the male miner is a romantic figure, mythologized as valiant and brave, whose body is locked in struggle against the Earth. The binary opposite of the miner is the mining company, which, blinded by self-interest, fails to recognize the worth of its workers, and instead uses up their bodies and communities, only to halt operations and relocate when the resources are depleted. The enduring evidence of the mining operations, empty towns and fractured topography, serves as a physical reminder to those left behind of the greed of the company, and how it exploited generations of men as workers and women as caretakers of their sons and husbands (Ibid.: 127-140).

To write meaningfully about masculine enterprises, 'masculinity' in various forms must be confronted. I encountered a particular style of it during my previous research on drilling rigs, where workers valued being stoic, competent and comfortable with mechanical equipment, and were derisive of physical weakness. In the broader project of oil and gas, masculinity is slippery. Connell's (2005) writing on hegemonic masculinity, the idealized dominant male masculinity that seeks to exercise control over females and lesser males, is instructive. The organization of oil and gas work at the labour level is often hierarchical, and encourages the emergence of an archetypal masculinity, one rigorously physical, independent, authoritative, and decisive, resulting in a sort of hypermasculinity (Mosher and Sirkan, 1984, propose a 'macho personality constellation', which encourages similar values). This emergence is itself a space for the development of hegemonic masculinity, which is ultimately about the 
suppression or overpowering of femininity with its binary opposite: dominance. Masculinity, by definition, becomes the absence of femininity. Since not all workers can achieve the archetype - if anyone can, as Grant (1996) has suggested - there must exist multiple 'types' of masculinities that workers can call upon or draw into play as necessary.

Through interviews, job shadowing, and employment with a GP-based company that routinely contracted to the oil and gas industry, I learned that work hierarchies heavily influenced the expression of masculinity. As an example, those who managed field crews from the electrical company where I was employed shared certain traits: they were all large, tall white males; they were extremely confident and assertive; and they all lead by example and expected their crews to work as diligently as their leaders. Displaying both physical and 'clever' competence are masculine values in oil and gas work, and are desirable at all levels of job hierarchy within the industry. Those who rise to leadership roles in the work crews, shops, and plants have most often moved up through the ranks as field employees - they have a long conversance with the culture, work, and expectations of the industry. They must then embody the above values - competence, confidence, physicality - and embody them with greater clarity than those they lead. There is little room for a field manager to have an 'off' day; they must be willing and able to exemplify the type of masculinity usual to the job in order to maintain their position and status.

So too, masculinity can transgress its own formulations. Filteau's (2014) research among drilling rig employees explored attitudes and understandings of what was meant "to be a socially dominant man in today's oilfield" (2014: 398). On the job sites visited, it was found that workers were actively engaged in renegotiating the dominant masculinity of their 
occupational culture, inverting the old categories of "rugged, self-sufficient and self-made" (Courtnay, 2006: 156), and breaking apart the existing hegemonic structures. Previous work values had been focused around toughness, physical strength, and the ability to endure, but the industry's institution of rigid safety protocols has undermined traditional hegemonic expressions of masculinity. Filteau observed that this had led some workers to adopt the mantle of safety as a masculinist enterprise, thereby constructing a new dominant masculinity category: that of the safe and cooperative worker, who leads by (safe) example, and actively disciplines those that do not conform to the new standard. This new standard places emphasis on team spirit, consensus building, positive relationships between workers, and encourages asking for help with any task, a substantial renegotiation of the previously dominant masculinity. As one of Filteau's participants indicated, "There's no such thing as a manly man anymore" (Ibid.: 408).

An exploration of masculinity must also include women. Halberstam (1998) questions what it means to be masculine, and for whom it is 'proper' to be or to act masculine. He suggests traditional views of masculinity have been heavily symbolized by middle class, white male bodies, despite women and minorities continually renegotiating the category (1998: 1-43). In explicitly rejecting the traditional construction of masculinity as the province of white males, a space is opened for exploring alternate forms of masculinity, moving beyond simple physical performance. Although Halberstam's work hinges on the notion of considering masculinity without men, it has value here: work sites in oil and gas are largely homosocial places, where stereotypes and proscriptions surrounding physical capability, individuality, and quickwittedness are deeply rooted. Halberstam reminds us to look beyond the obvious 
performances of masculinity, and recognize that there are likely to exist those that are deeply transgressive, even within a largely male-dominated workscape. More comprehensive understandings of masculinity can emerge when the traditional categories are deconstructed and the normativity of masculinities examined where they are situated.

Women are subjected to male-dominated work paradigms in many industries, and those who choose careers in oil face similar prospects. Miller (2004) interviewed over twenty women working as oil industry professionals in Calgary, and discovered that not only were there few women in positions of authority, but that they were expected to submit to an inherently paternalistic work system (2004: 50-55). Women who successfully navigated career politics found that simply mirroring usual male behavior was not enough, and that there were seemingly different sets of rules for men and women in the job (Ibid.: 67-69). Despite various forms of success as professionals in the oil industry, the women in Miller's study were all subjected to a masculinizing work system, one that rigidly enforced a code of traditional gender rules and roles. A variant of such a system is usual to work culture in the GP region, and it further masculinizes those working within the industry, while simultaneously feminizing those who do not.

The scope of oil and gas work enables multiple performative masculinities (Butler, 1993; Grant, 1996), which have emerged from a broader sense of what it means to be masculine in work. For workers in the GP region, masculinity must be navigated, both in work performance and in-group membership. They must both demonstrate particular masculine qualities while working, qualities subject to constant negotiation dependent on whom they are interacting with on the job site (administrators, contractors, co-workers), and also show that the ways they 
think about, perform, and portray their particular masculinity serves to define their positionality in the larger physical and social worlds. The interplay of performance and navigation is complex, and successful workers are well attuned to this interplay.

The remainder of this chapter is assembled into four sections that discuss and grapple with structures and ideas that both encourage and prop-up the types of masculinities usual to the project of oil and gas work. The first of these focuses on notions of peripherality and 'frontierness'. The community of GP as a frontier - a destination that is physically removed from a mainstream, urban centre and one that exists both as a physical and imagined boundary of place - is integral to the construction and maintenance of this arena. Within that space are narratives that heroize individuality, stoicism, and entrepreneurial innovation, all resonant in the masculine culture of GP. Tall tales, stories, myths, and legends, based around demonstrations of strength, drinking prowess, violence, and debauchery laid the frameworks for masculine norms, and while there are those who resist the dominant discourses (see Chapter 5, Section 5.3), there are more still who acquiesce and support them. Still, the complexity of frontier life admits many views.

The second section is concerned with the perpetuation of actions that intimate human dominance over a physical nature, one enacted through the work of extracting petroleum. The oil and gas industry's historical actions and attitudes toward the Earth are analogous of a container. A container can be understood as a hollow repository, in which valuable things can be stored, and in the project of oil and gas procurement, these valuables come in the form of extractive resources, trapped in the Earth. A trash container is one filled with the refuse and debris of life and living, and the projects of oil and gas often reduce the Earth from receptacle 
to dumping or hiding place for unwanted material generated by the work of procuring hydrocarbons. Exploration companies use both depth and scale to conceal the extent of their activities inside the Earth, underneath its surface. This cavalier enactment of domination aligns with frontierist masculine values, ones that prioritize human triumph over nature, through the of pitting machines against the Earth, in search of hidden resources.

The third section discusses how the perpetuation of the 'self-made man' is dependent on a job market that favours employees over employers, one where the availability of work far outstrips available workers. Such a situation enables and encourages labourers to become their own bosses, which implies that a shift in class mobility is possible, all while reinforcing and reifying masculine narratives of industrial work and the places where it is performed. The high concentration of choices for would-be workers also has other implications, including negotiating the meaning of company loyalty, self-advantage, and motivations, all of which are understood to be closely linked to market fluctuations. These workers then redirect influence back at the market, as expressed through expectations of salary, working hours, and 'perks', incentives offered by companies to keep 'good' employees. The ability to choose whom to work for, and when, and to expect a high degree of job mobility, is a substantial component of masculinity in the GP region, and it is wielded expertly by trades workers and oil and gas employees.

The final section focuses on how the high concentration of jobs available in the oil and gas industry in the GP region has contributed to a disconnect between those who work 'in the field' and those who 'sit in town'. Values and sensibilities regarding work, leisure, and job satisfaction are noticeably different among these two groups, and often at tension. Those who 
labour in oil and gas typically disparage those who do not, and question the ability of the other to perform physically demanding work and to provide for their families. Town workers are seen by oil and gas workers to be unable to perform the requirements that typify GP's particular style of masculinity. Those same town workers justify their choices by questioning the necessity of such large salaries, and instead advocate spending more time with their families, often questioning the intellect or morality of those who labour in oil and gas. Both groups understand their choices to be the 'right' ones, and neither is convinced that the cost/benefit analysis of the other is correct, or much worthy of respect.

The confluence of the above factors has resulted in types of performative masculinity that are inescapable in the GP region. They have permeated the social, recreational, and aesthetic landscapes of the area, and are evident in the vehicles that people drive, the clothing they put on, and the conversations they have with each other. Such embeddedness sends strong messages about gender and masculinity, and one of those messages is that it is good to be a man in the GP region, especially a white one, employed in the oil and gas industry - public markers of status and capability. However, they are also ones of possibility, and of vulnerability, as the most recent economic downturn in Alberta has keenly demonstrated. It remains to be seen if there will be significant renegotiations of what it means to be masculine in the oil and gas industry, and who will perform that masculinity (and for whom), and how it will be managed.

\section{1 - Oil and Gas as a Frontier}

"Frontiers are not just edges; they are particular kinds of edges where the expansive nature of extraction comes into its own... Frontiers create wildness so that some - 
and not others - may reap its rewards. Frontiers are deregulated because they arise in the interstitial spaces made by collaborations among legitimate and illegitimate partners... They confuse the boundaries of law and theft, governance and violence, use and destruction... and thus enable extravagant new economies of profit - as well as loss"

(Tsing, 2005: 27)

In examining the values and motivations of those who work in oil and gas in GP, it emerged that notions of GP as a 'frontier' needed to be interrogated: as participants spoke about enjoying an "outdoor lifestyle", "good quality of life", and "community", the implication that GP was somehow mythical as a destination arose. Certainly, it was a place that could provide the qualities above, chiefly through hard work and economic reward, but there remained the suggestion that it was also a place where much more could happen, a place that represented a frontier in the province, economically and imaginatively. What, exactly, is a frontier? Is it a place? Is it a time? Is it an 'it'? The malleability of the concept suggests that 'a frontier' can be understood as all those things, and more (or less). 'Frontier' is a fraught word, fraught because while frontiers can be destinations and sites, they can also be remembrances and evocations. As Tsing notes, "A frontier is an edge of space and time: a zone of not yet" (2005: 28). The implication, then, is that they are both socially and physically constituted, and perceived publically and personally. Frontiers can be gendered, places where "a man could be a real man, the rugged individual he was meant to be before civilization sapped his energy and threatened his masculinity" (Cronon, 1995: 76). The sites of oil and gas are frontiers of their own, and offer many opportunities for men to be 'real' and 'rugged', and for men to develop and negotiate masculine expectations. Frontiers encourage the enacting and performing of being 'a real 
man', under a gaze wherein stoic, individualist expressions of masculinity are encouraged, promoted, and shaped.

A frontier can be a place of prosperity and hope, and also generate despair and alienation. Frontiers can be multiplicitous - technological, social, economic, medical, physical, temporal, and on. Frontiers can be both full and empty - full of the stuff and waste of lived lives and yet devoid, conjured in terms of a terra nullius or far-off place. Frontiers entice people, encourage movement, inspire the drawing of lines on maps, signify colonialism, conjure meanings of nature, and challenge individuality. Ideas about and of frontiers are necessarily complex, changeable, and filled with movement and meaning.

In conceiving of GP as 'destination and frontier', it is useful to trace the arc of its production back towards potential sources. The emblematic romance of a vast, untamed frontier has social and historical cachet in GP, as conjured by the words of Turner, who famously characterized American boundaries as "the outer edge of the wave - the meeting point between savagery and civilization" (1920: 3). He credited this site of cultural collision with "the promotion of democracy", manifested through how "the frontier is productive of individualism" (Ibid.: 30). In his seminal thesis, Turner argued that the frontier added measurably to the character of its people. The following section is worth quoting at length here:

“... [It is] to the frontier the American intellect owes its striking characteristics. That coarseness and strength combined with acuteness and inquisitiveness; that practical, inventive turn of mind, quick to find expedients; that masterful grasp of material things, lacking in the artistic but powerful to effect great ends; that restless, nervous energy; that dominant individualism, working for good and for evil, and withal that buoyancy and exuberance which comes with freedom"

(Ibid.: 37) 
Turner was not alone among Western writers that passionately championed the challenges and opportunities represented by physical frontiers. Contemporary others, such as Curzon (1907), Fawcett (1918), Holdich (1918), Jones (1945) and Whittemore Boggs (1940), explored the political geography of these peripheries, and of the inherent difficulties of demarcating boundaries, accounting for human migration, and organizing sufficient legal enforcement. Many decades later, the ideas these geographers and scholars proposed are still at play in the GP region, an area with its own complex history of people and doings, and where the enormity of industrial ambition can appear limitless. The projects of oil and gas, forestry, and large-scale agriculture and ranching have physically imprinted the terrain, bending the landscape to the will and vision of those who labour there. Work sites have literally been 'civilized', in all attendant forms. Such civilization would not have been possible without the exuberant application of the kind of effort and inventiveness that Turner so admired. A similar admiration for the scope, scale, and sheer determination of the project of oil and gas is deeply rooted in the GP region.

As the work of Turner and his contemporaries show, much of the power of the frontier lies in its being imagined and idealized. Cronon (1995) understood the frontier as a "national myth" that took root in American values systems. He further notes that frontiers can symbolize a distrust of progress, exhibiting "ambivalence, if not downright hostility, of modernity and all that it represented" (1995: 76). The irony here is that in idealizing the frontier as a place where nature exists beyond modern human influence, it is simultaneously destroyed, as "the place where we are is the place where nature is not" (Ibid.: 79). That the views of Tsing, Turner, and 
Cronon do not align, is no tragedy, but rather, speaks to the vastness and exploratory qualities of frontiers as concepts, places, and ideas.

The oil and gas industry itself is a frontier, one that invokes the specter of Turner, and communities such as GP are micro-representations of it. If oil and gas exploration is understood as a continuous endeavour, one that is always seeking, always finding, and one that is predicated on the 'next' discovery, the excitement of which helps to keep the entire enterprise aloft, then it is truly a frontier, and one that exists perpetually. It has been fed, nurtured, and magnified by an industry possessed of a 'big strike/big play' mentality, one that fosters a relentlessly competitive spirit, and which richly rewards those who have outmaneuvered, outworked, and outwitted competitors. The hunt for oil and gas is the manifestation of capitalistic vibrancy, and it is deeply ingrained in Alberta's social fabric, history, and identity.

Public exposure to the industry often comes through media sources, presented in tidy snapshots of success and failures, which introduce buzzwords into the lexicon, such as "Arctic sovereignty" or "energy security". Energy companies also seek to project their own narratives into public consciousness, fashioning (and refashioning) their corporate images to best advantage. For example, in a 2012 campaign undertaken by Cenovus Energy, a major player in Alberta's oil sands, messages assuring Canadians that responsible resource development was a first priority were packaged in slick television advertisements broadcast to prime-time audiences. Five years later, the Cenovus message remained largely the same: “... To be a responsible developer of one of Canada's most important resources - the oil sands", achievable with "fresh, progressive thinking", and the ability to "minimize our impact on the environment 
while producing energy resources the world needs" (Cenovus Energy, 2017). A reading of the mission statements of other large resource companies active in Canada, such as Husky Energy, Suncor, or Encana, yields similar language and ideals.

In spite of frequent coverage in news and popular media streams focused on the industry, and energy companies enacting their own forms of damage control and proselytism, the processes of oil and gas are opaque to those not directly involved with them. An enduring reason for this lack of transparency has to do with peripherality, both in terms of the geographic locales that oil and gas work is enacted within, and in terms of a sociallyconstructed frontier. The physical terrain where the work of exploiting natural resources takes place is mostly removed from view, remote and difficult to access, often being performed in rural locales under cover of trees, or far out to sea. Drilling rigs are not often seen in Toronto or Vancouver - the work of resource extraction is done 'elsewhere'. Rooted in these peripheries, the project of oil and gas work itself can appear anachronistic: mechanistic, large-scale enterprise plagued by stereotypes, public reaction, and costly missteps. Such an endeavour seems out of place when considered from the vantage point of a large metropolitan centre. In late modern Western society, there is a sense that it would be better to be less reliant on such industry, or at least moving away from it. So too, physical distance diminishes oil and gas's vividness, and as a result, the industry is popularly invoked as damaging, corrupt, and polluting or merely unevolved and quaint.

Yet, beyond these spaces and dialogues, ones where much of Canada assumes itself to be post-frontier, actual frontiers continue to exist and emerge, as sites where workers migrate to earn large salaries, and simultaneously imagine and reimagine their own individuality, place, 
and history. As Ingold has written, "Human beings do not construct the world in a certain way by virtue of what they are, but by virtue of their own conceptions of the possibilities of being" (2000: 177) [emphasis mine]. In this way, migrants to an economic frontier enjoy considerable latitude in making the category over in their own image. There are dominant structures that remain in place, but the category of frontier itself is largely fluid, to be determined by those who seek it, and who then inscribe their own sensibilities onto it, which the next wave of new arrivals then discover and themselves inflect. The frontier is both being perpetuated and constantly being made over, resisting categorization, and instead existing as "a traveling theory, a foreign form requiring translation" (Tsing, 2005: 31).

Comingling in this potent space are the resource extraction corporations themselves, and they too rewrite the physical history of the sites they exploit, inscribing their presence onto the lives and into the cultural mores of those who live and work in the shadow of the industry. The extent of these physical, geographic, geologic, and social impacts is not inherently obvious to those removed from these spaces and this demonstrates a dual failure: (1) on the part of government and the public to hold resource companies accountable; and (2) as an indication of the degree to which the industry controls public messaging and downplays the negative outcomes of large-scale oil and gas development.

While 'the frontier' has for too long been conjured and cast as a highly Western and individualized phenomena, anthropologists and others are troubling the traditional narratives. Rodseth and Parker (2005: 4) point to the "burgeoning research on borders, diasporas, and contact zones - those 'transnational fields' in which peoples, commodities, and cultural ideas tend to mingle and recombine". These spaces and places of action and transformation have 
attracted the interest of scholars such as Appadurai (1996), Donnan and Wilson (1999), Hannerz (1996), and Wolf (1982), who have rethought the range and patterns of the making of frontiers. Others, such as Anderson (1991), Sahlins (1989), and White (1991) have grappled with the politics of identity at the borders of communities, explored the impact of imagination on the formation of communities, local, social and national, and discussed the need for mediation between parties who share an uneasy occupation of these contested spaces. Their work increases the texture of our understanding of frontiers, adding layers to the scholastic framework from which others can further explore the boundaries of boundaries.

As notions of frontiers, boundaries, and borders become more multi-dimensional, so too must the acknowledgement of the complexities and impacts of multiple actors with competing interests that operate within and around them. Michel Agier reminds us that "a long moment of uncertainty has settled on the world. Precarious life lasts longer and people grow used to it" (2016: 6). For him, a 'border' is a both a destination and an inescapable present reality: movement implies the crossing of thresholds, the disturbing of lines that dictate place and not-place. As a result, the view available from a 'border' is not the view from the 'center', and those who imagine borders as places of possibility and freedom, and then travel to or through them, are transformed. Their view has been altered through and by movement, and the world is consequentially different in the aftermath. This realization, that borders and margins are always moving, further complicates migrant perspectives of place, being, and history.

Beyond being places where economic, personal and social opportunities are imagined to exist, frontiers have short social histories, for they are constantly being reimagined. In also 
being what Tsing has termed "a space of desire" (2005: 32), what is possible in frontiers is continually negotiated. The frontier that GP invokes is simultaneously economic and physical: a site where a broad set of expectations about work, living, and relationships can be enacted, but also a place, one of space, trees, rivers, and hills, far from metropolitan life elsewhere in Alberta. The physical and social distance of GP from the mainstream encourages malleable expectations of life and work. As such, citizens and new arrivals invoke varying degrees of informal negotiation with community frameworks, and with the people, personalities and activities usual to the place.

While Agier's work focuses on the ramifications of borders and liminality for migrant diasporas, there are also implications for those who work in oil and gas. Life is precarious in frontier towns, places where citizens are exposed to the dominant norms and then cycled through channels of integration, intended to instill those norms or inspire the would-be citizen to seek refuge elsewhere. In thinking through this processual cycle, I was reminded of listening to a co-worker describe performing a count and physical inspection of his livestock. As he told it, animals were herded from holding pens into a narrow chute, one which would eventually hold them fast, where they could be inspected, and given the necessary injections. Leaving the pens, the animals were guided down a corridor, which branched into a ' $Y$ ' shape, and those that needed inoculations were forced to the right, while those that did not were pushed to the left. The norming processes that new arrivals to frontier towns undergo are similar. Like Schütz's stranger, the person seeking to "be permanently accepted or at least tolerated" (1944: 499), a citizen must 'fit' within sets of work and community expectations, and that fit will be socially pressured and tested. Those that are receptive or predisposed to the dominant narratives 
integrate into the community successfully, while those who are unable or unwilling to do so are 'selected out', pressured to leave their working and social groups through sanctioning, harassment, lack of mobility, job demotion, and other means. Despite the appeal of an economic frontier, there are still considerable barriers to citizenship.

Simultaneously, those who seek out frontiers must navigate expectations of femininity and masculinity. Frontiers enable and support masculine expression, and as this dissertation explores, working and social life in GP is highly masculinized. The oil and gas frontier formulates and encourages particular expressions of masculinity, ones which shape the ways workers appear, act, and communicate. Notions of the 'wildness' of the frontier and the opportunity to negotiate different ways of being also influence these expressions, and the promise of adventure, of the kind that involves physical effort, heroism, and the celebration of man's triumph over nature, powerfully link masculinity with frontier desire and possibility. These features both attract people to an oil and gas town such as GP, and serve to repel them.

\section{2 - Conceiving of Nature}

The relationships that the project of oil and gas have with nature are complex and far reaching. The act of exploration is centered around locating and retrieving valuable natural resources, many of which are difficult to access. The companies that seek for these resources mobilize capital, expertise, teams of workers, highly technologized equipment, and machines capable of radical geographic alteration (as captured by the images of Burtynski, 2009). Moore (2012) reminds us that "financialization has environmental consequences" (2012: 32), and that the "relations of power, labor, and capital move through, not around, nature" (Ibid.: 31). Support for such an assertion can be found in the oil and gas industry's attitudes to its work, which 
include two concurrent understandings of nature. The first of these concerns the construction of a physical nature, often understood as 'landscape' or 'the environment', a place imbued with real and symbolic value (Greider and Garkovich, 1994). This physical nature is apprehended both as a place that is constituted by the work performed there and as a repository of valuable resources which are obscured from view - they must be sought. It can only be, in Muir's words, "the great fresh, unblighted, unredeemed wilderness" (1979: 317), and its physical presence provides the necessary starting point for resource exploration.

Undergirding the continuing quest for oil and gas are three explicit assumptions regarding a physical nature. The first of these has to do with the "inactivity" of the site of exploration, where "the landscape itself appears inert: ready to be dismembered and packaged for export" (Tsing 2005: 29). The second is that the resources of the Earth are available as "free goods', what Peet notes to be "of no value other than that given by the economy" (1992: 48). The third is that the Earth has a seemingly unlimited capacity for absorbing and offsetting the impact of intense industrial activity. These assumptions contrast with what biophysical systems show to be true, chiefly that "society is part of a world where physical factors are often important and sometimes dominant, where some things are physically impossible, and where people have limited (albeit still considerable) freedom to choose their futures" (Ibid.: 49). The drive for profit while looking to global markets and economic trends for information has seen the oil and gas industry, at best, ignore or rationalize away the problematizing of these assumptions. More often, it has actively engaged in campaigns to discredit critics and criticism and denied the impacts of its projects on people, places, and economies. 
A socially-constructed nature springs from what must be the empty space of a physical nature: the envisioning of the act of resource exploration conjures a social nature, and brings it into being. This social nature can be understood as the setting in which the culture of the oil and gas industry operates and interacts, and how it reacts and solicits reactions from workers and outsiders (not unlike the 'social environment' discussed by Barnett and Casper, 2001). Both of these natures are 'real', in that they are "socialized... reorganized... [and] made into a material manifestation of social structure" (Busch, 1989: 7). They are also real in that they engender consequences, physically, to workers, visitors, and personnel, and socially, in that they can become sites of contest, protest, and disruption. The relationship between the physical and social natures of the oil and gas industry are inherently uneasy, but one cannot be withdrawn from the other.

While being predicated on exploiting extractive resources, ones reducible to ownership, units of measurement, capital allocations, and, ultimately, profit, conceptions of 'nature' do not remain untroubled within the industry. However, the form of its work and relationship with a physical nature has a particular dynamic, one in which human endeavour is the active component and the Earth itself, the object of this activity, is (ideally) passive. This 'relationship' is predicated on domination, the mastery of physical environments by human entities. Within this domination ideology, it is assumed that large-scale industrial activity has, at most, nebulous impacts on the Earth, and that such impacts can be recalled through the application of creative scientific enterprise, or simply hidden from view. Strong critiques of these notions have been issued from many quarters, and especially from environmental philosophy (see, for example Attfield, 1994; Callicott, 1979; Elliot, 1997; Hargrove, 1996; Sober, 1986; and Turner, 1994). 
However, the products and services enabled by the development of natural resources are of such value as to encourage ongoing and increasing exploitation. Physical and environmental disruption is not in itself consequential to the oil and gas industry and attitudes that challenge this position are understood as emanating from special interest groups and people with agendas disrespectful of capitalism.

The possible origins of an ideology that views the Earth as an unending, seemingly selfreplenishing and healing resource container expressly available to meet human desire are numerous. In this construction, the annals of Western thought, including interpretations of biblical scriptures, are not innocent. In the book of Genesis, Adam and Eve are exhorted to "be fruitful and increase in number; fill the earth and subdue it" (Genesis 1:28, KJV). This phrase neatly invokes a dualistic nature, at once passively Cartesian, requiring the firm hand of human stewards, and positively Hegelian, dependent on the power of man's creativity to bring it into being (Passmore, 1995). Environmental activists, such as Foreman (1998), have pointed to the arrogance of humanism, and its prioritizing of human reason and individuality over that of all other animals. For some feminist scholars, dominating nature has close parallels with the domination of women by men, with both histories being deeply rooted in a toxic patriarchy (Warren, 1990). Within philosophy, witnessing the human failure to find and extend community with nature evokes a tragic version of the Hegelian master-slave dialectic (Brennan, 2007). All these scholars have recognized that the gulf that stands between humans and nature is of our own making.

Another answer may be found exploring the works of Heidegger, specifically in apprehending the notion of 'being' and its uneasy relationship with technology. Such is our 
innate desire for technologicalism, writes George (2015), that "transforming what is natural into artefact or resource is one of the significant ways in which humans of all ages and places have related to their world" (2015: 51). This fetishism of technology profoundly unsettled Heidegger, who warned of the impending descent of humanity, in the form of a "transition to the technologized animal" (Contributions to Philosophy: 78). The unchecked being, in its modern Western manifestation, demands "the arrangement that places all objects and stuffs in a form for humans that suffices to securely establish human domination over the whole earth and even what lies beyond this planet" (Principle of Reason: 124). The interweaving of technological fetishism and the divine right to subdue offers a powerful impetus to realize the subjugation and exploitation of a physical nature.

In $17^{\text {th }}$ century Europe, ideas were proliferating about what nature was, how it was represented, and how humans were to interact with it. A considerable influence on the evolving interest in nature resulted from the work of the English philosopher and author, Sir Francis Bacon. A giant among scholars and scientists, the vision of scientific discovery he articulated was firmly guided by Christian principles. For Bacon, dominating nature was not only in line with scientific progression, it was a religious imperative to "let the human race recover that right over nature which belongs to it by divine bequest, and let power be given it" (1997: 108). In man's conquering of nature, the true splendor of divinity could be realized. That the roots of Bacon's ideas about the natural world can be witnessed in the culture of the modern oil and gas industry says much about their impact: the modern industry is heavily scientific, promotive of technological innovation, and predicated on an assumption of the Earth as a bountiful and complicit provider. The continued domination of nature may be more 
problematized than it was in Bacon's day some 400 years ago, but the projects of oil and gas continue to grow and multiply. They serve as a significant reminder that in the clash between industrially-realized human endeavour and ecology, a global thirst for oil and gas far outstrips concern or consideration for nature.

\section{3 - The 'Self-Made Man' and "Being your own boss"}

"All the people that I know that have piles and piles of money... Every one of 'em... were the boots on the ground. I could name literally a dozen or more, and we're talking multi-millionaire, big time assets, experience, all the resume that goes along with it and whatever, and they usually come from the ground up."

-Jason, contractor (2013)

Chief in attracting workers and migrants to the GP region are opportunities to realize economic gains, through labouring in resource-intensive industries such as forestry, agriculture, and most frequently, oil and gas. The usual trajectory for workers is to experiment with different sectors within the industry to determine best-fit. Those who are ambitious often undertake trades training or leverage job experience to start their own companies or work as a for-hire contractor. When the industry is in a boom cycle, the opportunities to go into business for oneself multiply rapidly, and jobs for the company-minded are also plentiful. These jobs and opportunities can vanish just as quickly simply due to fluctuations in the global resource markets, with the effects becoming more marked during a protracted economic downturn (as witnessed repeatedly in Alberta).

Despite a prevailing attitude that workers in the GP region enjoy strong agency, the choices they make in terms of their engagement with the oil and gas industry are 
laden with conditions. Each of the dominant work streams - that of employee or contractor - are accompanied by sets of costs and benefits, which the would-be worker must navigate skilfully in order to be best advantaged economically. Even then, larger structural and market factors can have considerable impact on those choices, such that what seemed liked solid reasoning and planning one year may be shown to be ill-advised the next. This section will focus on exploring the point-of-view of both employees and employers, and how those sets of cost and benefit are apprehended. The discussion will be informed by information gained through interviews and while working in the electrical company, and from other research participants who spoke about their experiences working with particular companies or in starting their own.

Job mobility is a prime value for oil and gas workers in the GP region, and a willingness to change companies without attempting to work out differences of opinion or solve job conflicts was normative. The reactivity of workers often mimicked the larger ebbs and flows of the industry, and this significantly impacted the expectations and attitudes of the companies that were active in the region. Brian, a 45-year old field technology specialist with many years of experience, indicated that his current company strove to reduce his autonomy. He described a work scenario requiring him to wait in the company shop until being called to a job out in the field, "No work until they say so". This sort of liminal experience could last for days, but is considered a standard feature of the industry, jokingly referred to as 'hurry up and wait'.

While waiting, there was little for Brian and his field co-workers to do, but the company had to pay them for being in the shop (albeit at a lower rate), so a tense 
dynamic would emerge: the employees wanted to be in the field, away from the surveiling eye of managers, and receiving their usual wage. Meanwhile, the company administrators would grow upset because the workforce was still being remunerated but not performing its duties. At such times, it was usual for managers to make disparaging remarks to the employees, or to imply that the lack of field work was somehow a worker fault. For their part, Brian and his co-workers would resist the characterization, and then accuse the administrators of not planning the jobs properly, or make jokes about their perceived inability to actually manage. The tension in the employer/employee relationship remained close to the surface, maintained by the fact that the shop-field scenario often repeated itself. Workers understood their bosses as wanting to micromanage every facet of the job, and seeking to find ways to undercut employees' abilities to earn their wages. Managers, then, understood their employees as selfabsorbed, disrespectful, and lacking loyalty, likely to leave the company at the first sign of trouble or opportunity elsewhere. Brian summed this relationship: "Like, they know everybody is lookin' for a better job, I mean everybody, and so they treat you like dirt while you're around, don't expect ya to stay, so why be nice?"

Ho (2009) notes that for Wall Street employees, job instability is a given, and that the inherent risks that newcomers face are 'worth it' in terms of opportunities to earn large sums of money. In this way, Wall Street jobs are better understood as "financial relationships". Ho's participants were convinced that Wall Street was uninterested in employees beyond their ability to furnish new clients, cut deals, and keep the firms making money and growing. All other considerations were either dismissed as irrelevant to the situation at hand or simply 
implied that workers should clearly be aware as to what to expect when engaging with 'The Street'. Similarly, companies in the GP region had recognized that workers could be empowered by market volatility, and developed strategies to best accommodate this volatility. Participants referred to this, broadly, as 'company culture', and it was agreed to be a major factor in considering an employer. The electrical company that employed me was oriented to hiring the best available staff, with the hope that workers would view themselves and the company as engaged in mutually beneficial and reciprocal relationships. If it was obvious that a potential employee was highly self-interested, efforts would be made to find another candidate, but in the event of a labour shortage, the company would have to take such workers as could be found. Adding to this dynamic were high rates of job turnover during busy times something witnessed frequently at my own company. My immediate manager was displeased with ongoing employee reactivity, but acknowledged that "you can't make everyone happy" and that "people are always gonna do what they want". Like Wall Street workers, oil and gas employees are economically privileged, and a high degree of self-interest was to be expected.

Other companies employed a more austere approach to labour relations, letting it be known that they too could focus strictly on self-interest. Participants described work experiences with companies where they were viewed with suspicion, repeatedly told that they were not particularly valuable, and often begrudged the equipment and other necessities of their job, being made to justify need, use, loss, and replacement. In a number of these instances, the companies in question were large and well-established. Participants were unsure if the size of the company was directly related to their negative experiences, but a number of them noted that within the larger companies, the 
expectation of worker turnover was higher, and the disconnect between employees and managers more noticeable. Participants understood the culture of the larger companies to prioritize profits over people, being predicated on the expectation that even with a volatile labour pool, the sheer number of workers drawn to the region would ensure continued operation.

It was not unusual for both employees and employers to be cynical about their respective relationships. Employers viewed their employees as motivated only by economics and self-interest, ready to move "down the street" as soon as frictions came up in the work place or available work diminished. From the employee perspective, employers were overbearing, micro-managing, mired in company inertia, and unwilling to properly compensate their workers for going above and beyond job duties. Jeremy, a field technician, described a situation in which he and a co-worker developed a technique for performing a critical field procedure. This technique could have both saved the company money, in terms of time spent on the job and labour resources, and added to its prestige in the industry. He and his partner chose not to share the technique with the company, and instead left to start their own, which focused on the implementation and utilisation of the technique. When asked why he did not share this information with his former employer, Jeremy indicated that since it had been conceived during a working shift, the technique would then be owned by the company. As an employee, he was unlikely to benefit in any way from sharing this information - no financial remuneration or job promotion. In fact, he was certain he would not have received as much as a simple 
'thank-you': "So why would I share this, ya know, when they're just gonna take it, make more money with it, and I get nothin'? It don't make sense".

Jeremy's framing of his experience echoes the cynicism that participants

expressed. For workers, the values and priorities of companies are highly vague, only discernible as tight-fisted and oriented toward disadvantaging those that worked for them. For companies, employees are unpredictable, self-interested, and requiring of supervision. There are, of course, those on either side that navigate conflicts and tensions more easily and reasonably, but they appear comparatively rare. Most often, the relationships between employers and employees mimic the reactive nature of the industry itself, constantly false-starting and drawing back, surging forward, and then stopping suddenly. The wide gulf between the two entities is as yet impossible to bridge.

\subsection{1 - Company Man or Contractor}

Two common trajectories for oil and gas work in northern Alberta are those of employee of a company or working as a self-employed contractor. In the GP region, it is usual for new recruits to the oil and gas industry to work for a few years in a variety of job capacities, both for the experience and to see if a particular sector of the industry suits. As an example, Ted began in oil and gas by working on a service rig, and after a year, made the move to a drilling rig. Two years later, he decided to become a well operator, which lead to a position in a gas processing plant. At that point, Ted had a number of options in front of him: he could continue being an employee of a company and steadily build his seniority, following a traditional model of employment. Alternately, he could begin an apprenticeship in the skilled trades and become a self-employed contractor, 
which could bring about greater earning potential and work specialization, but which also introduced new risks, such as locating clients and bearing the cost of buying equipment. Ted eventually chose the latter path, and through his years of working in the region for different oil and gas companies, had the requisite skill set and contact list to start his own company and compete directly with former employers. The route Ted chose was one often taken by skilled labourers and tradespeople in the GP area, especially during boom times, when jobs and work are at a surplus. His rationalization was simple: "I wanna be my own boss".

Small companies and contractors have to find their niche in providing services for the oil and gas industry. For example, a locally-based production company with six employees is unlikely to be able to compete against an established world-class producer, such as Husky Energy; this company simply has more resources, capital, and a larger workforce at its behest, ensuring that it can outbid, outmaneuver, and outwork the smaller operation. The sheer span of the industry, however, often yields opportunities for smaller, more reactive operators to exist.

In the GP region, prime opportunities for small operations lie in the service sectors, in providing reparation, maintenance, and support to the oil and gas industry. My employment with an electrical company necessitated regular contact with both short- and long-term employees and contractors. In that company, the focus was providing industrial electrical services, but in purchasing a local HVAC company (heating, venting and air conditioning), management hoped to increase capabilities and grow the business. On both the electrical and HVAC sides, the bulk of employees were tradespeople, and enjoyed good levels of pay and 
respect as skilled labourers (for more on trades, see this chapter, Section 3.3.2). Despite this, skilled workers were apt to change companies if they sensed an advantage elsewhere, but less inclined to start their own competing business. In the 9 months that I was with the company, at least four tradesmen left to work for competitors, and others followed after my employment had finished.

A few months after leaving the company, in a chance conversation with a former coworker, I learned that one of the senior HVAC tradespeople, a man named Ed, had "gone out on his own". Given his specialization in the GP region, the move to offer services independent of a parent company or employer was not unusual. In Ed's case, a number of start-up costs for such a business existed, including procuring a service vehicle, equipment, and insurance. I asked my former co-worker what sort of capital outlay this would require, and he indicated that a new truck suitable for the job would cost around $\$ 75,000$, and that new was preferable to used, given that "you never know how that thing has been treated". Regardless, the vehicle would then need to be outfitted with an aluminum canopy, one that would sit in the box or on the deck. A new canopy, with adequate shelving, paint, tool chests, and logos could easily cost $\$ 20,000$. This same canopy would have to be filled with tools and equipment, some of which Ed already possessed. My former co-worker assumed that a further investment of around $\$ 5000$ would cover the necessary tools and incidental equipment. Still required would be business insurance, and any associated marketing costs, such that an aspiring small services business owner in the GP region could expect an initial capital outlay of around $\$ 100,000$ to 'open the doors'. Granted, this degree of cost is significantly less than launching a full-fledged services company, and so the financial risk was perceived as comparatively small. There also 
existed the belief that if the business venture failed, the demand for experienced tradespeople was such that a person such as Ed would simply go back to working for a former employer or a chief competitor - a relatively secure fallback plan.

Other sectors within oil and gas also showed room for small-scale enterprise. Bill, a 25year old transport driver with a large company, had been moving fracking fluid in the GP region for nearly two years. His aspiration was to purchase a transport truck, and lease it on with the same company. Over lunch one day, he said, "After a few years of that, I can start my own company, you know, a few trucks and guys workin' in the fuckin' trees". Bill was resolute in that working for a company was not his life's ambition. In fact, he only did it so that he could learn "the ins and outs of ownership" so as to be better equipped when starting his own operation. He looked forward to the future: “Sure, it'll be a pain in the ass, runnin' all them trucks and stuff, but I wanna be my own boss. Lottsa people want that. I can do that here in the next coupla years". For Bill, working within a transport company was a necessary step toward becoming an independent operator, and he was intent on mining the resources of the company he worked for - their equipment, client roster, and services offered - in order to benefit himself at a later time.

For other entrepreneurs, the variety of sectors in the oil and gas industry provided opportunities to better position themselves as contractors. This was the case for Tim and Tina, a late-20s couple with small children, who owned a company that provided pipefitting services. Prior to obtaining journeyman qualifications for the trade, Tim had been planning to work in another capacity within the industry:

"[It began with] Me welding, and starting a welding apprenticeship, 'cause I welded in high school, and I thought that's what I wanted, 'cause I was good at it, and welders 
make lots of money. But, I, ah, got out and seen what each of them did, like out in the field, 'cause I'd been in the shop the whole time, and I was like 'Okay, welder's under a compressor, welding in the mud, looks uncomfortable, and that guy's sittin' in a truck looking at drawings and doing drawings, and telling those guys what to do'... welder, pipefitter, I think I'Il go this way. I got outta welding right then, and got into pipefitting".

In six years of providing contractor services, their company had grown, and in the previous two years, Tina had acted as the accountant. In asking them about how they viewed opportunities in the industry, Tim noted that new recruits often tried out different types of oil and gas work to discover where their natural inclinations lie: "People go try service rigs, or they go fracking... I tried to sell cars at one point, didn't really like it, trying to swindle people [laughter]".

For his partner Tina, a Francophone who relocated from Quebec, the GP region had seemed like a place where she could realize her aspirations to "have a man-type job", one which could provide physical and mental challenges that she had been unable to find in her home province. For a few years, she worked alongside Tim, assisting him in the field and with shop projects. Unfortunately, she had been unable to receive her own technical training, as "I keep getting pregnant, so I am unsure what I am gonna do next, because it's hard, you know, to do that kinda work and have children... maybe when my kids kinda start school, I will get back to it, 'cause I really like it, you know, I get some muscle". When I asked what drew her to work in the oil and gas industry, Tina pointed to her dislike of conventionality:

"Well, I don't like working, you know, like 8 to 5, I really get bored of that. So, you can, I don't like that. I like work outside, I like, ah, I like [to] work with men, you know, I don't like woman. I like them, so it's just... We [her and Tim] do a lot of driving, a lot of traveling, and we see some, like there's so much to see, experience, to do... We are paid big bucks sometimes, to do nuuthin', and when we're together, it's pretty awesome" 
Both Tim and Tina identified as "very ambitious" and planned to continue working in the GP region for the long term, as there was "no reason to leave... Most everybody around here works in it [oil and gas], lots of perks". I stayed in contact with Tim for about 18 months, and in that time his business continued to grow, as did his family. He had no plans to return to being an employee with a company, and was looking towards expanding operations, possibly taking on some employees and buying another service vehicle to meet the demanding workload. For Tim, being a contractor provided the right blend of opportunity, prestige, and profit, and when last we spoke, he continued to be optimistic about the endurance of the industry. For Tina, the promise of economic remuneration, combined with physical work, had encouraged her to relocate to Alberta. While she acknowledged that motherhood was her primary focus at the time, she was insistent that she would find her way back to the oil and gas industry later, either as with her own training, working alongside Tim, or entirely on her own, in a self-directed manner.

\subsection{2 - Trades Work and Education}

Workers with skilled trades certification are well represented in Alberta's oil and gas industry. Employment with the electrical company regularly exposed me to tradespeople, and enabled the gaining of insight into the relationships between trades work and the industry. Trades in Canada are formalized, and it is usual to hold certification in the jurisdiction of training. In the early 1950s, there were no formal policies that assisted tradespeople in seeking work in provinces other than that where they had been certified. With government incentive, and after the First National Conference on Apprenticeship in Trades and Industries held in 1952, The 
Interprovincial Red Seal Program was created. It sought to "help harmonize training and certification requirements across Canada" (Red Seal Program, 2014). Today, this program is known simply as 'Red Seal', and is considered the working standard for tradespeople across the country.

Trades training features combined periods of classroom and on-the-job experience. Typically, trainees begin the 4-year process as apprentices, and move through the ranks at regular intervals. It is usual to be mentored throughout the process, and apprentices are required to accumulate a predetermined number of hours of work in each stage of training. Once that stage is reached, they are permitted (and encouraged) to write the requisite exams to prove their capabilities, and then continue to the next level. Each year of successful training is accompanied with a raise in pay, and the end goal is to achieve Journeyman certification (known as 'your ticket', in trades parlance).

Throughout trades training, there are significant periods of classroom study required. It was rare for the tradespeople I interviewed and worked with to speak positively of the scholastic component. For most, it was simply a necessary step in achieving a necessary certification. For many tradespeople, and indeed, most participants, secondary education was useful only if it led directly to job security or financial gain. In this way, trade certification qualified, but years of university training did not. It was usual to be chafed by participants and co-workers about my "useless" education, and at times I was the object of obvious pity. Extended scholastic training was unusual to my participants, and ill-suited to meet their expectations of its purpose. 
Several months into the research, an electrician named Dean joined the work cohort at the electrical company. Dean was alleged to have a Master's degree in electrical engineering and his presence was well received by other staff. In fact, in addition to his trades certification, he possessed a 1-year diploma in electrical engineering. Curious as to why his training was so well respected, we were able to discuss it at some length. Dean believed his training enabled him to function at a higher level of capability, in an occupation that views itself as inherently useful and productive. As an electrician, he routinely navigated complex systems of wiring, switches, breakers, and computers, all of which played key roles in keeping oil and gas projects moving forward. By contrast, pursuing "highly theoretical" scholastic training had demarcated me as less useful, especially as this training guaranteed no tangible economic benefit. This in itself was hardly surprising: the value systems of the oil and gas industry prioritize technical and practical knowledge and demonstrable skill, employed to maximum financial benefit. The respect that Dean commanded came not only from his considerable aptitude as an electrician, but because he elected to take further technical training that added to his job capabilities. The divide between 'useful' and 'useless' types of education was supported by GP's social value systems, in which useful education was categorized as that which engendered substantive economic gains or prestige. Educational pursuits which did not directly lead to either were viewed as undesirable, and more often, as "a complete waste of time".

This reactivity to what could be understood as a useful/useless dichotomy regarding education is worth examining. Arnot (2004) has argued that Willis's sociological classic, Learning to Labor (1977), pulled back the curtains on identity construction, revealing that the mechanisms of its creation were impacted by 'the lads', effectively demonstrating how 
masculinity is built into and shaped by educational systems. Like 'the lads', many tradespeople are working class white men, who do not typically enjoy middle class advantages. Trades work is often physically laborious, prioritizes the construction and production of tangible goods and outcomes, and represents a high-water mark of economic achievement for the labourer class. Willis's insights on how 'the lads' understood their relationality to the dominant education structures (and then reacted to them) are useful in exploring the priorities and values of the tradespeople I worked with and interviewed. Co-workers frequently reported that they had been drawn to trades work because it offered both stability and financial reward, and because the work itself appealed, offering opportunities to "work with my hands", and reproducing a shared understanding that tradespeople provide tangible societal services.

Also like 'the lads', many tradespeople shared the belief that 'school' (an umbrella category for education and scholastic training) is not a good fit for them, for reasons ranging from a lack of interest, to an inability to pay for it, to feeling that they were simply not capable of meeting the requirements. Some participants recounted negative early experiences with high school and education, while others were simply dismissive of it. Their reasons and rationales differed, but they were united in their rejection of what could be considered the traditional route to middle class affluence and respectability.

However, GP tradespeople differ from Willis's 'lads' in a fundamental way: 'The lads' rejection of education is total. They disdain high school, as well as the teachers who they perceive as trying to constrain their ability to 'have a laff', and mock fellow students who conform to scholastic rules and rhythms (1977: 11-49). By contrast, labour workers in GP practice a more nuanced form of education rejection and selection. They recognize that in 
order to achieve the highest salaries available to labourers, they must pass through trades training, which includes practical and classroom components. That they mock or are dismissive of scholastic training that does not directly correlate to an increase in earning ability shows that they understand the usefulness of education from an economic cost-benefits standpoint. While 'the lads' of Willis's study were effectively reproducing the category of working class in Britain, tradespeople in GP are actively constructing a new category for labourers, one in which particular types of education are leveraged for earning potential, while creating a space for workers to continue to reject middle-class admiration for post-secondary schooling.

Emerging from this selective rejection of middle class ascension and the perceived values that accompany it, is a singular dilemma: the desire to simultaneously occupy two radically different social worlds. In GP, tradespeople seek out the economic advantages of the middle-class, but are protective of and actively retain the characteristics of the labour class that strongly resonate with them, such as traditional gender roles, conservative social values, and a host of performative masculinities. The especially savvy leverage their skills and connections in pursuit of a salary that is comparable with that of a white-collar professional, while adhering to and perpetuating social and working values that are conversant with labourer sensibilities. Desiring to employ their considerable resources to improve both their own lives and those of their offspring (including, perhaps ironically, educational opportunities), all the while remaining firmly fixed in the social webs of the labour class, was not viewed as a contradiction. Rather, it was simply understood as the masterful manipulation of economic opportunity that sprung from a 'free' market, leveraged against those who typically controlled the flows of capital. 
Actively being manipulated within these economic flows was social capital, a vital and finite resource in the oil and gas industry. Tradespeople well understood the usefulness of connections and networks, and the more entrepreneurial among them, those who were selfemployed or had started their own companies, wielded social capital differently than did those who laboured as employees. The self-interest demonstrated by tradespeople employed at the electrical company was accompanied by flexible attitudes towards such networks. If social capital can be understood as "the operation of a social process, where non-cooperative action would lead to a reduction in information and resource flows" (Anderson and Jack, 2002: 195), then a willingness to contravene networks and existing relationships in order to profit is unusual. And yet, a number of employees within the electrical company acted entirely out of immediate self-interest, making little effort to enhance or maintain connections either within the company that employed them or with those that utilized their services. They had effectively gone 'job blind', convinced that in an over-heated economy, the demand for their services was such that they could decide whom to work for, and when. They were unable or unwilling to employ traditional strategies of ingratiation or relationship-building.

Such short-term thinking is not without precedent in the oil and gas industry. In Schmidt's (1989) exploration of two of Canada's early oil and gas entrepreneurs, Albert Parker "Tiny" Phillips and William Randall "Frosty" Martin, the unique personality and skill sets needed to succeed in the industry inevitably led to a form of elitism: "We jumped from place to place like foxes, to wherever we could get the most money. There weren't too many of our breed then and we could afford to be snooty" (1989: 52). It is important to note that tradesworkers are the elites among labourers, and command both high salaries and working-class respect. 
Those salaries are pushed even higher when the work is within an oil and gas context, and a regular pattern of boom and bust cycles has influenced the development of both an entitled attitude toward work options and one that places priority on satisfying a sliding scale of individual wants and needs.

Tradespeople who were employees in the oil and gas industry and who prioritized shortterm gain and job mobility hindered their own ability to endure a downturn. If, as Anderson and Jack suggest, social capital is predicated on the assumption that "networks of relationships constitute a valuable resource for the conduct of affairs" (2002: 195), those who did little to develop them would then have few job options outside of the industry. The all-important relationships "have a crucial role to play in the success of individuals", such that "economic exchanges are influenced by a level of trust and familiarity between economic agents" (Ibid.: 195). Employing a strategy of short-term gain worked against tradespeople, rendering them vulnerable in times of industry downturn, and prejudicing former and future employers against them. Whether they were unaware of contravening what social capital they had built up, or simply were unconcerned about it due to high demand for their services is perhaps a theme for future investigation.

\section{4 - Job Dichotomies: Working in the Field versus Working in Town}

Those who worked in field positions within the oil and gas industry in the GP region and those who had jobs based in the city itself were often divided by their choices. Framing an exploration of these boundaries and the crossing of them through the lenses of three participants, it will be shown that the sensibilities that inform the work choices people make in oil and gas communities are both subtle and complex, and necessarily adaptive. For Anne, an 
experienced medic transitioning from being stationed on-site to a job in town, the move was fraught. Her host of changes included a significant salary decrease, a destabilization of purpose, and a sudden re-entry into social worlds with radically different rhythms and expectations. Peter, a former industrial fire responder who two years prior had returned to the local college to study, made a conscious choice to switch to a town-based working life. It was a move which he viewed as positive and as a sign of his own personal maturity. Lastly, Erik, an IT professional, had never worked in oil and gas, despite having friends and family members with many years of experience within the industry. His choices were keenly influenced by a life-long proximity to the industry, which had positioned him to witness the changeable fortunes of a boom and bust economy, and the resulting impacts on people and businesses in town. Through examining the insights and experiences of these participants, a more comprehensive understanding of the contrasts that define those who work afield and those who remain in town will emerge.

A connection with Anne was made possible through a local message board advertisement, and an interview was arranged at a local coffee shop. She arrived in a large, colourful truck, bearing a bumper sticker that read 'Fuck you, I bought it'. When asked about this message, she indicated that it was usual in GP for girlfriends and wives of oil and gas employees to drive their partners' vehicles, it being widely-assumed that men paid for goods, and women then displayed them. Anne did not subscribe to this popular view, and as an independent, business-minded woman, operating in a highly gendered and socially conservative community, enjoyed educating anyone who encountered her (quite conspicuous) vehicle as to how it had been obtained. 
Anne was able to articulate and analyze local wisdom regarding an 'us vs. them' polarity, and she spoke thoughtfully during interviews. As noted, Anne was transitioning from fulltime work in the field to an office-based business in GP. Her transformation from 'field worker' to 'town worker' was not yet complete, and during an early interview, she made mention of her disbelief at becoming "one of these people" (indicating those who were in the coffee shop, and presumably, working in town). Anne's habitus was being disrupted, and she was undergoing a powerful period of adjustment, one that included financial, social, and personal factors. In discussing the challenges of moving from field work to town work, her new economic reality was a primary concern:

"We get paid a shitload for doing very little, and people in town make much less [money]... which is a serious reality check when you come from oil patch wages down to what is an average salary working outside the "patch".

She was also acclimating to an accelerated pace, having been a "glorified TV watcher" and "really expensive insurance policy" while in the field, to managing multiple people, clients, and a fleet of vehicles.

When asked how she was coping, Anne was already speaking about her years in the field in the past tense. She indicated that "[being a medic is] Not a career, it is a job... You age ten years in the span that most people age five, you age fast in the "patch". She was intentionally introducing distance between herself and her former profession, in an attempt to ease the transition from a particular set of social, financial, and personal realities into new, considerably different ones. The tactic of distancing herself from the recent past as a means of easing the present was a strategy that 'made sense': Anne had spent years prioritizing her 
working life over that of romantic relationships, marriage, and family. The prospect of suddenly renegotiating those choices was overwhelming, and introducing psychological distance or a form of historical revisionism could help her to move ahead and away from a career than had been all-consuming.

Notwithstanding the apprehension that her new life had introduced, Anne's decision to leave the field position had been a strategic one. She was seeking to add balance to her existence, and was lonely, acknowledging that it was "impossible" to sustain the working hours and job demands while searching for meaningful social or romantic connections outside of the job. In discussing how the pressures of industry work impacted relationships, she raised the issue of high rates of infidelity and materialism:

"[Working in oil and gas] Destroys a lot of people, a lot of families, and I wouldn't recommend having a family while working in the 'patch. Everyone goes in thinking, 'We can handle this, we can handle this'... I tell the women, you know, he's gonna cheat. You have to accept that. Women don't understand the life style. It's like military wives... You either have a wife that loves you for your money, or doesn't love you at all. Trying to find someone who loves you for who you are, it just doesn't happen [in GP]".

Anne's response sounds cynical, but when weighed against the backdrop of a community where relationships often fail and marriages do not last, it was less so. GP is a key destination for a young and ambitious working population, whose resulting salaries afford them the ability to consume conspicuously. These factors contribute to generating an air of excitement about the town, and when the oil and gas industry experiences a boom, the 'me first' attitudes evident among tradespeople and contractors were equally featured in romantic relationships and friendships. Anne's views were formed around these community realities, where people 
have developed an 'easy come, easy go' attitude, and where a laissez-faire outlook is common and even expected.

Eventually, the degree of sacrifice Anne had made in her work and social life was weighed against the financial remuneration available, and found wanting. At the time of our interviews (2013), she had been working for eight years, and purchased her first home at the age of 22. She elected to not attend a university or college, had no children, and was not in a steady relationship. Through being active in social media, she had connected with former high school classmates who were finishing post-secondary degrees, having children and purchasing starter homes. Viewing their successes through her own set of changing lenses had encouraged Anne to think more critically about her years of work in the oil and gas industry:

"What do I have to show for it? A half-paid off house, a newer vehicle, and nobody... It's like that whole story, you have two wolves inside you, fighting, at all times. Oil patch people feed the wrong wolf, the one that will never be satisfied. That's Alberta".

It is important to note that Anne's views on relationships, economics and the social mores of GP did not make her an outlier. Her insights into the social rhythms and sensibilities of GP were astute, and attitudes and views similar to hers were usual to participants, coworkers, and friends in the GP region. However, she was unusual in her ability to articulate the cause and effect of living in a community that prioritized economic gain over all else, and in her willingness to critique the structures that were in place enabling the perpetuation of such a system.

Further along in his transition out of the oil and gas industry was Peter, who had left the field two years previously and returned to town, working and studying there. He 
was resolute in his decision to leave the industry, despite having to hold a series of lowpaying jobs to continue studies (including, much to his amusement, piloting an icecleaning machine at a local arena). The transition to lower-paying work had been aided by the fact that he had begun his working career in these sorts of jobs years earlier. While still a teen, Peter left a job in a hardware store after being encouraged to apply to a safety service company by an existing employee visiting the store. Word-of-mouth recruitment has been and continues to be a staple of the oil and gas industry, especially during a boom time. This process is often simple: in Peter's case, he was approached by a stranger and asked how much money he made per hour. He responded with a figure, and the recruiter indicated he could make much more with the new company, encouraging him to seek an interview. Curious, Peter connected with the company, and was interviewed, a process which he categorized as "quick, and they hired me pretty quickly". The actual hourly rate of pay was lower than that of his town job, but the number of hours on offer, plus benefits and company vehicle, made the offer attractive. This job marked the beginning of his decade-long stint working in the oil and gas industry.

In time, the life of constant disruption, one in which the demands of the job were required to be prioritized over all else, pushed Peter to a breaking point. He relayed an experience where he and another person had been called to a remote well site to be on hand in the event of a fire. The company dispatch coordinator indicated that the duration of the job was likely to be "four or five hours, nothin' to worry about":

"Left the shop at $8 \mathrm{am}$, got there at $10 \mathrm{am}$, road bans were on, so I had to be there early, started displacing at one in the afternoon, at one in the morning, I went and said, 'Hey, do you mind if me and my partner here have naps, you know, he'll sleep 
and I'll be up watching stuff and then we'll switch and dadada'... So, I let him sleep, he's quite new, he was quite new, I let him sleep for an hour and a half, so it's like 2:30 in the morning, I've been up since seven, and working since eight, uhm, I go to sleep at 2:30, I swear I closed my eyes for thirty seconds, and all of a sudden there's banging on the door, and there's a huge fireball just outside of the truck, like I opened the door and it was like I was at a furnace. So, I get the pump engaged, and we put out this fire, and so, the whole flare stack is ruined, the propane line coming off the manifold is gone, so they had a tiger torch that they lit and taped to the flare stack, as a pilot light. Wonderful, this is safe, uhm, and then the consultant, no safety meeting, no stopping work, no saying 'Ok guys, this is what happened, this what we did wrong, ok let's get back to work', it was just like 'Let's keep going', nothing happened. Ok, that's great, so about half an hour later, it's on fire again... So that was interesting, still no safety meeting, no incident reports of any kind, paahhh [in disgust]. It's insane, twice more this thing lights on fire, and I've been phoning the office, 'Hey, do you have any relief?' 'No'. Greeaattt. So, the next morning, at like ten in the morning, somebody finally gets out there, 'cause I wasn't gonna drive that truck back there, I was exhausted. I coulda maybe done it, but I coulda maybe killed somebody. So, I think I got back home at like, two in the afternoon. That's stupid, so stupid".

The experience Peter relayed was not unusual to his job, and the toll it took, plus pressures to work in unsafe or unpredictable situations, led him to decide to leave the industry and attend college to train in another profession. In moving on from oil industry work, he acknowledged that it both enabled and forced him to make different choices ("good for the short-term, not good for the long-term"). The irony of being employed by a safety company that tacitly condoned being on the job for $60+$ hours in a single shift was not lost on Peter, and such occurrences outweighed the financial rewards promised by the work. A growing fear that he could seriously injure or kill himself and others while being exhausted at work was a major factor in deciding to leave the industry. Opportunities to pursue hobbies, relationships, and meaningfully engage with the larger world were another major factor, and the possibility of a return to "normal life" was too great to ignore. 
Anne and Peter's experiences differed significantly from that of Erik, who worked in a town-based technical job. Despite having friends and family who worked in the industry, Erik did not, and in ways, he embodied the thoughtful resister - educated, engaged, socially progressive, and critical of materialistic pursuits. Initially, he made efforts to help recruit participants, including members of his family, and we became friends. At some point, I made a conscious decision to not include him more formally in the research, for strictly selfish reasons: his friendship was (and is) valuable, and I did not want it to be reducible to participation in an ethnographic study. Erik was more of a confidant, someone comfortable engaging with deeper meanings and semiotics about life in a resource economy and how that shapes and colours social worlds. In this way, despite not being represented as a formal participant, his ideas and interpretations were frequently consulted, and his willingness to explore any subject over our regular beer-and-chicken-wing sessions brought me a great deal of comfort, as well as challenge.

Erik was also one of few people I met during the research that was actually local to GP, and like Anne, was a keen observer of its reputation and intrigues, although with less weathered lenses. He was by turns bemused by the oil and gas history of GP, and critical of it. During one of our "bullshit sessions", he sheepishly admitted that his father, Bill, was the likely originator of a ubiquitous vehicle aesthetic of the GP region, that of the $4 \times 4$ truck on tall tires. Before relaying the history of this enduring aesthetic, a few words on the symbolic power of vehicles in the GP region are in order. In traveling in the city of GP and the regions near to it, the $4 \times 4$ truck is nearly ubiquitous: it is the vehicle of choice for both companies and private owners, and it is usual for each group to physically demarcate their vehicles in some fashion, 
whether it be through paint scheme and graphics, or aftermarket parts and accessories. The resulting vehicles are highly visible and stylized, providing indicators about the value systems of those who choose to drive and present them. For many field workers in oil and gas, large, expensive trucks are not only a means of transportation, but of relaxation and recreation, and serve as tangible symbols of their hard work and resultant economic success. In some cases, a truck can actually become a de facto home, complete with entertainment/dining space and bedroom. Whatever the aesthetic vision, the ownership of a truck is an important part of the social identity and norms of the GP region.

To return to Erik's anecdote: in the 1970's, his father, Bill had thought to install tall tires on his truck to make water crossings easier during spring breakup, a time when the GP region is wet and susceptible to flooding. The idea worked well, and other local people began to emulate it. Large tires eventually become a standard part of the vehicle aesthetic of the region, and over time, the tires grew taller and wider. Trucks, too changed: they were modified to appear even larger, and made more powerful. In service to a burgeoning form of vehicular expression, an entire sub-economy was built up in the region around accessorizing the rolling behemoths, offering a near-endless litany of modifications providing the cost could be met. The more extreme expressions of such vehicles are known, somewhat derisively, as 'rig rockets' (see Figure 2.0 for an example), owing to be being extremely powerful and highly popular among young men who do the work of drilling for oil and gas. 


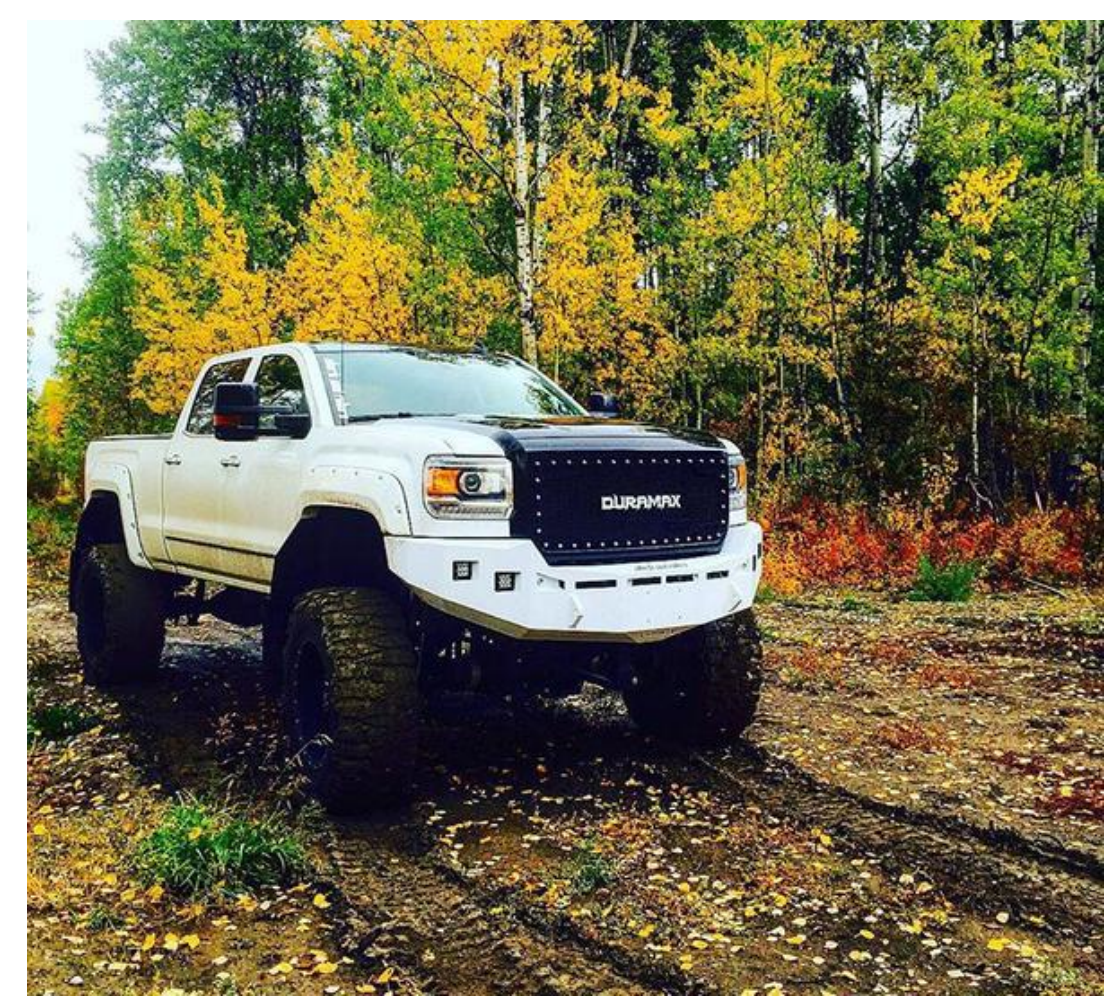

Figure $2.0-4 \times 4$ truck usual to GP (courtesy of pinterest.com)

The disinterest that Erik demonstrated toward working in the oil and gas industry resulted not from a lack of opportunity but because he prioritized job and family stability. He also preferred to do work that was both intellectually and personally challenging. This was evident in his career in local IT, which yielded a humble salary and high levels of work-related pressure. Long-term career prospects were modest, and any movement Erik would experience within in would be lateral. There were frequent opportunities to offer his services as a technical consultant, but such a move would have had consequences for his family life, of which he was openly protective. That he remained unmoved by potential financial rewards was suggestive in a town where such rewards are a key draw.

There were also ethical dimensions to his choices. Erik did not weigh the costs of largescale industrial exploration lightly, and his perspectives on human endeavour and achievement 
had been both influenced and tempered by having lived alongside several cycles of GP's 'fortune-or-failure' resource economy. He was critical of modern natural resource development, and noted that Alberta's history of low corporate taxation for the purposes of attracting business investment and development had contributed to a climate of distrust between resource companies, local and provincial governments, and the citizens of GP. Erik wanted sustainable business and development models for his city and region, in which he (and fellow citizens) could raise children safely and productively, and where those children could have a similar future. He recognized that the boom and bust cycles of the oil and gas industry were influenced by a host of factors, but pointed to a lack of local infrastructure to assist in softening the bottom of such cycles. He also questioned the unchanging attitudes of those who had lived through a number of these patterns, but who either could not conceive of ways to change the rhythms of the fallout or contributed little to building the capacity of the community to manage them. For Erik, living and working in GP entailed a host of responsibilities, the foremost being to live as an engaged citizen - politically, communally, and intellectually. Through this, he was best able to pursue the kinds of changes he wanted to see in his city. His desire for an orderly, productive, safe, and thoughtful community drove his decisions to work in town, and his choice to actively push against the stereotypes of life in a northerly resource community.

\section{5 - Chapter conclusion}

The interplay of the three large categories explored in this chapter - masculinity, the frontier of oil and gas, and nature - is tremendously powerful. Within the GP context, these categories are packed with a wealth of history, working-class values, and idealized characteristics regarding 
how labour is to be performed, and the oil and gas industry seeks to utilize the power of these categories to its best advantage. In attracting and build its workforce, the industry understands there will always be found those who are willing to engage in controversial, potentially dangerous labour work for high salaries, as well as those who are attracted to peripheral places and opportunities. Add to this the potency of masculinity, with its performative expressions and the rewarding of working class, (mostly) white males, along with the enduring appeal of men triumphing over nature, and it becomes clearer still as to why the industry has for so long had a masculine orientation.

The oil and gas industry must also leverage masculine values and worth in order to engage an effective workforce - one that is by degrees both pliant enough to be made useful to the industry - and simultaneously able to perpetuate the image of the sturdy, lone-wolf male, toiling for both the good of self and of the nation. In this way, the industry enters into what could be understood as a 'masculine bargain', one in which beyond workers simply being rewarded for their abilities, they are indoctrinated in the culture of the oil and gas industry, and encouraged to perpetuate its values among each other, and in their non-working peer groups. As this dissertation explores, many of these values are inflected with masculine expectations, and those expectations then shape relationships, attitudes towards community, and personal sense of worth.

An important component of the masculine bargain can be found in the notion of a frontier. Frontiers encourage imagination: they enable the possibility of being, and of things that can be dreamed and then achieved. Within such imagination can be conjured a world for men who understand themselves to be undervalued in modern society, and who may be angry 
at so being undervalued. The frontier is a place of solace for such men, and may be apprehended as a sort of Xanadu for the disenfranchised or socially alienated among them. The oil and gas industry has effectively harnessed the call of the frontier, and used it to attract workers and to demonstrate success narratives. The industry knows that the power of the frontier is potentially transformative: because it is a place of imagination, the industry can heavily influence what the physical and social realities of the frontier might be; it has the opportunity to formulate the frontier as a scape that well serves its industrial profit motive. Meanwhile, the frontier continues to resonate as a destination for those who seek to reorient or renegotiate their lives. In this, such persons are already primed for being made over in the image of the industry. As long as frontiers remain profitable zones of interest to the oil and gas industry, they will also remain fertile grounds for the recruitment, perpetuation, and inculcation of masculinity.

Also connected to the masculine bargain is nature, an entity that for the purposes of oil and gas work, exists to be plundered. Oil and gas exploration is enormously impactful on physical terrain, and the sheer scale of operations is both a sign and symbol of industrial purpose. Men, in tandem with machines, prod the Earth, forcing it to give up its concealed goods, inviting phallic analogies, but there is more at play here than simply that: oil and gas work does not so much represent a form of triumph over nature as it does the calculated domination of it, an effect that reinforces the masculine orientations of this work and the values that accompany it. This domination positions the oil and gas industry as arbiters of the Earth's resources, permitted to conceive and enact massively transformative industrial programs, despite pushbacks from people, groups, and governments. This is masculine 
expression taken to an extreme: a systematic overwhelming of the very planet on which we live, while the source of any protests aimed at this expression are simultaneously feminized and othered. Meanwhile, nature endures, at least for the present.

Both connected to the three preceding categories, and influenced by them, are notions of working worth in the GP region. Self-made men feature prominently in the mythos and culture of oil and gas, those who achieved success with their 'boots on the ground'. Their success is often credited to sheer resilience and innovation, and is the sweeter for those who forge a path as contractors. The usual career trajectory of trading your labour for a wage is not inherently problematized in the oil and gas industry, but those workers who are able to summon the capital and connections needed to directly compete with established companies represent the pinnacle of achievement in working-class masculinity.

These are the labour kings, and the gulf between them and those workers who reject oil patch sensibilities and values and instead seek a more stable, town-based working life, is vast. That these groups have little in common is not so noteworthy, but each is oriented to a radically different way of being in what is effectively a small community, and one that does not offer the anonymity and urban cover of metropolitan living. In this, they are often required to interact, and each is dismissive of the other, convinced that their particular value system is the correct one. This tension serves to reinforce the importance of the choices made by each of these two groups, contributing to the maintenance of a wide social gap between them, which adds to the polarity that characterizes life in GP. 


\section{Chapter 4}

\section{0 - Key Cultural Components of GP}

As described in the previous chapter, GP has a reputation for attracting workers, and then affording them the opportunity to develop or improve technical trades and oil and gas-related skill sets that can be employed all over the world. In conversations and interviews, company managers and long-time residents frequently indicated that GP has acted as a training ground for the best and brightest in the oil and gas industry, but so often failed to retain them in the longer term. When asked why, participants drew parallels between the northern and isolated nature of their community and its reputation as a temporary pass-over for ambitious and technically-minded workers. They also pointed to a history of booms and busts in the region, and to a resulting volatile labour pool a high degree of mobility for workers. Their anecdotal experiences are supported in a host of literatures, including economics and rural sociology, which posit that many oil and gas-based towns and cities see a high number of migrant workers and ensuing rates of job loss and turnover during boom and bust periods (see, for example, Ferguson, 2014; Fernando and Cooley, 2016; Jacobsen and Parker, 2014; and Tunstall, 2014). Many of these same participants also noted that extractive resource communities enjoy dubious reputations, ones often rooted in a public understanding of oil and gas exploration as actively damaging to the environment and disruptive of the natural order of the Earth and its geographic arrangements. England and Brown (2004), in exploring the socially irreconcilable narratives of farming and resource extraction, note that rural North American agricultural practices are often viewed favourably, as a form of stewardship, a "peaceful coexistence" 
(2004: 317) between humans and the physical terrain they cultivate. By contrast, resource extraction activities are thought to be chaotic and disorderly, frequently "characterized by ethnic complexities, labor disputes, liquor, prostitutes, riotous living, and booms and busts" (Ibid.) It is useful to note that GP has a considerable history of agricultural activity, as well as ranching and animal husbandry, and practitioners have clashed with companies and municipalities over oil and gas development, and in some cases, been openly hostile and organized in their protest of it (with the Ludwig/Boonstra family at Trickle Creek being the most prominent of these figures; see Chapter 5, Section 5.3.1 for more). In others, ranchers have profited significantly through collecting compensation payments from oil and gas exploration that has taken place on grazing land leased from the crown (Alberta Farmer Express, 2015), which has served to cloud the issue regarding the utility and acceptability of oil and gas exploration in agricultural communities. Participants generally indicated that there had to be a balance struck between agricultural and oil and gas activities, but no one was certain what that balance could be or how to achieve it.

Spikes in the prices of oil and gas significantly drive job opportunities and worker migration into resource extraction communities. This meant it was not uncommon for longerterm GP residents to witness a cyclical influx and then exodus of workers. Jacobsen and Parker (2014), in their exploration of US boom towns, suggest that while communities and residents experience short-term economic and employment benefits during a resource extraction explosion, the fallout that accompanies the bust portion of the cycle reduces their economic and social positionality to below what it had been prior to the occurrence of a boom. Participants, in recounting their own struggles and triumphs or those of friends and family, 
noted that they were closely aligned with the cyclical nature of resource booms and busts, and spoke meaningfully of the disillusionment, fear, and dread that accompanied the loss of earnings, employment, mobility, and personal expression. As Bill, a field operator with nearly 30 years of experience relayed, the positive expression of these states is inexorably hinged on the oil and gas industry "being busy, and stayin' that way".

Over a long enough time period, it was assumed that the best talent would seek opportunity elsewhere when the local oil and gas economy was in a state of ebb (personal communication, 2013), and there exists ample anecdotal evidence to bear out such an assumption. However, Winkler, et al (2011) suggest that despite a historical record of migration from resource communities to larger, urban centres, a trend that favours relocating to rural areas has been growing, once characterized by an appreciation of and for "... the natural environment for amenity qualities, including scenic views, recreational opportunities, wildlife habitat, and rural culture" (2011: 349). An interest in such 'amenities' clearly resonated with a number of participants, and served to raise questions about what was understood to be a largely one-way flow of talent. GP's northerly location means that it experiences long winters, marked with cold weather and heavy snowfall, so outdoor recreational activities such as snowmobiling, cross-country skiing, and ice fishing are widely popular. Geographically, the Peace Region is heavily-timbered, which makes it attractive for hunters of elk, moose, deer, and a variety of types of fowl. Mild weather and long sunshine hours during summer months enable social and recreational activities to be undertaken until late into the evening, and naturally rustic and scenic terrain, proximal to lakes, rivers, and mountains, make the region a popular recreation, travel, and camping destination. 
Beyond this, in the nearly two years I passed there, GP had an intangible quality to it that people were aware of: a distinct thrum, as if living on the pulse of something exciting. I spoke often with co-workers, roommates, and participants about this intangible quality, and most agreed it could be felt, but was difficult to name. Some accounted for it as the 'vibe' that exists in a remote community filled with job opportunities and young people. Others, perhaps more cynically, believed it to be the simple hum of commerce, the economic thread that connected (or ensnared) the community and its citizens. Whatever the 'it' was, I too was soon swept up, to the degree that an old friend made the journey to GP to experience this unaccountable energy for herself.

There are also downsides to being in a community that seethes with economic energy, and two in particular were recurring. Rampant job opportunity in GP during the time of fieldwork (2012-2014) meant that workers sought to opportunize themselves explicitly, and traditional job values such as employee loyalty or company support were constantly being redefined in terms of "what's best for me" (personal communication, 2013). Another potential downside lay in GP's raison d'etre: people lived to work, and often defined themselves through what they had accomplished and experienced by working. While this can make for interesting research, a long period of time spent in a community so focused on defining itself through work and earning ability can be exhausting for those who do not self-identify in the same manner. By the time I left the field in July of 2014 , a saturation point had been reached, and I needed a change of locale. Interestingly, the economic climate in GP began to alter drastically in the fall of 2014 , as the oil and gas industry entered a protracted period of decline, one that has continued during the writing of this thesis. Curious about the potential value of a comparative 
view, I made a brief trip back to GP in March of 2016, and my experience was a markedly different one than during the boom months that accompanied my initial arrival in 2012. This experience was mentioned in brief in the introduction of the thesis and is further explored in Chapter 6.

In wrestling with the meanings and implications of why people come to a place like GP and what induces them to stay, three themes recurred. I utilize the following sections of this chapter to discuss of them, and how they relate to remaining in GP in the 'long-term'. Here, I acknowledge that the category of 'long-term' is both an ambiguous one and difficult to place a particular numerical value on. Several interview respondents, in recalling the temporal periods they lived and worked in GP, were surprised at how much time had passed, and issued comments such as "Where has all the time gone", or "I only planned to be here for a year... But it's been 20". While participants generally agreed that several years could constitute a "Iong time", there was no consensus in terms of how many years actually meant 'long-term'; rather, time was understood and expressed through markers of what had happened or been accomplished, and sometimes via sensational occurrences, such as ongoing interest with Weibo Ludwig, and the anti-oil and gas activities of the communal group at Trickle Creek Compound in the 1990s (for more on this, see Chapter 5, Section 5.3.1). In the majority of instances, job changes, economic variations, and family dynamics were employed to measure and locate lengthy passages of time, and to both give account of and pay tribute to being in a community in the 'long-term'.

In preface to discussion, each of these themes are framed within the local and larger consequences of working life in and around GP. They have been derived from hours of 
interviews, conversations, job shadowing, chatting, and socializing with residents and participants. It is likely that links or similarities to aspects of life in oil and gas towns all over Alberta, and indeed, across Canada, could be recognized, both as qualities of small-community living, and as features of industrial economies and the communities that house them. These three themes are (in order of exploration):

1. The value of generosity. GP residents are proud of and promote themselves as 'good citizens', active in charity and volunteerism, community support activities, and neighbourhood associations and groups.

2. Fixation with money/pursuit/acquisition. This was locally understood as economic 'freedom'. Many research participants understood GP as an economic destination, one that could improve their fortunes and enable a material lifestyle.

3. An enduring belief in oil and gas. The notion of 'the end of oil' was largely unthinkable for participants, co-workers, and residents of GP. History, narrative, and desire have all conspired to entrench the oil narrative deeply into the social psyche of residents of oil and gas towns, and GP exemplifies these attitudes and understandings.

\section{1 - The Value of Generosity}

Prior to a discussion of community-based generosity, it would be fruitful to lay out a working definition as to what is meant by 'community', in and around a place such as GP. Notions of community invariably give rise to questions that seek to explore it, to speak to its making/unmaking, or to disturb conventional understandings of what the thing 'is', making it a difficult concept, as it can be both full of meaning and utterly devoid of it. Scholars across disciplines have written meaningfully and movingly on community, and especially so in the 
sociological literatures (see, for example, Bauman, 2011; Creed, 2006; De Genova, 2005; Elliot, 2010; Herbert, 2005; Murphy, 2007; and Rose, 1996), all the while failing to establish exactly what community is and what it means to the people who inhabit them. My own attempts to wrestle with notions of community are littered throughout this thesis, but for the purposes of establishing a reasonable baseline, this useful definition of community comes from the sociologist Amitai Etzioni (1997), who wrote:

"Community is defined by two characteristics: first, a web of affect-laden relationships among a group of individuals, relationships that often crisscross and reinforce one another (rather than merely one-on-one or chainlike individual relationships), and second, a measure of commitment to a set of shared values, norms and meaning, and a shared history and identity - in short, to a particular culture"

The web that Etzioni so clearly describes was evident in the relationships that I shared with participants, co-workers, and friends in GP. As strangers, initially, we gathered around shared interests, and bonds grew out of spending time together. We assessed the values and pursuits of each other, and then decided whether to continue those relationships, and how to shape and influence them. In short, we were community-building, creating meaning and connections, as were thousands of other people all around us, with their own social groups, values, and involvements.

Participants understood that they were part of some form of community in significant ways, even if they did not express this explicitly. This understanding was linked to longstanding community initiatives or ideologies that had captured the hearts and minds of residents. One of these resonated especially strongly throughout the GP region, in what I have termed a 'culture of generosity'. Through interactions with townspeople, participants, co- 
workers, and new friends, I became aware of it as a financially-and-temporally-focused form of community-building, enacted in a variety of public theatres. This culture of generosity was manifest in a number of community initiatives usual to GP, including corporate and community philanthropy, volunteerism, and donation and fundraising drives, but was localized in particular ways, through a shared language and interpretation of these activities and their outcomes anchored in value systems that 'make sense' in the GP region.

My early understanding of how deeply rooted GP's community sense of obligation could be was initially awakened through day-to-day research activities. Accessing communities and groups that lay beyond research participants, I was able to meet with members of local outreach organizations, city councillors and planners, emergency services administrators, and educators. Interactions with them often included suggestions to attend and participate in local events that were focused around charitable activities, intended no doubt to both bolster my connection to the community and to encourage participation in these events.

It is critical to keep in mind that life in a resource-extraction dependent community is routinely work-focused, often to the exclusion of social activities. Despite considerable demands on the time of GP citizens, there existed significant opportunities to fill non-working hours with philanthropic endeavours, such as through fundraising for community associations, volunteering with mental health outreach groups, or promoting awareness of the need for youth literacy and education. As my own awareness of the social hints that encouraged 'good' citizens in GP to actively partake of such opportunities matured, I also began to seek them out, and incorporate them into my own life there. While work is always going to be a major focus for resource extraction community residents, GP's social values place pressure on residents to 
engage in philanthropic activities outside of working hours, even if that meant reducing time available for other activities, such as socializing in bars, participating in recreational sports, or relaxing at home with family. Clearly, not every GP resident could or would answer the call to engage in community-minded activities and events, but in my experience, a large proportion of them did, and were vocal advocates for the perpetuation and propagation of the values that encouraged such endeavours, as well as the events and causes themselves.

Attempting to discover to what degree GP was a natural 'booster' community, and what impact the corporate philanthropy (also known as corporate social responsibility, or CSR) practiced by the oil and gas companies had in influencing the boosterism, was largely unsuccessful. One participant joked that this was a "chicken or the egg kinda question", all the while reassuring me that northerly communities "stick together" and "take care of each other, long before oil came around". In further discussion with this participant, he alluded to settler and pioneer history in northern Alberta, indicating that people in the GP region had developed a sense of community obligation due to the harshness and remoteness of the environment, and the need to work together to build and maintain their livelihoods and communities - what he termed "pioneer spirit". While I accepted his rationale for believing his community to have the interests of its residents at heart, a question remained: if we accept that the impacts of corporations on communities can range from the tangible to largely hidden, what can be inferred about the degrees of influence a community has on the corporate organizations that operate within it?

Business and management literatures focused on corporate social responsibility (known as (SR) have increased dramatically since the early 2000 s, and yield a cornucopia of views on 
the rules, expectations, and pitfalls for corporations and communities that enter into partnerships (see, for example, Cadbury, 2006; Crane et al, 2008; Crowther and Aras, 2008; Escobar and Vredenburg, 2011; McWilliams and Siegel, 2000; Sen and Bhattacharya, 2001). McWilliams et al (2005) define CSR as "situations where the firm goes beyond compliance and engages in actions that appear to further some social good, beyond the interests of the firm and that which is required by law" (2005: 3). In GP, evidence of such actions by companies active in the area were legion, ranging from the sponsoring of local cultural events to the spearheading of community improvement initiatives. The degree to which this corporate 'support' was a usual and accepted component of the backdrop to life in GP is illustrated in the following example. In the winter of 2013 , a roommate invited me to attend a junior-league hockey game, which pitted the local team against one from another major oil and gas community. Arriving to the arena, the (literal) signs of corporate activity were inescapable: huge, illuminated billboards proclaimed the partnership between the arena and a major oil and gas company. Inside, as we lined up to purchase beverages, glossy slogans and advertisements pledging responsible exploration by resource companies to the region were in evidence on every wall. Sitting in the bleachers, the commentator for the game announced that the evening's action was made possible by a host of sponsors, most of which were oil and gas companies headquartered in the province. Corporate logos were also embedded in the arena ice itself, ensuring that the eyes of the spectators fell on them no matter when their attention was directed toward the sporting action. The event was an encapsulation of corporate branding and messaging, with the lines demarcating the city of GP and the company benefactors purposely blurred. 
After attending the game, I was left to wonder how the local culture of GP had (if at all) shaped the form and function of CSR that was in evidence. Marquis, et al (2007) discuss the impact that metropolitan communities can exert on the 'corporate social action' (or CSA) of companies headquartered in said communities. They suggest that correlation between a company's social license to act and its financial security is inconclusive, believing that such practices are largely shaped by geological location and the host community's ability to influence and shape the legitimacy of corporate activities. The authors also note that large companies often fail to account for the degree of connectedness between local residents and their networks, and are thus unable to apprehend how these community pressures can come to bear on CSA. Du and Vieira (2012), in their examination of the corporate social responsibility mandates employed by resource extraction companies, laid bare the public distrust and cynicism that often accompanies controversial industrial sectors. They acknowledge that such companies need community legitimacy and social licence to operate, and suggest that focused attention to public reaction and perceived reputation is required. Without expressly saying so, the intimation is that sensitivity to public perception is no longer optional.

My own sense is that the community of GP and the oil and gas companies that operate within it share a complex relationship, one that comingles social memory and change, but which ultimately remains underappreciated by either side. It is reasonable to assume that GP's settler, agricultural, and forestry history has rendered the area less dependent on oil and gas resources than other northerly communities lacking such economic diversification. However, the oil and gas industry has been active in and round GP since the 1970s, and social memory is variable: many of my research participants were unfamiliar with a GP "before oil", and indeed, 
could not conceive of it. This is unsurprising, given that in presenting itself as a fast-paced, industrial destination, GP is a site potent with ambition and meaning, one "propelled by change" (Nora, 1989: 8). Residents under the age of 50 would simply be unaware of a past and present that was not heavily linked to the fortunes of oil and gas.

The sheer draw of the oil and gas industry to the GP region is breathtaking. Companies who staked their claims early helped to build the area's reputation as a training ground for innovative, hard workers. As the industry grew and proliferated, demand for labour power and specialized technical skills increased dramatically, and incentivization multiplied through the money to be made, job opportunities to be had, and the chance for self-expression and performance in a peripheral location. All these things have also influenced social memory. If two or three generations of workers are familiar with a GP that has tangibly prospered through the economic promises of oil and gas, such prosperity has, in effect, 'always been'. Recall the notion of the pioneer spirit, one of building critical networks and relations with neighbors and community members, so as to yoke the strength of the membership and succeed against a harsh physical environment. This ethos has been latched onto and capitalized upon by the corporations that operate in the GP region: they seek social license through the exchanging of money and community-building in ways that resonate with GP's nostalgic social values, understanding that the summoning of an idealized, settler past, struggling against the odds, is well received in northern Alberta. Given the protracted recession still buffeting the province at the time of writing, it remains to be seen if continuing to invoke such an ideal can still summon a legitimate symbolic power in GP, while the same corporations that have deftly wielded it continue to cut work force numbers and disburse their oil and gas holdings in the region. 


\subsection{1 - The Good Citizen: Make Money and Turn It Back into The Community}

Median household incomes for GP are some of the highest in Canada. While many residents use their earning power to achieve consumer desires and personal ends, a significant proportion of them also choose to invest money and time back into the community that enabled them to succeed. One of the ways this can be seen most readily is through volunteerism. Statistics Canada (2010) noted that 55 percent of Albertans over the age of 15 were involved in volunteer activities, a significantly higher proportion than the national average of 47 percent. The community of GP also features high rates of volunteerism, as noted by a Vital Signs report, which found that 56.5 percent of city residents over the age of 15 identified as volunteers (Community Foundation of Northwestern Alberta, 2013). In August of 2016, The GP Volunteer Services Bureau website showed 76 registered volunteer organizations, with corporate sponsors including companies such as Encana, Aquaterra, and Weyerhaeuser (Volunteer GP, 2016). Additionally, GP is home to a Rotary club with over 300 members, which distributes hundreds of thousands of dollars to local projects and associations in the form of scholarships and bursaries (GP Rotary, 2016). Successful local business owners, entrepreneurs, and investors were routinely found among the memberships of such clubs and associations.

Through a referral by another participant, I met with Tracey, a woman in her late 20s, with close ties to GP's arts and culture scene. In conversation with her, I learned that funding for local artists and creative ventures was frequently subsidized by community donors. We shared anecdotes about how people in GP built community through volunteering and donations, and speculated that in a place such as GP, one that is geographically and intellectually peripheral, local volunteerism and cash donations added substance and enabled meaning-making within it. Through contributing to the building of something tangible, be it a 
dance studio or a hockey arena, and by offering their time, skills, or financial resources, residents were actively pushing against this peripherality, and creating community.

I was to learn that the participation of men and women in the activities of charity and volunteerism were often gendered: men were most frequently away working, and as such, contributed money to the community. Women, who most often were at home with children or who worked at what was characterized as a 'supplemental' job, donated their time and expertise. As I was to learn through exploring the arts community in GP, much of the creative programming, and its inception and management, was the domain of women (for more on this, see Chapter 5, Section 5.2). In GP, this was a 'natural' outcome, as men were busy with the 'real' work of extracting oil and gas, and women were at home, sometimes with part-time jobs, and raising children and building community through outreaches, activities programs, and fundraising. The gendered expectations of men and women in GP shaped the very structure of how volunteering, donating, and contributing to community is 'done'.

After connecting with Tracey, my interest in exploring donor culture in the city was aroused, and through a fortunate observation, I stumbled upon a key indicator. In meeting a participant for an interview, I arrived early to a bustling coffee shop. Standing in line near the cash register, I noticed a small, clear plastic donation box, of the kind found in convenience stores, gas stations, and other retail places of business. In my previous experience, it had been usual for these boxes to be nearly empty, only containing a few random coins. The box at this particular shop was packed with bills, in denominations up to $\$ 50$ (that were visible). There could have been hundreds of dollars inside it, and people continued to add yet more money as they paid for their food and drinks. 
Over the next few months, I took note of the contents of these donation boxes

wherever they could be found. Without exception, all over the city of GP, the boxes were filled with cash, and displays of financial generosity were not confined to them alone. During the Christmas holiday season, Salvation Army volunteers rang bells for donations inside grocery stores, their red buckets heavy with the weight of contributions. Collection plates for families in need were passed around at sporting events, and returned overflowing with coins and bills. Boys and Girls clubs, knocking on doors in quiet cul-de-sacs, selling baked goods, expected to sell out on every block. Athletes looking for financial backing to make trips to international competitions were featured on local radio stations, and the canvassing campaigns would run several times an hour, until the funding goal was met, which often occurred within a few days. These activities shone a light onto a component of how GP society understood the utility of money, and how it could be wielded in what was perceived as socially useful ways. In time, I observed that charitable activities in GP had two visible streams: one largely for those who had money to contribute but limited time to offer; the other for those who had time available, but little money. Where a person could fit into these streams added complexity to GP's social dynamics, as each stream had its own particular system of reward and reinforcement, but again, these streams were highly gendered, with wealthy men often making financial contributions in lieu of their time, and women offering their time instead of money.

For those who contributed their time to community causes, the investment was often deeply personal. One of my participants, Jan, an artist and mental health practitioner, passionately advocated for at-risk persons in GP. She acted as a mentor, den mother, and community police officer, and assumed the lead in whatever capacity was necessary to provide 
relief, humanity, and dignity to struggling and at-risk citizens. She firmly pushed against discrimination, encouraged hope, and refused to be content in a community that was so often fractured by economic opportunities, and where those at the bottom of the social ladder are misunderstood, mistrusted, and undervalued. People like Jan worked to build community because they believe that people should all have opportunities, and that they are worthy of being supported. She remained uninterested in accolades or awards, despite being highly respected by social and civic entities in the community. Jan's 'reward' was to be an impetus for social and policy change in GP, and that reward was not highly formalized, and did not involve public displays or dinner ceremonies.

By contrast, it was usual for regular or large donors, investors, and prominent community supporters to receive effusive and public praise, awards, and to enjoy high levels of social good will and capital. This could include having one's name announced overhead at local hockey games, or being commemorated in sculptures erected in parks, bearing inscriptions of gratitude. While anonymous donors certainly did exist, there were fewer of them, and fewer still were the physical tributes to them, which speaks to expectations within the donor culture that has developed in GP: there are those who do not seek tribute for their contributions, but formal recognition, especially public, remains a significant motivator for ensuring large donations of time and money.

In dwelling on the features of being a donor in GP, it is pertinent to ask what else could be happening in these transactions, beyond a simple desire to engage community and, in some respect, to be recognized for it. In her exploration of the contentious nature of community, Dorow (2013) builds upon Rose's (2001) concept of 'ethopolitics', defining it as "a set of 
governing strategies that act on the ethical dimension of human life, fostering the self-managed engagement of individuals in their collective destiny" (pp. 57-58). For Dorow, these governing strategies can be seen acting within the relationships that workers have with a place like Fort McMurray, long considered an economic destination only, and less one in which to put down filial roots. In response to the risk of citizens living as perpetual economic tourists faced by that community, Dorow argues that three forms of neoliberal community investment are encouraged: the first of these being "investing at home" (pp. 65-68), followed by "investing by 'giving back"' (pp. 68-70), and finally "investing in capacities" (pp. 71-73). While all three of Dorow's categories are worthy of examination, the notion of 'giving back' to community is particularly pertinent for a discussion on volunteerism in GP.

As Dorow explains, the Alberta community of Fort McMurray encourages a form of neoliberal "giving back" among its citizens, a catch-all term that encompasses volunteerism, capacity building, and local expertise, formalized in a manner that resonates with what Rose (2000) has termed "ethical citizenship" (p. 1398). While Fort McMurray and GP demonstrate different histories and population demographics, they have in common a highly developed petroeconomy, and are both destinations for immigrants and Canadian migrants, mostly male and under the age of 30, seeking high-paying jobs in the oil and gas industry. GP's volunteer network is highly sophisticated, and prides itself on including successful local entrepreneurs, visionaries, and investors within its ranks, a tangible demonstration of the power of ethical citizenry, as those whose success has been enabled by the "general condition of opportunity" (Dorow, 2013: 68), now find themselves obligated to remit a form of payment, usually offered up in terms of time - a precious commodity in the oil and gas industry - or money, which tends 
to be more readily available but the giving of which is governed by a number of factors, including timing, amount, distribution by an appropriate agent, and reception. All of these factors must be met and must then unfold in a fashion consistent with GP's dominant social values.

My own experience volunteering in GP offered lessons on not only community, but on masculinity and the social expectations placed on citizens who seek some form of assistance. After a few months of research, I connected with a learning council, and offered my services as a tutor. I was taken on board, and during the next 16 months, worked with a number of students. One particular person, a man in his late 20s named Ben, became a regular, long-term student. Ben had little formal education, and struggled with reading and writing. Despite this, he was determined to become a welder, and needed to pass second-year Journeyman examinations, which included practical and written components. Further obstacles included Ben's lack self-confidence, and the fact that he had a naturally cautious disposition, which singled him out among the ranks of the confident, jocular men in his cohort. I learned there were resources on offer for disadvantaged learners through the Journeyman program, but he did not want to "bother" the administrators, and, as Ben later admitted, was apprehensive about being singled out for being "different in a bad way" (personal communication, 2013). Over time, he articulated the root of the issue to me: asking for help sent a negative message to both instructors and fellow students in the Journeyman program, and would only make him the butt of further jokes and disrespect. It was informally understood that it was better to have failed in silence than to have been perceived as needing any sort of accommodation - an attitude that is not out of place in many sites where masculinity and physical labour are 
performed. Ben accepted this as an inescapable reality of his situation, something I failed miserably to do.

As our relationship developed, Ben felt more comfortable confiding his program-based worries to me, but never accepted any of my offers to intercede on his behalf with program administrators. Happily, our marathon weekend sessions led to improvement. His speech grew more confident, and his reading progressed several grade levels in as many weeks. The litmus test was passing his second-year examinations, which he did easily. This felt like an intense victory for both of us, and we continued to work together for the next 12 months, and through his third-year examinations. Ben's considerable progression as a student encouraged his confidence to blossom, and shortly after completed his third-year training, he was offered and accepted a job in another province. He and his family made the move shortly afterwards, and as of 2016, had remained there.

I admit being pleased that Ben was able to succeed, but also wondered how those without his combination of drive and family support may have fared. Ben recognized that he needed help, and so reached out to the learning council. This act alone marked him as unusual in the highly masculinized working culture usual to the region. Addis and Mahalik (2003) tell us that "men are often characterized as unwilling to ask for help when they experience problems in living" (2003: 5). Studies abound showing that men, when compared with women, frequently avoid seeking assistance for life difficulties, including medical issues (Gijsbers Van Wijk, et al, 1992; Griffiths, 1992; Jackson, 1991; Neighbors \& Howard, 1987; Rafuse, 1993); psychiatric treatment (Gove, 1984; Gove \& Tudor, 1973; Greenley \& Mechanic, 1976; Howard \& Orlinsky, 1972; Vessey \& Howard, 1993); and substance abuse (McKay et al, 1996, Thom, 1986). 
In this way, Ben's intention and action in contacting the council and seeking a private language tutor could be interpreted as an act of subtle subversion, a recognition that the system he was expected to flounder within was inherently unfair and wrongheaded. Another possibility may be that Ben sought to address his need in the most private way possible, one that took him far away from the prying eyes and cutting humour of his classmates. We did not reach a level of intimacy in our relationship that permitted exploration of Ben's deeper rationales, and so my intuitions regarding his motives remain speculative.

Further lessons were to follow through my volunteering channel, and one particular instance neatly encapsulated the nature of GP's particular version of ethical citizenship. Late into the first winter of tutoring with the council, I received a phone call about meeting with a potential new student, named Roch, who had an exceptional backstory. Arriving to the council intake office, I met a friendly young man, who paced nervously, and often looked out the window toward his dog, tied up outside. After an introduction, an administrator asked Roch to "tell his story", which ran thus: he had been born in Montreal, and his mother had died when he was a pre-adolescent. His father's health was also fragile, and by the time Roch reached early adolescence, he was absent from school, and caring for his dying father. He actively hid from scholastic and city authorities, and when his father finally passed away a few years later, Roch was effectively homeless. Uncomfortable at the prospect of being consigned to state care, he lived on the streets in Montreal for a time, and eventually fell into nomadism. At the time of our meeting, Roch was in his mid-20s, and had traversed Canada from coast-to-coast several times. News of work opportunities encouraged him to stop over for the winter in GP, 
but his fractured education and socialization meant that he struggled with reading, writing, and communicating in culturally appropriate ways.

As we spoke, it became apparent that Roch had often sought to integrate into a community, seeking to find reprieve from the life of the road. Over time, he had developed expectations about the shape and substance of "support" that could be accessed in what would always be a temporary community for him. In hearing him speak to this, part of my attention was focused on the intake administrator's reaction, and another part on what I knew to be true about masculine values in GP: that hard work, individualism, and overcoming difficult situations was normative for men, and expected. Roch's ideas of what constituted usual and reasonable support networks - subsidized housing, meal plans, work placements, and so on - were incongruent with these established masculine values. I was not surprised when the administrator responded negatively, indicating that newcomers to the community who utilized support services were expected to start their new lives, ones that included holding down a job, and demonstrating social worth through being "a good citizen". For my part, I attempted to mediate the rapidly eroding meeting, but was not effective, and anticipated that Roch's stay in GP would neither be long nor pleasant.

As it happened, I only met with Roch once more, about two weeks later. During our brief encounter, we mostly spoke about what he perceived as the difficulties of becoming a GP citizen. He was frustrated by the fact that in order to qualify for a subsidized living space, he had to log long hours at a tedious job, and that his dog was neither welcome in the apartment or at the workplace. He was also required to frequently check in with a social services liaison, and his relaxed attitude towards time and work commitments was a source of considerable 
friction in that relationship. Roch was ultimately not prepared for the social expectations of citizenship in GP. Indeed, they were both more difficult and less interesting than life on the road, and shortly after our last interaction, a Council administrator advised that he had left town abruptly, and with no warning. It was hardly surprising, and I could imagine Roch vanishing back into the network of roadways that had nurtured him for so long.

These experiences with the Learning Council also offered insight into cultural values in GP, including demonstrating how practicality, responsibility, and a 'take-charge' attitude were admired and expected from volunteers. I met and worked with a number of learners during that 16-month period, and instruction on the part of the Council in terms of what lessons should consist of, how they were to be structured, and how progress was to be marked was minimal. I came to understand that it was simply assumed I would have the learner's best interests in mind, and that any achievement would leave them better off than previously. Curiosity led to formulating potential reasons for the Council's 'arm's length' approach to learning, such as wondering if it could be attributed to the fact that as a highly educated tutor with previous experience, I was simply a rare sort of volunteer in that community. Or, perhaps this was an organization that took an inherently practical view of education and volunteers, offering a large degree of autonomy in services with the inherent expectation for performance placed on the individual. The development of such an organizational culture would have been in line with the general social values of the region, but as I was unable to research it to any degree, my thoughts here remain conjectural. 


\section{2 - Fixated with Money: The Pursuit of Economic 'Freedom'}

Economic gain, or as some participants termed it "economic freedom", is a significant component of personal achievement in GP. The salaries that oil and gas workers command enable lifestyle and opportunity choices that would be unavailable to those who earned less. With economic gain being a standard by which success is measured, new recruits to oil and gas frequently assimilate the values of prioritizing making money and then enjoying the fruits of their labours through forms of consumption (see Houser, 2010 for more). Some workers are content to luxuriate in their profits, while others leverage their economic opportunities to create larger ones, to advance their careers, or become owners and business operators themselves.

The remainder of this section will explore and discuss the working and economic experiences of four male participants, all of whom had logged significant time in the oil and gas industry, and who provided critical and reflective answers to interview questions. Two of these, Thomas and Vince, were fellow co-workers at the electrical company, while I met Peter though another participant, and Jason at a community event. With the exception of Vince, who migrated from Ontario, all of the men discussed here were local to GP. Each recognized that the work opportunities in the region could finance a particular lifestyle or help to provide access to other industries, and all processed and attempted to realize those opportunities in different ways.

Thomas, a trade-certified electrician, used the money earned from his day job primarily to finance the expansion of his family farm. Along with his father, he aspired to add to their farm land holdings in the GP area, the cost of which is significant. At the time of research (2012-2014), a survey of local real estate websites offering farm-suitable property for sale 
showed that the cost per acre could reach as high as $\$ 20,000$ CDN (Ovlix, 2016). As a young farmer is unlikely to possess the capital and credit rating to purchase the several-hundred-toseveral-thousand acres of farm land desired, expanding a farming operation can be extremely slow. Thomas regularly worked more than 60 hours per week on electrical projects in the oil and gas industry, and in a good year would earn a gross salary of $\$ 200,000$ or more. Because oil patch work is busiest from November through April, when the ground is frozen, he was able to assist with farming in the spring and summer months while working fewer hours for the electrical company. In the winter months, his father oversaw farm activities, while Thomas's significant earnings enabled planning land and equipment acquisitions. His certification as a tradesperson offered other options: if work in oil and gas was intermittent, his skill set would be valuable to commercial contractors based in GP or in nearby centers. This meant that he could choose how to divide his time between both pursuits to best suit his interests and pursue his farming aspirations.

Peter, a 29-year old from the Peace Region, viewed oil and gas work as a means to leverage himself into a better life and career. He entered the oil and gas stream looking for adventure, and over a decade spent in the industry, found more of it than he had thought possible. After working several years as an oil and gas fire responder and then a manager, Peter decided to leave the industry and enter post-secondary studies. During an interview, I asked him if the long hours, time away from family, and uncertainties of working in the oil patch had been worth the financial gain:

"Yeah, it is. 'Cause, when you're young and single, go away, stay in camp, it's great. Keeps ya out of trouble, for one thing, 'cause ya can't drink and do stupid stuff, for one thing. Well, ya can, but's pretty risky. You make lots of money, so that when you 
are home, you can go and blow it on whatever you want, doesn't matter, but then you get into a relationship, maybe, or you get tired of being gone all the time, you want a life, so you go work in the office, and you spend more time at home, and make less money, but, depending on the kind of person you are, it's probably worth it... It's so worth it. If I hadn't done it, man, I wouldn't be coming back to school right now and getting an education, I would still be staying in camps and driving fire trucks all over northern Alberta and B.C... So, it's definitely worth it".

Peter clearly enjoyed the challenges of his work and the feeling of satisfaction that accompanied solving complex field problems, but the years of isolation, lack of work stability, and unpredictable nature of the industry wore him down. His decision to return to school was both influenced and enabled by oil and gas work: he now had the money to pay for postsecondary training, and the desire to apply his capabilities in a different setting. During another interview, Peter indicated his intention to use his work ethic and problem-solving intuition to launch a new career, one that was peripheral to oil and gas. In planning to stay in the GP area and set up a business based around his new occupation, Peter demonstrated the utility of economic choices available to those who work in the oil and gas industry - he was, in essence, mapping out a new economic future, one enabled and supported by years of labour in the oil and gas industry.

An electrician co-worker named Vince had relocated to Alberta, seeking work in oil and gas specifically to pursue financial gain and kick start his stalled career. He had recently purchased a rental property near Toronto, and wanted to marry his fiancé in the near future. After nearly seven years of working electrical jobs in Ontario, he came to the conclusion that without a significant salary boost, he was not going to be able to achieve certain short-term 
goals. In an interview, when asked why he chose Alberta, Vince emphasized the practical considerations of the move:

"[on working in Ontario] There's a few different styles, for my trade, anyway. You're either workin' for the little guy, whose, you know, under paid n' overworked, or you're with the union, and your job would be, ah, either with maintenance or with a municipality. And that's really all there is... Everyone's on a budget, it's a hustle and bustle, it's the true rat race, really is, and you're doin' small projects, tighter deadlines, and it's not like here [Alberta] where people are a lot more laid back"

"[on coming to Alberta] Ah, just the opportunity, really. It basically boiled down to looking at the long term. I mean, you can get so much further ahead when you come out here, there's not enough people and a lot of positions, right? So for me, I would've, in Ontario, and this is the way it is in any industry, generally, you have to wait for your turn [emphasis his] to move up. It's not based on reward, per se, like it is here. Whereas if you're aggressive out here, you move up fast. There, not so much, you have to wait for the guy above ya to retire"

For Vince, working in the GP area was temporary, and undertaken with specific goals and outcomes in mind. By relocating to Alberta and working diligently in the field for a few years, he was able to rise to the head of an electrical field crew, an achievement which would have taken much longer at home in Ontario. During that time, the wages he received were significantly higher than back home, and he also enjoyed the increased prestige that accompanied his position as a manager. Ultimately, Vince was able to return to Ontario with an expanded resume, which would also pay dividends at home, through increasing his appeal to employers and presumably leading to increased remuneration, owing to his leadership experience in Alberta. In recognizing the opportunity in a busy oil and gas industry, Vince effectively sidestepped the traditional work cycle of an electrician in his home province, and simultaneously benefitted himself monetarily and experientially. 
Several months into the research, at a community event, I was introduced to a man in his early 30s named Jason. Jason had significant family roots in the GP area, and he had worked in a variety of roles across oil and gas sectors. When we met, he was freelancing as a technical consultant, specializing in troubleshooting and solving problems related to any aspect of the equipment, operations, and technological processes of drilling for oil and gas. Jason agreed to participate in my research, and was interviewed a number of times, providing a wealth of industry information and gossip. As his capabilities grew, job demands often took him to international work sites, and his business was continually expanding. Despite his relatively young age, Jason was extremely experienced in the industry, and well known for being a quick thinker and capable problem solver. He also had trained with a number of high profile industry figures, who through dint of their acumen and ingenuity, had become wealthy persons of influence in the region.

During our discussions, Jason spoke frankly about his experiences and connections in the industry, including making the decision to leave working with a company where his steady rise within it was nearly assured, to go out "on his own" and try to succeed as a private consultant. According to him, this decision was somewhat forced, as he had become embroiled in a contentious legal dispute over ownership of technologies with his former employer, technologies that he had been instrumental in spearheading and developing, as well as pressing into service. Despite such a setback, Jason's 'get-it-done' attitude, and a willingness to problem solve, along with his extensive contact list, ensured that his name would be both familiar and attractive to potential clients. Prior to striking out on his own, Jason's vision for leveraging a 
non-traditional career out of his knowledge and connections was focused on building a career that provided him with personal advantages and challenges:

“The moment that I announced it publically, I started gettin' phone calls. It's always been 'Come do this, come do that', problem is, I have always had a vision for what I wanna do, and it's lofty because it involves getting paid for your expertise only, and man is that ever hard... I was married to a Kiwi, still technically am, and my vision was, you know, when I didn't feel like being in Grande Prairie because the weather was unbearable, or something pissed me off, I could go to New Zealand for 6 months at a time... The whole point of that dream though, is that I'm, still doing things, it wasn't about me walkin' away from work, it was about me still being able to be involved in things that I believed in... that's like, everyone's dream, uhm... if you love your work, you'll never work a day in your life"

The four men above all earned large salaries, and each of them leveraged those salaries in order to pass through the oil and gas industry and into occupations and lifestyles that they considered preferable. For Thomas, the electrician-cum-farmer, his specialized sets of trade skills enabled a sizeable earning potential, one he utilised for the building of a larger farming operation. Thomas's economic plan was based around efficiency and temporality: he purposefully worked long hours during the winter months, when farming obligations were less consuming. He also recognized that as an electrician in the oil and gas industry, he would only be able to sustain such intense physical output for a limited number of seasons, and so had decided to "make hay while the sun shines" - to be productive while conditions were most profitable and his body most able to endure. This productivity was supported by a longer-term vision, one in which he and his father could continually assess the size and success of their farming operation. As the farm developed, Thomas could take on a larger role there, and lessen his time in the oil and gas industry, thereby neatly applying his abilities to the local labour opportunities in order to realize his dream of becoming a full-time farmer. 
Unlike Thomas, Peter spent a number of years enjoying the fruits of his labours without a particular direction or plan. However, he grew restless and disillusioned with the demands of this role, and realized that his earning capabilities could engender a life change: in this case, entering a post-secondary education program that would retrain and reskill him. Besides providing a portal to a new working life, one not tied to or dependent on the oil and gas industry, Peter's life change also offered the promise of job mobility. Even though he planned to operate a business in the GP region, he very much saw his new working venture as buildable and operable elsewhere, which he viewed as a tremendous source of personal freedom. Although Peter reached a saturation point with the industry, he indicated that the experiences had and skill sets acquired were worth the frustration of the job. Whether he would have felt this way if the work did not pay so well is unlikely, but in choosing to (eventually) use the substantial wages earned to fund a life and job change, Peter was able to capitalize on his oil and gas trajectory and realize a plan.

Of the four men, Vince had the most well-defined plan for his time in Alberta. He was able to adhere to a strict timeline goal and realize his aspirations of returning to Ontario with a healthy bank account and managerial experience. This took substantial discipline, planning, and follow-through on Vince's part (at one point, he had slept on a fold-out bed in the hallway of a house for several months), but without the significant economic boost he received by relocating to Alberta to work in the oil and gas industry, achieving his goals would have taken many years longer. That he was able to follow through with his plan, and not become mired in the work and social scenes of GP for a much longer period of time also speaks to his resolve. 
For Vince, the move to GP was always going to be a temporary one, effected expressly to improve his financial fortunes and advance his career trajectory.

Jason's version of economic freedom was one in which he had the power of choice: to discriminate between the sorts of jobs he would take on as a technical specialist, and those he would pass over, and to have the capital to choose not to work at all, if it suited him. In this, he had less of Thomas's particular plan for leveraging his worth, and his goals were not as defined as those of Vince, who followed a tightly constructed roadmap toward success. However, Jason was highly ambitious, and had the connections, the intuition, and the industriousness to both market and make himself indispensable to a select group of clients. In following up with him in the spring of 2016, I learned that he had left GP, and relocated to the United States several months earlier, taking a job with a flourishing industrial company, where he could further his skill set and continue to challenge himself. It was a typical move for Jason: he anticipated the lengthy economic downturn, and utilised his connection networks and innate charisma to land a job interview. Once he was actually able to meet the hiring committee, being hired was essentially assured. For people like Jason, GP offered entrée to economic advantage, and if properly cultivated and wielded, this advantage could yield huge dividends all over the world.

\subsection{1 - Trapped}

The lure of economic enrichment is a powerful motivator, and the oil and gas industry offers a myriad of options for achieving it. New entrants typically work long hours as labourers, and with time and perseverance, may rise to managing people, equipment, and companies. Those with entrepreneurial vision often identify a particular need and decide to create a business or industrial service from the ground up. Still others take use their trades training as an entrée 
into the oil and gas industry. Those with post-secondary schooling in geology, business, or management can rise high and command requisite salaries and prestige.

Despite the promises of economic success, however, significant downsides also exist, and research participants were keenly aware of them. For Karen, a field manager in the scaffolding trade for a GP-based company that worked all around the region, navigating job demands while maintaining a presence in her family was incredibly demanding. Meeting for an interview early one winter morning, over a heaping plate of pancakes and syrup, she offered this insight:

"If you wanna have a family, and you wanna have relationships and friends and a life, don't even go into it [the oil and gas industry]. It's good money, but you trade everything else to get it. I do it 'cuz I had no choice. But if I had to do it again, I would look really hard for an alternative... Very realistically, l'll have lots of money at the end of this, but I won't have a boyfriend or a husband or a family, my kids are mad at me most of the time 'cuz I'm never there... they don't get to be kids 'cuz I'm gone, and at the end, when they get pissed off enough, and they leave and everyone else leaves, l'll have lots of money but that'll be it, so..."

Karen spoke at length about her background, which involved growing up in a strict religious family in Northern Alberta, and how her tumultuous teen years - including having her first child at sixteen - made it difficult for her to remain in the small community. Having been raised on a farm and acclimated to hard, physical work, the oil and gas industry was a viable option. She acknowledged that the curve could be steep for women, and was aware that sexual favours may be offered and exchanged for advancement. She, did not, however, selfcharacterize as a "pretty girl", as "They [men] see us as more like one of the boys, we're not in the bathroom doin' our makeup at work". For Karen, employing a hard-boiled persona and a willingness to work unceasingly, often faster and more proficiently than her male counterparts, 
was directly attributed to her being successful in the oil patch, a success, as she alluded to above, most often measured in earning capability. Such success had obvious costs, which she regularly experienced, but the familial and social price of her achievements had not dissuaded her from working in the industry.

25-year old Darren had migrated to GP from British Columbia, hoping to improve his financial fortunes. After a number of years on drilling and service rigs, he turned to emergency services work, and was hoping to become a paramedic. One of my early interviews, Darren wanted to speak about his experiences at length, so he and I regularly met up over beers and burgers. We frequently discussed the reactive nature of oil and gas work, and how it involved being 'on call' - waiting to be summoned to a job. Darren's comments illustrate a common frustration related to the uncertain nature of the oil and gas industry, and how for workers, the job is often reducible to 'hurry up and wait':

“I'm in limbo, it's not on call, but it is on call, you don't get paid to be on call. It sucks man, it sucks so much... that is one thing I can say that people don't understand... a lot of people say 'Hey, how long do you have off', well my days off are like, 'Hey, guess what, this job's done, we don't have another job, we'll call when the next job comes up'... You don't know how many jobs there are or how close you are to working... You can only work 24 days [per month] and then you have to be switched out, but you don't wanna tell people too much, 'cause you might have a contract that you don't wanna give up... You're all doin' the exact same job, too, so you don't ever wanna talk about wage either (laughs)... very delicate."

Both Karen and Darren had several years of experience working in the oil and gas industry, and had been attracted to the work for its economic reward. As they learned, though, there were a number of hidden costs that accompany earning such a large wage, and each spoke thoughtfully about the personal sacrifices necessary in order to keep their respective 
jobs. In Karen's case, her work choices actively alienated her immediate family, and job demands made it nearly impossible to keep social appointments or nurture relationships with her children or romantic partners. She acknowledged that her future was one that was likely to be lonely, and was clearly of two minds about the costs of her work, but remained ultimately unwilling to leave the industry. Without explicitly saying so, I sensed Karen hoped that through working hard and saving money, she could make up for lost years at a later time, using wealth to ingratiate herself to family members. Other participants spoke openly about calling on their economic ability to purchase gifts, take trips, or arrange parties as a replacement for time lost being involved and present in the lives of loved ones and friends, but the success of this strategy was questionable. As one of my co-workers noted, "Ya can't buy love, can't hardly even buy respect" (personal communication, 2013).

For Darren, moving to the GP region and working in oil and gas initially represented a break from a predictable and unfulfilling life in British Columbia. Having been able to work in a number of different sectors across the oil and gas industry meant that after a period of settling out, he was able to pinpoint where he wanted his career path to lead. An increasing dissatisfaction with hours of down-time as an on-site medic had influenced his decision to become a fully-qualified paramedic, and to then leverage his skill sets into finding a job that offered more stability and less waiting. However, Darren was caught up in a web of circumstance and decision-making: he could not afford to quit his job to undertake full-time training to become a paramedic, and so was completing the training part-time, on his days off from work. This had the effect of significantly increasing the timeline for completion, which was a source of frustration and discouragement to him. A further tension came in the form of 
the unknown, in this case, the likelihood of actually completing the training and successfully gaining a job as a paramedic.

At the time that he was participating in the research, Darren rented a large, wellfurnished apartment that was rarely lived in, owned a $\$ 60,000+$ sports car that was infrequently driven, and spent much of his time away from work drinking in local bars, hoping to connect with people and brush aside the pressure and loneliness of his job and life situation. He was effectively trapped by the tensions between his ambition and his choices, and was unwilling or unable to commit to a single course of action. This inherent struggle impacted him immensely and seemed to manifest in a consuming need to connect meaningfully with people.

Unfortunately, his work schedule and access to community provided limited options for social outings, and his pattern of seeking them out in bars and restaurants often involved heavy drinking - which did little to quell feelings of unease or to assist in making a conscious decision to commit to a course of action. Darren was stuck in a negative loop, one in which he made enough money to consider other options, but not enough to be able to fully commit to them. His unhealthy relationship with the oil and gas industry held him fast, a significant irony, given that he had viewed it as both an economic accelerator and an opportunity to widen his career path.

\section{3 - Weathering the Up and Down Cycles of Oil and Gas}

Despite the impacts of a protracted recession, residents in the GP region expected to weather economic trials and continue to evolve the local economy and region in creative and innovative ways. This attitude is in part informed by recent history: the bottom of the boom $\mathrm{n}^{\prime}$ bust cycle has been experienced by GP residents a number of times previously, and as recently as the 
recession period of 2008-2010. Beyond simple historical familiarity, however, there are a number of key aspects that contribute to and assist in reinforcing and reproducing residents' belief in yet another boom, and the remainder of this section will be devoted to their discussion. These aspects are, firstly, the notion that the oil and gas industry will continue to exist, through dint of its sheer size and ubiquity. Secondly, that GP residents understand themselves to live in an oil-dependent world, one in which the utilisation of oil and its products and by-products is firmly entrenched. Thirdly, the perception that as an oil and gas producer, the GP region not only contributes to provincial and federal economic engines, but actively renegotiates complex political and historical narratives with regard to Alberta's positionality within Canada. Finally, and relatedly, there is the question of GP's resource-based economic productivity as an integral part of a provincial and national provision scheme, through which royalty and transfer payments are levied, and from which other provinces, with fewer desirable natural resources to exploit, benefit from Alberta's significant income tax base.

\subsection{1 - Belief: The Oil and Gas Industry Will Always Exist}

As has been noted, the price of oil hovered around $\$ 100$ per barrel during the research period.

Since that time, prices dropped to well under $\$ 30$ per barrel in early 2016, prompting international interest (British Broadcasting Corporation, 2016). By early 2017, prices had been relatively stable near or at the $\$ 50$-per-barrel mark. An emerging reality of the ongoing low price for a barrel of oil is that the industry must learn how to be profitable with lower pricing structures. According to a recent industry report, a primary concern for oil and gas companies lies in cutting costs and continuing to effect progressive environmental policies, viewed as critical to ensuring continued social licence to operate (Swart and Otremba, 2017). This could 
mean significant changes to the business of procuring, refining, and exporting oil and gas, including where companies operate, in what capacity, and for how long. Since late 2014, there has been a period of profound uncertainty in the global oil and gas markets, and like many other oil-producing nations, Canada is at the behest of these forces and rearrangements. Much of this thesis was written while living in Calgary, which had an unemployment rate of $10.3 \%$ by November of 2016 (Statistics Canada, 2017). Being able to regularly view the empty floors of the downtown high-rise home offices of oil and gas corporations was a sobering reminder of the scale of change that can occur in a short span of time. At times, the contrast between the two worlds I had been straddling was breathtaking: since leaving the field, ongoing economic disorder in Alberta has devastated the province, resulting in massive job cuts, scores of workers relocating, and a provincial unemployment rate of $8.5 \%$ (Alberta Government, 2016). Recalling the unbridled activity of GP's red-hot economy during a boom period oil seemed fantastic, as if a radically different set of realities had simply been imagined.

Despite the unpredictable outlook in the province of Alberta, the narrative of an enduring oil and gas industry has continued to resonate with GP residents and citizens because they have afforded it social licence to act and propagate, and willed it to continue. The source of this social license is two-fold: firstly, it was initially brought about by the high levels of remuneration that oil and gas companies offered in return for access to the community's physical and social resources and their complicity in procuring, distributing, and exporting oil and gas. High wages and bountiful employment had the effect of linking the interests of the community - things like quality of life, employment, and the ability to attract and retain residents - directly to those of the corporations that act there: access to resources, a 
supportive population, and permissive regulations. The complexity of these relationships increased over time, and the host community became acclimated to, even defensive of, the actions and ideologies of the corporations. In the event that certain companies sought to make the host community a base for operations, the relationship was further solidified, generating expectation on the part of the community that this relationship would carry on in perpetuity. It was then in the best interest of the community to grant such companies social license, and this has reinforced the industry's ability to endure.

Secondly, it is in step with the view that markets are inherently competitive and that such competition is an extension of a Hobbesian understanding of nature and the struggle to live. That the capriciousness of oil and gas fortunes has failed to unsettle deeply held beliefs in the enduring power of the industry among GP-region residents has transpired, in part, because of the cycle of booms and busts that have recurred regularly since the early 1970s (Alberta Centennial History Society, 2006) and which have become normalized as part of the market rhythm. A research participant named Trevor, who worked as a field well operator discussed this idea during an interview:

"Every single big corporation has its own interest. They have the want and the need to ensure that they continue to thrive. And that's nature, actually, that's as close to nature as the economy will ever get. But at the same time, a lot of people say 'Oh, we shouldn't fall victim to our base instincts, we should be a little more intelligent'. Base instincts, though... that is the way it goes"

Trevor was not the only participant to make allusions to concepts like 'nature' or 'the natural order of things' in terms of understanding the machinations of market economies. While it is unlikely that the average GP resident is conversant in all the economic factors 
usual to market structures, participants and co-workers exhibited a comprehensive understanding of the direct connection between industry and decades of prosperity in their community, and how tenuous that correlation could be, in the flux of global market forces.

Further, GP residents were aware of historical examples of towns and communities that had tied their economic fortunes to the industrialism of railways, mines, steel, or vehicle factories, of the sort immortalized in the works of Dennis, et al (1974), Dunk (1991), Lucas (2008), and Willis (1982). They also understood that when those industries faltered and declined, so too did the communities that had been yoked to them, but this did not have the effect of lessening their belief in the staying power of oil and gas. Why could this be? I contend that the tenacity of the belief that the oil and gas industry will endure has been shaped and formed over the decades of interaction by industry with the people, place, and history of GP. What other options do residents have except to offer support for the industry when it is experiencing a downturn? With so many either actively employed by the industry, or having family members and friends working within it, or in some way connected or reliant upon it, there is little choice but to vociferously defend it - taking care not to bite the hand that feeds. While this history does not render the industry impervious to criticism (see Chapter 5, Section 5.3 for more on resisters and outliers), it does serve to temper negative reactions to industry, and forms a significant part of the working identity of those who have been caught up within its mechanisms. Willis (1982) noted that for working-class boys in 1970s England, the paths to success lay in choosing labour work, and actively pushing against the 
directionality of their educational curriculum. In GP, the normative path for men to succeed has been similar: dispensing with public school education as quickly as possible and instead investing their labour into the oil and gas industry, thereby earning high salaries.

The question needing to be asked is, "To what degree is this actually a choice?", given the alternative. If people wish to remain in the community, success most often means being employed in the industry, a "buy-in" that is now two or three generations old, and firmly rooted in the psyche, ideologies, and identity of GP residents. To resist that buy in is to set oneself up in opposition to the dominant employment scheme in the region, an act that has gender, economic, social, and political ramifications. Such a refusal is as near an act to treason as can be made in a resource extraction community - it categorizes the resister as an outlier, and a failure (See Chapter 5 for a discussion of 'town workers'). Given this, and that GP has a strong local culture of support for industry forged through exchange relationships, the continued existence of a firm belief that the industry will prevail is unsurprising.

\subsection{2 - Life in an Oil-Dependent World}

"Oil and gas, it's not gonna die down, if you think about it, look around you're always gonna see cars on the road, there's always gonna be that need for petroleum, the need for those fossil fuels, the petroleum industry is never gonna die, unless they start making [fuel] out of water"

- Billy, transport driver

"I think it's here for a long time, you know, I mean, there'll be jobs here for quite a while, you know, in the industry. I think it's still something for poor people to do for quite a while, I think. Be it good or bad, I don't know" 
"Build the pipelines, export it to the Asian countries. Gas is gonna go up, and we're gonna be busy every day. Whereas oil, people say 'Oh, it's the end of oil', well, we're just gonna switch to gas... There's such a huge market for oil in North America, we don't have any left over to send overseas... Once we open up to Asian markets, it will change the world, I don't care what anybody says, way too much money involved, it's gonna go through, and it's good for Canada's economy as well"

- Darren, EMT (Emergency medical technician)

As noted in the introduction of this thesis, Canada is an oil-dependent society. From fueling the vehicles consumers drive, to comprising integral parts of desirable products, to providing the energy needed to heat and cool the homes, buildings, and places people congregate, oil and gas, in many forms, are inescapable. Oil has been absorbed into the fabric of Canadian life to such a degree that its penetration is nearly total. To consciously remove oneself from the sphere of oil and gas would require drastic steps, possibly involving relocating to a remote area and surviving hand-to-mouth.

This degree of oil proliferation was well understood by participants who had years of experience in the industry, and it often formed a central basis for their understanding of how oil and gas had become necessary. Jerry, a seasoned local entrepreneur with over 30 years of experience and who had made a name for himself as an overseas well containment specialist (focusing on controlling well fires and explosions) remained optimistic that demand for hydrocarbons would continue "for at least 50 years" (personal communication, 2013). He was also convinced that a desire for gas in emerging major markets would more than make up for lack of US-based demand. Jerry strongly believed that Canada had been myopic in not courting other international clients sooner. Rather than just following the example of the United States, 
he was convinced that Canada should have been leading the charge into new frontiers "all over the world".

Other participants understood oil and gas opportunities to be global as well, but in different ways than Jerry. For a time, I struggled to find the words to communicate this, but eventually realized that part of why many participants, co-workers, friends, and residents understood oil and gas to be so usual to regular life came directly from the fact that it is so usual to life in and around GP: one is literally immersed in the burning of hydrocarbons and fossil fuels, from the exhaust streams of trucks in town, to the roar of large engines on job sites, to the ever-visible gas flare stacks dotting the landscape. The smell of fuel burning, of the grease of engines and equipment, and the din created by the cacophony of machines is inescapable.

To be in an oil and gas town is to confront a type of revelry in the consumption of that which is produced. For GP residents, outdoor hobbies were often focused around cars, motorcycles, snowmobiles, and ATVs, as well as boats and RVs. The streets were often crowded with new and modified vehicles, and those who chose to walk or ride bicycles in town took their lives into their own hands, making themselves active targets of derision, scorn, and disrespect - why would anyone walk if they could drive? The very act of choosing not to drive could itself have unintended consequences, as was revealed during an evening of drinking with a roommate. One of my roommates, Tyler, let it be known that he viewed people who rode bicycles as being unsupportive of the local oil and gas industry. That he believed such people were unlikely to work in oil and gas and to have originated from somewhere besides GP was not in itself remarkable; what was remarkable was the conflation of a choice with an act of 
subversion: that people who chose to ride bicycles were enacting political statements as much as making transportation choices. Tyler understood "bicycle riders" to be the sort of people who would maintain a left-wing agenda, be generally unsupportive of industrial activity, and actively seek to limit the ability of people such as himself to earn an "honest living". Ultimately, Tyler felt threatened by a choice that ran counter to the dominant social narratives in GP, and reacted with a form of local protectionism, i.e., support for industry. Views like Tyler's were not unusual among GP residents, and for many who lived and worked there, actions and opinions that did not ultimately support industry were understood as inherently against it.

At first blush, Tyler's 'for us or against us' binary appears simplistic. However, there is more at play here than seemingly appears, and a comparison is illustrative. In a recent paper (2017), geographer Laura Pitkanen details the history of contaminated housing sites in a community in southern Ontario. A number of home owners received notice that their properties demonstrated higher-than-normal levels of radioactivity. A significant stigma arose, such that the resale value of homes, and even the attractiveness of entire neighborhoods, was compromised. Homeowners wishing to sell and seek guarantees of safe residence endured a gauntlet of responses, delays, and excuses. Faced with diminishing home value, some would-be sellers chose not to disclose the results of the testing or to simply not pursue the matter further. As Pitkanen writes, "Silence is thus a means to protect property values from the stigma of waste" (2017: 1542). Tyler, too, is enacting a form of protection, but rather than viewing the oil and gas industry as waste-making or as itself stigmatic, he had chosen to support its presence in GP because it enabled him to earn a good deal of money and enjoy an enviable lifestyle. Those who did not share his positive views of the industry, and made such views 
public, were perceived as a danger to the economic order that had come to be usual to the region. Tyler's reaction speaks to a fear that the broadcasting of negative opinions or the enacting forms of protests against the oil and gas industry would inevitably lead to its choosing to uproot from the community and go elsewhere, leaving behind a crumbling infrastructure and effectively closing off the economic dreams and hopes of a community enrichened through taking a permissive tone with the industry.

Given the views held by Jerry and Tyler, it would be fruitful to further explore the attitudes of participants who understood the modern world to be in a permanent relationship with oil and gas. Darren, the EMT quoted at the onset of this section, had his perspective shaped through years of viewing the oil and gas industry from a distance, from a neighboring province. He then spent several more years working in the industry, in a variety of capacities, before settling on his job as an emergency services responder. For Darren, a perceived desire for oil and gas emanating from regions outside of Canada was the necessary proof of universal human need and reliance, and the economic windfall that could accompany the feeding of such desire would then act as a key incentive to install the necessary business frameworks.

The intersubjectivities of oil and gas are tremendously complex, and it is unlikely that Darren (or many other participants, for that matter) could possibly account for all the frameworks - cultural, social, and economic - that would be necessary for Canada's increased entrée as a global gas provider. Regardless, Darren held particular views, shaped by his experience and understanding, and his words and attitude demonstrated an enthusiasm for the translocation of a particular set of capitalist sensibilities into new spaces, regardless of the resultant difficulties or incompatibilities. That he was not unique among participants in 
understanding the embeddedness of oil and gas in GP society as a series of economic and capitalist linkages tells us something about the larger views of those who have linked economic salvation to that industry: these relationships hinge on a logic that prioritizes a nearly spiritual fervor for financial gain, encouraging adherents to 'spread the word' through missions of their own, cloaked in the promises of economic salvation. Relatedly, in the early days of the Trump presidency, the longstanding and controversial proposal to build the Keystone XL pipeline was approved (Financial Post, 2017), a move that could prove impactful in reinforcing participants' firmly held beliefs about the growth and endurance of the industry.

Critiquing ideas about capital and value usual in a peripheral, reactive, extractive resource economy is not without risk. As Ferguson has written, "Critical analysts of society are like generals - always at risk of, as they say, 'fighting the last war.' Once the work of critique is done, we often look up to find that the struggles now are elsewhere, the dangers have changed. A new analysis is required" (2005: 377). The breathtaking economic reformulation that has taken place in Alberta since mid-2014 exemplifies Ferguson's warning. The time spent in writing this thesis, after nearly two years of immersion into a heated-up community and job market, where hope, ambition, and arrogance ran high in equal measure, has also offered its own lessons. Writing about the halcyon days of an oil and gas community during a protracted economic downturn requires a particular agility, as the narratives of two very different worlds compete for the writer's attention. The values and attitudes of GP residents toward the monolithic nature of the oil and gas industry invite questions and complications. The particular logics that govern their social and physical worlds need to be further troubled, but for now, they remain firmly in place, important to those that hold them. Until those logics are more 
comprehensively queried, it is unlikely that beliefs related to continued longevity of the oil and gas will be much changed.

\subsection{3 - Reluctantly Contributing to 'The Nation'?}

In grappling with Alberta's positionality within Canada, it is important to acknowledge the impact of the province's historical trajectory on its ideological development. The geographic area that came to be known as Alberta had traditionally been occupied by a broad range of First Nations peoples, including the Blackfoot, Blood, Cree, Gros Vente, Peigan, and Sikisika (Dempsey, 1979). Prior to the $19^{\text {th }}$ century, immigration to the province had been extremely limited. A confluence of events, including the Canadian government's pursuit of treaty-making in the 1870s, the completion of the Canadian Pacific Railway in 1885, plus sweeping immigration reform policies championed by Clifford Sifton, then Canada's Minister of the Interior, were expected to bring many new immigrants into Alberta (The Canadian Encyclopedia, 2017). As it happened, another decade passed before immigrants arrived in significant numbers, but the flow continued steadily until the outbreak of the First World War (Canadian Museum of Immigration at Pier 21, 2017).

In 1905, Alberta officially became a Canadian province, and under the direction of its first premier, Alexander Cameron Rutherford, sought increased independence from the central government in Ontario. Unlike all the other provinces, Alberta was not granted land or resource autonomy - control of which was to remain in the hands of the federal government (Brennan, 1992). Unsurprisingly, this decision was not well received in the new province, and Alberta's politicians waged a protracted and bitter campaign to gain control over what they viewed to be provincial resources. This was formally achieved in 1930, but as Harvey Locke, 
writing for Literary Review of Canada magazine (2014) notes, a tangible distrust of government oversight and regulation has persisted in the social fabric of the province to the present day. The lingering effects of this historical distrust were also evident in the comments and anecdotes of participants. In an interview with Jess, an EMT who co-ordinated a busy familyowned mobile medical services business, I mentioned that my University was located in Ontario. She responded by alluding to one of Alberta's most enduring points of contention with the federal government, the issue of provincial equalization payments:

\begin{abstract}
"It made me laugh, when they came, ah, when the people are like, ya know, 'We're a have not', Ontario says we [Alberta] have to share our oil things, I'm like, 'You're ridiculous', you honestly think that's gonna fly? We may not have the vote, but we will branch off and join America prior to givin' you fuckers money (laughs)... we know that once it's [voting] hit Manitoba, you guys [Ontario] know who's won the election, you know, you're just gonna pretend that we're involved. You guys [Ontario] are like Park Place in Monopoly, eh, and we're the guys on the other side of the ' $G o^{\prime}$ ', we're twenty-five bucks to you... What if we just traded Quebec for Alaska and called it a day (laughs)? An' then everybody's like 'Well, Quebec doesn't really want to separate', and we're like (smiles) 'Commmme onnnnn', right, we know, we work with you Frenchies, we know what you say, you guys hate us"
\end{abstract}

Such protectionist comments were not unusual among participants. Alberta has long viewed itself as an independent, innovative, and individualistic place, and one with a healthy suspicion of any perceived attempts by external powers to police development, politics, or municipal affairs. It is also important to note that since the 1960s, Alberta has been a significant employer of Canadians from across the country, and during boom years in the mid1990s to early 2000s, was something of a "second promised land" for large numbers of Canadian economic migrants (Hiller, 2009). This sustained migration has not been lost on the province's residents, politicians, and captains of industry, and has contributed to the building of 
an expectation that Alberta is a prime work destination for those whose own provinces cannot offer the same economic advantages. This same economic destination also generates significant levels of provincial and federal tax, owing to comparatively high levels of income. The fact that Alberta has not received equalization payments since 1963 (Canadian Broadcasting Corporation, 2016) has done little to defuse hard feelings toward the federal government, or to diminish the Canadian East/West dichotomy.

Even though Alberta enjoys a reputation as an employment destination for Canadian (and international) citizens, the view from the inside is not always positive. In asking Jess to clarify her comments, she indicated that for most people, "the grass is always greener" elsewhere:

"We sit there and go, 'Ontario has it so much easier than us', you know, they can just count on everyone else to do everything for them and they just get to reap the rewards. And you guys [people in Ontario] are going 'Fuck those fuckers have so much fuckin' money', yeah, we spend it as fast as it comes in, we're as broke as you guys are over there. We just don't show you that, right. We're the, we're like, we're the Stepford province: everything looks perfect from the outside."

Jess's words could be a cautionary tale for would-be newcomers to Alberta, seeking their economic fortunes. Her analogy of the province being like the characters from a popular film, one where people live what appear to be perfect, effortless lives, is telling: Alberta has constructed an image for itself as a collection of rough and tumble, rugged individuals, standing tall among an assemblage of provinces that lack the wherewithal to succeed on their own. Further, Albertans have adopted this moniker, and it resonates deeply at home, but fails to achieve the same level of reverence in other parts of the country, suggesting the existence of a disconnect between how Albertans think of themselves, and how others think of Alberta. As 
Jess's comments illustrate, that disconnect can be highly contentious where the sharing of resources and resource wealth with the rest of Canada is concerned.

\subsection{4 - Provincial and National Provider}

The oil and gas industry contributes significant amounts of money to the province of Alberta by way of royalty payments, the fees paid by resource companies to the province for the rights to access and develop natural resources on crown lands. Royalties are calculated based on two major factors, those being the amount of oil and gas (and bitumen) being produced, and the usual market prices in effect for those produced goods (Alberta Government, 2016). In terms of dollar amounts, the revenue generated by these payments is appreciable: for 2015 , the Government of Alberta reported that natural gas and by-product royalties were $\$ 989$ million, with conventional oil adding $\$ 2.25$ billion, and the oil sands contributing a further $\$ 5.01$ billion, for a total of approximately $\$ 8.28$ billion (Alberta Energy, 2016). These totals are substantially lower for the fiscal year of 2016 - at $\$ 2.41$ billion - having been severely impacted by both the protracted decline in market pricing and a drop in global demand for oil and gas.

As has been made clear, oil and gas production contributes significantly to Canada's economy. In 2016, Natural Resources Canada released a report entitled'10 Key Facts on Canada's Natural Resources'. This report indicated that energy contributes approximately 7.3 percent to Canada's Gross Domestic Product. For the year of 2015, investments of over \$107 billion were made by resource companies, with the energy sector accounting for $\$ 90$ billion of that total. In the period of 2010-2014, natural resource sectors returned $\$ 27$ billion to government. Resource exports for 2015 were valued at $\$ 231$ billion, and more than 400 major resource construction projects are currently (2017) in the planning or construction phase, 
representing a 10-year cycle, with a total investment value of $\$ 691$ billion, $\$ 598$ billion of which is derived from energy projects.

Like all provinces, Alberta receives money from the federal government in the form of transfer payments. These payments are divided into four distinct programs, which include categories for health care and social assistance. For the purposes of this section, the focus will be trained on the Equalization program. Canada's Department of Finance states that "equalization enables less prosperous provincial governments to provide their residents with public services that are reasonably comparable to those in other provinces, at reasonably comparable levels of taxation" (Department of Finance Canada, 2016). Of the ten provinces and three territories, Newfoundland \& Labrador, Saskatchewan, Alberta, and British Columbia do not receive equalization payments.

For residents of GP, this was a particular sore spot. Participants and co-workers understood that the federal government used tax money to equalize provinces fiscally, but took exception to what they viewed as disproportionate amounts of tax paid by Albertans, which was then used to prop up the economies of provinces that generated less wealth. An accompanying view was built on the notion that the recipients of equalization payments were somehow undeserving of them, especially those made to the province of Ontario. Part of this understanding was rooted in the well-perpetuated East/West schism that features in Alberta's relationship with Ontario and the Federal government. By contrast, the Maritime provinces were less openly disrespected (with perhaps the exception of Newfoundland), but still the target of a kind of derisive pity. As an experienced gas compressor mechanic opined, "Poor bastards. Any of them guys worth a shit are here, anyways". 
Another aspect to be considered though, is that of a shared Canadian identity, and the uneasy relationship that some residents of GP had with it. The idea of Canada as a united, single entity, one that works toward common goals and assists those that cannot help themselves was not one that resounded with the social values of a self-made community such as GP. The same attributes that are admired in oil and gas work - stoicism, creativity, inventiveness, individuality, and a capacity to endure - are also expressed in the social mores shared by GP residents. People there work hard, play hard, and certainly help each other out, but those same values gathered around self-sufficiency influence the sort of help that is offered, and determines to whom it is offered. This ethnically homogenous, highlyindividualized sociality is not particularly accepting of difference. It does, however, offer adherents neatly constructed ideological categories in which to place others. Ontario and Quebec, for example, both frequent targets of provincialist anger in Alberta, are at once too far away and not far enough away. They are 'too far' in the sense of their geographic location beyond the physical and social worlds of GP residents - and thus not worthy of consideration. However, they are also 'too near', in the sense that federal mandates are issued from Ontario, a place often viewed by GP residents as being in collusion with nebulous forces in Quebec, which have the effect of constraining, imposing, or in any other way restricting the activities of Albertans, chiefly, that of developing, producing, and exporting oil and gas.

\section{4 - Chapter conclusion}

The relationships that GP has entered into with the oil and gas industry are predicated on mutual benefit. These benefits are realized through industry investment into the community, through supporting social endeavors, and in the creation of jobs and work that are highly 
profitable. The community of GP responds to these inputs by propping up the industry through localized support for its projects and by providing labour for the projects of oil and gas. In agreeing to play host to the activities of oil and gas, people in GP also agree to shoulder the potential burden of their outcomes, be those financial, environmental, social, or, most likely, a combination of all three. The industry is reliant on GP to both legitimize its presence in the region, and to provide unquestioning support for its projects, and so the industry is selfinterested in contributing to making GP an attractive place in which to base its operations. However, stable 'community' is not easily achieved in remote, frontier locales where workers are drawn into jobs that are predicated on a boom and bust cycle. As a result, values that promote the reinvesting of one's economic gains or the volunteering of one's free time have arisen as a means of ensuring that the community remains viable. During an up cycle, when workers, residents, and entrepreneurs are realizing significant profits, the resulting philanthropy and volunteerism pumped back into GP acts as a form of 'storing up': filling the shelves in anticipation of leaner times. Community schemes, outreach strategies, and building projects grind to a halt during a down cycle, so the community is highly dependent on the generosity and effort of hard-working 'Good Citizens' when the oil and gas industry is experiencing a busy period.

Understandably, not all residents appreciate the features (or social rules) of such a community. As has been explored previously in this chapter, some seek to advantage themselves monetarily in the short term, or to increase their skill sets in order to affect a job transfer elsewhere, rather than investing into the community with a view to become part of it. Taking this further, these are people who would be understood in GP as 'bad citizens', ones 
indifferent to local expectations of community generosity or who actively refuse to participate in it. If we allow that expectations of 'good citizenship' includes investing money or time back into the community, then the expectations for those who live and operate beyond this category are effectively lessened. Typically, to earn a lot of money in GP is to invite the attention of other residents and of the larger social community. At that point, it is only a matter of time until one is drawn into the web of generosity that is expected from those who profit by living and working there. To demur would constitute a major social breach, a refusal of the social contract of the region. However, such expectations of philanthropy within GP are most explicitly aimed at those who earn large amounts of money. An irony here then, is that the grandest expectations of community support are placed on those who can best afford it: a sort of redistribution scheme with echoes of socialism, an ideology that oil and gas companies - and their employees - would be highly unlikely to endorse.

Beyond the development of local practices and sensibilities, it is in the best interests of both residents of GP and the oil and gas industry to work together for a stable and productive community: this desire undergirds GP residents' support for oil and gas, and coupled to the strong belief in Alberta's contribution to Canada's greater economic good, reifies the importance of the oil and gas industry in the area. GP as a community, and as a working destination, is shown to be hospitable to the industry and supportive of those who work within it, and thus the cycle can continue to be perpetuated. Ultimately, GP and the oil and gas industry have developed extremely close linkages, ones rooted in history and mutual benefit, and ones that will support both parties through a protracted economic downturn. 


\section{Chapter 5}

\section{0: Beyond the Stereotypes}

This chapter explores examples of resistance and difference. The experiences of the people and groups examined here can be understood through what Darts (2004) has termed "ideological struggles within the realm of the everyday" (2004: 315). Within the GP region were numerous people and groups not represented by the usual values and norms. The hypervisibility of stereotypical performances of masculinity, including traditional gender expectations and conspicuous consumption, often concealed the lives and actions of those who chose not to be, or who wished not to be, part of the dominant frameworks that support the projects of oil and gas. It is these people and groups that are discussed in this chapter, and whose resistance can be understood as occupying a spectrum, one that ranged from quiet refusal of overarching norms, through community-supported expressions of rejection, to physical resistance and violent action.

Through exploring the experiences of these people and groups, it will be shown that the GP region is a place suffused with complexity. In it, acts of resistance are similarly complex, and this is especially evident for women, for whom simply residing there requires navigating a host of deeply entrenched gendered expectations. Ong, et al (2011), in researching the representation of women of colour in STEM (science, technology, engineering, mathematics) fields, note that they face a double bind, where gender and ethnicity coalesce and impact the ways women experience work. Those women who chose jobs in the oil and gas industry also faced a complex double-bind: the need to shed their femininity while working, and then having to take it back up in their personal and social lives. In managing those expectations, the women 
featured here enacted their resistance skillfully, frequently turning expectation back against the issuer. Despite their efforts, the seemingly simple act of claiming a space in which to be productive, competent, and respected often remained elusive.

Providing respite from gender-bound proscriptions of life in the region was a flourishing local arts scene. It offered support, space, and connectivity, and brought together expressive people from all over the region. Within this community, creativity was celebrated as anathema to normative understandings of how time, money, and energy was to be expended. Beyond encouraging creativity and expression, the artistic community also provided a social network for the proliferation of ideas and trends. I include a glimpse into my own participation in this community as part of the analysis, and show how the seemingly simple act of seeking out likeminded people to form a musical project can trigger a host of resistive practices and ideas. For some residents of the region, life in the shadow of the oil and gas industry took a darker form. The members of Trickle Creek farm, near Hythe, Alberta, are infamous in Western Canada, as was their patriarch and spiritual leader, Wiebo Ludwig. Intent on living a selfsustaining and remote life, the group was thrust into an acrimonious relationship with the oil and gas industry when gas exploration began to take place near them. Their responses to the intrusion, including allegations of mischief, endangerment, and vandalism, led to the prosecution and subsequent imprisonment of Ludwig. Social sympathy for the plight of the group evaporated late one night in June of 1999 when a teenage girl named Karman Willis was shot and killed while in a vehicle that was joyriding on Trickle Creek property. Members of Trickle Creek admitted no responsibility in the shooting, and Ludwig issued comments about the local teens involved that angered residents of surrounding communities. Labeled both an 
eco-warrior and an eco-terrorist, Ludwig appeared to enjoy courting controversy, taunting investigators and delivering sounds bites formed from biblical scriptures. Years after his death, the legacy of his history, and that of Trickle Creek itself, remains controversial in the region.

While the promise of economic enrichment can be attractive, it can also divide communities, including those of First Nations people. Urquhart (2010) reminds us that Indigenous views of development of oil and gas resources are highly variable: "To imagine a consensus... is to conjure an illusion, a myth" (2010: 2). This variation was evident in the divisions among members of Horse Lake First Nations (hereafter, HLFN), some of whom were struggling to assert their traditional power, while others sought to invest in the power of oil and gas development. Unlike the membership of Trickle Creek, which unilaterally rejected any form of oil and gas development on or near their property, various First Peoples in the GP region entered into partnerships with oil and gas corporations, brokering deals for land access, and bargaining for job and wealth creation. A Chief at HLFN was intent on benefitting from exploration, and his pro-oil and pro-business policies were actively enriching certain members of the band while simultaneously alienating others. Those not within the inner circle, including some Elders, were afraid to critique the Band council for fear of being sanctioned. Also at issue was the weathering of traditional teaching and ways of knowing for younger members of the Band. Attrition, fear, and the promise of economic reward were key factors in creating divisions, pitting youth against elder members, and the drive to modernize - promoted as best realized through economic and capital gain - seemed to be unavoidable. 


\section{1 - Sex in Oil and Gas?}

As has been shown throughout this thesis, the work of oil and gas is highly gendered, which is reflected in the hetero-normative sensibilities of the GP region. Within these sensibilities, it is understood that men and women have different work and social suitability, and that attitudes, behaviours, and actions are tightly governed by the categories of 'male' or 'female'. Gender is also understood to be, if not the same as biological sex, for the most part interchangeable with it. In a culture that values and reinforces masculine performance, and which prizes and rewards displays of masculinity, the category of 'feminine' is constructed as one of opposites, and also tightly rule-bound. Not surprisingly, any indication or demonstration of femininity is only suitable for women. The categories admitted little variation, and for the most part, were not porous.

The normative understandings of sex and gender in the GP region make it usual for men to work in well-paid labour jobs, while women are most often employed in retail or services that cater to customers and clients in town, rather than out in the field. A notable exception can be found in the emergency and medic services stream, where it is usual for those with training in first aid and life support to pass their work shifts at a field site. Localized understandings of gender and sex still accompany this work, as the job of being a medic is considered "good for women", or, less commonly, suitable for men thought to be feminine (a male medic participant endured endless charges of 'gayness' by field personnel for choosing work that contravened normative understandings of jobs suitable for men).

Prioritizing conventional roles for men and women is also reflected in the usual cultural displays. Restaurants, bars, and clubs are most frequently staffed by attractive young women, clad provocatively. Women are also heavily featured as front-line hotel staff, customer service 
representatives, and receptionists for professional services. Local radio programs feature advertisements that cater to gendered understandings of work and sociality. A particularly notable one was in job recruitment, and featured a gruff-voiced man who promised high rates of remuneration, job challenges, and unlimited working hours for potential employees. The caveat was that applicants needed to possess demonstrable work experience, and that experience was of a certain type, immediately discernible by the phrase (and tone) uttered by the man as the ad concluded: "If all you've ever done was play with your joystick, this job ain't for you". The message was instantly clear, but with bifurcated meaning: the job being offered was for 'real' men, and real men were not to be found at home playing video games. The sexual play on words further solidifies the advertisement as grounded in working-class male sensibilities, ones where a male demonstrating job incompetence equates to being a 'jerkoff'.

I commented on this advertisement to a group of co-workers who had all heard it, and they agreed that it was both clever in its use of double entendre, and typical of recruitment campaigns for industry work. One co-worker indicated that he appreciated the "no bullshit" message, and thought that it would help the hiring company to "weed out the kinda guys that no one wants". Another co-worker, despite liking the presentation, was less sure of its efficacy, questioning how well people really listen: "Everybody wants a job, right? So, they are gonna apply everywhere, and if it's busy, they are gonna get hired, even by this company who is tryin' to be clever. That shit doesn't matter when you need bodies". During fieldwork, a number of advertisements similar to this one featured on local radio stations.

While sex and gender expectations broadly impact men doing the work of oil and gas, they impact women at every juncture. The focus of this section is with the work choices of 
three different women in the GP area. It explores how stringent gender and sex expectations impacted those choices and how they navigated dominant expectations in creative and empowered ways. Mary, who worked in town, found herself constantly battling traditional roles and expectations. In response, she chose to stage her own forms of quiet revolt. The two others, Anne and Marnie, both worked either directly in the oil and gas industry or alongside it, and each of them acknowledged, and then consciously (and publically) rejected sexist, chauvinist, and patriarchal components of the culture. These three women shared in common an ever-present burden of social judgment about their work choices, belief systems, and the way they presented themselves to larger GP society. Each of them constructed particular means and methods of responding to and navigating these social obstacles, and each sought to advantage herself within them.

\subsection{1 - The Weight of Traditional Roles}

The weight of normative sex and gender roles and expectations of women in the GP region is considerable. Female participants were acutely aware of these expectations - expectations of the sort that Foucault recognized as "banal... but the fact that they're banal doesn't mean they don't exist" (1982: 779), and such widely-spread banality had consequences. They spoke movingly about finding ways to empower themselves within the social confines. Often however, simply navigating the markedly different rules sets for men and women required the bulk of their energy. This was the experience for Mary, a 30-year old employed in an office. She was born in GP, and then moved to Ontario as a young girl. When her parents divorced, she returned to the GP area with her mother, and lived in a small town for a time. Her home life quickly deteriorated, so Mary was placed in foster care for a period of years. At the age of 
16 , she quit high school to work, and moved in with a boyfriend. It was a fractious time, and one in which she was growing increasingly aware of the lack of local opportunities available, and how limited a future in the area might be. Mary soon realized that a fundamental problem was that she was essentially powerless, so "instead of running from the system, I started working the system".

'Working the system' for Mary meant living in subsidized housing, while holding a job and attending high school. She navigated a series of low-paying jobs and failed relationships, and at the age of 18 , found work at a local casino. Patrons who had success at gambling often tipped well, so Mary's financial fortunes improved for a time. However, she struggled with her day-to-day responsibilities as a recipient of government subsidies, increasingly immersing herself in drinking and partying. Leaving the casino, she returned to high school and completed Grade 12. She was interested in becoming a social worker, "having been a part of that system myself", but ultimately found herself drawn to marketing. When we met, she had been working with a community-based civic group and captaining their social media and outreach efforts, a role that was developing and seemed likely to continue for the long term. This job had introduced a measure of stability for her and her 8-year old son, and she was looking forward to future opportunities.

For years, Mary had struggled to find a place for herself professionally and personally in the tightly-constructed frameworks of GP's relationship rubric. Within the dynamics of how romantic relationships 'are done', assumptions of cheating or being cheated upon were inherent. Mary had dated a number of men who worked in the industry, and the unpredictable nature of the work meant that they were often called away on short notice, and gone for 
indeterminate periods of time. The expectation was that Mary would put her social life on hold during those times, and withdraw from friends and outings, especially those involving other men. Any perceived failure to adhere to these expectations could result in severe consequences. Here, Mary discusses the realities of a previous relationship, one in which she was aware of her own tenuous positionality as a fetish object subject to discipline:

"If I go to the shop, I wasn't allowed to talk to any of the guys in the shop. Uhm, very few of them would talk to me. I had been in the shop, I had played in the shop, like, when nobody else was there, I had watched them [inaudible], and relay systems, and all that wonderful jazz, but I was very much a doll, a trophy, and I knew it. Even when we went to a Christmas party, one of my mother's cousins had married a guy who was already working there, and they're older, she recognized me right off the bat, and started chatting with me, telling me how she owned a company here in town and the whole 9 yards. I got punished, severely [laughs], and I'm like 'she was family', right, 'she was female' [laughs]. I mean, she was family, like, c'mon".

Mary's treatment at the hands of her boyfriend demonstrates a host of assumptions that undergirded their relationship, and chiefly, that she was reducible from human to compliant, attractive object, a remaking that has many roots, including Biblical ones. As Nussbaum (1999) notes, "Objectification entails making into a thing... something that is really not a thing" (1999: 218). Heflick, et al (2011) found that a focus on women's physical appearance served to erode belief in their competencies and trustworthiness, effectively rendering them 'less human'. Mary understood that she was a sort of trophy to be displayed, but she struggled with being remade into a desirable object, one her current boyfriend tried to coach and correct into behaving and presenting in a manner he found appropriate. Despite the draconian restrictions placed on Mary's conduct, the same standards did not apply to her boyfriend, which was a constant source of friction. Over time, the relationship moved through 
emotional abuse and trust issues, and into dangerous, physical altercations. At that point, Mary withdrew, and took her then 2-year old son, relocating to a small town outside of GP.

Mary also found the heavy emphasis on traditional values in the GP region burdensome, and made references to how distasteful they were:

D: Can you tell me a little bit more about the traditional values, what do you mean by 'traditional values'?

M: The redneck values. Uhm, men get to party, drink, hunt, fish, do the manual labour around the house, woman's in the house, cooking, cleaning, having kids, raising kids, not allowed to work, yeah.

D: Is there a lot of that here?

M: Yes. I was supposed to apparently have been married off and pregnant by the time I was 18 [laughs]... My cousins are rude, ignorant, see women as objects, my brother is the same way... I lived with one of my cousins for about 6 months, and I watched the girls come and go, like they were prostitutes. It was horrible... and living with him you got degraded and they see this as okay. You're a woman, so you're lesser.

The impacts of these normative attitudes towards sex and gender further communicated to Mary that as a woman she was only fit to be objectified and restricted. Unfortunately, this was not an unusual experience for women living in the region. Wives and partners of co-workers, friends, and acquaintances acknowledged the persistent double-standards governing what men and women did, how they did it, and who they did it with. Having lived in other communities, ones where presumptions about the roles men and women occupy were more negotiable, added perspective to Mary's views. This provided her with a comparative framework, one which showed the degree to which understandings of gender and sex were informed locally. However, her broader framework was also a source of frustration, as she knew that "things 
aren't like this everywhere", but a host of factors, including family and job opportunities, conspired to keep her in the region.

Although she worked outside the oil and gas industry, Mary knew well that GP's gender and sex-based expectations were further complicated by the industry's working requirements, especially the necessity of standing by to be sent to the field and being on the job for uncertain periods of time. This reactivity contributed significantly to men and women building their own lives and pursuits largely apart from each other. Those who were in relationships would then have to navigate the particular expectations and ideals of their partners when coming into contact. These periods of contact - days off, holidays, or work stoppages - were often short or of unpredictable duration, and the work of relating and questioning what people understood to be true of women and men was not a priority. This cycle was difficult to break: men typically earned the highest salaries, and were regularly away from their families, leaving women to attend to children and all domestic duties. For these reasons, the arc of 'traditional values' was normative to GP. As long as the archetype remained functional, there was little need to generate an alternative value system to address the unique needs and rhythms of such a community.

Despite the discord, Mary had not suffered traditional expectations silently. Beyond creating a healthy home life for her young son, her reactions to GP's gendered way of life were characterized by a steady firmness in her refusals. By the time she began participating in the research, she refused to date men who worked in the oil and gas industry, knowing well the expectations they were likely to have. She also refused to be made to feel that she was somehow a lesser person, simply for being a woman. And, she refused to accept GP's 
expectations of how she should act, where she should work, and what sort of education she should have. For Mary, the result of these refusals was a life that was "lonely, at times, and hard", and one that required a tremendous amount of energy and willingness to see through. It was also a kind of life wherein she could provide an alternative example to her son, to his friends, and to their parents. Mary also brought her refusals into the workplace, and actively influenced co-workers and their clients. I spent time at her place of work, and her style of engagement was not aggressive but confident. She was not a confrontational person, but was firm, resolute, and formidable. She had decided to enact a quiet refusal of GP's dominant gendered values, and this refusal was present in all aspects of her life.

\subsection{2 - Negotiating Gendered Expectations}

There is a substantial literature on the experience of sexual segregation at work, especially as it relates to women (see, for example, Acker, 1990; Hartmann, 1976; Lennon, 1987; Siltanen, 1994; Wharton and Baron, 1991). In the GP region, women who want to work in roles that fall outside the norms of gender acceptability - and labouring in oil and gas does - can expect their competence to be continuously challenged. In attempting to succeed in the largely male space of oil and gas work, women will experience being "ridiculed... they're bullied, they have to prove themselves ten times more than a guy does" (as relayed to me by the female partner of a participant, 2013). For female participants who worked in industry, it was usual to endure harassment, stereotypes, unwanted sexual advances, disrespect, and uncomfortable social and physical realities. A common strategy for combating such an oppressive work environment was to adopt an aggressively masculine persona and direct it towards male co-workers. Female participants often framed their successes in terms of being able to "give it back" to their co- 
workers, and "refusing to put up with the bullshit". To better understand their experiences, I draw on the day-to-day work encounters of two women who held field manager positions. Through actively seeking to reduce their femininity - which simultaneously reduced perceptions of incompetence - and by performing as masculine - loud, tough, aggressive - they were able to win the compliance (and sometimes respect) of their male co-workers and subordinates. Additionally, female participants had to manage all this within a work system where some of the women present adopted an "emphasized femininity" (Connell, 1987), playing to the 'natural' hierarchies that separate men and women.

Marnie, a 29-year old woman, supervised a construction company in the region. She was a ticketed tradesperson, and had worked her way up the ranks over several years, from entry-level to managing a field crew as a foreman. Marnie quickly learned that in order to command respect from her mostly-male crew, she needed to act in ways that mimicked the masculine power structures they found usual:

“[It's the] young guys, that don't like takin' orders from girls that give you a hard time. They don't like that you are above them in the pecking order, and they take it as almost, like, a personal blow that you're ordering them around. I've had words with many, many, many guys... I have a big mouth. And I yell, and I swear [laughs]. You have to just do it right off the bat, 'cause if you let them get away with it once, then pretty soon all of them get on your case, and I learned that the first time... I learned that you just have to not let them get away with it. And you can tell when it's just because you're a girl. So, you just can't let 'em. You have to put your foot down right away, just if you don't, it won't stop, so. I don't have any problems with that, because I'm kind of a bitch, so [laughs]... You just have to know when to use it, that's all. But if you're not a person who can stick up for yourself when you need to, then you're not gonna make it out here as a girl. You just won't; they'll just kill you [laughs]. They'll just run you down so bad that you'll just quit". 
Marnie's ability to meet her male co-worker's jibes and return them in part contributed to her success as a manager. Another contributor was the frequent deployment of anger, an emotion understood to encourage male workers to submit and produce. Marnie was expert in wielding anger, and used it as both a tool for broadcasting her expectations to the work crew, and as a means of overriding those who questioned her authority. Through deftly summoning and employing anger, she commanded respect, and established dominance.

Invoking anger - or intimating the appearance and wielding of it - assisted Marnie in navigating a masculine work world, and possibly contributed to co-workers grudgingly accepting her as an honorary man. In an exploration of the complexly ritualized interactions of men and women in the US Navy, Höpfl (2003) notes that "women introduce ambivalence into the workplace and in military life this is not an inconsequential observation" (2003: 27). This same ambivalence unsettles the masculinity of the oil and gas world, and as Höpfl has written elsewhere, "the satisfactions which men derive from work appear to make them more susceptible to the construction of particular frames of organizational behavior" (2000: 86). Marnie's very presence in this largely-male space was disruptive to such behaviour, and her willingness to stay within it and stake a claim of expertise was difficult for her male co-workers to parse. In becoming 'angry', she effected a masculine trait, that of making herself 'like a man'. As an act of resistance, affecting anger could seem like a failing, but it was not: Marnie was able to command a crew, and demanded to be respected within the working sphere. Her status as an honorary man was simply that - honorary - but the achievement of it was far from simple. That she had children and tried to provide them with a stable and safe home life meant that she had to finely divide home and working life. Given the rarity of women occupying her 
position in the industry, Marnie's resistance is all the more significant for its endurance and its success in demanding job respect from co-workers and underlings.

Anne developed her own method for navigating a masculine working world, that of the friend with a sharp tongue. Her sarcastic style of speaking was exercised to great effect among the mostly male working cohorts, marking her as someone "not to be fucked with":

"There's a lot of women that come out there, and in their first coupla months... you don't come out there dressed like a tramp in camp, with your makeup on, you just don't. Your best bet is to be one of the guys. Not a guy, but one of them, someone they can go to and talk to, and, they're all gonna try to sleep with you... but it gets better"

Unlike Jones (1995), a camp cook in Alberta's oil patch in the 1970s who arrived at her first job dressed as if attending an evening ball, Anne never displayed her femininity on the job, a conscious decision on her part. She did, however, make strenuous efforts to be both 'like the guys' and to establish that she was a professional, one dedicated to her job and not seeking casual romantic adventure. In this way, Anne confronted gendered expectations of how women are anticipated to act and be in the oil and gas industry. Through her employment of caustic humour and demonstrable willingness to be helpful and friendly to her co-workers, she was also able to construct a "no bullshit" persona, one that helped her to guard against unwanted advances, but that also worked as a way to win a sort of grudging acceptance to a largely homosocial group.

Anne's employment of humour was both a survival strategy and a means of group ingratiation. Oil patch humour often reframes or juxtaposes gender and sex understandings in masculine ways, so it is unusual for women to deftly navigate the complex interplays of 
gendered joke-telling. As Hay (2000) points out, humour "reinforces solidarity between the two jokers, while marking a social boundary between them and other participants" (2000: 710). However, Anne was able to leverage her quick-witted humour as an entrance point for establishing relationships with her co-workers, and for building solidarity. She was also able to employ it as a means of sanctioning or shaming them if they acted inappropriately towards her or others.

Unlike some of the other women who spoke about their experiences in the oil and gas industry, Anne did not believe that women could actually achieve equal status. She encountered the gendered expectations of oil and gas jobs and work as inherently skewed towards favouring men and male bodies. I asked her expressly if expectations for women were as transparent as they are for men:

D: As a woman, do you have to be better at the work to be considered average? Compared to a man, say?

A: Well, that's the thing, though. Like, you can slack off, and they're like 'Oh, she's just a woman', right?

D: Right.

A: So, you have it both ways, right, it's kind of a double standard. If you work harder than the men, it's just 'Oh, she's overtrying', and if you work less than a man, it's 'Oh, she's a woman', you know, 'She can't really lift that' or 'She can't really do that".

Anne had witnessed a number of women who were new to working in the industry fall back on gendered expectations of their abilities, especially if the work was physically difficult, or if they sensed that they could leverage their femininity as a means of achieving favour. Neither Anne nor Marnie respected women who adopted these tactics, and for a number of reasons. Marnie was especially scornful of women who tried to use their femininity to leverage their worth. In her view, such tactics actively contributed to the perpetuation of the 'weak woman' stereotype, 
while simultaneously undercutting the efforts of those - such as herself - who strove to erode gender barriers through the demonstration of aptitude and competence. In this, she was confronting what Pyke (1996) has called "an essential gender order", one in which "notions of masculinity and femininity - and men's greater resources, status, and power relative to women - are seen as natural and inevitable" (1996: 529). Adherence to the dominant norms and expectations by other women effectively undermined Marnie's efforts, and this type of complicity roused her anger.

Anne's criticism had more nuance, as she recognized that for some women, overt sexuality was a time-tested tactic, deployed out of self-interest and desire for preservation. Still, the actions of other women had also impacted her negatively, in that she came up against the same gendered expectations as did Marnie and had to actively work to break them back down. Unlike Marnie, she didn't hold women who adhered to traditional expectations in low esteem; she simply acknowledged that they were likely to be a fixture of working life in oil and gas and focused her energies on making her own path to success.

Both Marnie and Anne self-identified as "bitches", a quality they understood to be valuable for navigating a masculine working world, and each had adopted masculinizing traits and methods of problem-solving in order to facilitate their positions among their male coworkers. In her experience working in construction among mostly male crews, Paap (2006) encountered the "Bitch-Dyke-Whore taxonomy", a label presented as a category of belonging, but which actually served to protect the considerable privilege that male construction labourers enjoyed. Paap notes that on construction sites, "women were portrayed as sexual and political outsiders, their work abilities ranked a distant second in importance to their marked social 
status. These beliefs meaningfully influenced the culture of the workplace. Not surprisingly, they tended both to reflect and reproduce the male dominance of the industry" (2006: 80). Rather than waiting for a label to be placed on them, Marnie and Anne were forthright about being 'bitches'. As women in male spaces, they were permanent outsiders, and through the act of being 'bitches' - determined women who are neither demonstrably gay nor seeking to leverage their sexuality into a better job situation - Marnie and Anne were able to win (a little) room for themselves to exist. Through being 'bitchy', they were also able to lay a claim to the work they were doing: 'bitches' can be productive, because they often "have something to prove" (ibid.: 90), while 'dykes' and 'whores' are alternately incomprehensible or figures of inherent disrespect.

The experiences of women such as Anne and Marnie took place within a dense fog of gendered expectations, job roles, financial goals, relationships, competitiveness, and struggles of self. The endurance necessary to continue along such an arduous path suggested a particular question: was it worth the effort? I asked this of Marnie, and she paused before replying, "I'm not sure. I don't know". Her conflict was palpable. However, at that time, the lure of financial remuneration was winning out, and a busy field season that promised a salary in excess of $\$ 160,000$ was a temporary antidote to deeper questions about the costs of this work. By contrast, when asked the same question, Anne responded with a historical narrative that focused on enduring:

"I've gone through ups and downs, my whole life. We went from having, you know, my dad was making $\$ 200,000$ a year and that was back in, what, 1990s, so that's over $\$ 400,000$ now, that's a huge chunk of change, to being completely broke on Christmas Day... We were $\$ 500,000$ in debt because my mother was an oilfield wife, 
she spent it as fast as it came in [laughs]... Our family has gone through it all, and I've done that, too... And we're gonna keep doing it".

Both of these women were clear-sighted about the expectation and the trials of labouring in the oil and gas industry. They recognized the inherent financial advantages that could be realized, and the mountain of challenges that accompanied such opportunity. That they had both continued to work in the industry for a number of years speaks to their aptitude and motivation. It also says a great deal about how we find value in work and how we perform it, and how that performance involves sets of micro-negotiations that are influenced by factors such as compensation, norms, and expectations. In enacting their particular forms of resistance, both Anne and Marnie had to find places where they could reasonably insert their claims to knowledge and membership. Like the "intrepid risk takers" explored by Scott (1998), both women realized that outright revolt against the dominant masculinist system that governs the industry would have simply resulted in them being turned out, perhaps bodily. For that reason, women who attempt to create their success in the oil and gas industry must do so creatively, with an awareness of the interplays of masculinity, gender, and sex.

\section{2 - Arts Community}

There were many people in the GP region who chose to work outside the oil and gas industry, as discussed in Chapter 3, Section 3.4. Among those who identified as town workers, there could be seen to emerge a broadly knit group of resisters that consciously rejected the core values of industry work, prioritizing their own pursuits and ideas of community. Not only was this rejection made explicit through a refusal to practice usual patterns of consumption and 
through actively criticizing the industry, it was also present in the forms of community-building projects that pushed against oil and gas 'culture'. These included a thriving arts scene, which encouraged local music and dance, mental health outreach and awareness programs, and a wide variety of volunteer services focused on self-improvement. These activities, groups, and endeavors formed a community-bounded project of resistance, one that rejected industry value systems prioritizing consumption, risk, and overwork, and instead articulated the promotion of inclusion, creativity, and support. The arts community was also an important place for the contribution, voices, and ideas of women, for it was assumed that they would be more comfortable within such spaces than would men.

GP is an established shopping hub and destination for people from all over northern Alberta, as well as Eastern British Columbia and the Northwest Territories. This drawing power has extended into its cultural community, one that boasts a vibrant arts and cultural scene, including Indigenous artists, local musicians, and writers. Enmeshed within this community were youth outreach groups, mental health organizations, and promotional entities, which marketed local artists and musicians, and arranged spaces for them to display their work or perform live shows. The local College provided theatre space for professional art and entertainment activities, including dance rehearsals and performances, travelling music and comedy appearances, and fundraisers arranged around talent showcases featuring local and professional performers.

Beyond existing as creative contributions to the community, the artistic scenes in GP provided places of belonging for those who found themselves outside the dominant social narratives. As a result, these scenes were populated with young people, including students and 
town workers. These same scenes also provided spaces for community involvement for those that the work of oil and gas often leaves behind: wives, girlfriends, children, and partners. It was through the efforts and foresight of women living in the GP region that an artistic and compassionate community flourished. This was evident in the programming of the local art gallery, offering classes to stay-at-home moms, the state-of-the-art public library that held ESL training for newcomers to the area, and in the student-oriented work training programs held in multiple centers. The promotion of artistic and compassionate pursuits helped to humanize a community that otherwise could appear austere, one largely predicated on trading labour power for the opportunity to realize economic advantage.

Locating and exploring the artistic scenes of GP added dimension to my own understanding of the community. During field research, I visited bars and clubs where live music was promoted, and it was there that I began to see both that there existed a vibrant local music scene, and that it was diverse in terms of styles, genres, and practitioners. Having grown up in a musical home, and playing electric bass guitar from a young age, I decided to reach out to local musicians, in the hopes of locating some like-minds to start or join a music project. Placing an advertisement on the classifieds site 'Kijiji' led to contact with a drummer. After a brief improvised 'jam' session in his home, it was evident that we shared some musical chemistry, which inspired us to seek out other musicians. Another series of advertisements posted on Kijiji over the course of a few months yielded our third, a person who could both sing and play guitar. We shortly-after added a fourth member, but the developing dynamic did not support this inclusion, and he left the group after a brief time. Within several weeks, 'the band' had a number of songs written, and after a period of approximately six months, we were 
playing in local venues, promoting our material on various social media sites, and preparing to record an album. My involvement in the group lasted a total of 15 months, and culminated in the recording and mixing of an album of original songs, which was released cost-free on a music services site. A final live show was scheduled for mid-June of 2014 , and I permanently withdrew from GP less than a month later.

That I was a member of a band is itself not especially notable, but the circumstances surrounding its formation, and the working lives of the other members themselves, are relevant to the discussion at hand. At the time of its inception, all the members of the group were working in some facet of the oil and gas industry, including machinery maintenance, fluid transport, and electrical services. This meant that not only were there significant demands on each person's time, there were also industry and seasonal factors that rendered work intervals highly irregular. Other complications included family dynamics, volunteering obligations, locating suitable rehearsal spaces, and attending to personal matters in other provinces. Coordinating rehearsal and writing sessions so that all members could attend was a constant trial. Despite these challenges, the camaraderie of sharing in the creative process of music making far outshone any logistical impediments.

The formation and maintenance of a musical project during field research offered views into completely different life worlds. My experiences as an ethnographer and as a creative sometimes mashed together. The result, as Geertz (1995) wrote, was often "a matter of living out your existence in two stories at once" (1995: 94). It was through this dynamic combination of research and creative process, that the degree and scope of resistant activities that were enacted by the arts community became illuminated. I began to see that my own involvement 
with the community could be understood as a form of stance or statement issued toward the dominant norms. The possibilities of my involvement prejudicing my research or worse, the views of participants, were concerning. In fact, I did not achieve any personal peace with this issue, but instead decided to let events take the course they would, for better or for worse.

Over time, it became apparent that there were key three reasons that the forming of and performing within a band were acts of resistance. The first of these has to do with the economic costs associated with membership. What is meant by this is simply the financial burden of procuring the equipment necessary to 'make music'. As concerns hobbies in the region, the dominant recreational outlets approved for men included hunting, fishing, and shop craft, all which were assembled around motorized vehicles, including sports cars, trucks, ATVs (all-terrain vehicles), snowmobiles, boats, and RVs (recreational vehicles). Interest in and pursuit of hobbies based around motor vehicles engendered the need for substantial capital. Those who drew high salaries were uniquely positioned to participate in such hobbies. By contrast, the relatively low cost of assembling a few musical instruments and sound equipment - all of which could be rented on a short-term basis from a local shop - ran counter to the 'traditional' non-work activities for men.

It is important to note here that the band did not take an overtly political stance: we were not staunch advocates of anti-consumerism for example. Indeed, each of us recognized that to a degree, consumption is and was an inescapability, and that the costs of living in a resource-extraction community must be met in a number of ways. Rather, the band as an entity came to embody an alternative to unchecked consumerism, one that existed at a distance to what Morton (2007) describes as "the stuff-your-face logic of capitalism" (2007: 
116). In ways, it was an exercise in both discipline and moderation, a stripped-down response to an environment that placed a high degree of value on profligate accumulation.

In choosing to pursue creative activities such as forming a band, we were effectively rejecting what Holt and Thompson (2004) have termed "compensatory consumption", that being consumption intended to bolster any masculine shortcomings. While the drummer in our band participated in some of these activities, each member also explicitly framed their commitment to forming a musical group as a form of critique. The realization of this critique was then the refusal of normative masculine expectations, and renegotiating both how men ought to spend their money and the expected outcome of that investment: on music and music-related items, with the result being artistic fellowship, instead of on motorized vehicles, which would simply reinforce usual male activities and relationships.

Secondly, making music is an act of creativity, one that is, as Schütz (1951) reminds us, based around the making of social relationships. Beyond volunteering, activities that do not lead to a form of direct remuneration, or rather, whose benefits are intangible or not immediately discernible, are neither highly valued nor encouraged within GP's dominant social structures. Creative expression not rooted in consumption is therefore mostly outside of the dominant narratives, and its inherently subjective nature is not easily reconciled in such narratives. Engaging the creative process was an especially powerful reaction to the normative values of the region, ones that imply there are constraints on expression, and that there are inherently 'good' forms of it, as much there are inherently 'bad' forms. If we understand that there is a financial consideration that undergirds the normative value systems of oil and gas workers, it is revealed how activities or expressions that are not similarly undergirded threaten 
the status quo. Artistic creativity, then, operates beyond GP's usual masculine categories and both challenges and resists being subsumed by the dominant norms.

Thirdly, making the commitment to being a member of a musical group is a significant drain on the amount of non-working time that is available to those employed in oil and gas. Time is a valuable commodity in the GP region, one that is counted, weighed, measured, spent, and lost, and one that is inextricably tied to calculations of monetary value. The act of committing one's time to a pursuit that neither guarantees economic return nor a tangible outcome is, within the scope of the normative value systems, an act of resistance. Such a commitment indicates that the practitioner either embraces or explores a value system that is at odds with those that are usual to the area. It is both a challenge to conceptions of how nonworking time is to be employed and what is to be done with and during that time. One particular band member, who had an even more unpredictable schedule than the others, explicitly prioritized carving out time for music, even if it meant sacrificing rest or eating. For him, the time spent with band members was a way "to feel like a fucking human", a sense of being that his work schedule effectively removed.

My own involvement with musical projects has a long history, and each one has had elements of apprenticeship: people to learn from, rhythms to be apprehended, social dynamics to navigate, and challenges to overcome. The same was true of the band in GP, but the apprenticeship component differed. That my mentors were the other band members should be obvious, but there was a new cognitive element at work in the creativity, a move to "deliberately bring the thinking to the surface" (Collins et al, 1991: 2). Our collective awareness of the band existing as a noisy refusal was evident early on, and that awareness bolstered the 
project. The resulting apprenticeship was one based in difference, formed in the knowledge that it was a paean to that which was unseemly or unusual. It had its own system of costs, and was certainly not without challenges. However, the outcome of this apprenticeship was realized not through financial remuneration, but instead as an opportunity to summon a creative and vital connection between people, what Biehl-Missal (2013) understands as "an aesthetic experience that is able to convey embodied and tacit forms of knowing in fuller, richer, and potentially stimulating ways" (2013: 76). That the experience of being a member of this band was enriching is beyond doubt, but more importantly was the depth of the connection that it facilitated between myself, other band members, and ultimately, our cocommunitarians in the arts. This type of connection, one based around creative and emotional affects, is at best, undervalued or ignored by large-scale industrial capitalism, and at worst, actively eroded or dismantled, if not denied entirely.

\section{3 - Other Resisters}

Beyond the responses of women such as Mary, Anne, and Marnie, and removed from the folds of the arts community, other GP-region residents resisted the dominant narratives that supported and sustained the projects of oil and gas exploration. This resistance included tactics such as questioning problematic aspects of the industry, including political, economic, and environmental issues, through socially acceptable means such as 'grumbling' or 'bitching'. Other residents sought to distance themselves entirely from the industry, and to live as if it simply did not exist, or was a monolithic thing that could somehow be avoided. Still others took a more opportunistic view, reasoning that if interacting with the industry was unavoidable, it was best to negotiate potential relationships with an eye to profiting, usually through 
prospects of wealth distribution and job creation, while refusing to be defined by their positionality and proximity to the industry.

The responses and tactics of such people and groups featured components of what could be termed 'ordinary' resistance and refusal. Like the "relatively powerless groups" Scott witnessed (1985: 34), many of those living in the GP region operated within working-class frameworks, and were only too aware of their lack of power when grappling with the immense structures of oil and gas. As well, challenging the dominant features of a community in the thrall of such a large industry engendered a host of risks. For those lacking the social capital or influence to authorize policy or infrastructure changes, calculated forms of resistance and refusal remained viable options. The degree of the resistance and refusal enacted, however, ranged from outright hostility and violence to subtle contravention of normative rules and expectations. Further complicating responses were the evolving relationships to industry that could be seen developing among groups such as the aforementioned HLFN. In the flows of capital, power and history, resistance and refusal can become sites that are at once complex and multifaceted, and yet changeable and inconsistent.

This section explores two key assemblages in opposition of the industry. These are a publically-withdrawn religious group and members belonging to HLFN. The relationships these two groups had developed with oil and gas were often highly charged, and always complexcomponents of history, economics, sociality, and community were all at play, influencing the actions and reactions of the actors. For the residents of Trickle Creek, a religious sect residing on a secluded farm north-west of GP, oil and gas development introduced massive disruption into a purposely humble way of life. The attempts made to mitigate the impacts of 
development through legal channels were largely unsuccessful, leading members of the group to undertake their own countermeasures, which included damaging oil and gas equipment, rigging well locations with explosives, and blocking access to work sites. The resulting media and community publicity in the GP region and beyond highlighted the mechanisms of imbalance that characterize relations between land owners and energy companies, mechanisms still in place today, and that continue to be questionable.

Within HLFN, contact with the oil and gas industry served to erect divisions among members of the Band. Exploration companies offered attractive amounts of remuneration for access to land holdings. Such monies could be used to improve living conditions on the reserve, diversify HLFN's economic interests, and generally increase the quality of life of residents - as well as contribute to self-sufficiency. Additional potential benefits were job creation and increased ties to industry, through the building of partnerships and work projects. Considerable downsides included the difficulty of negotiating with corporations from unequal positions of power; the uncertain long-term economic, social, and environmental impacts of oil and gas exploration on Band lands; and the erosion of traditional authority through prioritizing financial gain and material wealth.

\subsection{1 - Trickle Creek Farm}

The residents of Trickle Creek farm exemplify a group that moved beyond subtle or sociallyapproved forms of resistance, and into direct activism, through the incorporation of covert and violent activities. The alleged activities of the members of Trickle Creek and the enduring controversy of their patriarch, Wiebo Ludwig (for more on Ludwig, see Arsenault, 2012; Guidotti, 2008; Joosse, 2017 and Nikiforuk, 2002), represent an extreme reaction to the oil and 
gas industry. Joosse (2017) characterized Ludwig as “Canada's most prominent convicted environmental saboteur" (2017: 54), while an editorial piece written by politician and environmental activist Tooker Gomberg found him to be an "imperfect hero", by degrees a darling of the green environmental movement and simultaneously "a patriarchal diehard, a fundamentalist, anti-gay - and arrogant" (Now Toronto, 2002). The sabotage campaigns carried out by members of Trickle Creek were a direct reaction to what they perceived as an illegitimate intrusion of oil and gas exploration. The resulting controversies captured the attention of energy companies active in the region, local residents and workers, law enforcement agencies, and the larger world for many years. Ludwig died in 2012, and it remains unclear to what degree (if at all) his passing has changed the tenor or focus of those who remain at the farm.

Trickle Creek's origin story is uncomplicated. It was founded in 1985 by two religious leaders from Ontario, Wiebo Ludwig and Richard Boonstra, who purchased land near Hythe, Alberta. It was their intent to form a community in which to lead a socially withdrawn life, in accordance with a particular Dutch Christian doctrine (as relayed to me by a senior member of the community). The families relocated to northern Alberta, and worked to become selfsustaining, keeping animals, building their own efficient housing, and producing biodiesel to power equipment. The fledgling community was propelled into notoriety through the $1990 \mathrm{~s}$ and 2000s, being at the epicenter of allegations of bombings, criminal mischief, destroying oil and gas installations, and endangering working personnel. As noted above, Wiebo died in April of 2012 of esophageal cancer, and his eldest son, Josh, assumed a leadership role in the 
community. Through introductions made by a scholar familiar to members of the group, an opportunity to visit the farm was arranged.

I arrived at Trickle Creek on a cold, clear day in late February, 2013. Leaving my vehicle, I was ushered into a dining hall, where lunch was being served. I dined with several men and youths, and we were waited upon by women who hardly spoke, and who withdrew once the meal began. During it, I was questioned at length about my (apparent lack of) religious beliefs, and made to understand that it was unlikely that I could apprehend the purposes of the group, or even the reasons for its existence. Richard Boonstra in particular was at pains to apprehend the reason for my visit. After a time, the meal ended, and Josh led me on a far-ranging tour of the farm, where I was shown the work and animal husbandry stations, and introduced to male and female members of the group engaged in tasks that ranged from woodwork, to making soap, to dentistry. The visit concluded in the late afternoon over a glass of home-made wine, shared with Josh, and his mother, Mamie. Shortly prior to departing, I was presented with a copy of 'Wiebo's War', a 2011 documentary film directed by David York. The experiences of that day left a deep impression, and I wrote a number of journal entries focused on it over the next several days.

During the week that followed, I re-watched 'Wiebo's War', having seen it once previously. In the film, the residents of Trickle Creek are shown as retiring, religiously observant people, hard-working and attempting to live a self-sustaining life in a sparsely populated area. Unhappily, the land they own lies atop a large natural gas field, and, over time, encounters with energy companies seeking to explore the field turn hostile. Resource development coincides with livestock being born with health defects, children falling ill, and 
finally, the delivery of a still-born baby. Soon after, oil and gas well sites in Alberta and eastern British Columbia begin to be vandalized, and suspicion falls on members of Trickle Creek. Ludwig does little to dispel the rumors, and for a time, is viewed as a heroic, arch character, waging an ecological battle with a much larger foe. Public good will dissipates quickly, though, when a group of teens joyride through the farm late at night, and a rifle is discharged at the vehicles, killing 16-year old Karman Willis. The members of Trickle Creek neither claim innocence nor admit responsibility, and Ludwig's condemnation of the teens and their parents elicits wide-spread anger in the community. More legal troubles follow, and in 2000, Ludwig, after being formally charged for sabotaging oil and gas well sites, is imprisoned for 19 months. After serving the time and returning home, a period of relative quiet descends on the region. In 2011, it is discovered that Ludwig has esophageal cancer. He spends his final days in the company of his family, building his own coffin, and reflecting on his life, giving a few interviews with trusted journalists. On April $9^{\text {th }}, 2012$, he dies at home, and is interred above ground in a secluded area on the farm.

This film frequently presents footage of members of Trickle Creek being subject to intense police interest, manifested in midnight searches, random requests for statements, and scare tactics. Throughout it all, they appear calm, in good spirits, and make light of the situation, often through employing wry humour. Through my lens as a viewer, and as someone who had recently visited the farm, I received the impression that through years of contact with law enforcement and other legal entities, intrusion had been normalized, and reactions to it had subsided. My own experience seemed orchestrated and controlled, in that what I was shown at the farm, the information received, and those I had contact with, was pre- 
determined. The overall impression was that this group had become masterful in their presentation and handling of messages, and compared to midnight search warrants executed by armed police officers, my short visit was easily managed.

Despite not being certain as to what role Trickle Creek could play in my research and subsequent analysis of oil and gas activities in the GP region, I hoped to continue to build an association with its residents. Truthfully, I was conflicted about how this relationship could evolve. Josh had been clear that he did not want Trickle Creek's history used as a leveraging point against the oil and gas industry, which was understandable, given their contentious reputation. They had been through much, and perhaps did not wish to continue the "fight" at that time. As it happened, there was no further development of the relationship, and for reasons largely practical. In a follow-up phone call with Josh, I was informed that that "the family" was uninterested in my further presence or contact with Trickle Creek. When asked why, the answer was simple: I had nothing to offer them, and everything to gain for myself. Unless I was willing to advocate on their behalf or make some other substantive contribution, my curiosity was simply not worth their time.

In the week that followed this brief, final conversation with Josh, I was frustrated with the outcome, believing that a good deal of time and resources had been used up for what amounted to little more than a rural social call. Reflecting on the experience, my understanding of it became better formed. The opportunity to spend time (short though it was) with a polarizing group that stood in direct opposition to the dominant ideology and economic engine of the GP region was significant: visiting Trickle Creek caused ripples in my small social pond, where friends, colleagues, and research participants asked questions, issued 
indictments, and repeated myths about the farm, its history, and its polarizing leader. More importantly, the Trickle Creek visit encouraged a broadening of my research explorations, and provided further impetus to seek out other individuals and groups who problematized oil and gas development.

The visit was also instructive on a personal level. I was raised in a rural, prairie community, one that generally viewed outsiders with suspicion, and where self-reliance was valued. The steely united front demonstrated by the Trickle Creek membership toward combating what they understood as overt intrusion by a destructive entity was, in ways, admirable, and seemed a 'natural' response to a caustic situation that offered few satisfying legal outcomes. I could envision myself in similar straights, and reacting in similar fashion. I do not condone the alleged activities of the group concerning the oil and gas industry, but viewed from their vantage, such reactions were hardly surprising. I do not know if my ambivalence is a particular danger of anthropology or even if it was something that emerged during a period of fieldwork; perhaps it is just my own personal taint. However, many researchers come uncomfortably close to situations that are both morally compelling and repulsive. As our own instruments of measure, we strive for objectivity, acknowledging that it is always a pursuit and never an achievement. That same pursuit is troubled by engaging with the material of our study, that being the ebb and flow of human life, with all its various joys and troubles, rules and contradictions. Trickle Creek revealed to me the weighty difficulty of briefly connecting with a group of people who had a complicated history and then attempting to delineate where they might fit into my broader understanding of the oil and gas industry. It also revealed the depth of my privilege, in being able to simply quit the GP region when I no longer wanted to be there, 
a privilege that many of those represented in this research did not have. I tried to keep this lesson in mind for the duration of my time in the region, and was glad that it came early on in the research.

\subsection{2 - Horse Lake First Nation (HLFN)}

Oil and gas exploration has a multitude of impacts on First Nations groups, including disrupting community (O’Rourke and Connolly, 2003; Parlee, 2015; Westman, 2013a), unsettling hunting and ecological practices (Dana et al, 2009; Gregory and Trousdale, 2008; Nuttall, 2008), and introducing detrimental environmental and health consequences (Huseman and Short, 2012; Kryzanowski and McIntyre, 2011; Stephens et al, 2006; The Royal Society of Canada, 2010). The scale of industrial intrusion, the intensity of its exploration, and the resulting environmental and cultural disruption further victimizes First Nations peoples. Simultaneously, government mandates encourage the pursuit of economic self-sufficiency, and First Nations groups are often forced to choose between the continuation of government support and seeking corporate partnerships to fund sustainability. This is manifested in "an increasing companionship being established between corporations and First Nations, one that the government supports and fosters", such that "dependency of First Nations on government programs is slowly shifted to a new dependency on corporate intervention" (Slowey, 2001: 272). First Nations people are effectively wedged between industry and government, and the consequences of being allied with either side are significant.

When the projects of oil and gas collide with the lives of First Nations people, the resulting relationships birth a series of tensions. Among these are competing conceptions of community, and ideas about why it is meaningful and what it encompasses. In grappling with 
these ideas, Westman (2013b) presents a view of oil exploration through a lens of Cree and Métis mythology. In this view, the industry is shown as obsessed with growth, and inherently wasteful, neglecting the true meaning of 'community', in that "correlates such as landscape, social organization, past or future people, nonhuman sentient beings, and spiritual connections" remain unconsidered (2013b: 213). This lack of consideration extends into the negotiations between community residents and company agents, where "the flat and sometimes glib technical arguments" are presumed to outweigh those that come from the "emotional, experiential" accounts of First Nations people who recount long histories of living on, foraging within, and interacting with affected areas (Ibid.: 215). The two parties have radically different ideas of what community is, what it encompasses, and how it is enacted. This results in conflicting, and often incompatible, narratives between First Nations and those who exploit natural resources on a commercial scale.

Such tensions are further complicated by the economic promises offered by oil and gas development. As Nuttall notes:

"Renewed interest in developing the oil and gas resources of northern Canada presents Aboriginal peoples with possible economic opportunities as well as significant social and environmental risks. From Inuvik in the northern NWT to High Level in northern Alberta, the Mackenzie Gas Project hearings have been filled with rich testimony from Aboriginal people about both the memories and the present realities of traditional hunting, fishing and trapping ways of life. People have spoken powerfully and emotionally about being out on the land, but they have also expressed their fears for the future of Aboriginal communities both with and without the oil and gas industry. Stories of traditional life and testimony about the persistence of Aboriginal culture also provide a discursive context for the expression of hopes for the achievement of economic independence".

(2008: 632) 
While the residents of Trickle Creek had clearly demarcated their opposition to oil and gas exploration, the positions of a number of First Nations Bands in the GP region were murkier. Large Bands, such as that of Sturgeon Lake Cree Nation and Sucker Creek First Nation, had developed long-standing business relationships with oil and gas producers, and were witnessing jobs and revenues generated. Others, like HLFN, were in the midst of a changing relationship to the industry, one that increasingly favoured the economic enrichment that can accompany exploration on Band territory.

Through a contact at GPRC, I was able to connect with two members of HLFN: Elaine, an Elder, and Emily, who had recently returned to live in the Horse Lake community, and was being mentored by Emily. These women agreed to speak to me about what they understood as a significant shift in attitudes among band leaders regarding the economic opportunities of oil and gas exploration. The money that oil and gas exploration offered in exchange for land access is and was significant, and at the urging of a new chief, the Band council had entered into partnerships with a series of resource companies. Concerned HLFN elders, who advocated traditional ways of being and understanding the Earth, found themselves in opposition to Band members more interested in benefitting financially. Within such a climate, dissenting voices had been diminished, and the participants I interviewed were acutely concerned for the education and cultural training of younger generations. A potential risk was that in the search for meaning, young people would be encouraged to find it in materialism, rather than in traditional ways and teachings. HLFN was undergoing a contentious shift in priorities, and the promises of economic enrichment were difficult to resist. 
I arranged to visit HLFN for an interview, and interviewed Elaine and Emily conjointly, and although they initially both displayed signs of nervousness in speaking with me, our "big conversation" (Elaine's categorization) became more frank and open as the interview progressed. Both women were politically active on the reserve and deeply concerned with the impact that oil and gas money was having on how the Band was making decisions. The financial opportunities offered by oil and gas had divided the HLFN community, pitting younger people against older, and demarcating hard boundaries between traditional ways of knowing and those marketed as progressive and profitable.

The bulk of what Elaine shared centered around what she viewed as the increasing (and alarming) influence of oil and gas exploration on her people and their territory. She advocated a nuanced approach to ecological preservation and traditional use practices, but the incredible revenues offered by oil and gas exploration groups had led to a shift in Band governance. In Elaine's view, the HLFN tribal council operated like a cabal of insiders: those loyal to the Chief and his vision - in this case, profiting from oil and gas exploration on Band territory - reaped economic and political rewards. Those who were opposed, or even questioning of the impacts of development in the long-term, were frozen out.

During our session, I learned that Elaine had been reluctant to speak with me due to her tenuous positionality within the Band. As an Elder, she had the authority to voice concerns or raise questions regarding Band activities and decisions, but her views were increasingly considered out of step with those of the younger members, and especially with those who advocated oil and gas development. She worried about drawing too much attention to herself, for fear of being even further marginalized by her community. An immediate concern was that 
she was growing older, and had few relatives on the reserve to rely upon. This fact meant that she was increasingly careful about agitating or pushing back against the Band's will. A number of her fellow Elders were experiencing similar dilemmas, so it was difficult for them to present their "true voices" to the Band. Instead, they had to frame criticisms and disagreement subtly, and meet with interested outsiders like myself discreetly.

Much of Emily and Elaine's frustration and concern resulted directly from the ways contact with oil and gas exploration rearranged their physical and social community. Unfortunately, the repatterning they were experiencing has not been unusual:

[For] “Aboriginal communities of northern Alberta, oil has been and remains a pivotal factor in breaking down communities of humans and nonhumans as traditionally conceived, and replacing them with a community that is unequal, atomistic, more disconnected from its environment, and largely dependent or lumpenized".

(Westman, 2013b: 213)

Adding to those frustrations were the cabal-like operations of the Band and its inner-circle members: those loyal to the Chief and his vision for HLFN - profiting from oil and gas exploration on Band territory - reaped economic and political rewards. Those who questioned the wisdom of teaming up with industry, and recognized the need to "get past the idea that partnerships focused on economic development will address the disadvantage faced by communities" (Taylor and Friedel 2011: 832), were actively marginalized. Emily and Elaine were experiencing persecution by their own membership, within their own community, and struggled to balance their position within HLFN against what they understood as necessary activism. Lamentably, their views were increasingly out of step with those of other HLFN members, and they found themselves being marginalized and made objects of suspicion in the 
community.

In what began to feel like a pattern, shortly after the visit to HLFN, I received word through my College contact that Elaine was not interested in speaking with me again. I was unsurprised: she had seemed ill-at-ease throughout our entire history of contact, from my attempts to arrange a suitable interview time, to determining a location, and rescheduling both of those several times. She was clearly fearful of being viewed as critical of the new Chief's policies, and speaking to outsiders such as myself could have hardly helped. I remain grateful to both Elaine and Emily for being willing to meet with me at all, when the risks for doing so were considerable, and I was saddened that the voices of a passionate Elder, and her protégée, were being neutered. I also thought of the future for HLFN, and the race to partner with industry. What could the outcomes look like?

Taylor and Friedel (2011) warn that for First Nations people, the promises of privatepublic partnerships (known as 3Ps) rarely align with the outcomes. In exploring the history of government policies aimed at Aboriginal relations, they note "the term 'partnership' connotes equality, cooperation, and consensus", but find that the "actual workings of partnerships are anything but equal, and the effects include fragmentation, competition, and lack of overall accountability" (2010: 815). Elaine and Emily had similar fears, especially as concerned the increased focus on competitiveness and the resulting friction within the HLFN community. In their view, the prioritization of economic gain, encouraged by government and corporate agents, was eroding the value of traditional forms of knowledge in HLFN culture, aimed at replacing it with a neoliberalized vision that was usual to the region. Within such a climate, the few voices of marginalized insiders such as Elaine and Emily were unlikely to prevent this 
change.

\section{4 - Chapter conclusion}

This chapter discusses those for whom the dominant narratives and values of the oil and gas industry do not resonate. To live in and around GP is to encounter the industry at every turn: in the parking lots of grocery stores, in the classrooms of schools, and in restaurants and at sporting events. Oil and gas is inescapable in the region, and each of the groups explored in this chapter, women pushing against gendered expectations, the arts community in GP, the residents of Trickle Creek, and the community of HLFN, were impacted widely by this inescapability. Rather than being resigned to complicity (which is, arguably, easier to accomplish), these groups formulated means of responding to the intrusion and the toxic elements of the culture of the oil and gas industry. Women in GP are buffeted by sexist expectations and assumptions, effectively locked into a 'no-win' game: they are challenged and disrespected if choosing to work alongside men, and diminished if they undertake traditional roles. For the arts community in GP, promoting creative ways of being was a significant rejection of oil and gas culture, which values above all productivity and profit. Under Weibo Ludwig's stewardship at Trickle Creek, resistance eventually took the form of violence and vandalism, rooted in the frustration of an inability to keep oil and gas development (and its resultant impacts) off their land and out of residents' lives. At HLFN, a vocal minority of Elders were still willing to invoke traditional authority, and to speak truth to power, questioning the wisdom of increased ties between the Band and the industry.

Mary, Marnie, and Anne shared common struggles, but each had her own approach to dealing with and moving through them. Mary's journey, from a broken home through a 
tumultuous adolescence into an emergence as an empowered adult, is an inspiring one. During research, I met and interviewed other women who had origin stories that shared similarities with Mary's experiences. These other women did not wish to go on record, and a few were noticeably upset and frightened in revisiting their experiences through speaking with me. A particular difference in Mary's situation was that she also indicated feeling fear, but that it soon transformed into anger, which over time, she was able to harness and direct in productive ways. As she become more aware of the boundaries of her anger, she also gained clarity about the gendered society she was living in, and was inspired to resist it, even as she raised her own son within it. Mary's awareness of her secondary status as a woman in GP had informed her anger, and made it purposeful.

By comparison, Marnie and Anne's resistance was more direct, working alongside and commanding the labour of groups of men in the oil and gas industry. Anne's ability to develop hard-edged joking relationships with the men in her work crew was pivotal to her longevity in working in the field. She was careful to keep these relationships superficial, and quick to verbally discipline those who misunderstand the parameters. This is not to imply that she was able to navigate the work and the expectations of gender easily, as her very presence in such a homosocial workspace was unusual, and often elicited comments and attention. At best, she could only ever be 'like a man', without actually achieving the status and acceptance of one.

Marnie, as a boss and manager, often faced challenges to her authority, ones that would recur with any change of field staff, or even during slow working periods. Her tactic of responding to any challenge with an exaggerated display of anger was largely effective, but had the result of rendering her leadership monotone in character. Like Anne, she would never 
become a man, the standard unit of respect and value in oil and gas work, so her leadership opportunities could never fully develop - she was stuck in a liminal space. Both she and Anne were rejecting expectations of what it means to be a woman in GP, and exploding the local categories for what women do, say, and think. As brave and admirable as this is, neither Marnie nor Anne expected to experience the kind of working success that is essentially assured for a man possessed of similar capabilities and drive. As a result of this reality, both Marnie and Anne had developed a type of resigned cynicism about their work, and about themselves as exemplars of women succeeding in the oil and gas industry. They were resisting the dominant values of the GP region, but their struggles were unlikely to encourage many other women to take on the same challenges.

In GP's arts community, those who participated were often at odds with the dominant masculine structures of the city, and the programs that catered to the wives and partners of oil and gas workers were conceived, planned, and administrated by other women. There were certainly men present, especially in the local music scene, but the relative dearth of them in other arts areas is suggestive: viewed from an oil and gas worker perspective, men that have an ongoing association with the creative community in GP are problematic. Their very participation in the arts scenes means they have already failed as archetypes of masculinity, and beyond that, they operate in close proximity to feminine worlds, ones in which feelings, ideas, creativity, and expression are valued over capitalist logic and labour. Such men are ideologically dangerous to others, especially those who have willingly entered into exchange relationships with the oil and gas industry. As well, the various forms of resistance enacted by the arts community are troubling to dominant narratives because they can be subtle, eschewing 
large machines and labour forces for verse, pianos, and paint. The observable response on the part of industry to this sort of localized resistance has largely been to withdraw, and reinforce the various masculine ideals that render creative expression unnecessary and uninteresting. But still, creativity continued to grow, and the industry, ever mindful of fluctuations in public good will and social license, would be sure to note any such growth.

The trials of the residents of Trickle Creek serve as a stark reminder of the power of the oil and gas industry, a power that can overcome legal and moral appeals for exploration to cease. The nature of the struggle of these residents against the industry has been valorized, mythologized, and even made the subject of an artistic performance in a Toronto theatre (The Globe and Mail, 2017). For a number of years, there was an observable public compassion for their plight, empathy for their struggle, and admiration for their willingness to stand against an intrusive industry. The shooting of Karman Willis, and Ludwig's subsequent public comments, effectively ended the public support, and recast the members of Trickle Creek as dangerous extremists. The community has long since been vilified, and even though Ludwig himself has been dead several years, the negative associations are not easily removed.

For those living in Trickle Creek, their positionality in the physical and social worlds of Alberta has always been problematic: residents have agreed to and lived under a strict, masculinist interpretation of biblical scriptures, governed by (what can appear) austere male leadership. This way of life places men firmly above women in terms of power and decisionmaking, and reinforces an overarching gender narrative, one where men and women have 'natural' roles and expectations. Such beliefs place them effectively far outside mainstream society, and indeed, they themselves sought to achieve this isolation, wishing nothing more 
than to live quietly, in humble religious reflection. Their struggle with the oil and gas industry thrust them into a very public light, one that for several years, they navigated with aplomb. That Trickle Creek residents had been understood to be withdrawn, religious fundamentalists prior to these struggles mattered less as they came to be known as a group willing to stand up to an entire industry. After the tragedy of Karman Willis, Trickle Creek was recast once again as a dangerous outsider, an unwanted neighbor, and symbolic of home-grown eco-terrorism. For all their desire to live apart from society, Trickle Creek residents were forced to engage with it, and ultimately, the projects of oil and gas continue on. The controversial legacy of the community endures in the Peace Region and elsewhere, but so do the symbols of the oil and gas industry: oil and gas sites, wells, and flare stacks dot the landscape around Trickle Creek. No one, seemingly, can forestall the industry indefinitely.

The unrest unfolding at HLFN was directly impacted by the outreach efforts of the oil and gas industry: a new Chief, encouraged by the financial success of other Bands in the region, sought to enrich his own Band through partnering in development schemes with the industry. With Elders such as Elaine actively problematizing these partnerships, the new Chief took a hard line, pitting the authority of Elders against the authority of the Band Council, and dividing the community. This strategy played to the industry's hand, as it well knows that a divided community will soon fall, and a community that is economically struggling is unlikely to refuse promises of economic enrichment, partnerships, and cooperation. The price of the resistance of a small group of determined Elders and their protégées was social uncertainty, the potential for being ostracized in their own community, and being labelled a 'trouble maker', certain to be 
excluded from any improvements that oil and gas money might bring to Band life. Despite this, a vocal minority continued to question the wisdom of oil and gas partnerships.

Sadly, the appeals to traditional authority at HLFN are unlikely to have made little difference. As has been written throughout this thesis, the impact and influence of the industry in the GP area is inescapable: it is an ever-searching, ever-consuming, divide-and-conquer approach to resource extraction. People, towns, and land are methodically digested, their essences devoured, and then discarded as the industry moves on to its next frontier. This is not to imply that resistance is somehow futile, that it is a thing simply destined to fail. Rather, the resistance of the sort examined in this chapter pays homage to the strength and resilience of the human spirit, and can be understood as a necessary attempt to trouble the structures and assumptions of the oil and gas industry in a place where its presence is neither new or notable. That the impacts of the industry remain - for now - assured is not to say that are to remain this way in perpetuity. As larger dialogues encourage Canadians and the world to come to grips with the present and future of oil and gas exploration, community-based resistance strategies are sure to be part of the conversation. 


\section{Chapter 6}

\section{0 - After the Bust: Revisiting GP}

In the time since leaving the field (summer 2014), the economic and employment landscape of

GP has been altered. The ongoing economic recession in Alberta has also impacted the GP region in significant ways. A Government of Alberta report indicated that in the first quarter of 2016, the average number of El (employment insurance) recipients in GP had risen by $196 \%$ (Government of Alberta, 2016). The report concluded that "most Alberta municipalities have been impacted by the economic slowdown which resulted from falling oil and gas prices and declining oil and gas investment. The hardest hit municipalities are generally those that are heavily dependent on the oil and gas services sector" (2016: 7). Jackie Forrest, a reporter for the Financial Post, visited GP in late 2015, and reported a $42 \%$ decline in drilling activity, based on a year-by-year scale ('Grande Prairie finds ways to innovate during downturn', 2015). In June of 2016, the Daily Herald Tribune, a GP-based newspaper, reported that economic woes in the region had negatively impacted home sales: realtors estimated the number of houses sold for the year at approximately 1500 units, echoing the recession years of 2009 and 2010 ('It's a buyers' market in Grande Prairie', 2016). By contrast, 2014 saw nearly 3,000 homes sold in the GP region (Ibid.) Late in 2016, the real estate market continued to heavily favour buyers over sellers.

Because the landscape for working and living in GP had changed consequentially since the summer of 2014, I thought it would be useful to revisit the community in late February of 2016. I travelled from Calgary, which lies about 725 kilometers south east, making the trip by 
car. The last sizeable town before reaching GP, Valleyview, sits at the foot of territory claimed by the Sturgeon Lake Cree Nations. Previously, the divided highway terminated west of Valleyview, becoming a two-way road for a stretch of some 20 kilometers, with a much-reduced speed limit. This zone was infamous for instances of traffic bottlenecking, so it was pleasantly surprising to discover the highway twinning project complete, and a 110 kilometer-per-hour posted limit for the remainder of the drive to GP. That there was little traffic on the road was particularly noteworthy: during fieldwork, this had been a very busy stretch of highway.

Arriving to the outskirts of GP, a familiar site came into view, that of an expansive auction yard on the south side of the highway, filled with large equipment, including earthmovers, trucks, and other industrial machines. A sign announced a major auction in the next few weeks, and tuning into a local radio station soon yielded an advertisement for the same auction, indicating that much of the equipment had come from the complete disbursement of several industrial companies, including those focused on pipeline work. Driving into the city, the overall level of traffic was modest, and the storage yards of drilling and gas companies were crowded with rigs and other equipment, a sign of reduced field activity. Hotel parking lots contained few vehicles, and the restaurant chosen for the evening's meal, once difficult to access, was essentially empty.

Time spent traversing the lengths of the city, as well as visiting some outlying communities, proved illuminating. Traffic west-bound of GP was also sporadic, and the number of large transport vehicles and drilling rig moves were few. In town, gas stations, coffee shops, and stores remained open for business, but the usual line-ups and crush of customers were absent. One morning, stopping into an old coffee haunt, I found myself the only customer in 
what had been a reliably busy spot. In speaking with the owner, I learned that the economic downturn had resulted in a significant reduction in business, and she was clearly in survival mode. I stayed for forty minutes, sipping coffee, and eating a breakfast sandwich, and no one else visited the shop or used the drive-through services in that time. Two years prior, this would have been unthinkable.

I arranged a lunch date with a former participant, and learned that he had lost his industry job nearly a year prior, and was working three days a week in town. His wife was also working, but their future was uncertain: at one point, prior to the downturn, they had planned to relocate to Ontario. They were now contemplating selling their large home, and purchasing a more modest one, banking the additional monies, and beginning the search for a new home in Ontario. He was hesitant, though, as the market value of his current home had dropped, and in order to sell it quickly, it would need to be priced much below market value, a trend that was playing out online through advertisements of local goods for sale. Rental properties, highpriced and difficult to come by during my research period, were now plentiful and comparably affordable. Rent incentives, such as a free month's accommodation, low-cost damage deposits, and willingness to accept pets and children, even smokers, featured regularly in the ads. Monthly contracts were advertised in bold letters, a complete reversal from 2014, demonstrating a shift from a renter-and-seller market to one favouring the rentee-and-buyer. A friend who managed a kitchen in a popular restaurant noted that while the number of diners had been tapering off since fall of 2015, the months of January and February of 2016 were particularly dismal. Another friend, an employee at the local College, expressed concern with what he viewed as a growing tide of petty and violent crime being visited upon GP. A 
subsequent online search returned some bleak findings: Maclean's magazine ranked GP as the city with the most violent acts per population in Canada for 2015, as well as topping the list for drug crimes ('Canada's most dangerous cities 2016: How safe is your city?', 2016). In December of 2015, the Canadian Broadcasting Corporation noted that a sting operation on an acreage near GP resulted in the recovery of more than 40 stolen vehicles and various tools and equipment, with a reported value approaching one million dollars (Canadian Broadcasting Corporation, 2015). According to the Daily Herald Tribune, the Edmonton RCMP indicated that the number of vehicles stolen in 2013 was 266, with the number rising to 402 in 2014 . That number was 636 by July of 2015 ('Rampant auto theft in GP: Stats', 2015). Looking more broadly at the province of Alberta, Statistics Canada (2016) published crime statistics showing that the Police-reported Crime Severity Index (CSI), which accounts for Criminal Code incidents, had been largely static between 1998 and 2005, trending downward in 2006 through 2013, and then experiencing a sharp uptick in 2014, levelling off in 2015 . The degree of relation between GP's increased crime and Alberta's most recent economic downturn is speculative, but given the significant layoffs, high levels of income earned previously, and increasing amounts of household debt among all Canadians, a positive correlation can be assumed.

\section{1 - So What?}

The world has a troubled relationship with oil and gas, and Canadians are by no means immune to such troubles. On the one hand, we are highly reliant on the goods, services, and products that oil and gas exploration enable, from the vehicles we drive, to the computers we work on, to the phones used to connect us with friends and family. On the other, there is growing concern about the scale of impact of the projects of oil and gas, environmentally, socially, and 
economically. Petroleum extraction is often 'ugly', and uses up incredible amount of resources, including fresh water, electricity, timber, animals, and humans. There are Canadians who champion alternative energies, and would be pleased to see the oil and gas industry disappear. Others remain highly protective of the industry and its infrastructures. Thus far, the foresight, planning, and infrastructure necessary to make a significant shift away from carbon-based energy forms has not yet been realized in Canada.

In Alberta, oil and gas is inseparable from the provincial economy and from the province's identity, with many people, businesses, groups, and governments reliant on the revenues generated by the industry. So too, the federal government is dependent on oil and gas exploration, for it generates incredible tax revenues. This all has implications for Canada because a protracted downturn in the industry means job losses for oil and gas migrant workers (and those in other petroleum-extracting provinces). It also means outmigration for communities in oil-producing provinces, resulting in a decreased tax base for supporting and maintaining local infrastructure. An overall decrease in tax revenues then has to be made up in other ways, at all levels of government. These effects quickly spread beyond GP, out of Alberta, and impact the rest of the country. One current example is Trans Canada's recent (September 2017) decision to cancel the Energy East pipeline. Denis Coderre, then mayor of Montreal, celebrated the stoppage (Montreal Gazette, 2017), while voices from prairie provinces and the Maritimes bemoaned the loss of jobs and revenue generation. Oil and gas operations are clearly contentious, and a scan of Canadian attitudes toward the industry will reveal a plethora of views and opinions. 
How oil and gas is understood by Canadians, then, is important, and what takes place in GP matters for the rest of the country. It needs to be understood that as a major employer in Canada, work opportunities in oil and gas draw people, mostly men, from all over the country. Living in a city like GP is to be immersed in cultural programming that promotes conservative attitudes towards women, sexuality, and gender; to work in oil and gas means that same programming is intensified. GP, then, is a place where particular values and ideologies that are resonant with oil and gas work can be trialed and passed on. Outsiders relocate to communities like GP and are exposed to such narratives, which may already be acceptable or may require a period of indoctrination in order to determine goodness of fit. While inside the host community, workers will have these ideas and values impressed upon them time and again, and they are likely to be influenced by them. The loop might remain closed at that point, an example of rural social indoctrination, but those ideas and values also travel, carried away by workers who visit friends and family, and who relocate out of the community. They take on a social life of their own, and even though the values and attitudes usual to oil and gas may not be reflective of those common to cities such as Halifax or Montreal, they will always find adherents among working-class people.

These ideas also travel with the oil and gas industry itself, which makes its bases in communities such as GP, Fort McMurray, and Lloydminster, but the impact and reach of the industry is country-wide. That impact is directly negotiated and influenced by a community like GP, which actively helps to increase the social license that the oil and gas industry has to act. It does so because of a lack of other meaningful choices: the industry acts as a support and an anchor, and contributes economically to a place like GP; the investment is real, it is effective, 
and it is observable. In this way, communities across the country are essentially pitted against each other, depending on their orientation toward or away from oil and gas, and those that have oil and gas investment talk past those who do not. As well, the industry is masterful at discounting Canadians' protests or concerns regarding extraction, and a much-employed rebuttal to such concerns has been to insinuate that the industry is increasingly transparent, but that the public has failed in its obligation to be equally informed. This kind of rebuttal resonates in a community such as GP, where residents imagine themselves to be knowledgeable about the oil and gas industry simply because they work within it. As a result, feelings of loyalty and support to the industry are actually strengthened. This is as far as the industry has had to go with social licence: buying or generating acquiescence from peripheral communities that are ground-zero for the actual extraction, and staving off protests that originate in Toronto with legal-speak and convoluted corporate mandates, all the while propagating conservative oil and gas values that pit the province of Alberta against the rest of the country. And this is why what happens in GP matters for the entirety of Canada.

A particular reward of undertaking research in GP and the Peace Region has been to explore the richness of small-town living. GP is certainly a worker's destination, a place to write or negotiate an economic and social present or future. But it is also more than that: participants offered and shared diversity, intrigue, achievement, loss, and alienation. Spending nearly two years being immersed in the Peace Region - living, working, researching, volunteering, and socializing in it - showed me that oil and gas communities have depth. That they often present simply as destinations for economic gain means that time and effort is required to see below the surface, to apprehend the complexity, pull back the layers, and to let 
questions and observations incubate. In GP, I was able to simultaneously interact with its people, its history, and its views of itself, as well as its visions of the future. It is a community that features heavy investment by residents, and owing to its economic diversity, one that is less likely to wither away as the economic downturn in Alberta continues. GP at once brims with energy, inventiveness, talent, and ambition, and is simultaneously constrained by geography, local value systems, and market forces. Within this duality, life there can be both vivid and unpredictable.

The performance of gender and masculinity in GP offers insights into the culture of oil and gas work, its value systems, and how it rewards and disciplines those labouring within it. The workplace culture of oil and gas values physical expressions of masculine capability, and makes valuable an muscularized body, which presents as both a fetish object and as symbolic of how the industry views itself. Within this hypermasculine culture, the categories of sex and gender are effectively interchangeable, and each is tightly bounded, permitting little movement for the men and women that are placed into them. Behaviours, attitudes, physical displays, and ways of communicating are proscribed, and favour men in both work and social settings. For women in GP, navigating sex and gender is a continuous and daunting process. Despite such austerity, women continue to demand respect and to aim for equal recognition of proficiency in oil and gas work. Moving toward equality or significant diversity in oil and gas will be long and difficult, but the journey has been started. GP could once again serve as a barometer for such change. 


\section{2 - Outro}

We sit in the cab of a truck, somewhere off the Two Lakes Road, far from anyone, alone with the tic-tic sounds of an engine cooling off, a bit of a breeze, and many hectares of rough timber and broken ground. It has been a long day, and we are both tired, but happy and content each in the company of the other. I take long drinks from a water bottle, and Terry gulps noisily from a can of soda. As we sit, daylight slowly melting into twilight, a wolf appears. I see it first, and thump Terry on the leg. His eyes widen, and his lips pull back in a grin. We watch it lope along in a zig-zag fashion, a few hundred meters away, head continuously popping up, ears high. And then, it is gone, vanishing into a thicket. Terry continues to grin, and we stay silent, each lost in thought about the creature, and how fortunate we are to have seen one. The county offers a bounty of a few hundred dollars for the ears of a timber wolf, but neither of us had even moved in those few seconds.

Terry starts the truck, and the rough rattle of the diesel engine cuts into my reverie. We slowly amble along the broken ground, and back up onto the access road. I keep thinking about the story that Anne relayed in a recent interview, about the wolves inside us, each fighting to be fed. I think of my time in GP, and how hard people work there, how much they hope for the future, and how angry they can become when these things do not yield what is expected. And I realize that the wolf is an allegory for what is valued in working life in GP, outwardly stoic, moving through the atmosphere with confidence and purpose, but also at the behest of the unknown. For the wolf, this is to constantly check the wind, scan the horizon, and listen intently. For workers, it is to look for opportunity everywhere, and to make the move to a different job situation at the first sign of trouble in the old one. It is to be reactive, always hunting, and 
placing yourself before everyone else. It is about pitting oneself against all else. And, it is often to be alone.

My thoughts drift back to the truck, and Terry, as we move slowly onto the highway, and speed up, returning to the city. The day in the bush has been instructive, and I am grateful.

Behind us, the trees and animals fade into the blackness. Just ahead, the city of GP looms, and we are drawn to the lights. 


\section{Bibliography}

Abrams, Laura S. 2010. Sampling 'Hard to Reach' Populations in Qualitative Research: The Case of Incarcerated Youth, Qualitative Social Work, Vol. 9, No. 4, pp. 536-550.

Acker, Joan, 1990. Hierarchies, Jobs, Bodies: A Theory of Gendered Organizations, Gender and Society, Vol. 4. No. 2, pp. 139-158.

Addis, Michael E. and James R. Mahalik. 2003. Men, Masculinity, and the Contexts of Help Seeking, American Psychologist, Vol. 58, No. 1, pp. 5-14.

Agier, Michel. 2016. Borderlands: Towards and Anthropology of the Cosmopolitan Condition, translated by David Fernbach. Cambridge: Polity Press.

AlbertaCanada. 2014. Region At A Glance, http://www.albertacanada.com/business/statistics/peace-country-region.aspx, accessed October 6, 2014.

Alberta Centennial History Society. 2006. Alberta Formed - Alberta Transformed, edited by Michael Payne, Donald G. Wetherell, and Catherine Cavanaugh. Edmonton: University of Alberta Press.

Alberta Energy.

2016. Resource Revenue Collected, http://www.energy.alberta.ca/About_Us/2564.asp, accessed January 26 ${ }^{\text {th }}, 2017$.

2015. Coalbed Methane FAQs, http://www.energy.alberta.ca/NaturalGas/750.asp, accessed February 7, 2015.

2015. What Is Oil Sands?, http://www.energy.gov.ab.ca/oilsands/793.asp, accessed February 6, 2015.

2014. About Oil Sands: Facts and Statistics, http://www.energy.alberta.ca/oilsands/791.asp, accessed February 18, 2015.

Alberta Federation of Labour. 2007. Going the Wrong Way: Women and Wages in Alberta, http://www.afl.org/index.php/Winter-2008/going-the-wrong-waywomen-and-wages-in-alberta.html, accessed February 18, 2015.

Alberta Geological Survey. 2012. Chapter 12: Devonian Woodbend-Winterburn Strata of Western Canada Sedimentary Basin, 
http://www.ags.gov.ab.ca/publications/wcsb_atlas/a_ch12/ch_12.html, accessed February 2, 2015.

Alberta Venture. 2011. Calgary's Identity Crisis, http://albertaventure.com/2011/04/calgarys-identity-crisis/, accessed September 3, 2016.

Anderson, Alistair R., and Sarah L. Jack. 2002. The articulation of social capital in entrepreneurial networks: a glue or a lubricant?, Entrepreneurship \& Regional Development, No. 14, pp. 193-210.

Anderson, Benedict. 1991. Imagined Communities: Reflections on the Origin and Spread of Nationalism. London-New York: Verso.

Appadurai, Arjun. 1996. Modernity at Large: Cultural Dimensions of Globalization. Minneapolis: University of Minnesota Press.

Ariweriokuma, Soala. 2008. The Political Economy of Oil and Gas in Africa: The case of Nigeria. London and New York: Routledge.

Arnot, Madeleine. 2004. Male Working-Class Identities and Social Justice: A Reconsideration of Paul Willis's Learning to Labor in Light of Contemporary Research, in "Learning to Labor in New Times", edited by Nadine Dolby and Greg Dimitriadis with Paul Willis. New York and London: RoutledgeFalmer.

Arsenault, Chris. 2012. The State-Corporate Nexus: Trading Social Benefits for Environmental Costs and Localized Vulnerability, in "Natural Resources and Social Conflict: Towards Critical Environmental Security", edited by Matthew A. Schnurr and Larry A. Swatuk. New York, NY: Palgrave Macmillan.

Atkinson, Rowland and John Flint. 2001. Accessing Hidden and Hard-to-Reach Populations: Snowball Research Strategies, Social Research Update, Vol. 28, No. 1, pp. 93-108.

Attfield, Robin. 1994. Rehabilitating Nature and Making Nature Habitable, in "Philosophy and the Natural Environment", edited by Robin Attfield and Andrew Belsey. Cambridge: Cambridge University Press.

Austen, Diane E., Thomas R. McGuire, and Rylan Higgins. 2006. Work and Change in the Gulf of Mexico Offshore Petroleum Industry, in "Markets and Market Liberalization: 
Ethnographic Reflections (Research in Economic Anthropology, Volume 24)", edited by Norbert Dannhaeuser and Cynthia Werner. Emerald Group Publishing Limited, pp. 89-122.

Avenue Edmonton. 2014. Burying the Hatchet?, http://www.avenueedmonton.com/articles/burying-the-hatchet, accessed February 4, 2015.

Bacon, Francis. 1997. The New Organon, in "Human Life and the Natural World: Readings in the History of Western Philosophy", edited by Owen Goldin and Patricia Kilroe. Peterborough: Broadview Press.

Barnett, Elizabeth and Michele Casper. 2001. A definition of "social environment", American Journal of Public Health, Vol. 91, No. 3, pp. 95.

Bauman, Zygmunt. 2001. Community: Seeing Safety in an Insecure World. Cambridge: Polity. Crowther, David and Güler Aras. 2008. Corporate Social Responsibility. David Crowther, Güler Aras \& Venture Publishing ApS.

Beaufort Regional Environmental Assessment. 2012. Oil and Gas Exploration \& Development Activity Forecast: Canadian Beaufort Sea 2012 - 2027, http://www.beaufortrea.ca/wpcontent/uploads/2012/04/Beaufort-Sea-OG-activity-forecast-2012-2017.pdf, accessed March 1, 2015.

Biehl-Missal, Brigitte. 2013. 'And if I don't want to work like an artist...?' How the study of artistic resistance enriches organizational studies, ephemera: theory \& politics in organization, Vol. 13, No. 1, pp. 75-98.

Bocking, Stephen. 2011. Our Wicked Addiction, Alternatives Journal, Vol. 37, No. 5, pp. 17-19. Bourdieu, Pierre. 1978. Sport and Social Class, Social Science Information, No. 17, pp. 819-840. Breen, David. 1993. Alberta's Petroleum Industry and the Conservation Board. Edmonton: The University of Alberta Press.

Brennan, Jason. 2007. Dominating Nature, Environmental Values, Vol. 16, No. 4, pp. 513528. 
Brennan, William J. 1992. The "Autonomy Question" and the Creation of Alberta and Saskatchewan, 1905, in "The Prairie West: Historical Readings", edited by R. Douglas Francis and Howard Palmer. Edmonton: Pica Pica Press.

British Broadcasting Corporation.

2016. Matthew West - Just how low can oil prices go and who is hardest hit?, http://www.bbc.com/news/business-35245133, accessed October $2^{\text {nd }}, 2017$.

British Petroleum. 2013. Statistical Review of World Energy, http://www.bp.com/content/dam/bpcountry/fr_fr/Documents/Rapportsetpublications/statistical_review_of_ world_energy_2013.pdf, accessed July 15, 2016.

Brune, Nick and Alistair Sweeny. 2013. Canada: The New Nation (Canada's Digital History Book III). Ottawa: Northern Blue Publishing.

Burtynsky, Edward. 2009. Oil, http://edwardburtynsky.com/site_contents/Photographs/Oil.html, accessed February 28 $8^{\text {th }}, 2017$.

Busch, Lawrence. 1989. Irony, tragedy, and temporality in agricultural systems, or, how values and systems are related, Agriculture and Human Values, Vol. 6, No. 4, pp. 4-11.

Butler, Judith. 1993. Critically Queer, GLQ, Vol. 1, pp. 17-32.

Cadbury, Adrian. 2006. Corporate Social Responsibility, Twenty-First Century Society, Vol. 1, No. 1, pp. 5-21.

Calgary Herald. 2016. Nelson - Pondering a future without energy wealth, http://calgaryherald.com/opinion/columnists/nelson-pondering-a-future-withoutalbertas-energy-wealth, accessed September $6^{\text {th }}, 2017$.

Calicott, J. Baird. 1979. Elements of an Environmental Ethic: Moral Considerability and the Biotic Community, Environmental Ethics, Vol. 1, No. 1, pp. 71-81.

Canadian Association of Oilwell Drilling Contractors.

2016. Rig Counts - Drilling (DR) - by Quarter, http://www.caodc.ca/rig-countsdrilling-dr-quarter, accessed August 31, 2016. 2016. Vision/Mission, http://www.caodc.ca/vision-mission, accessed July 18, 2016. 
2015. Drilling Crews, http://www.caodc.ca/drilling-crews, accessed February 28, 2015. 2015. Our Mission, http://www.caodc.ca/vision-mission, accessed February 28, 2015. 2015. Recommended Wage Rates for Drill Crew Personnel, http://www.mdslimited.ca/wages, accessed September 04, 2016.

Canadian Association of Petroleum Producers.

2017. Industry Across Canada: Newfoundland and Labrador, http://www.capp.ca/canadian-oil-and-natural-gas/industry-acrosscanada/newfoundland-and-labrador, accessed November 26 2017. 2016. Onshore Projects and Exploration in NL, http://atlanticcanadaoffshore.ca/projects-exploration-newfoundland-labrador/, accessed July 15, 2016.

2015. Basic Statistics, http://www.capp.ca/library/statistics/basic/Pages/default.aspx, accessed February 11, 2015.

2015. Industry Across Canada, http://www.capp.ca/canadalndustry/industryAcrossCanada/Pages/default.aspx, accessed January 11, 2015.

2015. Pipeline Map, http://www.capp.ca/canadalndustry/oil/Pages/PipelineMap.aspx, accessed January 28, 2015.

2015. Shale Gas, http://www.capp.ca/canadalndustry/naturalGas/ShaleGas/Pages/default.aspx, accessed February 8, 2015.

2015. Water use in Oil and Natural Gas Development in Alberta, http://www.oscaalberta.ca/wp-content/uploads/2015/08/Water-Use-in-Oil-andNatural-Gas-Development-in-Alberta-Fact-Sheet.pdf, accessed February $27^{\text {th }}, 2017$. Canadian Broadcasting Corporation.

2016. Donald Trump vows to greenlight Keystone XL if elected, http://www.cbc.ca/news/world/donald-trump-trans-canada-keystone-xl-pipeline1.3601927, accessed August 25, 2016. 
2016. Equalization panel aims to find fairness for Alberta, http://www.cbc.ca/news/canada/calgary/equalization-panel-aims-fairness-foralberta-1.3453666, accessed January 26 ${ }^{\text {th }}, 2017$.

2016. Fences come down around Lac-Mégantic disaster area, http://www.cbc.ca/news/canada/montreal/lac-megantic-fences-1.3750279, accessed September 17, 2016.

2016. Young Canadians more likely to see a future without oil and gas, http://www.cbc.ca/news/canada/calgary/ekos-poll-environment- youth-economy-oilgas-1.3498263, accessed September $7^{\text {th }}, 2017$.

2015. Barack Obama rejects Keystone XL pipeline citing 'national interest', http://www.cbc.ca/news/business/keystone-xl-pipeline-obama-1.3307440, accessed August 25, 2016.

2015. Grande Prairie bust nets $\$ 1 M$ in stolen property, http://www.cbc.ca/news/canada/edmonton/grande-prairie-bust-nets-1m-in-stolenproperty-1.3352716, accessed January 19, 2017.

CanadaCool. 2015. North American's first commercial oil well was located in Oil Springs, Lambton County, http://www.canadacool.com/location/oil-springs-first-commercial-oilwell/, accessed January 29, 2015.

Canadian Encyclopedia. 2016. Sir Alexander Mackenzie (Explorer), http://www.thecanadianencyclopedia.ca/en/article/sir-alexander-mackenzieexplorer/, accessed September 1, 2016.

Canadian Energy Pipeline Association. 2015. Facts, http://www.cepa.com/library/factoids, accessed January 28, 2015.

Canadian Museum of Immigration at Pier 21. 2017. Settling the West, https://www.pier21.ca/research/immigration-history/settling-the-west-immigration-tothe-prairies-from-1867-to-1914, accessed January 25 ${ }^{\text {th }}, 2017$.

Canadian Petroleum Hall of Fame. 2016. Dr. Karl A. Clark, http://www.canadianpetroleumhalloffame.ca/karl-clark.html, accessed September 3, 2016. 
Canadian Society of Petroleum Geologists. 1984. CSPG Special Publications: Pembina Oil Field In Retrospect, http://archives.datapages.com/data/cspg_sp/data/009/009001/1_cspgs p0090001.htm, accessed February 3, 2015.

Carroll, Hamilton. 2011. Affirmative Reaction: New Formations of White Masculinity. Durham, NC: Duke University Press.

Carter, Angela. 2016. The Petro-Politics of Environmental Regulation in the Tar Sands, in "First World Petro-Politics: The Political Ecology and Governance of Alberta", edited by Laurie K. Adkin. Toronto: University of Toronto Press.

Cenovus Energy. 2017. About us, http://www.cenovus.com/about/index.html, accessed February $3^{\text {rd }}, 2017$.

Charpentier, Alex D., Joule A. Bergerson, and Heather L. MacLean. 2009. Understanding the Canadian oil sands industry's greenhouse gas emissions, Environmental Research Letters, Vol. 4, No.1, pp. 1-11.

Chastko, Paul. 2004. Developing Alberta's Oil Sands: From Karl Clark to Kyoto. Calgary: University of Calgary Press.

City of Grande Prairie.

2017. Birth of the Swan City, http://www.cityofgp.com/index.aspx?page=667, accessed November $28^{\text {th }}, 2017$.

2017. Discovery of the Elmworth Deep Basin Gas Field, http://www.cityofgp.com/index.aspx?page=667, accessed November 28 ${ }^{\text {th }}, 2017$. 2017. History of Grande Prairie, http://www.cityofgp.com/index.aspx?page=667, accessed November $18^{\text {th }}, 2017$.

2014. Centennial Spectacular An Enormous Hit, http://www.cityofgp.com/index.aspx?page=33\&recordid=2975\&returnU RL=\%2Findex.aspx\%3Fpage\%3D33, accessed September 29, 2014.

2014. Quick Statistics, http://www.cityofgp.com/index.aspx?page=756, accessed September 29, 2014.

Collections Canada. 2002. Alberta's Natural Resources: Leduc: Causes \& Effects, http://www.collectionscanada.gc.ca/eppp- 
archive/100/205/301/ic/cdc/www.abheritage.ca/abresources/history/h istory_leduc_during_strike_no1.html, accessed February 2, 2015.

Community Foundation of Northwestern Alberta. 2013. Grande Prairie's Vital Signs, http://www.vitalsignscanada.ca/files/localreports/2013_CFNWA_REPORT.pdf, accessed September 7, 2016.

Connell, R. W. 1987. Gender and power. Stanford, CA: Stanford University Press.

Courtnay, Will H. 2006. Rural Men's Health: Situating Risk in the Negotiation of Masculinity, in "Country Boys: Masculinity and Rural Life", edited by Hugh Campbell, Michael Bell, and Margaret Finney. University Park, PA: Penn State Press.

Crane, Andrew, Dirk Matten, Abigail McWilliams, Jeremy Moon, and Donald S. Siegel. 2008. Introduction: The Corporate Social Responsibility Agenda, in "The Oxford Handbook of Corporate Social responsibility", edited by Andrew Crane, Dirk Matten, Abigail McWilliams, Jeremy Moon, and Donald S. Siegel. Oxford: Oxford University Press, pp. 318.

Creed, Gerald W. 2006. Reconsidering Community, in "The Seductions of Community", edited by Gerald W. Creed. Santa Fe, NM: School of American Research Press.

Cricco-Lizza, Gianna. 2012. Hydraulic Fracturing and Federalism: Injecting Reality into Policy Formation, Seton Hall Law Review, Vol. 42, No. 2, pp. 703-740.

Coronil, Fernando. 1997. The Magical State: Nature, Money, and Modernity in Venezuela.

Chicago \& London: The University of Chicago Press.

Cronon, William. 1995. The Trouble with Wilderness; or, Getting Back to the Wrong Nature, in "Uncommon Ground: Rethinking the Human Place in Nature", edited by William Cronon. New York: W. W. Norton \& Co.

CTV News. 2013. Death toll in Lac-Megantic disaster now set at 47, http://www.ctvnews.ca/canada/death-toll-in-lac-megantic-disaster-now-set-at-471.1374099, accessed September 17, 2016.

Curzon, George Nathaniel. 1907. Frontiers. Oxford: The Clarendon Press. 
Daily Herald Tribune.

2016. It's a buyers' market in Grande Prairie, http://www.dailyheraldtribune.com/2016/07/24/its-a-buyers-market, accessed January 19, 2017.

2015. Rampant auto theft in GP: Stats, http://www.dailyheraldtribune.com/2015/09/10/rampant-auto-theft-in-gp-stats, accessed January 23, 2017.

Dana, Leo Paul, Robert Brent Anderson, and Aldene Meis-Mason. 2009. A study of the impact of oil and gas development on the Dene First Nations of the Sahtu (Great Bear Lake) Region of the Canadian Northwest Territories (NWT), Journal of Enterprising Communities: People and Places in the Global Economy, Vol. 3, No. 1, pp. 94-117.

Darts, David. 2004. Visual Culture Jam: Art, Pedagogy, and Creative Resistance, Studies in Art Education, Vol. 45, No. 4, pp. 313-327.

Davis, Charles. 2012. The Politics of "Fracking": Regulating Natural Gas Drilling Practices in Colorado and Texas, Review of Policy Research, Vol. 29, No. 2, pp. 177-191.

De Genova, Nicholas. 2005. Working the Boundaries: Race, Space, and Illegality in Mexican Chicago. Durham, NC: Duke University Press.

Dempsey, Hugh Aylmer. 1979. Indian Tribes of Alberta. Calgary: Glenbow Museum. Dennis, Norman, Fernando Henriques and Clifford Slaughter. 1974. Coal Is Our Life: An analysis of a Yorkshire mining community. London: Tavistock Publications Limited.

Department of Finance Canada. 2016. Federal Support to Provinces and Territories, https://www.fin.gc.ca/access/fedprov-eng.asp, accessed January 26 ${ }^{\text {th }}, 2017$.

de Rijke, Kim. 2013. Hydraulically fractured: Unconventional gas and anthropology, Anthropology Today, Vol. 29, No. 2, pp. 13-17.

Discover the Peace Country. 2014. Grande Prairie Statistics, http://www.discoverthepeacecountry.com/htmlpages/statistics.html, accessed October $1,2014$. 
Donnan, Hastings and Thomas M. Wilson. 1999. Borders: Frontiers of Identity, Nation and State. Oxford: Berg.

Dorow, Sarah. 2016. Governing Through Community in the Oil Sands Zone, in "Governing Practices: Neoliberalism, Governmentality, and the Ethnographic Imaginary", edited by Michelle Brady and Randy K. Lippert. Toronto: University of Toronto Press.

Dorow, Sara and Sara O'Shaughnessy. 2013. Fort McMurray, Wood Buffalo, and the Oil/Tar Sands: Revisiting the Sociology of "Community", Canadian Journal of Sociology, Vol. 38, No. 2, pp. 121-140.

Drew University. 2012. Professor goes West to Study Fracking. Video document, http://www.youtube.com/watch?v=6f_ECc1Xqh4\&feature=youtube_gda ta, accessed February 27 2017.

Du, Shuili, and Edward T. Vieira Jr. 2012. Striving for Legitimacy through Corporate Social Responsibility: Insights from Oil Companies, Journal of Business Ethics, Vol. 110, No. 4, pp. 413-427.

Dunk, Thomas. 1991. It's a Working Man's Town: Male Working-Class Culture. Ottawa: Carleton University Press.

Elliott, Brian. 2010. Constructing Community: Configurations of the Social in Contemporary Philosophy and Urbanism. Toronto: Rowman \& Littlefield.

Energy BC, 2016. Evolution of Canada's oil and gas history, http://www.energybc.ca/cache/oil/www.centreforenergy.com/shoppin g/uploads/122.pdf, accessed September 1, 2016.

England, Lynn, and Ralph B. Brown. 2003. Community and Resource Extraction in Rural America, in "Challenges for Rural American in the Twenty-First Century", edited by David L. Brown and Louis E. Swanson. University Park, PA: Penn State University Press.

Epp, Henry T. (Editor). 1993. Three Hundred Prairie Years: Henry Kelsey’s “Inland Country of Good Report". Regina: Canadian Plains Research Center.

Ernst and Young. 2017. How do we regenerate this generation's view of oil and gas? An EY poll of US consumers and oil and gas executives finds workforce challenges are ahead for the 
industry, http://www.ey.com/Publication/vwLUAssets/ey-oil-and-gas-perspectivesgenerations-views/\%24FILE/ey_survey_careers.pdf, accessed September $7^{\text {th }}, 2017$. Escobar, Luis Fernando and Harrie Vredenburg. 2011. Multinational Oil Companies and the Adoption of Sustainable Development: A Resource-Based and Institutional Theory Interpretation of Adoption Heterogenity, Journal of Business Ethics, Vol. 98, No. 1, pp. 39-65.

Etzioni, Amitai. 1997. The New Golden Rule: Community and Morality in a Democratic Society. London: Profile.

Exxon Mobil. 2011. There's more in a barrel of oil than just gasoline (Auth. Ken Cohen), http://www.exxonmobilperspectives.com/2011/06/05/theres-more-in-a-barrel-of-oilthan-just-gasoline/, accessed March 3, 2015.

Faubion, James D. and George E Marcus (Eds). 2009. Fieldwork Is Not What It Used To Be: Learning Anthropology's Method in a Time of Transition. Ithaca and London: Cornell University Press.

Faugier, Jean and Mary Sargeant. 1997. Sampling hard to reach populations, Journal of Advanced Nursing, Vol. 26, pp. 790-797.

Fawcett, Charles Bungay. 1918. Frontiers: A Study in Political Geography. Oxford: The Clarendon Press.

Ferguson, James. 2005. Seeing like an Oil Company: Space, Security, and Global Capital in Neoliberal Africa, American Anthropologist, Vol. 107, No. 3, pp. 377-382.

Ferguson, Nelson, 2014. From Coal Pits To Tar Sands: Labour Migration Between An Atlantic Canadian Region And The Athabasca Oil Sands, Just Labour, Special Issue, No. 17\&18, pp. 106-118.

Fernando, Felix N. and Dennis R. Cooley. 2016. Socioeconomic System of the Oil Boom and Rural Community Development in Western North Dakota, Rural Sociology, Vol. 81. No. 3, pp. 407-444.

Ferry, Elizabeth Emma. 2011. Waste and Potency: Making Men with Minerals in Guanajuato and Tucson, Comparative Studies in Society and History, Vol. 53, No. 4, pp. 914-944. 
2005. Not Ours Alone: Patrimony, Value, and Collectivity in Contemporary Mexico. New York: Columbia University Press

Filteau, Matthew R. 2014. Who Are Those Guys? Constructing the Oilfield's New Dominant Masculinity, Men and Masculinities, Vol. 17, No. 4, pp. 396-416.

Financial Post.

2017. As Ottawa and Alberta dither, Trump embraces the oilsands with Keystone $\mathrm{XL}$ nod, http://www.financialpost.com/m/wp/news/energy/blog.html?b=business.financ ialpost.com/news/energy/trump-hard-wires-the-oilsands-into-america-firstenergy-plan-with-keystone-xl-push \&pubdate=2017-01-25, accessed January $25^{\text {th }}$, 2017.

2015. Comment: Grande Prairie finds ways to innovate during downturn, http://business.financialpost.com/news/energy/comment-grand-prairie-finds-ways-toinnovate-in-downturn, accessed January 19, 2017.

Foreman, Dave. 1998. Putting the Earth First, in "Environmental Ethics: Divergence and Convergence", $2^{\text {nd }}$ Edition, edited by Richard G. Botzler and Susan J. Armstrong. Boston, MA: McGraw-Hill.

Fortun, Kim. 2012. Ethnography in Late Industrialism, Cultural Anthropology, Vol. 27, No. 3, pp. 446-464.

Foster, Peter. 1985. From Rigs to Riches: The Story of Bow Valley Industries Ltd. HarperCollins Canada.

1983. Other People's Money: The Banks, the Government and Dome. Toronto: Collins. 1979. The Blue-eyed Sheikhs: The Canadian oil establishment. Don Mills, On: Collins. Foucault, Michel. 1982. The Subject and Power, Critical Inquiry, Vol. 8, No. 4, pp. 777-795. Frasier Institute. 2013. Studies in Energy Transportation: The Canadian Oil Transport Conundrum, authored by Gerry Angevine, with introduction by Kenneth P. Green, http://www.fraserinstitute.org/uploadedFiles/fraser-ca/Content/research- 
news/research/publications/canadian-oil-transport-conundrum.pdf, accessed February 21, 2015.

Fusco, Leah. 2007. The Invisible Movement: The Response of the Newfoundland Environmental Movement to the Offshore Oil Industry. MA thesis.

Garstad-Rosenau, Elsie. 1997. Oil Patch Recollections of 'The Way Things Were'. Canada: Self-published.

Geertz, Clifford.

1996. After the Fact: Two Countries, Four Decades, One Anthropologist. Cambridge, MA: Harvard University Press.

1975. Common Sense as a Cultural System, The Antioch Review, Vol. 33, No. 1, pp. 526.

GeoExPro. 2013. Heavy Oil from an Ancient Reef, http://www.geoexpro.com/articles/2013/06/heavy-oil-from-an-ancient-reef, accessed July 15, 2016.

George, Siby K. 2015. Heidegger and Development in the Global South. Mumbai, India: Springer.

Gijsbers Van Wijk, C. M., Kolk, A. M., Van den Bosch, W. J. H. M., \& Van den Hoogen, H.J. M. 1992. Male and female morbidity in general practice: The nature of sex differences, Social Science and Medicine, Vol. 35, pp. 665-678.

Global News. 2014. Alberta Economy: Migration To Alberta is Exploding, http://globalnews.ca/news/1220698/migration-to-alberta-is-exploding/, accessed March 3, 2015.

Gorz, André. 1982. Farewell to the Working Class: An essay on Post-Industrial Socialism. London: Pluto Press.

Gove, W. R. 1984. Gender differences in mental and physical illness: The effects of fixed roles and nurturant roles, Social Science and Medicine, Vol. 19, pp. 77-84.

Gove, W. R., \& Tudor, J. F. 1973. Adult sex roles and mental illness, American Journal of Sociology, Vol. 78, pp. 50-73. 
Government of Alberta.

2017. Unemployment Rate, http://economicdashboard.alberta.ca/Unemployment, accessed January 20, 2017.

2016. Economic Commentary: How the Current Slowdown is Affecting Alberta's Municipalities - June Update, https://www.albertacanada.com/files/albertacanada/SPCommentary_06-14- 16.pdf, accessed January 19, 2017.

2016. How Royalties Work, https://www.alberta.ca/royalties-how-royaltieswork.aspx, accessed January 26 ${ }^{\text {th }}, 2017$. 2014. History of Turner Valley Gas Plant, http://www.history.alberta.ca/turnervalley/about/history/history.aspx, accessed February 2, 2015.

2014. Mining, Quarrying, and Oil and Gas Extraction (NAICS 21): Gross domestic product, https://www.ic.gc.ca/app/scr/sbms/sbb/cis/gdp.html?code=21\#gdp2, accessed January 28, 2015.

Gow, Sandy. 2005. Roughnecks, Rock Bits, and Rigs: The Evolution of Oilwell Drilling Technology in Alberta, 1883-1970. Calgary: University of Calgary Press.

Grande Prairie Volunteer Services Bureau. 2016. Sponsors, http://www.volunteergp.com/about-us/sponsors, accessed August 4, 2016.

Grant, Judith. 1996. Bring the Noise: Hypermasculinity in Heavy Metal and Rap, Journal of Social Philosophy, Vol. 27, No. 2, pp. 5-30.

Gray, Earle.

2000. Forty Years in the Public Interest: A History of the National Energy Board. Vancouver: Douglas \& Mclntyre. 1982. Wildcatters: The Story of Pacific Petroleums and Westcoast Transmission. Toronto: McClelland and Stewart. 1970. The Great Canadian Oil Patch. Toronto: McLean-Hunter.

Greenley, J. R., \& Mechanic, D. 1976. Social selection in seeking care for psychological problems, Journal of Health and Social Behavior, Vol. 17, pp. 249. 
Gregory, Robin and William Trousdale. 2008. Compensating aboriginal cultural losses: an alternative approach to assessing environmental damages, Journal of Environmental Management, No. 30, pp. 1-11.

Greider, Thomas and Lorraine Garkovich, 1994. Landscapes: The Social Construction of Nature and the Environment, Rural Sociology, Vol. 59. No. 1, pp. 1-24.

Griffiths, S. 1992. The neglected male, British Journal of Hospital Medicine, Vol. 48, pp. 627629.

Guidotti, Tee L. 2008. The Western Canada Study: Overview and Context, Archives of Occupational \& Environmental Health, Vol. 63, No. 4, pp. 163-165.

Hammersley, Martyn and Paul Atkinson. 2007. Ethnography: Principles in practice, $3^{\text {rd }}$ Edition. New York: Routledge.

Hannerz, Ulf. 1996. Transnational Connections: Culture, People, Places. London: Routledge. Hannigan, John. 2014. Environmental Sociology, $3^{\text {rd }}$ Edition. London and New York: Routledge.

Hargrove, Eugene C. 1996. Foundations of Environmental Ethics. Denton, TX: Environmental Ethics Books.

Hartmann, Heidi. 1976. Capitalism, Patriarchy, and Job Segregation by Sex, Signs, Vol. 1, No. 3, pp. 137-169.

Hay, Jennifer. 2000. Functions of humour in the conversations of men and women, Journal of Pragmatics, Vol. 32, pp. 709-742.

Heflick, Nathan A., Jamie L. Goldenberg, Douglas P. Cooper, and Elisa Puvia. 2011. From women to objects: Appearance focus, target gender, and perceptions of warmth, morality and competence, Journal of Experimental Social Psychology, No. 47, pp. 572581.

Heggenhougen, H. K. 1993. PHC and Anthropology: Challenges and Opportunities, Culture, Medicine and Psychiatry, Vol. 17, No. 2, pp. 291-289.

Heidegger, Martin. 1991. The Principle of Reason. Translated by Reginald Lilly. Bloomington and Indianapolis: Indiana University Press. 
1989. Contributions to Philosophy (Of the Event). Translated by Richard Rojcewicz and Daniela Valega-Neu. Bloomington, IN: Indiana University Press.

Hein, Frances J. 2000. Historical Overview of the Fort McMurray Area and Oil Sands Industry in Northeast Alberta (report prepared for the Energy and Utilities Board), http://web.archive.org/web/20080227201038/http://www.ags.gov.ab.c a/publications/ESR/PDF/ESR_2000_05.pdf, accessed July 15, 2016.

Herbert, Steve. 2005. The trapdoor of community, Annals of the Association of American Geographers, Vol. 95, No. 4, pp. 850-865.

Higgins, Rylan. 2005. Bodies for Rent: Labor and Marginality in Southern Louisiana, Anthropology of Work Review, Vol. 26, No. 3, pp. 12-22.

Hiller, Harry. H. 2009. Second Promised Land: Migration to Alberta and the Transformation of Canadian Society. Montreal: McGill-Queen's University Press. Ho, Karen. 2009. Liquidated: An Ethnography of Wall Street. Durham and London: Duke University Press.

Hoggart, Richard. 1957. The Uses of Literacy. Essential Books, Inc.

Holdich, Thomas Hungerford. 1916. Political Frontiers and Boundary Making. London: MacMillan and Co., Limited.

Holt, Douglas B. and Craig J. Thompson. 2004. Man-of-Action Heroes: The Pursuit of Heroic Masculinity in Everyday Consumption, Journal of Consumer Research, Vol. 31, No. 2, pp. 425-440.

Höpfl, Heather J.

2003. Becoming a (Virile) Member: Women and the Military Body, Body \& Society, Vol. 9. No. 4, pp. 13-30.

2000. Motivation, in "Organizational Behaviour Reassessed: The Impact of Gender", edited by Elisabeth M. Wilson. London: Sage Publications.

Hotchkiss, Harley. 2009. Hat Trick: A life in the Hockey Rink, Oil Patch and Community. Toronto: Dundurn Press.

House, J. D. 1980. The Last of the Free Enterprisers: The Oilmen of Calgary. Toronto: Macmillan. 
Houser, Dan E.

2010. Drilling Rig Workers in Alberta: Folk Models of Economics in the Oilfields. MA thesis.

2010. Working Hard and Staying Safe: Drilling Rig Hands in Alberta, in Donald C. Wood (Ed.), Economic Action in Theory and Practice: Anthropological Investigations (Research in Economic Anthropology, Volume 30). Emerald Publishing Group Limited, pp. 331-349.

Howard, K. E., \& Orlinsky, D. E. 1972. Psychotherapeutic processes, Annual Review of Psychology, Vol. 23, pp. 615-668.

Huffington Post. 2013. The Best Paying Jobs In The Alberta Oil Patch, http://www.huffingtonpost.ca/2013/02/01/best-paying-jobs-alberta-oilpatch_n_2602506.html, accessed November $18^{\text {th }}, 2017$.

Hunter, Bea. 1995. Last Chance Well: Legends and Legacies of Leduc No. 1. Edmonton: Tree Frog Press, Ltd.

Huseman, Jennifer and Damien Short. 2012. 'A slow industrial genocide': tar sands and the indigenous peoples of northern Alberta, The International Journal of Human Rights, Vol. 16 , No. 1 , pp. $216-237$.

Husky Energy. 2015. Downstream, http://www.huskyenergy.com/operations/downstream/, accessed February 24, 2015.

Ingold, Tim. 2000. The Perception of the Environment: Essays on livelihood, dwelling and skill. London and New York: Routledge.

International Energy Agency. 2012. Golden Rules for a Golden Age of Gas: World Energy Outlook on Unconventional Gas, http://www.iea.org/publications/freepublications/publication/weo-2012--special-report---golden-rules-for-a-golden-age-of-gas.html, accessed February 15, 2015. Jackson, C. 1991. Men's health: Opening the floodgates, Health Visit, Vol. 64, pp. 265-266. Jacobsen, Grant D. and Dominic P. Parker. 2014. The Economic Aftermath of Resource Booms: Evidence from Boomtowns in the American West, The Economic Journal, Vol. 126, No. 593, pp. 1092-1128.

Jones, Beverley Joyce. 1995. High Heels 'n' Oil Rigs. Prince George, BC: Caitlin Press. 
Jones, Stephen B. 1945. Boundary-Making: A Handbook for Statesmen, Treaty Editors and Boundary Commissioners. Washington: Carnegie Endowment for International Peace. Joosse, James Paul.

2017. Leaderless Resistance and the Loneliness of Lone Wolves: Exploring the Rhetorical Dynamics of Lone Actor Violence, Terrorism and Political Violence, No. 29, Vol. 1, pp. 52-78.

2014. Leaderless Resistance, Radical Environmentalism, and Asymmetrical Warfare. PhD thesis.

JWN Energy. 2017. Special report: Oilsands Competitive Outlook, http://www.jwnenergy.com/article/2017/5/special-report-oilsands-competitiveoutlook/, accessed September 20 2017.

Kelly, Erin N., Jeffrey W. Short, David W. Schindler, Peter V. Hodson, Mingshen Ma, Alvin K. Kwan, and Barbra L. Fortin. 2009. Oil sands development contributes polycyclic aromatic compounds to the Athabasca River and its tributaries, Proceedings of the National Academy of Sciences, Vol. 106, No. 52, pp. 22346-22351.

Kerr, Aubrey.

1998. Judy Creek and Beyond. Calgary: S.A. Kerr. 1994. Redwater. Calgary: S.A. Kerr

1991. Leduc. Calgary: S.A. Kerr

1986. Atlantic 1948 No. 3. Calgary: S.A. Kerr.

Kimmel, Michael S. 2013. Angry White Men: American Masculinity at an End of an Era. New York: Nation Books.

Kinchy, Abby, Kirk Jalbert and Jessica Lyons, 2014. What is Volunteer Water Monitoring Good For? Fracking and the Plural Logics of Participatory Science, in "Fields of Knowledge: Science, Politics and Publics in the Neoliberal Age", edited by Scott Frickel and David J. Hess. United Kingdom: Emerald Publishing Group.

Kryzanowski, Julie A. and Lynn McIntyre. 2011. A Holistic Model for the Selection of Environmental Assessment indicators to Assess the Impact of Industrialization on Indigenous Health, Canadian Journal of Public Health, Vol. 102, No. 2, pp. 112-117. 
Kurek, Joshua, Jane L. Kirk, Derek C. G. Muir, Xiaowa Wang, Marlene S. Evans, and John P. Smol. 2013. Legacy of a half century of Athabasca oil sands development recorded by lake ecosystems, Proceedings of the National Academy of Sciences, Vol. 110, No. 5, pp. 17611766.

Ladd, Anthony E. 2014. Environmental Disputes and Opportunity - Threat Impacts Surrounding Natural Gas Fracking in Louisiana, Social Currents, Vol. 1, No. 3, pp. 293311.

Lauver, Lori S. 2012. Environmental Health Advocacy: An Overview of Natural Gas Drilling in Northeast Pennsylvania and Implications for Pediatric Nursing, Journal of Pediatric Nursing, Vol. 27, No. 4, pp. 383-389.

Lennon, Mary Clare. 1987. Sex Differences in Distress: The Impact of Gender and Work Roles, Journal of Health and Social Behavior, Vol. 28, No. 3, pp. 290-305.

Leonard, David W. 2005. The Last Great West: The Agricultural Settlement of the Peace River Country to 1914. Calgary: Detselig Enterprises.

Leppard, Henry M. 1935. The Settlement of the Peace River Country, Geographical Review, Vol. 25, No. 1, pp. 62-78.

Levine, Deborah, et al. 2011. Formative Research on MySpace: Online Methods to Engage Hardto-Reach Populations, Journal of Health Communication, Vol. 16, No. 4, pp. 448-454.

Literary Review of Canada. 2014. The two Albertas: Old differences split the province, but are mostly ignored in the East, by Harvey Locke, http://reviewcanada.ca/magazine/2014/04/the-two-albertas/, accessed January $25^{\text {th }}$, 2017.

Lucas, Rex A.

2008. Minetown, Milltown, Railtown: Life in Canadian Communities of Single Industry. Oxford University Press.

1971. Minetown, Milltown, Railtown: Life in Canadian Communities of Single Industry. Toronto: University of Toronto Press.

Lynd, Robert Staughton. 1939. Knowledge for What?: The Place of Social Science in American Culture. Princeton University Press. 
Maclean's Magazine.

2016. Canada's most dangerous cities 2016: How safe is your city?, http://www.macleans.ca/news/canada/canada-most-dangerous-cities-2016-safe-yourcity/, accessed January 19th 2017.

2010. Canada's Most Dangerous Cities: 2010, http://www.macleans.ca/news/canada/national-crime-rankings-2010/, accessed September 16, 2014.

Malm, Andreas. 2016. Fossil Capital: The Rise of Steam Power and the Roots of Global Warming. London and New York: Verso.

Manitoba Water Caucus. 2014. Hydraulic Fracturing, http://mbwatercaucus.org/issues/hydraulic-fracturing/, accessed February 27 2017.

Manta. 2014. Companies in Grande Prairie, http://www.manta.com/world/North+America/Canada/Alberta/Grande+Prairie/, accessed October 2, 2014.

Marquis, Christopher, Mary Ann Glynn, and Gerald F. Davis. 2007. Community Isomorphism and Corporate Social Responsibility, Academy of Management Review, Vol. 32, No. 3, pp. 925-945.

Matz, Jacob and Daniel Renfrew. 2015. Selling "Fracking": Energy in Depth and the Marcellus Shale, Environmental Communication, Vol. 9, no. 3, pp. 288-306.

McKay, J. R., Rutherford, M. J., Cacciola, J. S., \& Kabasakalian-McKay, R. 1996. Gender differences in the relapse experiences of cocaine patients, Journal of Nervous and Mental Disease, Vol. 184, pp. 616-622.

McKee, et al. 2000. Family Friendly Policies and Practices in the Oil and Gas Industry: Employers' Perspectives, Work, Employment \& Society, Vol. 14, No. 3, pp. 557-571. McWilliams, Abigail and Donald Siegel. 2000. Corporate Social Responsibility and Financial Performance: Correlation or Misspecification?, Strategic Management Journal, Vol. 21, No. 5, pp. 603-609.

McWilliams, Abigail, Donald S. Siegel, and Patrick M Wright. 2005. Corporate Social Responsibility: Strategic Implications, Rensselaer Working Papers in Economics, No. 506, 
pp. 1-32.

Merkel, Lori, Cara Bicking and Deepa Sekhar. 2012. Parents' Perceptions of Water Safety and Quality, Journal of Community Health, Vol. 37. No. 1, pp. 195-201.

Miller, Gloria E. 2004. Frontier Masculinity in the Oil Industry: The Experience of Women Engineers, Gender, Work and Organization, Vol. 11, No. 1, pp. 47-73.

Mitchell, Timothy. 2011. Carbon Democracy: Political Power in the Age of Oil. London and New York: Verso.

Montreal Gazette. 2017. Denis Coderre calls TransCanada 'arrogant', claims Energy East victory, http://montrealgazette.com/news/local-news/denis-coderre-calls-transcanadaarrogant-claims-energy-east-victory, accessed March $12^{\text {th }}, 2018$.

Moore, Jason W. 2012. Crisis: Ecological or World-Ecological?, in “Depletion Design: A Glossary of Network Ecologies", edited by Caroline Wiedemann and Soenke Zehle. Amsterdam: Institute of Network Cultures.

Morton, Timothy. 2007. Ecology Without Nature: Rethinking Environmental Aesthetics. Cambridge, Massachusetts, and London, England: Harvard University Press.

Mosher, Donald L. and Mark Sirkan. 1984. Measuring a Macho Personality Constellation, Journal of Research in Personality, Vol. 18, p. 150-163.

Murphy, Brenda L. 2007. Locating social capital in resilient community-level emergency management, Natural Hazards, Vol. 41, pp. 297-315.

Murray Li, Tanya. 2014. Land's End: Capitalist Relations on an Indigenous Frontier. Durham and London: Duke University Press.

National Energy Board. 2015. Estimated Canadian Crude Oil Exports by Type and Destination, https://www.neb-one.gc.ca/nrg/sttstc/crdlndptrlmprdct/stt/stmtdcndncrdlxprttpdstneng.html, accessed January 10, 2015.

Natural Resources Canada.

2017.

10 Key Facts on Canada's Natural Resources, http://www.nrcan.gc.ca/sites/www.nrcan.gc.ca/files/files/pdf/10_key_facts_nrcan_201 7_en.pdf, accessed December 22 ${ }^{\text {nd }}, 2017$. 
Alberta's Pipeline Regulatory Regime, http://www.nrcan.gc.ca/energy/infrastructure/pipeline-safety-regime/16444, accessed February $11^{\text {th }}, 2018$.

2016. 10 key Facts about Canada's Natural Resources, http://www.nrcan.gc.ca/sites/www.nrcan.gc.ca/files/files/pdf/10_key_facts_nrc an_2016-access_e.pdf, accessed January 26 ${ }^{\text {th }}, 2017$. 2015. Key Facts and Figures on the Natural Resources Sector, http://www.nrcan.gc.ca/publications/key-facts/16013, accessed July 15, 2016. 2015. North American Natural Gas Market: 2015-2016 Heating Season Outlook, http://www.nrcan.gc.ca/energy/sources/natural-gas/17894, accessed July 15, 2016. 2014. About Crude Oil and Petroleum Products, http://www.nrcan.gc.ca/energy/fuel-prices/4597\#domestic, accessed January 29, 2015. Neighbors, H. W., \& Howard, C. S. 1987. Sex differences in professional help seeking among adult Black Americans, American Journal of Community Psychology, No. 15, pp. 403417.

New Brunswick Museum. 2015. Magnificent Rocks: Stoney Creek Oil, http://www.nbm$\mathrm{mnb} . c a / m a g n i f i c e n t$ rocks-roches_magnifiques/the_periodsles_periodes/lower_carboniferous-carbonifere_inferieur/community_connectionsconnexions_communautaires/stoney_creek_oil-stoney_creek_petrole-eng/, accessed February 1, 2015.

New York Times. 2016. In Canada, a Direct Link Between Fracking and Earthquakes, https://www.nytimes.com/2016/11/18/science/fracking-earthquakes-albertacanada.html, accessed November $8^{\text {th }}, 2017$.

Nielsen, Arne. 2012. We Gambled Everything: The Life and Times of an Oilman. Edmonton: The University of Alberta Press.

Nikiforuk, Andrew.

2010. Tar Sands: Dirty Oil and the Future of a Continent. Vancouver/Toronto/Berkeley: Greystone Books.

2002. Saboteurs: Wiebo Ludwig's War against Big Oil. Vancouver, BC: Greystone Books. 
Nora, Pierre. 1989. Between Memory and History: Les Lieux de Memoire, Representations, Vol. 0 , Issue 26, pp. 7-24.

Northern Alberta Institute of Technology. 2016. Rig Technician, http://www.nait.ca/program_home_81322.htm, accessed July 15, 2016.

Now Toronto. 2002. Flawed Messiah: Lost in the Wilderness with Weibo Ludwig, by Tooker Gomberg, https://nowtoronto.com/news/flawed-messiah/, accessed April 18 ${ }^{\text {th }}, 2017$.

Nussbaum, Martha C. 1999. Sex and Social Justice. Oxford: Oxford University Press.

Nuttall, Mark. 2008. Aboriginal Participation, Consultation, and Canada's Mackenzie Gas Project, Energy \& Environment, Vol. 19, No. 5, pp. 617-634.

Oil Price.

2017. “Dirty, Difficult, and Dangerous": Why Millennials Won't Work In Oil, http://oilprice.com/Energy/Energy-General/Dirty-Difficult-And-Dangerous-WhyMillennials-Wont-Work-In-Oil.html, accessed September 7 $7^{\text {th }}, 2017$. 2015. The Real History of Fracking, https://oilprice.com/Energy/Crude-Oil/The-RealHistory-Of-Fracking.html, accessed November 17th 2017.

Ong, Maria, Carol Wright, Lorelle L. Espinosa, and Gary Orfield. 2011. Inside the Double Bind: A Synthesis of Empirical Research on Undergraduate and Graduate Women of Color in Science, Technology, Engineering, and Mathematics, Harvard Educational Review, Vol. 81 , No. 2, pp. 172-208.

O’Rourke, Dana and Sarah Connolly. 2003. Just Oil? The Distribution Of Environmental And Social Impacts Of Oil Production And Consumption, Annual Review of Environment and Resources, No. 28, pp. 587-617.

Paap, Kris. 2006. Why White Working-Class Men Put Themselves - and the Labor Movement in Harm's Way. Ithaca and London: Cornell University Press.

Paladino, Stephanie and Jeanne Simonelli. 2013. Hazards So Grave: Anthropology and Energy, Culture, Agriculture, Food and Environment, Vol. 35, No. 1, pp. 1-3.

Parkins, John R. and Angela C. Angell. 2010. Linking social structure, fragmentation, and substance abuse in a resource-based community, Community, Work \& Family, Vol. 14, No. 1, pp. 39-55. 
Parks Canada, 2009. National Historic Sites in the Mountain National Parks: First Oil Well in Western Canada National Historic Site of Canada, http://www.pc.gc.ca/docs/v-g/pmmp/lhn-nhs/puits-well_e.asp, accessed January 29, 2015.

Parlee, Brenda L. 2015. Avoiding the Resource Curse: Indigenous Communities and Canada's Oil Sands, World Development, Vol. 74, pp. 425-436.

Passmore, John. 1995. Attitudes to Nature, in "Environmental Ethics", edited by Robert Elliot. Oxford: Oxford university Press.

Peet, John. 1992. Energy and the Ecological Economics of Sustainability. Washington, DC: Island Press.

Pembina Institute.

2013. Alberta's Oil Sands, http://www.pembina.org/oil-sands/os101/alberta, accessed February 5, 2015.

2009. Mining VS In Situ Fact Sheet, https://www.pembina.org/reports/mining-vs-insitu.pdf, accessed September 21 2016.

Peppard, Christina Z. 2012. Fresh Water and Catholic Social Teaching: A Vital Nexus, Journal of Catholic Social Thought, Vol. 9, No. 2, pp. 325-351.

Petroleum History Society. 2014. Alberta's First Natural Gas Discovery, http://www.petroleumhistory.ca/history/firstgas.html, accessed February 1, 2015.

Petroleum Services Association of Canada.

2015. Hydraulic Fracturing Explained, http://www.oilandgasinfo.ca/fracopedia/hydraulic-fracturing-explained/, accessed February 7, 2015.

2015. Industry Overview: Downstream Industry, http://www.psac.ca/business/industry-overview/, accessed February 25, 2015.

Pitkanen, Laura. 2017. Black Wednesday: Radiation, stigma and property values, Environment and Planning A, Vol. 49, No. 7, pp. 1537-1555.

Poole, Amanda and Anastasia Hudgins. 2014. "I care more about this place because I fought for it": exploring the political ecology of fracking in an ethnographic field school, Journal of Environmental Studies and Sciences, Vol. 4, No. 1, pp. 37-46. 
Preston, Jen. 2013. Neoliberal settler colonialism, Canada and the tar sands, Race \& Class, Vol. 55, No. 2, pp. 42-59.

Pulp \& Paper Canada. 2003. The Team Behind The Grande Prairie Mill, https://www.pulpandpapercanada.com/news/the-team-behind-the-grande-prairie-mill1000129219, accessed November $28^{\text {th }}, 2017$.

Pyke, Karen. 1996. Class-Based Masculinities: The Interdependence of Class, Gender, and Interpersonal Power, Gender and Society, Vol. 10, No. 5, pp. 527-549.

Rafuse, J. 1993. Men's attitudes about seeking health care may put them at risk, conference told, Canadian Medical Association Journal, Vol. 149, pp. 329-330.

Red Seal.

2014. Red Seal Trades, http://www.redseal.ca/trades/tr.1d.2s_l.3st@-eng.jsp, accessed October 6, 2014.

2014. Trades In Canada, http://www.red- seal.ca/trades/tr.1d.2s_c.1n.1d.1-eng.html, accessed January $31^{\text {st }}, 2017$.

Robert, Elliot. 1997. Faking Nature: The Ethics of Environmental Restoration. London and New York: Routledge.

Rodseth, Lars and Bradley J. Parker. 2005. Introduction: Theoretical Considerations in the Study of Frontiers, in "Untaming the Frontier in Anthropology, Archaeology, and History", edited by Bradley J. Parker and Lars Rodseth. Tucson: The University of Arizona Press.

Rose, Nikolas.

2000. Community, Citizenship, and the Third Way, American Behavioral Scientist, Vol. 43, No. 9, pp. 1395-1411.

1996. The death of the social? Re-figuring the territory of government, Economy and Society, Vol. 25, pp. 327-356.

Rotary Club of Grande Prairie. 2016. About Us: Where We Fund, http://www.gprotary.com/, accessed August 4, 2016.

Rubin, Herbert J. and Irene S. Rubin. 2005. Qualitative Interviewing: The Art of Hearing, $2^{\text {nd }}$ Edition. California: Sage Publications, Inc. 
Ruddell, Rick, Dheeshana S. Jayasundara, Roni Mayzer and Thomasine Heitkamp. 2011. Boomtown Policing: Responding to the Dark Side of Resource Development, Policing, Vol. 5, No. 4, pp. 328-342.

Ruddell, Rick et al. 2014. Drilling Down: An Examination of the Boom-Crime Relationships in Resource-Based Boom Counties, Western Criminology Review, Vol. 15, No. 1, pp. 3-17.

Sahlins, Peter. 1989. Boundaries: The Making of France and Spain in the Pyrenees. Berkeley - Los Angeles - Oxford: University of California Press.

Sawatsky, Elisabeth. 2009. Doodlebugging in Saskatchewan: A Wife Remembers. Your Nickel's Worth Publishing.

Schmidt, John. 1989. Growing Up in the Oil Patch. Toronto: Natural Heritage/Natural History Inc.

Schuetze, Christopher F. 2013. Is Canada's Oil Too Dirty For The EU?, http://rendezvous.blogs.nytimes.com/2013/05/13/is-canadas-oil-too-dirty-foreurope/?_php=true\&_type=blogs\&_r=0, accessed September 29, 2014.

Schütz, Alfred.

1951. Making Music Together: A Study in Social Relationship, Social Research, Vol. 18, No. 1, pp. 76-97.

1944. The Stranger: An Essay in Social Psychology, American Journal of Sociology, Vol. 49. No. 6, pp. 499-507.

Scott, James C.

1998. Seeing like a state: How certain schemes to improve the human condition have failed. New Haven: Yale University Press.

1985. Weapons of the Weak: Everyday Forms of Peasant Resistance. New Haven: Yale University Press.

Seidman, Irving. 2006. Interviewing as Qualitative Research: A Guide for Researchers in Education and the Social Sciences, $3^{\text {rd }}$ Edition. New York and London: Teacher's College Press. 
Sen, Sankar and C. B. Bhattacharya. 2001. Does Doing Good Always Lead to Doing Better? Consumer Reactions to Corporate Social Responsibility, Journal of Marketing Research, Vol. 38, No. 2, pp. 225-243.

Shilling, Chris. 1991. Educating the Body: Physical Capital and the Production of Social Inequalities, Sociology, Vol. 25, No. 4, pp. 653-672.

Shrivastava, Meenal and Lorna Stefanick. 2012. Do Oil and Democracy Only Clash in the Global South?: Petro Politics in Alberta, Canada, New Global Studies, Vol. 6, No. 1, ISSN (Online) 1940-0004, DOI: https://doi.org/10.1515/1940-0004.1147.

Siltanen, Janet. 1994. Locating Gender: Occupational Segregation, Wages and Domestic Responsibilities (Cambridge Studies in Work and Social Inequality: Vol. 1). London: UCL Press, Ltd.

Slowey, Gabrielle A. 2001. Globalization and Self-Government: Impacts and Implications for First Nations in Canada, American Review of Canadian Studies, No. 31, pp. 265-281. Smandych, Russell and Rodney Kueneman. 2010. The Canadian-Alberta tar sands: a case study of state-corporate environmental crime, in "Global Environmental Harm: Criminological Perspectives", edited by Rob White. London and New York: Routledge.

Sober, Elliot. 1986. Philosophical Problems for Environmentalism, in "The Preservation of Species", edited by Bryan G. Norton. Princeton: Princeton University Press.

Statistics Canada.

2017. Census Profile, 2016 Census - Grande Prairie [Population Centre], Alberta and Nova Scotia [Province], http://www12.statcan.gc.ca/census-recensement/2016/dp$\mathrm{pd} / \mathrm{prof} /$ details/page.cfm?Lang=E\&Geo1=POPC\&Code1=0336\&Geo2=PR\&Code $2=12 \& D$ ata $=$ Count $\&$ SearchText=Grande\%20Prairie $\&$ SearchType=Begins \&SearchPR=01\&B1=All, accessed January $24^{\text {th }}, 2018$.

2017. Census Profile, 2016 Census - Grande Prairie, Alberta and Saskatchewan, http://www12.statcan.gc.ca/census-recensement/2016/dppd/prof/details/page.cfm LLang=E\&Geo1=POPC\&Code1=0336\&Geo2=PR\&Code2=47\&D ata $=$ Count $\&$ SearchText=Grande\%20Prairie $\&$ SearchType=Begins $\&$ SearchPR=01\&B1=All, accessed November $28^{\text {th }}, 2017$. 
2017. Labour force characteristics, adjusted seasonally, by census metropolitan area (3 month moving average), (Calgary (Alta.), Edmonton (Alta.), Kelowna (B.C.)), http://www.statcan.gc.ca/tables-tableaux/sum-som/l01/cst01/Ifss03k-eng.htm, accessed January 23 ${ }^{\text {rd }}, 2017$.

2016. Police-reported crime statistics in Canada, 2016, Chart 6, http://www.statcan.gc.ca/pub/85-002-x/2017001/article/54842-eng.htm, accessed December 29th 2017.

2016. Population and Dwelling Count Highlight Tables, 2016 Census, http://www12.statcan.gc.ca/census-recensement/2016/dp-pd/hlt-fst/pd-

$\mathrm{pl} /$ Table.cfm ?Lang=Eng\&T=801\&SR=1\&S=3\&O=D\&RPP=25\&PR=48\&CMA=0\#tPopDwell, accessed November $2^{\text {nd }}, 2017$.

2015. Distribution of employed people, by industry, by province, http://www.statcan.gc.ca/tables-tableaux/sum-som/l01/cst01/labor21a-eng.htm, accessed February 11, 2015.

2015. Motor vehicle registrations, by province and territory, http://www.statcan.gc.ca/tables-tableaux/sum-som/l01/cst01/trade14a-eng.htm, accessed July 15, 2016.

2014. Households and The Environment: Energy Use, http://www.statcan.gc.ca/pub/11-526-s/2013002/part-partie1-eng.htm, accessed January 29, 2015.

2011. Focus on Geography Series, 2011 Census, http://www12.statcan.gc.ca/censusrecensement/2011/as-sa/fogs-spg/Facts-csdeng.cfm?LANG=Eng\&GK=CSD\&GC=4819012, accessed September 29, 2014. 2010. Chart 6: Volunteer rate by province or territory, population aged 15 and over, 2007 and 2010, http://www.statcan.gc.ca/pub/11-008-x/2012001/c-g/11638/c- g06eng.htm, accessed September 7, 2016.

Stephens, Carolyn, John Porter, Clive Nettleton, and Ruth Willis. 2006. Disappearing, displaced, and undervalued: a call to action for Indigenous health worldwide, The Lancet, Vol. 367, No. 9527, pp. 2019-2028. 
Suncor. 2105. The Early Years (1917-1960), http://www.suncor.com/about-

us/history/the-early-years, accessed February 26 ${ }^{\text {th }}, 2015$.

Swart, Andrew and Silke Otremba. 2017. Innovation in Oil and Gas: Canada 2016, https://www2.deloitte.com/ca/en/pages/resource-evaluation-andadvisory/articles/innovateoilgas.html, accessed January 23 2017.

Sweeny, Alastair. 2010. Black Bonanza: Canada's Oil Sands and the Race to Secure North America's Energy Future. Ontario: John Wiley \& Sons.

Taylor, Alison, Robert McGray and Bonnie Watt-Malcolm. 2007. Struggles Over Labour Power: The Case of Fort McMurray, Journal of Education and Work, Vol. 20, No. 5, pp. 379-396.

Taylor, Alison and Tracey Friedel. 2011. Enduring neoliberalism in Alberta's oil sands: the troubling effects of private-public partnerships for First Nation and Métis communities, Citizenship Studies, Vol. 15, No. 6-7, pp. 815-835.

The Canadian Encyclopedia. 2017. Alberta, http://www.thecanadianencyclopedia.ca/en/article/alberta/, accessed January $25^{\text {th }}$, 2017.

The Globe and Mail.

2017. Peace River Country fails to live up to Wiebo Ludwig story, https://www.theglobeandmail.com/arts/theatre-and-performance/theatrereviews/peace-river-country-fails-to-live-up-to-potential-of-wiebo-ludwigstory/article34046841/, accessed March 15 ${ }^{\text {th }}, 2018$.

2014. I want to work in the oil sands. What will my salary be?, https://www.theglobeandmail.com/report-on-business/careers/career-advice/life-atwork/i-want-to-work-in-the-oil-sands-what-will-my-salary-be/article17438086/, accessed November $18^{\text {th }}, 2017$.

2014. Judge rules Alberta can be sued over fracking allegations, province may appeal, http://www.theglobeandmail.com/news/alberta/judge-rules-alberta-can-be-sued-overfracking-allegations-province-may-appeal/article21569070/, accessed February 15, 2015. 
2013. Imperial Oil Leads Push to Drill Deep in Canadian Arctic, http://www.theglobeandmail.com/report-on-business/industry-news/energy-andresources/major-oil-companies-apply-to-drill-deep-in-canadian-arctic/article14596797/, accessed January 10, 2015.

The Guardian. 2017. Keystone pipeline defiance triggers further assault on citizens' rights, https://www.theguardian.com/us-news/2017/may/03/keystone-pipeline-protests-landrights-south-dakota, accessed November 25 2017.

The Huffington Post. 2013. Enbridge Northern Gateway Protest Rallies Held Across BC, http://www.huffingtonpost.ca/2013/11/16/enbrige-oil-sandsrallies_n_4288393.html, accessed September 16, 2014.

Theodori, Gene L. 2009. Paradoxical Perceptions of Problems Associated with Unconventional Natural Gas Development, Southern Rural Sociology, Vol. 24, No. 3, pp. 97-117.

The Parkland Institute. 2012. Women's equality a long way off in Alberta: Gender gap remains the widest in the country, http://parklandinstitute.ca/research/summary/womens_equality_a_lon g_way_off_in_alberta1, accessed February 15, 2015.

The Royal Society of Canada. 2010. The Royal Society of Canada Expert Panel: Environmental and Health Impacts of Canada's Oil Sands Industry, https://www.ceaaacee.gc.ca/050/documents_staticpost/59540/82080/Appendix_E_-_Part_09.pdf, accessed March 18 ${ }^{\text {th }}, 2017$.

The Star. 2016. Little progress in rail safety in the wake of Lac Mégantic. Bruce Campbell (au), https://www.thestar.com/opinion/commentary/2016/04/14/little-progress-on-railsafety-in-wake-of-lac-mgantic.html, accessed July 16, 2016.

The Walrus. 2013. Big Mac, author Taras Grescoe, http://thewalrus.ca/big-mac/, accessed September 20, 2014.

Thom, B. 1986. Sex differences in help-seeking for alcohol problems: The barriers to helpseeking, British Journal of Addiction, Vol. 81, pp. 777-788.

Thompson, E. P. 1963. The Making of the English Working Class. New York: Pantheon Books. 
Town of Drayton Valley. 2014. Drayton Valley History, http://www.draytonvalley.ca/history/, accessed February 3, 2015.

Transportation Safety Board of Canada. 2014. Lac-Mégantic runaway train and derailment investigation summary, http://www.tsb.gc.ca/eng/rapportsreports/rail/2013/r13d0054/r13d0054-r-es.asp, accessed July 16, 2016.

Tsing, Anna Lowenhaupt. 2005. Friction: An Ethnography of Global Connection. Princeton, New Jersey: Princeton University Press.

Tubb, Daniel. 2015. Muddy Decisions: Gold in the Chocó, Colombia, The Extractive Industries and Society, Vol. 2, No. 4, pp. 722-733.

Tunstall, Thomas. 2014. Economic Impact of the Eagle Ford Shale, Petroleum Accounting and Financial Management Journal, Vol. 33, No. 2, pp. 11-22.

Turner, Frederick Jackson. 1994. The Invented Landscape, in "Beyond Preservation: Restoring and Inventing Landscapes", edited by A. Dwight Baldwin, Judith De Luce, and Carl Pletsch. Minneapolis: University of Minnesota Press. 1920. The Frontier in American History. New York: Henry Holt And Company. Urquhart, lan. 2010. Between the Sands and a Hard Place? Aboriginal Peoples and the Oil Sands. Working Paper no. 10-005. Buffet Centre for International and Comparative Studies Working Paper: Energy Series.

Van Manen, Max. 1990. Researching Lived Experience: Human Science For An Action Sensitive Pedagogy. New York: State University of New York Press.

Vessey, J. T., \& Howard, K. I. 1993. Who seeks psychotherapy?, Psychotherapy, Vol. 30, pp. 546553.

Wacquant, Loïc. 2004. Body \& Soul: Notebooks of an apprentice boxer. New York: Oxford University Press, Inc.

Warren, Karen J. 1990. The Power and Promise of Ecological Feminism, Environmental Ethics, Vol. No. 2, pp. 125-146. 
Westman, Clinton N.

2013a. Cautionary Tales: Making and Breaking Community in the Oil Sands Region, The Canadian Journal of Sociology, Vol. 38, No. 2, pp. 211-231. 2013b. Social Impact Assessment and the Anthropology of the Future in Canada's Tar Sands, Human Organization, Vol. 72, No. 2, pp. 111-120.

Wharton, Amy S. and James N. Baron. 1991. Satisfaction? The Psychological Impact of Gender Segregation on Women at Work, The Sociological Quarterly, Vol. 32, No. 3, pp. 365-387.

White, Richard. 1991. The middle ground: Indians, empires, and republics in the Great Lakes region, 1650 - 1815. Cambridge: Cambridge University Press.

Whittemore Boggs, S. 1940. International Boundaries: A Study of Boundary Functions and Problems. New York: Columbia University Press.

Williams, Raymond.

1961. The Long Revolution. London: Chatto and Windus.

1958. Culture \& Society. London: Chatto and Windus.

Willis, Paul.

1982. Learning to Labor: How Working Class Kids Get Working Class Jobs. Columbia University Press.

1977. Learning to Labor: How Working Class Kids get Working Class Jobs. New York: Columbia House Press.

Willow, Anna J. and Sara Wylie. 2014. Politics, ecology and the new anthropology of energy: exploring the emerging frontiers of hydraulic fracking, Journal of Political Ecology, Vol. 21, pp. 222-236.

Winkler, Richelle, Cheng Cheng and Shaun Golding. 2011. Boom or Bust? Population Dynamics in Natural Resource-Dependent Counties, International Handbook of Rural Demography, Vol. 3, pp. 349-367.

Wiseman, Hannah Jacobs. 2009. Untested Waters: The Rise of Hydraulic Fracturing in Oil and Gas Production and the Need to Revisit Regulation, Fordham Environmental Law Review, Vol. 20, pp. 115-170. 
Wolcott, Harry F. 2001. Writing Up Qualitative Research, $2^{\text {nd }}$ ed. Thousand Oaks: Sage Publications.

Wolfe, Linnie Marsh (Ed). 1979. John of the Mountains: The Unpublished Journals of John Muir. Madison, WI: University of Wisconsin Press.

Zoeller, Hessen R. 2016. This hated city: 'Deadmonton' - Edmonton's alter-ego, in “The Urban Uncanny: a collection of interdisciplinary studies", edited by Lucy Huskinson. New York: Routledge. 